\title{
Agricultural intensification in Nepal, with particular reference to systems of rice intensification
}




\section{Thesis committee}

\section{Promotor}

Prof. Dr T.W. Kuyper

Personal chair at the Department of Soil Quality

Wageningen University

\section{Co-promotor}

Dr H. Maat

Assistant professor, Knowledge, Technology and Innovation Group

Wageningen University

\section{Other members}

Prof. Dr P.C. Struik, Wageningen University

Prof. Dr P.J.G.J. Hellegers, Wageningen University

Dr W.A. Stoop, STOOP Consult, R\&D for tropical agriculture, Driebergen-

Rijsenburg

Dr M.P. Temudo, University of Lisbon, Portugal

This research was conducted under the auspices of the Wageningen Graduate School of Social Sciences (WASS) 


\section{Agricultural intensification in Nepal, with particular reference to systems of rice intensification}

\section{Rajendra Uprety}

Thesis

submitted in fulfilment of the requirements for the degree of doctor at Wageningen University

by the authority of the Rector Magnificus

Prof. Dr A.P.J. Mol, in the presence of the

Thesis Committee appointed by the Academic Board to be defended in public

on Monday 12 December 2016

at 11 a.m. in the Aula 


\section{Rajendra Uprety}

Agricultural intensification in Nepal, with particular reference to systems of rice intensification

204 pages

$\mathrm{PhD}$ thesis, Wageningen University, Wageningen, NL (2016)

With references, with summary in English

ISBN: 978-94-6257-965-1

DOI: http://dx.doi.org/10.18174/392853 


\section{DEDICATION}

To my beloved parents late Ganga Prasad Uprety and Laxmi Devi Uprety 


\begin{abstract}
This thesis deals with agricultural intensification in Nepal. The initial focus of the study was the System of Rice Intensification (SRI), as introduced in Nepal from 2001. The multiple factors affecting SRI adoption, modification and dissemination together with the option to apply SRI in different combinations of its components result in a variety of SRI applications. For the same reason the effect of SRI on overall agricultural and livelihood development of Nepalese farmers has to be evaluated within the variety of farming systems in which it is applied.
\end{abstract}

Despite government policies to promote rice cultivation, national rice production is declining. Farmer livelihood strategies, as reflected in rice farming systems, and field management strategies were influenced by several agro-ecological and socio-economic factors. Livelihood and field management strategies of rice farmers are interconnected. In the study presented here four livelihood strategies and three kinds of field management strategies are distinguished. Two livelihood strategies can be characterized as more intensive and more productive; the other two are less intensive and less productive. Livelihood strategies are more family resource-based strategies, while farmers' field management strategies are more context-dependent. Field management strategies were characterized by forms of nutrient management. Intensive management strategies had most similarities with SRI. But rice intensification is not achievable as a general strategy.

Government policies (fertiliser subsidies) encourage increased fertiliser use. Study results didn't show any significant effect of volume of fertilisers on rice yield but the combined use of organic manure and mineral fertilisers resulted in the highest average rice yields. Irrigation management is another important factor for rice production. Field management is influenced by the reliability of water which was better in farmers' managed irrigation system. Choice of rice varieties influenced the overall rice farming system and cropping intensity and preference of varieties for rice cultivation by scientists and by farmers were different in eastern Nepal. Most popular varieties were those not recommended by science and policy and were disseminated farmer to farmer.

The introduction of SRI in Morang district resulted in several changes in rice farming, but only part of the farmers have adopted such technologies, and adoption has been only in part 
of their fields. Other farmers have incorporated some SRI practices in their conventional practices. After the introduction of SRI, farmers further tested, re-packaged or hybridized SRI methods to make SRI ideas suitable for their agro-ecological and socio-economic environments. In order to reform Nepalese rice farming, we need to recognize that different farmers, with different livelihood strategies, and with access to different kinds of fields, need different forms for agricultural intensification. High-intensive farmers prefer to use modified SRI methods where there is good irrigation and drainage facilities. There are many possibilities for improvement of the existing nutrient management practices of rice farmers in Nepal. Nutrient management will be useful to increase rice production because the majority of farmers currently use fertilisers non-judiciously. The SRI-recommended practices (younger seedlings, early weeding, use of organic manure, and alternate wetting and drying (AWD) irrigation) will be useful to improve the nutrient use efficiency of rice farmers. Cost-reduction strategies and less labour-intensive cultivation practices will be appropriate options to improve existing rice farming system of Nepal. Participatory cultivar selection and dissemination will be better strategies to introduce new, promising rice cultivars among rice farmers. 


\section{Acknowledgements}

It has been a long journey for me from that time when I read a beautiful and attractive article on SRI written by professor Norman Uphoff in LEISA magazine. That article inspired me to do something for the development of rice sector in Nepal. After that, thousands of peoples connected with me from around the world, contributing to refine my knowledge, skill and thinking about SRI and rice farming system of Nepal and abroad. I am very thankful to all those people and societies who were connected and contributed to my professional journey.

First of all I want to remember the day when I wrote a short message to doctor Harro Maat on his wall about his research interest. That message connected me to Harro and laid a path for me to Wageningen University as a PhD candidate, leading to the defence of my thesis. I will never forget this connection which brought me to the best University of the world and converted me from an active SRI promotor into a researcher and rice professional. In this professional journey Harro always support me as a good guide, friend and supervisor. He supported me whenever I needed help in technical matters, thesis writing and when I was sick and in trouble. I enjoyed his company and warm welcome at his home during festivals time with his family. I am very thankful for that.

My promoter professor Thom Kuyper connected with me later when I arrived in Wageningen but without his uninterrupted support I may not have been able to stand here to defend my thesis. I am very thankful for all your support as a guide and guardian during my PhD. I will always remember all your efforts and support during data analysis, thesis writing, review of manuscript and many more, you were always available for me whenever I needed your guidance and help, through face-to-face meeting or at Skype conversation. I will never forget all those events and forever maintain good memories of you.

Connections with professor Paul Richards, doctor Willem Stoop and doctor Dominic Glover have always inspired me and supported me to sharpen my thinking and analytical capacity and also broaden my understanding about technology and its innovation process. I maintain 
good memories of the time Dominic visited my study area. It was an opportunity for me to learn from his rich experience. I will always remember Willem's and Nadamo's warm welcome and hospitality during my visits to their home. I am very thankful for their friendship and support. I remember the unexpected first meeting with professor Van den Ban when I was standing in front of the ABN-AMRO bank to activate my new ATM card. He supported me and we connected with each other and I got several chances to learn from his experiences.

I am thankful to doctors Kees Jansen, Sietze Vellema, Conny Almekinders and all faculties and friends of the former Technology and Agrarian Development (TAD) group, now members of the Knowledge, Technology and Innovation (KTI) group, for their support and guidance. I am very thankful to doctor Atul who supported and guided me during data analysis. I will remember Inge Ruisch for all her administrative and logistic support. But foremost her smile and energetic appearance always inspired me to be active.

The Nepalese student community of Wageningen has always been friendly and supportive in this journey. I want to remember Kalasram, Hom, Surya, Ram, Shyam, Anita, Nabin, Kulprasad, Sushil, Durga, Goma, and all others who were at Wageningen when I was there. I am also thankful to all my fellow $\mathrm{PhD}$ candidates who became friends during my time at Wageningen, especially Kazbek, Carolina, Valerie and Rica.

I sincerely acknowledge many friends and farmers who connected with me and contributed in completion of my field work, my boss Mohan Bahadur Thapa, Kedar dai, Sarojkanta, Sagar, Basanta, Kashi, Bishnumani, Abhimanu, Chandra, Kishor, Gobinda and all others respondent farmers who gave their full support during my research.

My parents who always want to see me as my family's first $\mathrm{PhD}$. They were very happy on my selection for the $\mathrm{PhD}$ at Wageningen but my father is no more in this world to see his son's PhD defence even though my mother lost her memory due to Alzheimer. But I always feel their blessing and love around me. I learned honesty, hard work and dedication from their life, which has always inspired me and activated me to search possible alternatives 
during hard times of my life. I want to remember continuous support and encouragement of my brother Mohan Krishna Uprety. From the very early stage of my student life till now, he has always been there to support me. Thanks also to all my family members who have always supported and inspired me for this journey. Without their support my journey may not have been complete. Special thanks to my beloved wife Rekha who always stood behind me, taking care of our children Raj and Rose during my absence and has always given me a lot of energy and inspiration for my journey. I could not have completed this journey without your support. Thank you Rekha! My lovely two kids Raj and Rose's smiles and young spirit have always inspired me and made me feel more lively. I always see my dream slowly growing in my kids and it inspires me to work more and achieve more.

Finally, I am thankful to all of you whom I have not mentioned here by name but all you great people I will always remember.

\section{Rajendra Uprety}

December 2016

Wageningen, The Netherlands 


\section{TABLE OF CONTENTS}

Abstract vi vi

Acknowledgements viii

Acronyms and abbreviations $\quad$ xii

$\begin{array}{lll}\text { Chapter } 1 & \text { Introduction } & 1\end{array}$

$\begin{array}{lll}\text { Chapter } 2 & \text { Rice-growing practices in Nepal } & 19\end{array}$

$\begin{array}{lll}\text { Chapter } 3 & \text { Rice farming and livelihood strategies of rice farmers } & 37\end{array}$

$\begin{array}{lll}\text { Chapter } 4 & \text { Variation in field management strategies among rice growers } & 61\end{array}$

$\begin{array}{lll}\text { Chapter } 5 & \text { Nutrient management and its effect on rice yield } & 81\end{array}$

$\begin{array}{lll}\text { Chapter } 6 & \text { Importance of water availability and reliability of supply } & 101\end{array}$

compared to water volume for enhanced rice production

$\begin{array}{lll}\text { Chapter } 7 & \text { Recommendations for and adoption of different rice cultivars } & 115\end{array}$

$\begin{array}{lll}\text { Chapter } 8 \quad \text { General Discussion } & 139\end{array}$

$\begin{array}{ll}\text { References } & 160\end{array}$

$\begin{array}{ll}\text { Thesis Summary } & 181\end{array}$

$\begin{array}{ll}\text { Education Certificate } & 187\end{array}$

$\begin{array}{ll}\text { About the author } & 188\end{array}$

Publications during the $\mathrm{PhD}$ study 189 


\section{Acronyms and abbreviations}

ABTRACO: Agri-Business \& Trade Promotion Multi-Purpose Cooperative Ltd.

AIC: Agriculture Input Corporation

AICL: Agriculture Input Company Limited

ANOVA: Analysis of variance

APP: Agriculture Perspective Plan

ASC: Agriculture Service Centre

AWD: Alternate Wetting and Drying

CA: Conservation Agriculture

CBS: Central Bureau of Statistics

CIIFAD: Cornell International Institute for Food, Agriculture and Development

CVT: Coordinated Varietal Trial

DADO: District Agriculture Development Office

DAP: Di-Ammonium Phosphate

DDC: District Development Committee

DOA: Department of Agriculture

DOI: Department of Irrigation

DFID: Department for International Development

FAO: Food and Agriculture Organization

FFT- Farmers Field Trial

FM: Mineral-fertilizer Managed

FTF: Farmer-to-Farmer

FYM: Farm Yard Manure

GDP: Gross Domestic Product

ICIMOD: International Centre for Integrated Mountain Development

IFPRI: International Food Policy Research Institute

IPM: Integrated Pest Management

IRRI: International Rice Research Institute 
KCL: Potassium Chloride

LRFT: Low Rice Focus and Tenancy

MOAC: Ministry of Agriculture and Cooperative

MOAD: Ministry of Agriculture Development

MOP: Muriate of Potash

MRFO: Moderate Rice Focus and Ownership

MRFT: Moderate Rice Focus and Tenancy

NARC: Nepal Agriculture Research Council

NDM Award: Nepal Development Marketplace Award

NEDECO: Netherlands Engineering Consultants

NGO: Non-governmental Organization

NPK: Nitrogen Phosphorus Potash

NPC: National Planning Commission

NRRP: National Rice Research Program

NRs: Nepalese Rupees

OM: Organically Managed

PARDYP: People and Resource Dynamics Project

RI: Rice Intensification

RSTL: Regional Soil Testing Laboratory

SMIS: Sunsari Morang Irrigation System

SRI: System of Rice Intensification

SRFO: Strong Rice Focus and Ownership

VDC: Village Development Committee

WFP: World Food Program

WUA: Water Users Associations

Zn: Zinc 

Chapter 1

\section{Introduction}




\section{Introduction}

\subsection{Introduction}

In this thesis I explore changes in rice farming practices in Nepal, with particular attention to different strategies by various categories of farmers. Changes in rice farming practices have gained increased interest resulting from the introduction of the System of Rice Intensification (SRI). The characteristics of SRI and claims about its effectiveness, in particular for raising very high yields, resulted in a controversy, as summarized in Box 1.1.

\section{Box 1.1. The SRI controversy}

The System of Rice Intensification (SRI) is a farm-based method for irrigated rice developed in Madagascar by the French Jesuit-priest and agronomist De Laulanié (1993, 2003). It was discovered almost by accident. Due to time shortage of letting seedlings grow before transplantation, students were forced to use very small nursery seedlings of only 15 days old. These seedlings showed very vigorous tillering. It was reported as both resource saving (water, fertiliser and other external inputs) and increasing rice yields. In its typical form, SRI is based on five cultivation practices: (1) transplanting rice seedlings when they are still very young (less than 15 days) carefully and quickly; (2) planting seedlings singly and widely spaced thereby greatly reducing plant density; (3) maintaining soil mostly in an aerobic state and sometimes even including dry periods of a few days, thereby obtaining substantial water savings; (4) regular weed control, rather than weed suppression through flooding or through herbicide use, preferably with a rotary weeder that aerates the soil; (5) fertilization through organic amendments (compost, farmyard manure, green manure) rather than mineral fertilisers. Ultimately SRI is based on a plant physiological theory on tillering by the Japanese rice scientist Katayama; the management practices create conditions to allow rice plants to achieve their full inherent growth and production potential. Interestingly, the central focus on the biology of the rice plant (and the focus on biological soil quality, Randriamiharisoa et al. (2006) goes together with a view that SRI is cultivar-neutral, implying that no novel breeding efforts are required for SRI.

SRI was introduced to the Anglophone scientific world by Uphoff (1999, 2000, 2003) and 
Stoop et al. (2002). After its reported yield increases with simultaneous resource savings (Barison 2002; Koma 2002; Anthofer 2004; Satyanarayana 2004; Kabir 2006; Sato 2006; Uprety 2006), it was introduced in other countries in Asia, Africa and South America. Currently it is practiced in 50 countries. Its rapid spread raises major questions regarding dissatisfaction with conventional rice and the relevance of formal science under farmers conditions (Mishra et al. 2006; Thakur 2010). The spread of SRI was enabled through effective media representation and support networks (Haviland 2005; WWF 2007; Glover 2011; Basu and Leeuwis 2012).

Claims that SRI (and by implication not Green Revolution practices of rice cultivation) is based on the biology of rice plants were quick to receive scepticism, criticism and even outright dismissal by a part of the scientific community (Dobermann 2004; Sheehy et al. 2004, 2005; Sinclair and Cassman 2004; Latif et al. 2005; McDonald et al. 2006, 2008). These papers invited responses from the SRI community (Stoop and Kassam 2005; Uphoff et al. 2008; Stoop et al. 2009; Stoop 2011; Kassam et al. 2011). Especially claims of very high yields, yields that went beyond what is considered the yield potential for rice, raised much commentary. Kassam and Brammer $(2013 \mathrm{a}, \mathrm{b})$ in a paper devoted to Conservation Agriculture and the System of Rice Intensification reported a record yield of rice of $21.16 \mathrm{tha}^{-1} \mathrm{dry}$ weight in India; and Uphoff (2013) even reported a yield of 22.4 t.ha ${ }^{-1}$.

It is possibly this plant focus (rather than management focus) that contributed to this dismissal - the more so, as attempts to grow rice while saving water, nutrients (through management of soil organic matter) and pesticides form part of mainstream rice research (Belder et al. 2004, 2005; Bindraban et al. 2006; Bouman et al. 2006; Senthilkumar et al. 2009; Farooq et al. 2009).

Other issues surrounding SRI were the question whether SRI was a package (blueprint) with synergistic effects between the different elements or whether it can be seen as a decomposable and flexible scheme where individual elements can be adopted depending on local context; and the extent to which SRI had been adopted or not, and even, after introduction, been disadopted. Moser and Barrett (2003) noted a complex pattern of adoption and disadoption of SRI practices in Madagascar. Although SRI practices resulted in higher yields and better performance compared to conventional methods, its adoption rate was low. They also reported 
about disadoption, and continuation of conventional methods with only some elements of SRI, and slow and limited uptake of SRI by small farmers. Such studies also raised questions whether SRI was primarily beneficial to resource-constrained farmers or whether it would benefit the wealthier farmers, thereby exacerbating differences (Barrett et al. 2004).

The SRI controversy has been summarized by Berkhout and Glover (2011; see also Berkhout et al. 2015). Glover (2011) noted that part of the debate was not very fruitful, to some extent due to lack of data and recognized knowledge gaps. He therefore made a plea for an empirical turn where SRI, and other rice growing practices are studied.

Berkhout and Glover (2011) and Glover (2011b), in their reviews of the SRI debate, noted that despite all heated exchange of arguments on the technical merits and potentials of SRI, it is clear that SRI exists as a social phenomenon, but more empirical evidence about its uptake and functioning in agricultural practice is required. Glover (2014) also stated that SRI as a technology for improving rice is a distinctive phenomenon because the focus is primarily on crop establishment and crop management in the field rather than changing the characteristics of the rice plant through genetic techniques. This raises a further issue in the SRI controversy: to what extent is SRI a flexible set of practices or a blueprint; and should agricultural practices be classified only as SRI if all (or most) defining characteristics are present? Or, in a way that is probably more relevant for my thesis, to what extent can practices of intensification in agriculture in Nepal all be subsumed under SRI?

SRI and the controversy around it show the contested nature of agronomic change, referring not only to questions about how SRI works and its effects on the rice crop but also to wider social dynamics, for example labour availability, economic questions about costs, benefits and who profits most, and policy issues, for example the difference between national food security goals and the livelihood strategies of rural households(Sumberg et al. 2012, 2013; Maat and Glover 2012). These questions formed an initial source of inspiration for my $\mathrm{PhD}$ study. It should be noted at the outset that my study was not intended as an empirical test of the claims that SRI practices increase yield. Rather, my thesis is intended as an application of the method of technography in the field of rice-farming practices. Technography is an interdisciplinary methodology for the detailed study of the use of skills, knowledge and techniques in everyday life (Richards 2001; Jansen and Vellema 2011). In 
the framework of agriculture, technography focuses on the ways by which farmers respond to opportunities, adapt to constraints and solve problems in the combined agro-ecological and socio-economic domains. In the framework of the SRI controversy, applying a technographic approach implies an analysis of the changes in rice-growing practices by various categories of farmers. The integrative nature of technographic research involves examining material transformation, technology use and performance as a configuration of material and social elements (Richards 1989). The technographic approach, as specified in section 1.2.2 below, is taken up in this thesis and specified for the analysis of the agricultural intensification in Nepal.

Agricultural systems change as a result of complex, dynamic interactions of a diversity of agro-ecological and socio-economic drivers like agricultural intensification, concentration of production, cultivar choice, industrialisation, deregulation, economic liberalisation and urbanisation (Thompson and Scoones 2009). Diversity and complexity create a range of different contexts and therefore different outcomes in everyday practices for different farmers in different places. In order to understand agricultural change we thus need a highly located, context-specific assessment, rooted in understanding of agroecological, socio-economic and socio-technical dynamics of farming systems.

My thesis explores the performative aspects of SRI looking at both the technology (SRI) and the farmers utilising (elements of) the technology. I studied their overall influences on existing rice-farming practices, agricultural intensification methods (especially, but not exclusively, in rice growing), and diversified livelihood strategies of rice farmers.

In this chapter, I first elaborate the research background and conceptual framework in section 1.2.I then clarify my problem statement and research objectives in sections 1.3 and 1.4. This is followed by a detailed description of methodology in section 1.5. I conclude with a brief overview of the contents of the thesis in section 1.6.

\subsection{Background and design of the study}

\subsubsection{Rice research and development in Nepal}

In Nepal, rice is the main staple food crop. It is also the single largest contributor to the national gross domestic product (GDP). Rice growing accounts for about $50 \%$ of the total 
agricultural area in the country. It also provides around $50 \%$ of the caloric requirements supplied by cereals (Pokhrel 1995). Rice is not only the main staple food, it is also a major source of income and employment for rural people.

Until 1973, Nepal was a major rice-exporting country, with annual exports over 200,000 metric tons of milled rice. The Nepalese government had since the 1960s tried to stimulate rice growing by releasing a number of new and improved rice cultivars (NARC 2014). However, these stimuli were not very successful, and population growth without increasing yields per hectare resulted ultimately in a net shortage of rice, which then had to be imported from neighbouring countries. The government therefore tried to impose organisational reforms to improve agricultural research and extension services (Kaini 2004; Dahal 2010). In 1972 the Rice Improvement Program (now called National Rice Research Program-NRRP) was created for testing and developing new high-yielding rice cultivars in the country. Since then NRRP has engaged with identification of high-yielding and diseaseresistant cultivars (Pokhrel 1995). Within the last half century around 50 improved rice cultivars have been released and recommended in Nepal (NARC 2014). Despite these activities, stagnation in rice productivity (compared to other Asian countries) persisted. In recent years, the Nepalese government tried to revert that development, by raising productivity of rice-growing systems. Among the activities that were recently undertaken, SRI was introduced in Morang district in 2003 by DADO (District Agriculture Development Offices). SRI was proposed to be a package of practices that are cultivar neutral, require low external inputs and therefore fit with the requirements of resource-poor farmers (see Chapter 2 for further details).

\subsubsection{An interdisciplinary study of SRI}

Technology development and subsequent dissemination of that technology is not a simple process. There are several interactive processes going on side by side. Such processes are influenced by biophysical conditions of the agricultural systems and also by surrounding socio-economic and socio-technical conditions. The classic idea of technology transfer highlights processes of adoption, adaptation or modification, partial adoption and disadoption. The relative importance of these processes is context dependent and will be different for different groups of farmers and in different fields. Context here refers both to 
the biophysical and socio-economic context. Therefore a study on adoption and disadoption that a priori separates biophysical and socio-economic aspects will provide an incomplete picture and allows only partial understanding of the dynamic interplay of the social and the natural that takes place during agricultural intensification. It is necessary to explore why particular farmers use particular management practices in specific plots to understand this interplay. It is therefore imperative that such a study has an interdisciplinary design. Richards (1986) made a pioneering study of the complexity of West-African rice farms. He shows how farmers in central Sierra Leone use the geological characteristics of the landscape to create a range of fields, suitable for different types of rice, resulting in a farming system that anticipates the limited availability of labour throughout the season. In the West-African context these varied and flexible rice farms are a more stable and secure source of food and income than attempts from development agencies to develop the lowlands and swamps into irrigated rice fields. Although the West-African rice farms have a certain fixed structure and farmers apply similar techniques, exact use and application varies from season to season. Many factors causing these fluctuations are largely beyond control of the farmer, for example late or excessive rain affecting the quality of burning to clear a field. Anticipating fluctuations within the overall pattern of farming is what Richards (1989) termed agriculture as performance. This notion of performance is taken up in this study to look at the changes of inputs and techniques available to farmers in Nepal, as a result of the introduction of SRI, and how farmers employ these resources to optimize their farming systems.

Besides an understanding of how farmers use resources available to them in their own context, the research for this thesis also tries to understand farmers' responses to introductions by external agents. As explained in the next section, SRI was introduced to farmers in Nepal by the formal agricultural extension agency. To conceptualise this process of trying out and adjusting introduced innovations such as SRI, the combination of biophysical and socio-economic factors is again important. Stone (2007) conceptualizes farmers' responses to introduced technologies as a combination of social and environmental learning. Agricultural technologies evolve in interaction with the users. For farmers the introduction of new technologies implies a process of skilling and deskilling. This reskilling is a continuous process but does not happen automatically. The process of innovation 
diffusion, as described by Rogers (1983) thus implies a conducive agro-ecological and socio-economic environment in which social and environment learning takes place.

Rice is a main staple food for the people in Nepal and therefore a main source of food and income to sustain the livelihoods of rural farmers in the terai region of Nepal. There are different types of work to be performed from seeding to harvesting of rice cultivation. Different socio-economic (cultivar preference, labour availability, land tenure system, cropping intensity, availability of compost/organic manure, investment, profit, income) and agro-ecological factors (land type,available irrigation facility, field distance, rainfall, cultivar characters) influence the works of rice farming. The elements in agroecology and social-economic conditions are not the same for all farmers. That means that the process of reskilling due to the introduction of SRI is different for different categories of farmers. Therefore I have analysed the factors that affect the process of change, leading to different intensification pathways of rice farmers in Nepal.

\subsubsection{Agricultural Research and Extension in Nepal}

Agencies working with technology transfer constitute a very important component of the technology adoption process. It is necessary to generate knowledge about those agencies and their roles to understand their influence on technology adoption and dissemination of SRI. In Nepal there are two main actors working for agricultural technology development and dissemination. Nepal Agriculture Research Council (NARC) is responsible for research and the Department of Agriculture (DOA) takes responsibility for extension. Those two organisations both fall under the Ministry of Agriculture Development. I will briefly describe these organisations and their working situations. As I was a member of the extension system in the time period preceding, during and after my $\mathrm{PhD}$ thesis research (except for a brief period when I worked in Zambia immediately after my sandwich fellowship expired), I will also reflect on my own role as extension officer in this process. This reflection is provided in Chapter 8 (General Discussion).

There are all together 1772 offices (1703 offices under Ministry of Agriculture Development - Department of Agriculture and Department of Livestock Services (recently converted as the Ministry of Livestock and Birds) and Cooperatives (converted as the Ministry of Cooperative and Poverty Reduction); 69 offices under NARC, devoted to 
research). Of these offices devoted to service and extension, 49 offices are at central level and 50 further offices are at regional level. The numbers of district level offices is 227 . The largest number of offices (1377) is constituted by service centres and these are distributed across the country. There are 1823 scientists and support staff under NARC (Dahal 2010). The mandate of NARC is to test, verify and recommend new agricultural technologies or packages of practices for use by farmers. Such technologies and recommendations that are developed by scientists then pass to the extension service from where they are brought to farmers' fields through training, demonstration and seed kits. Under the Department of Agriculture there are 75 District Agriculture Development Offices (DADO) and 378 agriculture service centres (ASC) assigned to agricultural technology support (crops, horticulture, fisheries) (FAO 2010). DADO and ASC form the main outlet for new technologies that have been recommended and approved by research and that are intended for farmers. Regional laboratories (for soil, seed, and plant protection) and training centres play supportive roles. However, farmers do not exclusively depend on DOA and NARC for new technologies. Often farmers obtain new materials and practices (cultivars, fertilisers, cultivation packages) from other sources such as agro-input suppliers, agro-trade fairs from within the country, and especially from neighbouring India (Dhital 2004; Sanogo and Amadou 2010; Bhusal and Singh 2011), where, for example, fertilisers are much cheaper due to government subsidies (see Chapter 5).

In the field, one ASC has to cover about 8,000 farm households (Dahal 2010) by three front-line extension workers (at the level of Junior Technician or Junior Technical Assistant). Dahal (2010) mentioned some critical issues and challenges for the agricultural extension system in Nepal. These include low service coverage, poor technical competencies of the extension workers, low investment in agriculture, and poor infrastructure. Together, these shortcomings make the extension system function with low efficiency. To improve technical support and to increase coverage, the Department of Agriculture has started a group approach in 1989. This approach involves transfer of knowledge, technology and providing additional support and also credit to farmer groups. Through this approach, service providers (government and non-government partners) are working closely with farmers groups in training and technology dissemination. Currently, this group approach is the main approach for agricultural development in Nepal (K.C. et al. 
2003; ABTRACO 2008; Biggs 2008; IFPRI 2012). However, even under this approach the coverage of extension remains below $20 \%$ and service quality that is provided is still not very effective (Dahal 2010; Suvedi and McNamara 2012). Major causes for lack of effectiveness are the generalist (and hence not context or location specific) approach used by extension workers and the poor technical competencies of most of them.

\subsubsection{Investment for agriculture research and extension}

Currently, agriculture in Nepal contributes around one-third of national gross domestic product. Despite its importance for the national economy, public sector expenditure on agricultural development remains low. Average budget allocations to agricultural research and extension remain around $3 \%$ of the total national budget. It is less than $1 \%$ for agricultural extension and less than $0.5 \%$ for agricultural research (Dahal 2010), the remaining $1.5 \%$ is spent on subsidy of fertiliser. The allocation of budgets across salaries, operating costs and capital investments further affects the efficiency of agricultural research and extension. More than $67 \%$ of the allocated annual budget of DADOs and around 53\% budget of NARCs went to staff salaries (DADO 2012). Therefore there remains only limited budget for real agricultural research and extension work like research trials, laboratories expenses, trainings and demonstrations cost, mobility of staffs (materials/operational cost). Within this limited budget, the highest research expenditure by NARC was for vegetable crops (15\% of the research budget), whereas rice, despite its national importance, came second with $11 \%$ of the budget in 2009 (Rahija et al. 2011). The lower focus on rice, compared to vegetables, seems to fit with observations that as part of the agricultural intensification process, farmers switch from rice growing to growing of vegetables for urban markets (see Chapter 2).

\subsection{Challenges for agriculture in Nepal}

The three-years plan (2007-2010) referred to low production and productivity as the root problem in the agricultural sector. More specifically, it listed small land size and land fragmentation, inadequate irrigation facilities, and poor coordination between agriculture and irrigation, and inadequate supply of inputs (improved seed, fertiliser) as main problems for low production (NPC 2007). Additionally, the present land tenure system of Nepal is a 
hurdle for agricultural development (Agricultural Projects Services Centre and John Mellor Associates 1995; Sharma 2000; Sugden and Gurung 2012). Up to 1997, about $80 \%$ of the land in the terai (the lowlands) was cultivated by owners and $20 \%$ of the land was rented (CBS 1997). Since that time, the area of owner-operators decreased and the area cultivated by tenants increased (CBS 1997, 2002; Sugden and Gurung 2012; see also Chapter 2). Farmers who leave agriculture usually move to urban centres. Most of them are small and medium-size owner-operators (CBS 1993, 2002; Sugden and Gurung 2012). Only 13\% of the land was cultivated by big farmers with more than 3 ha land size. Besides the issue of tenure and landownership, further problems related to low agricultural productivity are lack or scarcity of improved cultivars, fertilisers, irrigation facilities, technology and training (Bhattarai 1998; Sugden and Gurung 2012). However, since the APP started (1997), the use of mineral fertiliser increased five times (Thapa 2002; MOAC 2011), improved rice seed increased more than five times (MOAC 2010) and irrigated area increased by 275,000 hectares. Despite these changes, productivity of rice remained more or less similar during the last decade. Farmers still leave agriculture (CBS 1993, 2002; MOAC 2011; Gumma et al. 2011), especially cereal-based conventional agriculture where rice is the main crop.

To counter these developments, the government has launched several initiatives to increase the use of irrigation, improved seeds, mineral fertilisers and pesticides. Moreover, several technology packages addressing crop management have been introduced, including Integrated Pest Management (IPM), Conservation Agriculture (CA)) and the System of Rice Intensification (SRI). It was attempted to implement these packages in the agricultural system in Nepal through the extension system, in order to raise production and profits and to achieve better livelihoods. In most cases the uptake and actual use of these technology packages was partial (Joshi and Bauer 2006a; Berkhout and Glover 2011). What the partial use of SRI implies for Nepal is the central focus of this thesis. The government has set a target to become food sufficient by increased rice production but despite the investments in inputs and technological packages, the target has not been achieved.

The way the government extension service introduced SRI in Nepal is described in chapter 2. There are several reports on SRI from around the world. Berkhout and Glover (2011) summarised the official and grey literature about the initiation and diversified development of SRI worldwide. They conclude that rice cultivation is highly diverse and 
growing conditions are often specific to a region, village, or even differ between households and plots. They also note that responses to SRI are highly diverse - from great enthusiasm to devastatingly negative. The empirical turn they call for is taken up here to study patterns of rice intensification in the eastern part of Nepal, which is the main bowl of food/rice production of the country. However, in Nepal the rice-growing environment (agroecological and socio-economic) is very diverse, including irrigated fields, rainfed upland and lowland fields. Farmers can be land owners or share-croppers. This thesis tries to provide further insight in the intensification processes taking place in this diverse ricefarming landscape.

\subsection{Research objectives, main research questions}

Most studies mentioned in Textbox 1.1. tried to establish direct (causal) relationships between inputs (mineral fertilisers, cultivars, attributes of elements of SRI, etc.) and outputs (agricultural production) but did not devote much attention to interactions and feedbacks of agro-ecological, socio-technical and socio-economic variables. They also used a rather naïve evolutionary model, whereby traditional rice-cropping systems were replaced by advanced practices, without paying much attention to trade-offs and diversification of agricultural systems and livelihood strategies that such new technologies provide. Therefore the main objective of my study was to explore and explain the diversity of rice farming and its intensification, using SRI as a particular example and trigger for further intensification within the (rice) farming system in Nepal. Specifically my study tried to answer the following questions related to current rice farming in Nepal:

1. To what extent is there variation in rice-farming practices in the terai in Nepal? To what extent is SRI (broadly circumscribed) part of that variation? How do livelihood strategies influence technology adoption processes of rice farmers?

2. What are the main factors (agro-ecological and socio-economic) responsible for the different pathways of intensification (including SRI). How do agro-ecological and socio-economic factors interact? What explains diversity in intensification (including SRI) among different fields managed by farmers?

3. What is the effect of rice intensification on conventional rice farming in the study area?

4. What are the causes for low efficiency of mineral fertilisers in many rice fields? What 
are influences of other forms of nutrient management (organic amendments) on rice yield?

5. What are the causes for the often low performance and efficiency of Nepalese irrigation systems (to judge from crop intensity and productivity)? How could performance be improved?

6. What explains farmer choice for recommended and non-recommended rice cultivars? What explains continued use of non-recommended rice cultivars in Nepal after highproductive improved rice cultivars have become available? Why do farmers still use low-productive local cultivars (like Basmati)?

\subsection{Methodology}

\subsubsection{Study area}

Morang district of eastern Nepal, situated between latitudes $26^{\circ} 20^{\prime}$ to $26^{\circ} 53^{\prime} \mathrm{N}$ and longitudes $87^{\circ} 16^{\prime}$ to $87^{\circ} 41^{\prime} \mathrm{E}$, has been selected for this study (Figure 1.1). It is the largest rice growing district of Nepal. Total rice-growing area of this district is about 94,000 ha and average rice yield is $3.1 \mathrm{t} \mathrm{ha}^{-1}$ (MOAC 2009). The district covers an area of $1,855 \mathrm{~km}^{2}$. It has a population size that grew from 843,220 (census 2001) to 1,028,362 (2011). This annual growth of $1.3 \%$ is due to population growth and migration (from Morang to the capital Kathmandu and from the mountainous areas to Morang). Biratnagar, the district headquarters, is the second largest city after Kathmandu and is the main industrial centre of Morang. Altitude varies from 100-2410 m. The climate type is subtropical, of the monsoon type with more than $2000 \mathrm{~mm}$ average annual rainfall. Average annual maximum and minimum temperatures are $30.6^{\circ} \mathrm{C}$ and $14.2^{\circ} \mathrm{C}$ respectively (DADO 2008).

The study was conducted in two village development committees (VDC - the lowest administrative unit), namely Jhorahat and Indrapur from June 2008 to December 2009. Some additional data were also collected afterwards. Information on both VDCs is presented in Table 1.1. 
Table 1.1. Details of the studied VDCs

\begin{tabular}{|c|c|c|c|c|c|c|}
\hline $\begin{array}{c}\text { Name of } \\
\text { the VDC }\end{array}$ & $\begin{array}{c}\text { Area } \\
\left(\mathrm{km}^{2}\right)\end{array}$ & $\begin{array}{c}\text { Population } \\
(2007)\end{array}$ & $\begin{array}{c}\text { Distance (km) } \\
\text { from Biratnagar }\end{array}$ & $\begin{array}{c}\text { No. of farm } \\
\text { households }\end{array}$ & $\begin{array}{c}\text { Cultivable } \\
\text { land (ha) }\end{array}$ & $\begin{array}{c}\text { Area under } \\
\text { rice (ha) }\end{array}$ \\
\hline Jhorahat & 13.17 & 5,414 & 10 & 788 & 1250 & 1180 \\
\hline Indrapur & 25.47 & 19,179 & 28 & 2650 & 2510 & 2250 \\
\hline
\end{tabular}

\subsubsection{Sampling methods and data collection}

These two village development committees were selected purposively. Both have similar extension support systems, being close to an Agriculture Service Centre. In both VDCs SRI was introduced in 2004 (Uprety 2005). Both VDCs have different social settings (see Chapters 3-7 for relevant differences between villages).

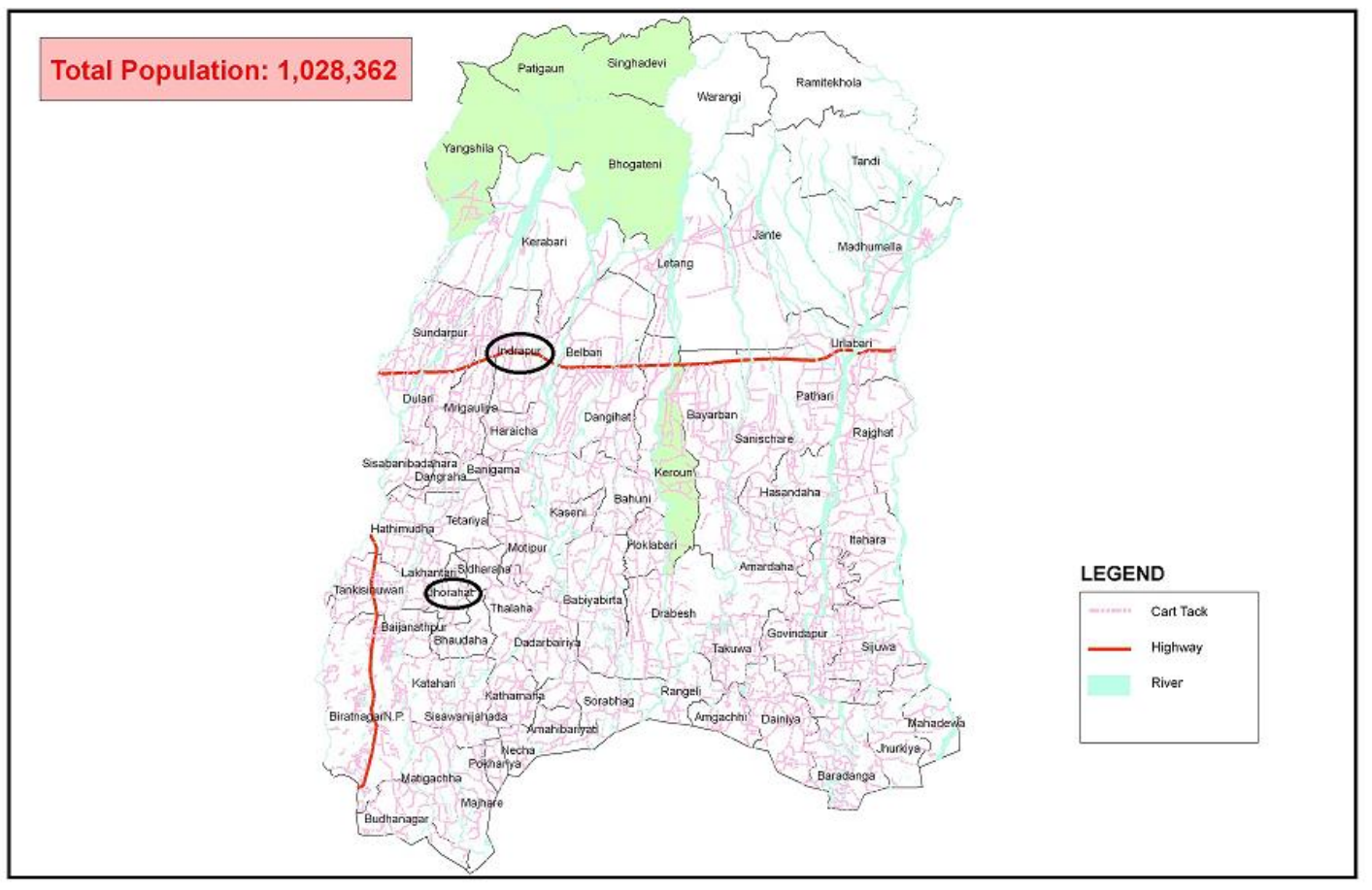

Figure 1. Study area. After http://en.wikipedia.org/wiki/Morang_District. The two VDCs (Village Development Committees), viz. Indrapur and Jhorahat are marked. 
I prepared a list of farmers in both VDCs with basic information on land holding and land tenure (like owner-operator, tenant, or mixed farmer). Afterwards 60 farmers (30 from each VDC) were randomly selected by systematic random sampling. All 60 farmers were rice growers. We monitored their activities (management) and their rice fields in weekly intervals from seeding to harvesting. The main purpose of the monitoring activities of farmers (that included the farmer's family) and fields was to collect data on their livelihood and crop management strategies. Who did what, where and when? What were the resource use strategies, patterns of intensification (land, labour, capital, knowledge) and livelihood diversification?

For this purpose the following information related to livelihood strategies (land size, land tenure, labour within the family, use of hired labour for different agricultural activities, seed use, fertiliser use, land operating system, rice yield as related to family demand, income from rice and other sources, main and secondary occupation by farmer and family members inside and outside agriculture, family size, cattle number, availability of machines, etc.) was collected. I calculated labour for rice cultivation. Both family labour, labour on an exchange basis, and hired labour was included. All labour data were converted to the same unit, number of person days. A normal day equals eight hours, generally starting around 7 AM and continuing up to 5 PM, with a two-hours break from 12 AM-2 PM. The unit of person working days ( 8 hours) forms the basis for wage in the area. In case machines were used, I counted labour on the basis of expenses for that particular work divided by the wage of one person day labour (equivalent labour number). Machine expenses have been based fixed on the basis of rental rate in the study area. Incomes of share-croppers and tenants were calculated after deduction of production costs and land rent (the part of yield that is shared with land owners). Other secondary data (like overall situation of agriculture development, irrigation facility, agriculture loan, poverty, population and its diversity, number of people involved in agriculture and non-agriculture occupations, etc.) were collected from DADO, District Development Committee (DDC) Morang, and comparable relevant sources.

At the same time I collected information on crop management practices by individual farmers in individual plots by observation and interviewing. Most of the farmers cultivated rice on more than one plot. Often those plots were different from each other by 
agro-ecological characteristics and / or by farmer management practices. Altogether I studied 165 rice fields (94 in Jhorahat and 71 in Indrapur) cultivated by those 60 farmers. Those 165 plots (which were different by topography, ownership, water accessibility and cropping intensity) were kept on season-long observation.

Instead of using a pre-conceived classification of farmers and fields (using an $a$ priori choice to classify farmers and / or their fields as SRI or non-SRI), I applied factor analysis to determine their pattern in livelihood strategies and land management. Part of the observed factors were used to construct similarity matrices, from which classification of livelihood strategies or field management was derived. Other observed factors were not used to construct the various categories, but were subsequently used to test for further differences between groups. Factors used in factor analysis of the livelihood strategy were land size, amount of rented land, family labour, fraction of hired labour, availability of bullocks and / or tractor, cropping intensity, average yield, machine use for land preparation, number of small animals, family rice need, number of occupations and family members in nonagriculture occupations. Similarly for the crop management strategies I used seedling variables (seedling age, number of seedlings per hill, hill density per square meter), days of transplanting (starting from the first transplanting in that particular village), use of mineral fertiliser and organic amendments such as manure and animal manure, weeding days after transplanting, topdressing days after transplanting, and percentage of nitrogen fertiliser used for topdressing. Livelihood strategies and field-level crop management strategies were assessed independently and subsequently correlated to test for common underlying causes for diversity.

Other variables like water availability, field distance, land type, land ownership, water use, cultivar use, etc., were not included in the factor analysis but their relations with particular forms of field management were analysed separately. Further details of data collection and analysis are presented in Chapters 3 to 7.

\subsubsection{Data analysis}

Statistical Package of Social Science (SPSS) computer software was used for data analysis. Factor analysis was used to cluster farmer livelihood strategies and field management strategies. This method is generally used to discover patterns of relationships among 
variables (Darlington 2012), or to reduce the number of variables and to detect structure in the relationship between variables (StatSoft 2012). I further applied Analysis of Variance (one-way ANOVA), Chi-square, likelihood ratio tests (G tests), and t-tests to test for differences between groups (of farmers and fields). Correlations between variables have also been calculated.

\subsection{Overview of the thesis}

Chapter 2 (Rice growing practices in Nepal) presents an overview of existing rice farming practices, land tenure and manure use. This chapter also serves as an introduction to the empirical chapters 3 to 7 .

Chapter 3 (Agricultural intensification and the livelihood strategies of rice farmers) explores livelihood strategies and their dynamics. It also looks at variation in technology adoption (pathways to intensification) among rice farmers. I present findings how farmers prioritise their family resources in different occupations in order to improve their livelihood. Further I analyse the relationship between livelihood strategies and (rice) intensification (research question 1 and 2). This chapter focuses on family-level livelihood strategies and the influence of new technologies.

Chapter 4 (Variation in field management strategies among rice growers) presents different crop management practices applied by farmers in particular contexts. This chapter focuses on field-level strategies or management practices applied on particular fields. I address the question why there is variation in management practices between different fields of the same farmer (research questions 2 and 3). Furthermore the effects of SRI introduction on overall rice farming in the study area are analysed.

Chapter 5 (Nutrient management and its effects on rice yield) specifies details about nutrient management on individual plots and its consequences for rice yield. It tries to understand differences in fertiliser use efficiency in relation to amounts and timing of fertiliser use and management of organic amendments. Increased fertiliser application was an important recommendation of APP and fertiliser use increased more than four times since 1997 (when APP started) but Nepalese rice productivity has not increased. This chapter analyses the reality behind this inefficiency of fertiliser application and nutrient management (research question 4). 
Chapter 6 (Water availability and reliability and rice production) presents the relation between water availability and reliability of supply with overall rice farming. There are several types of irrigation systems (publicly managed and farmer-managed; big systems and small systems) in Nepal. My data confirm the higher efficiency of farmer-managed irrigation systems over publicly managed systems and I try to explain causes for this finding (research question 5).

Chapter 7 (Rice cultivars recommended for and adopted in Nepal) describes the adoption of recommended cultivars and the continued use of non-recommended cultivars among rice farmers (research question 6). It links cultivar choice to livelihood strategies and pathways of intensification, as related to labour availability and costs.

Chapter 8 (General Discussion) summarises and synthesises the thesis. It provides recommendations for further research to better understand agricultural intensification in general (and rice intensification in particular) in Nepal. It also reflects on the role that agricultural research and extension could play. 


\section{Chapter 2}

Rice-growing practices in Nepal 


\subsection{Background}

Rice is the main food crop and the basis for livelihood in the Nepalese terai (lowlands) from time immemorial. During its long history, rice growing has undergone various changes and current changes in rice growing (including changes that relate to the System of Rice Intensification, SRI) are part of that dynamic. Initially rice was directly seeded or grown in nurseries and transplanted. Improvement of irrigation infrastructure implied more certainty about the moment there is enough water to start growing rice under flooded or submerged conditions, allowing timely preparation of nurseries and, consequently, many farmers shifted to transplanting. Animal (bullock) and human labour are still dominant sources of power for rice farmers, while mechanisation is mostly limited to simple tools and bullock-drawn implements although some farmers use power tillers and tractors. Land sizes for the majority of farmers are medium to small and under such conditions it is not always economical to keep a pair of bullocks year-round by all farmers. This has led to forms of differentiation. Traditionally and culturally land preparation and ploughing is the work of men. Families that do not have male labour for land preparation or ploughing (mostly widows and femalemanaged farms where the husband has a job outside agriculture) usually do not keep bullocks.

Initially, there were hundreds of local cultivars grown in Nepal. These cultivars were generally grown without mineral fertiliser. For those farmers animal manure or vegetative organic amendments were the main sources of nutrients. After the introduction of new highyielding rice cultivars, use of mineral fertiliser took off and is increasing. However, even after efforts from government and NGOs to introduce high-yielding cultivars and mineral fertiliser for higher yields, Nepalese rice farming is still a mixture of traditional and modern practices (for nutrient management and cultivar choice, see Chapters 5 and 7).

Transplanting rice seedlings is only possible when there is sufficient water on the fields for land preparation (puddling). Therefore water availability influences several rice cultivation practices (seeding, seedling age, seedling density, transplanting date, weeding etc.). However, in the majority of rice fields irrigation water is unreliable and farmers rely on rainfall. More than half of the rice-growing area in Nepal is rain-fed, and for these fields farmers need to wait for sufficient rainfall for land preparation.

This chapter provides an overview of existing rice cultivation practices (like nursery management, land preparation, transplanting and double transplanting methods, weed 
management, nutrient management, water management), history of SRI, land tenure system and labour role in rice farmingin order to provide the basic knowledge about Nepalese rice farming for the empirical chapters.

\subsection{Rice-farming practices in the terai of Nepal}

This section describes the cropping calendar and looks at adaptations therein as a function of cultivar choice and cropping intensity, which includes not only rice but also other crops in an annual rotation.

Rice growing:In Morang district rice can be cultivated in three seasons in cases of reliable and sufficient water availability. However, cropping intensities of $300 \%$ are not within the possibilities for all farmers, so many farmers grow only two crops per year (cropping intensity 200\%). The rainy (monsoon) season (June-November) is the main season of rice cultivation when farmers cultivate rice on more than 80,000 ha within the district. Winter-season rice (December-May) is cultivated on about 2,000 ha and spring-season rice (February-July) rice is cultivated on about 20,000 ha. Outside the monsoon season farmers also crop vegetables, pulses and other cereals. In order to achieve comparability between yields by farmers who vary in cropping intensity between $200 \%$ and $300 \%$ (and who partly grow other crops as well), all data on rice productivity are based on rice production in the monsoon season. As cropping intensity and productivity are usually correlated, actual differences in agricultural production by different farmers are therefore larger than inspection of the data on crop yield (in the main season) indicates.

In general winter-season and spring-season rice is cultivated only in areas with reliable or assured irrigation facility. Farmers normally use improved rice cultivars in winter (Jaya) and in spring season (Chaite2 and Hardinath 1; see Chapter 7). In general management practices of winter-season and spring-season rice are less diversified than those of mainseason rice. Main-season rice farming (monsoon season) is very widespread and occurs over almost all cultivated areas of the terai. There is a very large diversity in management practices, both agro-ecologically and socio-economically (Chapters 3 and 4).Main-season rice represents more than $80 \%$ of rice cultivation and production in Nepal. Because of the fact that almost all farmers grow rice during this period, labour shortage occurs, which results in increased wages 
for hired labour. Managing the cropping calendar is also a way to manage fluctuation in wage rates.

Nursery: Farmers start their activities of main-season rice cultivation after the onset of the monsoon rains with the preparation of nursery beds and with seeding (Figures 2.1 and 2.2). Farmers use two types of nursery beds. One type is the puddled wet bed and the other is the garden-type dry bed. The dry-bed type is very common in Kathmandu valley, on hill sides (and similar water-scarce areas as in other Asian countries, see Barker and Herdt 1985) and for rice cultivation in the spring-season nursery in the terai.

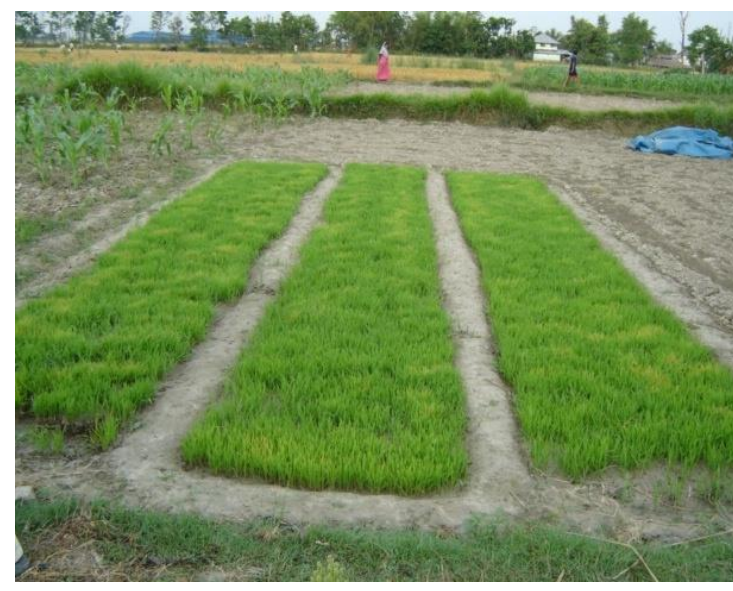

Figure 2.1. Dry-bed nursery (Indrapur, 2008).

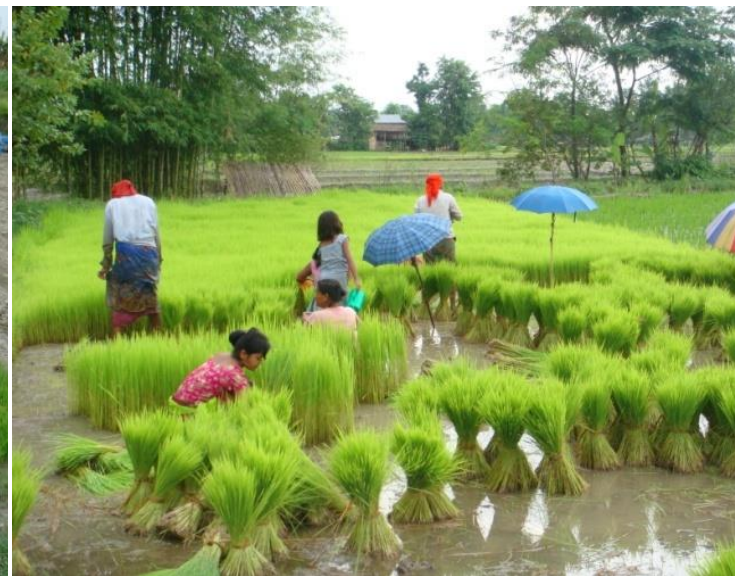

2.2. Puddled wet-bed nursery Indrapur, 2008).

Farmers state that the dry-bed nursery is the best option for seedling preparation if there is uncertainty of irrigation water. Another benefit of the dry-bed nursery, as reported by farmers, is related to seedling maturity. Farmers claim that dry-bed nursery seedlings remain physiologically younger and have more tillering capacity, even after a month, compared to puddled wet-bed nursery seedlings. The dry seedbed is also used to produce seedlings in a short period of time or for transplanting younger seedlings. The puddled wet bed is common for the main-season rice in the terai. Sometimes seedlings will remain in such nurseries for more than two months and in very high densities (resulting in overcrowding). This practice by farmers is primarily a time management strategy, related to uncertainties of water for land 
preparation and transplanting. In fact, it is very difficult to keep dry-bed nursery seedlings alive for longer periods in the absence of irrigation.

Land preparation: Land preparation is the second step in the cropping calendar of rice cultivation. Farmers use a bullock plough or tractor or power tillers (Figures 2.3 and 2.4). Farmers till their land three to four times before levelling, keeping an interval of several days between two rounds of tillage. After ploughing and uprooting weeds, these are left to decompose for several days before the next round of ploughing starts. However, this time interval is only possible for farmers who own bullocks or power tillers. Farmers who do not and hence depend on other farmers for bullocks or tractors for land preparation, need to hire and therefore try to finish land preparation and subsequent transplanting work within a short time span. They achieve this through repeated ploughing without those intervals of a few days.

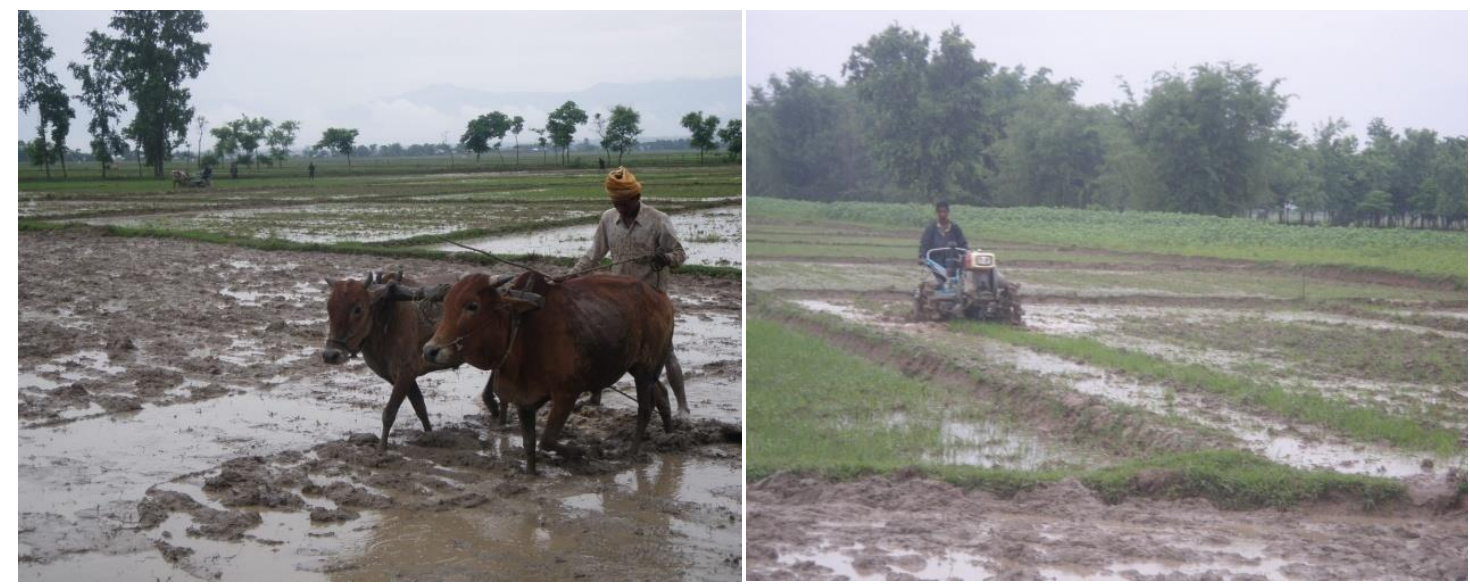

Figure 2.3. Ploughing and levelling of the Figure 2.4. Ploughing and levelling of the fields by bullock (Jhorahat, 2008) fields by power tiller (Jhorahat, 2008)

The strategy by owners of bullocks or power tiller to prepare land is generally considered better because of proper decomposition of weeds and previous crop stubble. In such cases weed problems are less severe. After land preparation seedlings are transplanted. Most rice seedlings are transplanted into puddled fields. Only in very few places is direct seeding in practice. This practice was not observed at all in Morang district. 
Fertilisation and manuring: After land preparation, and immediately before land levelling and transplanting seedlings, farmer apply basal doses of mineral fertiliser. Fertilisers used consist of urea (for $\mathrm{N}$ ), di-ammonium phosphate (DAP; for $\mathrm{N}$ and $\mathrm{P}$ - some soils strongly sorb $\mathrm{P}$, Schreier et al. 1999) and potassium chloride ( $\mathrm{KCl}$; stagnating or declining rice yields have been attributed to K deficiency; Dobermann et al. 1998; Fageria 2001; Ladha et al. 2003; Von Westarp et al. 2004; Boling et al. 2006).The recommendation by the public agriculture extension service is to apply DAP and $\mathrm{KCl}$ as basal application and urea for basal application and top-dress in split doses. Fertiliser recommendation is different for irrigated rice (100:30:30 $\left.\mathrm{kg} \mathrm{NPKha}{ }^{-1}\right)$ and rain-fed rice $\left(60: 20: 20 \mathrm{~kg} \mathrm{NPKha}^{-1}\right)$. Next to mineral fertiliser, organic amendments are used, both animal manure (but also subject to competing uses, see Box 2.1) and green manure. Recommendation for organic amendments is $6 \mathrm{t} \mathrm{ha}^{-1}$ (Agriculture diary 2011). Manures are generally incorporated after first ploughing (see Chapter 5 for further analysis).

Box 2.1. Competing uses for manure. The Tharu constitute a terai-indigenous community living in central to western Morang. Most of the Tharu depend on agriculture for their livelihood. They use most of their manure for guitha making (cattle dung cake that is used as fuel; Figures 2.5 and 2.6). Only a minor proportion of manure is used in fields. When they apply manure for agricultural purposes, they do not apply it in rice fields, but in fields with vegetables and spices like garlic. Especially garlic is a profitable and socially important cash crop for Tharu.
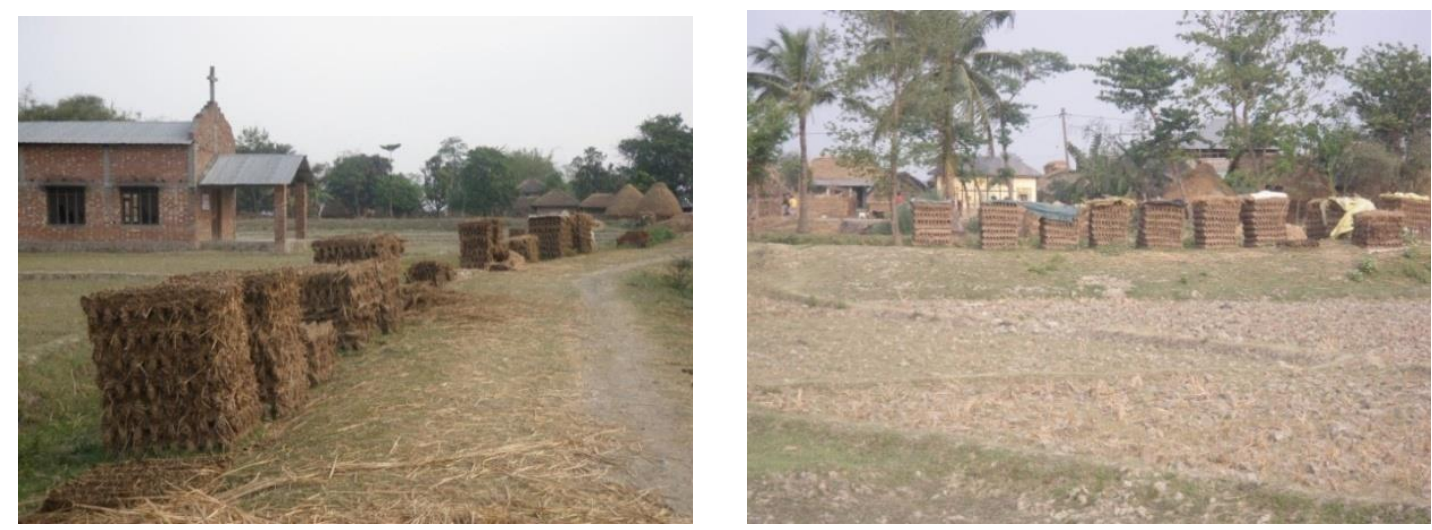

Figures 2.5 and 2.6. Guitha making (cattle dung cake) is characteristic for villages of the teraiindigenous Tharu community (Jhorahat, 2008). 


\begin{abstract}
The common feature in almost every Tharu community in the winter season is garlic cultivation and the use of vegetable gardens. These crops are controlled and managed by female members of the family. They use most of the manure (left after guitha making) and ash (kharani, the ash left after burning guitha or timber) on garlic and vegetable fields. In this community the production of food crops for domestic use is the responsibility of the male head, whereas the production of vegetables and spices for selling at local markets is the responsibility of the female members of the family (Mehta et al. 2014). Tharu people are well known to make tasty and spicy foods, for which garlic is a very important ingredient. While some part of garlic is for home use, the major proportion is for selling on local marketsand subsequent buying of important items in the weekly local market. They usually sell in small amounts. Because garlic is a very important crop for the community, it gets a lot of attention. Though they know the importance of manure for food crop production, they prioritise garlic and vegetables over rice.
\end{abstract}

Seedling preparation and transplanting: As a traditional practice farmers uproot, clean, and make a bundle (Figure 2.2) of seedlings one or two days before transplanting (Figure 2.7). If the field towards which the seedlings to be transplanted have to be transported is far from the nursery, seedlings will be transported by bullock cart (Figure 2.8). During uprooting, storage and transport a large part of the root system of older seedlings will be heavily damaged (the removal of adhering soil material makes seedlings less weighty for transportation) and desiccated. But most of the younger seedlings grown on dry nursery beds are uprooted carefully and transplanted immediately, resulting in less root damage (Figure 2.8). These seedlings survive better and resume growth almost immediately, whereas root-damaged older seedlings take eight to ten days to establish (turn green with new root system) in the main field after transplanting.

The age of seedlings for transplantation changed after SRI was introduced in Morang district. Generally age of seedlings for transplantation is less now and younger seedlings are used. Introduction of SRI was with a recommendation to transplant seedlings of eight to twelve days old. After several field tests, seedling age was standardised not any longer according to seedling age but according to seedling stage (three-leaf stage, which appears in seedlings of eight to twenty days old, depending on season and nursery management) (Uprety 
2011). Details about seedling age and the effect of seedling age on rice production will be presented in Chapter 4. In 2008 the range of seedling age in my study was 10-57 days. Seedlings were transplanted in densities ranging from 1-12 seedlings per hill, 11-49 hills per square meter. In all, seedling density ranged between 11-441 seedlings per square meter. These data show large variation in seedling age and density as part of different field management strategies.

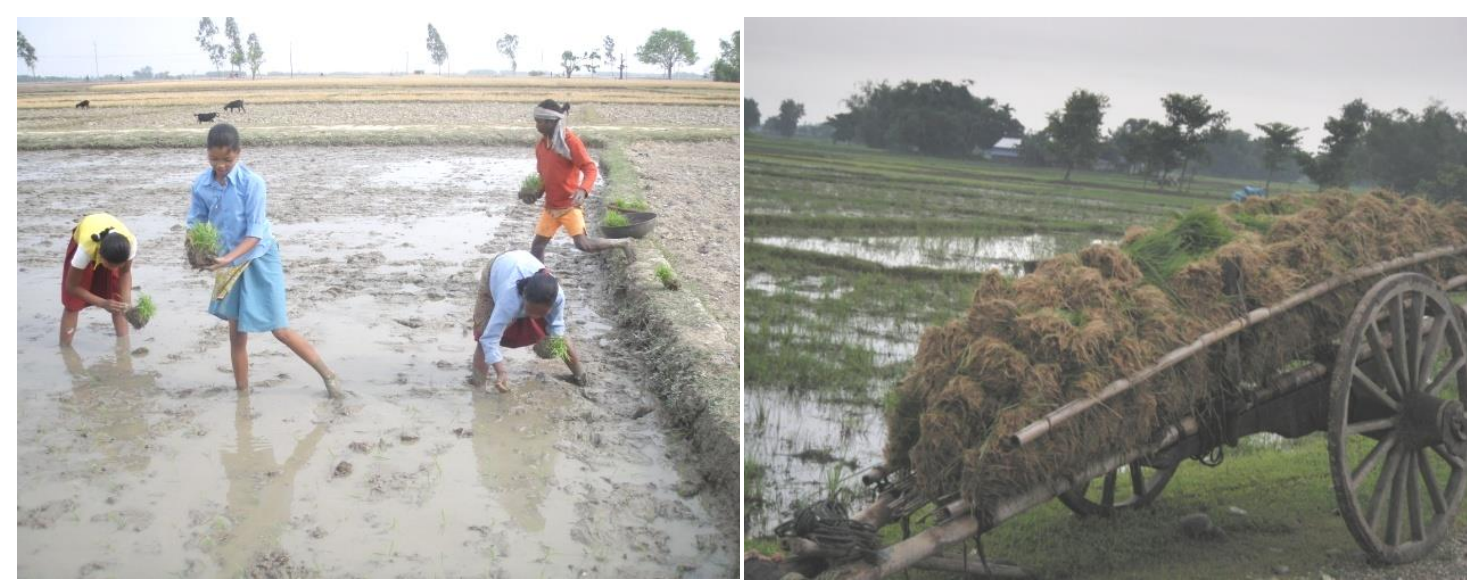

Figure 2.7. Transplantation of young Figure 2.8. Transportation by bullock cart of seedlings from dry nursery bed (Jhorahat, older seedlings for subsequent transplanting 2008). in puddled wet bed (Jhorahat, 2008).

In the Nepali calendar, the date Ashar 15, which falls around the end of June, has special significance for rice farmers in the terai as it is considered the prime day for rice transplanting. Transplanting between 15 days before and 15 days after Ashar 15 gives the best subsequent rice crop growth. However, it is not possible for every farmer to transplant rice always within this preferred time due to lack of water because of a delayed onset of the rains, or labour shortages and/or a limited access to ploughing implements and draught power.

Double transplanting: Double transplanting (Figures 2.9 and 2.10; Box 2.2) is a common practice in the terai. Double transplanting implies that farmers transplant their rice plants twice, with the main transplantation (the second transplantation) being delayed. With double transplanting farmers first transplant 25-30-days old seedlings at high plant density (seedling 
hills are 10-15 cm apart, with 6-10 seedlings per hill). For this first transplantation farmers use small plots (about 25\% of the intended area for second transplanting). 25-30 Days after first transplanting, when their fields become ready, these first-transplanted seedlings are uprooted completely and transplanted again. For that second transplanting farmers use a lower seedling density (1-3 seedlings per hill) at wider spacing of $15-20 \mathrm{~cm}$.

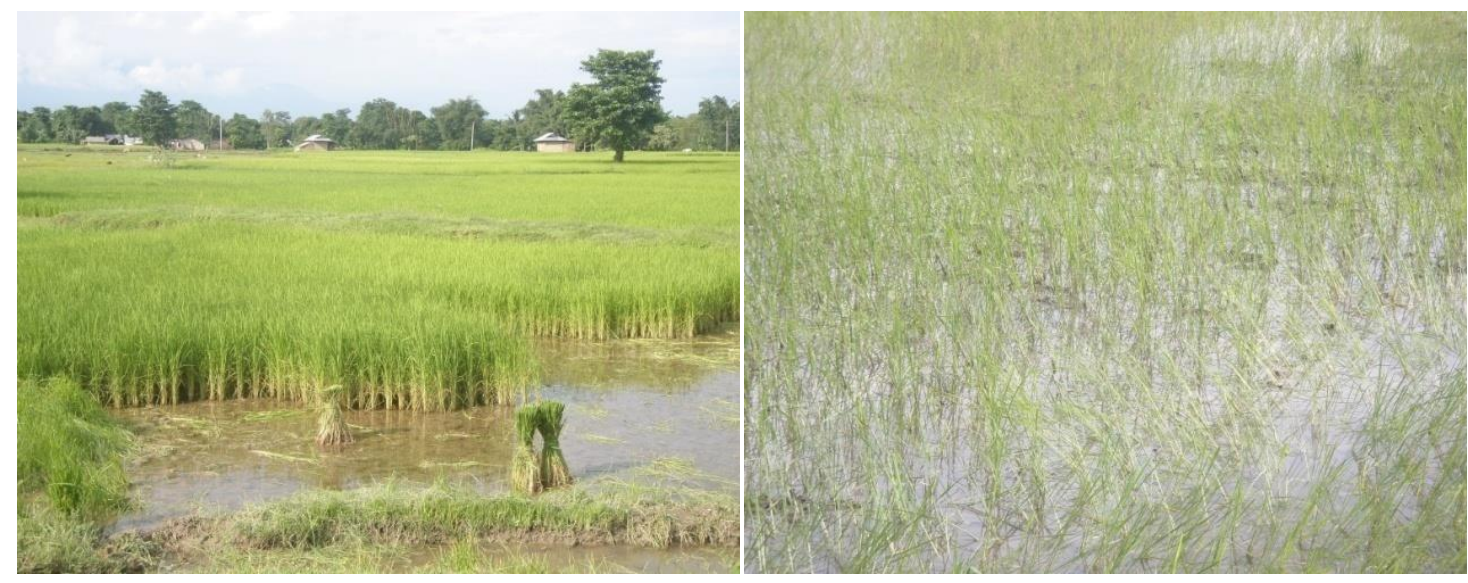

Figure 2.9. Double transplanting. Field after Figure 2.10. Double transplanting. Field after first transplanting (Jhorahat, 2008). second transplanting (Jhorahat, 2008).

At first sight, this method seems inefficient and too labour-intensive compared to single transplanting. However, under certain conditions this method is beneficial to farmers in two respects. First, farmers can save money by using cheap labour for their second transplanting, when most of the transplanting work has already been finished. Money saving for labour has to be traded off against more labour (for double transplanting on average 36 man days ha $^{-1}$ are used, compared to 29 man days $\mathrm{ha}^{-1}$ for conventional single transplanting). However, those farmers need less time and (paid) labour for weeding ( 4 man days ha $^{-1}$ for double transplanting compared to 17 man days $\mathrm{ha}^{-1}$ for conventional single transplanting). Taken together there is no significant difference in labour time between both methods if time for transplanting and time for weeding are added (Chapter 4). Moreover, yield of double-transplanted rice is generally higher than that of the conventional single-transplanted rice, when transplanting is delayed. Additionally, when farmers use Basmati cultivars for double transplanting, this will result in higher net-income due to its high selling price (Chapter 7). 


\section{Box 2.2. Double transplanting as profitable strategy for a big farmer: Double}

transplanting of rice has a different impact on different categories of farmers. Various factors explain the occurrence of double transplanting. Farmers in swampy lowland use double transplanting because in such fields transplanting will only be possible at a later stage (due to water stagnation at an early stage). In other cases, when sufficient water is unavailable, farmers resort to double transplanting because transplantation often has to be delayed.In some cases double transplanting is unrelated to water availability as in the case described below.

On August $17^{\text {th }}, 2009$ I went towards Indrapur from Jhorahat. In Banigama VDC (between Jhorahat and Indrapur, $12 \mathrm{~km}$ north of Biratnagar) about 50 labourers (the largest numbers of labourers that I observed during my study) were working in the rice field of Mr Ramesh Basnet. Ramesh Basnet lives in Biratnagar. He cultivates on 10 hectares of his own land. He depends on hired labour for most of the agricultural work, except for land preparation that he had completed with his own tractor. At that time he was using Basmati cultivar for double transplanting. He used 28-days-old seedlings for first transplanting and after one further month the first field was completely uprooted and transplanted againin the second field (Figure 2.11-13).

He provided three reasons for choosing double transplanting, cultivar choice and timing:

- By double transplanting he tried to manage yield reduction due to conventional transplanting that is delayed or to transplanting older seedlings;

- By choosing Basmati (a photo-sensitive cultivar) he tried to manage time to completion of the rice life cycle (while taking into account that the price for Basmati is almost double compared to other cultivars in local markets, which makes low production still quite profitable);

- By double transplanting he was less dependent on the competitive market for labour supply (at that time there was less than 5\%of the fields that needed to be transplanted and hence sufficient labour was available without having to pay additionally) for his transplanting. 


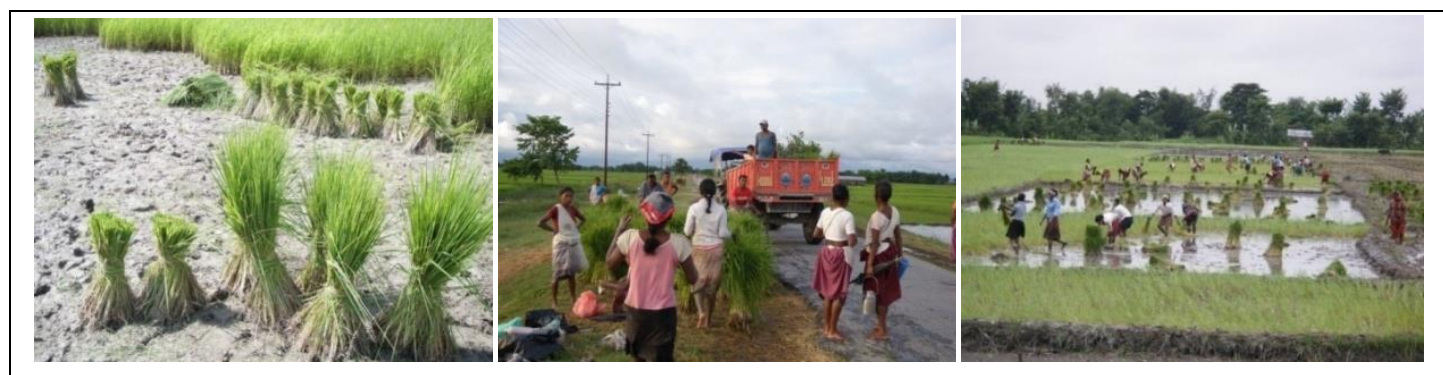

Figure 2.11-13. Sequence of double transplanting (uprooting from first field, transporting and transplanting again (Banigama VDC 2009).

After transplanting, major activities associated with rice cultivation are water management, weed management and nutrient management (mainly topdressing). Farmers use continuous flooding method of irrigation or alternate wetting and drying (AWD) system of irrigation (see Chapter 6 for an analysis of water management).

Most farmers manage weeds, but some farmers do not. Besides the weedmanagement effects of single and double transplanting, farmers use manual, chemical and mechanical weeding methods, depending on their specific farming situations. Plant protection measures are considered relatively unimportant. In case of severe disease or damage from insects, farmers consult with local extension agents or agro-input suppliers. Harvesting and threshing work are more or less similar for all rice farmers.

\subsection{Land tenure and rice farming in Nepal}

The land tenure system in Nepal (Chapagain 2000; CSRC 2009) influences overall agriculture as well as rice farming. Formal data provided by government agencies or the bureau of statistics Nepal indicated that about 24\%of cultivated lands in Morang district were under tenant cultivation. However, these data are considered to be incorrect (Sugden and Gurung 2012). The reason why these data are incorrect is due to the existence of several informal share-cropping agreements that are not registered by government agencies and not reported as such during agriculture censuses, even though they exist already for a long time. Share-cropping systems persist because they prevent land claims by tenants (Mohiyanihaktenant right on $50 \%$ cultivated land) which is not possible in informal system (Wily et al. 2008). Under this share-cropping agreement landlords provide land to tenants for cultivation 
and share $50 \%$ of the costs for seed and fertiliser. The other $50 \%$ of the expenses and all the work falls under the responsibility of the tenant. Whatever is produced from that land will be divided equally $(50 / 50)$ between landlord and tenant. The current situation is that a large part of the terai is cultivated under this share-cropping system.

In my study area around $53 \%$ of the land is cultivated by tenants and $47 \%$ by landowners. Land that is cultivated by tenants mainly consists of land under share-cropping arrangements (90\%), while land under a fixed-rent system constitutes only $10 \%$ of the land cultivated by tenants. Rice growing by tenants does not seem to be always very profitable. Among tenants $11 \%$ who grow rice do not have a positive earning and even lose on rice growing (costs exceeding profits), while $39 \%$ of the tenants get less than NRs. 5,000ha ${ }^{-1}$ as profit (whose value is equivalent to about 300-400 $\mathrm{kg}$ rice per hectare). Only $5 \%$ of tenants (all from Indrapur and working under a fixed-rent system) got more than NRs. 30,000ha ${ }^{-1}$ net profit from main-season rice in 2009. Besides that income, fixed-rent tenants further get income from the crops grown during the two other seasons (Barker and Herdt 1985) in better irrigated area like Indrapur (see Chapters 3 and 6). An example is provided in Box 2.3.Among the less profitable tenants $83 \%$ were from Jhorahat, mostly from the teraiindigenous community. Low profit was due to low production of rice that was less than 3 tonsha $^{-1}$.

Low income under share-cropping arrangements is due to the fact that rice farming is labour-intensive. Whereas tenants provide all the labour (and more than $80 \%$ of production costs go to labour), their share of benefits is only $50 \%$. So share-cropping tenants may not have much motivation to increase production. In fact, they are probably better off when they work in other areas and in other fields during peak time when wage rates are higher. Only in times when there are very limited opportunities for wage labour, do they work on their own rented fields. As a consequence, these farmers cannot optimise timing of activities in their own fields and are stuck in the low productivity of these fields. Such farming practices, where farmers are primarily obtaining income through their being hired as agricultural labourers and therefore remain stuck by the very low productivity on their own fields, has also been reported from various parts of Africa (Tittonell et al. 2010; Chikowo et al. 2014). 
Box 2.3.Gobinda Dhakal is a successful tenant farmer of Indrapur VDC with one katha (333 $\mathrm{m}^{2}, 0.03 \mathrm{ha}$ ) land He also rents one hectare land under fixed-rent system. During the mean rainy season he uses all his land for rice cultivation. In 2008 he used short-duration (120 days) Hardinath 1 cultivar in half of his rice land under SRI method, in the plot that was close to his residence. The yield was 4.2 tons from this 0.5 hectare. After harvesting rice he cultivated tomato, cauliflower, cabbage, potato and broadleaf mustard for commercial purpose. Up to 2008 he used a pair of bullock and sometime hired power-tillers for land preparation.

He showed me his newly purchased power-tiller that was run by his 13-years-old son. The power-tiller made land preparation work easier, quicker and more cost-effective. He also earned extra income by hiring out his power-tiller to other farmers.

He was planning to buy that 0.5 hectare of land from his landlord, the cost of which was finalised at NRs. 500,000. Saving so much money from one hectare of (rented) land is beyond imagination for the majority of conventional farmers. But he harvested 6.6 tons main-season rice ( 1.8 ton from the other 0.5 ha that was further from his residence), 5.6 tons spring-season rice, about 4 tons maize and wheat and more than 20 tons of different vegetables every year(just to give 1.8 tons rice to the landlord for the rent). Due to this profitable situation he was able to adequately manure his rented field. His wife and three children (who go to school but outside schooling hours and season work on his fields) support his farming and they have been improving their living standard year after year.
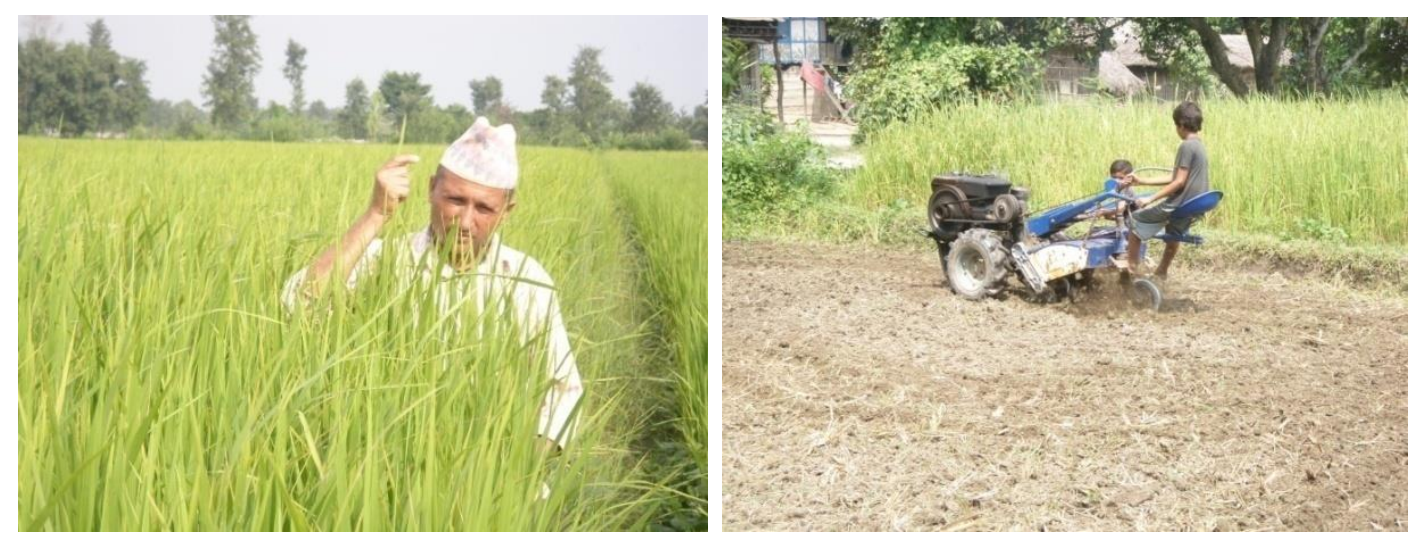

Figures 2.14-15. Gobind in his SRI field; his son preparing a field for vegetables by powertiller (Indrapur 2008). 


\subsection{Labour intensity and labour costs}

Figure 2.16 provides an overview of labour activities (based on my own data, collected in Morang district in 2009) and the costs involved with that labour, either own labour or hired labour. It does not differentiate labour costs according to farmer livelihood strategies (see Chapter 3). From the figure it is clear that land preparation (40\%) demands most labour costs, followed by harvesting with threshing (21\%) and transplanting rice seedlings (11\%). Other costs like seeds, mineral fertiliser and irrigation constitute less than $20 \%$.

Considering high costs associated with labour it is likely that farmer strategies involve decisions to strategically deploy labour, e.g., by evaluating the options for more remunerative activities outside agriculture, by hiring paid labour (even if this involves risks for lower-quality work and / or higher labour expenditure), or by investing in labour-saving strategies. It is also in the framework of labour-saving (or not) that the System of Rice Intensification (SRI) is relevant for rhiziculture.

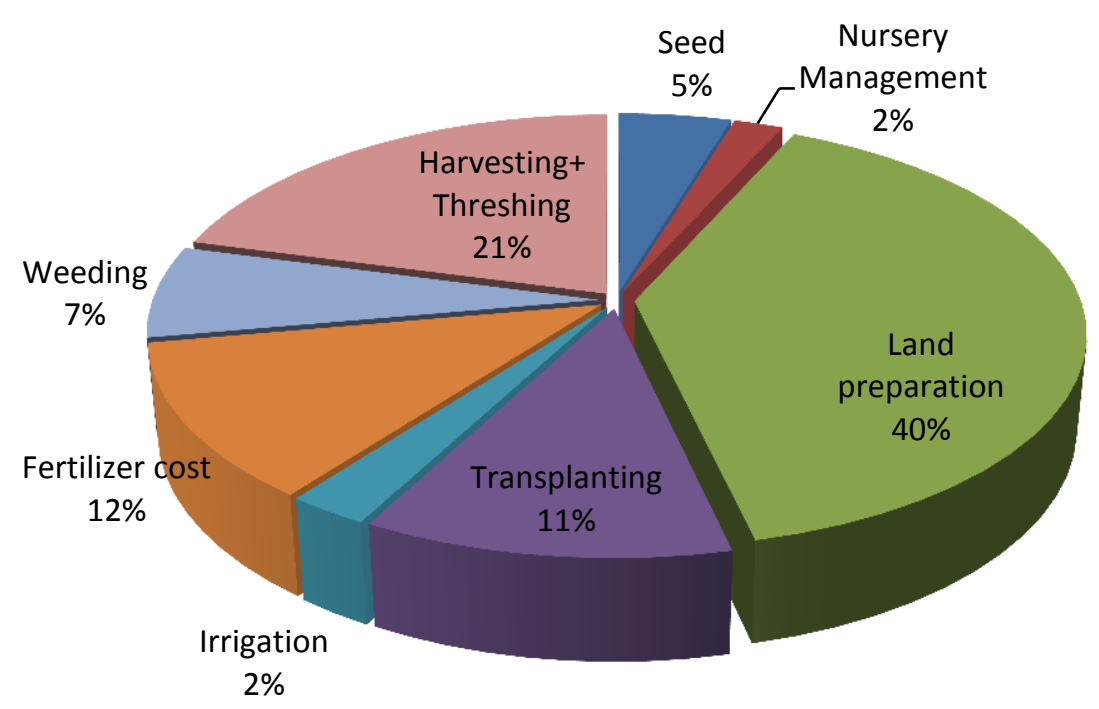

Fig. 2.16. Overview of labour costs for rice farming. Source own data, collected in Morang district 2009. 


\subsection{History of SRI in Nepal}

By the initiative of Professor John Duxbury of Cornell University (Ithaca, United States of America) in 1998 and 1999, SRI was tried, but rather unsuccessfully, at research stations of the National Agricultural Research Council. In 2001, there was another trial at the Bhairahawa research station under the National Wheat Research Program. These trials did not show the effects that are usually attributed to SRI. In fact, conventional practices gave a slightly higher yield (by 5.6\%). These trials seemed to demonstrate that SRI practices 'do not work' in Nepal (Uphoff 2007). However, when trials were repeated at Bhairahawa in 2002, SRI showed a 33\% yield advantage compared to conventional practices, and SRI trials in nearby farmer fields gave even 50\% more yield than did on-station trials (Bhatta and Tripathi 2005). However, a negative verdict on SRI had already been imprinted in the minds of agricultural scientists in Nepal due to the earlier reported lack of effects (Mahato 2011). Several senior scientists, including the former rice coordinator and the director of crop and horticulture research of NARC, had negative attitudes towards SRI. This negative attitude by several NARC scientists appeared in several formal and informal meetings that I attended. But the DOA and its professionals did change towards a more positive attitude after exposure to successful field experiments.

SRI testing continued by several enthusiastic professionals working under DOA and NGOs. SRI trials were undertaken at Sunrise Farms near Kathmandu in 2001 by the NGO Appropriate Technology Asia. These trials gave favourable but not strongly positive results. In 2002, the International Centre for Integrated Mountain Development (ICIMOD), working for the conservation and the better livelihood of the people in mountain regions, also began working with SRI under its PARDYP project in the Jhikun Khola watershed, documenting positive results in three years of farmer-centred trials (Dhakal 2005; ICIMOD 2007). In 2002 and 2003, the Sunsari-Morang Irrigation Project, funded by DFID and implemented by the Dutch consulting firm NEDECO, did comparison trials of SRI vs. improved practices vs. farmer practices through farmer field schools operating at 12 and then 13 locations throughout the irrigation system and produced an average of 8 tha $^{-1}$ (Uphoff 2006).

SRI took momentum after my involvement at the District Agricultural Development Office for Morang district. It started with one trial of $100 \mathrm{~m}^{2}$ in 2003 . The number of SRI users reached over 1,400 by 2005 , with SRI average yields of 6.3 tha $^{-1}$ compared to 3.1 tha $^{-1}$ 
when using conventional methods. During initial days, a CIIFAD small grant support and later on the NDM 2005 Award (organised by World Bank-funded Nepal Development Marketplace) provided funds for a SRI promotion project in Morang and Panchthar districts, and these funds were supportive to disseminate SRI within the project areas and in other parts of the country (Uprety 2005,2006, 2011, 2013; Dahal 2014). During NDM project several national and international media (TV, radio, magazines and newspapers) reported on the performance of SRI (Dixit 2005; Haviland 2005), which was very effective to disseminate SRI nationwide. Now government organisations (DOA, Department of Irrigation and Poverty Alleviation Fund, Ministry of Local Development), ERCU/FAO and several NGOs currently work towards SRI dissemination in Nepal.

Box 2.4. Case of Kishor Luitel: A high-productive owner operator farmer, Kishor of Jhorahat, transplanted his close and better irrigated plots $(0.3 \mathrm{ha})$ by using single seedlings of 11 days old at a spacing of $25 \times 25 \mathrm{~cm}$ ( 16 seedlings per square meter) in June but in another plot (0.2 ha), which was in far distance and without irrigation facility, he used 31days-old seedlingswith 2-3 seedlings per hill at around $20 \mathrm{~cm}$ spacing (more than 60 seedlings per square meter) 37 days after first transplanting. Even though he was not a big farmer, as he just cultivated 0.5 ha of own land, there was wide diversity within his farm. This diversity was likely driven by scarcity of water in some of his plots at the time of land preparation. If water would have been more easily available at that time, he would have finished his work quickly (all fields under similar management) because he used hired labour for his farming operations.

After successful demonstrations and positive trial results several organisations were involved in SRI dissemination in Nepal. They trained farmers and conducted demonstration trials to disseminate SRI among different farmer communities according to their organisational goal within their working areas. But the effects of SRI training were not observed equally everywhere. SRI intervention had different impacts on different farmers. Several farmers didnot use it anymore in the next season, whereas others applied it only in part of their fields or applied only some (but not all) SRI components in their larger fields 
(see Box 2.4). Only few farmers used the complete set of SRI practices in their whole fields year after year. These observations form a further reason for this study, in which I tried to explore agro-ecological and socio-economic relationships of intensification of existing rice farming systems, with additional focus on SRI in Nepal.

Preliminary studies of SRI in Nepal showed some successes, but also indicated that only part of the farmers shifted to SRI practices. There has been a previous debate about the causes of non-adoption or even disadoption by farmers (Moser and Barrett 2003; Senthilkumar et al. 2008). That debate has not yet yielded a conclusive outcome. I therefore undertook this study to investigate rice-growing practices among Nepalese farmers in Morang, including practices that would be classified as falling under the heading of SRI. However, it became clear that a dichotomous classification of practices as SRI and non-SRI does not do justice to the diversity of adaptive approaches to intensification that farmers take. I therefore decided to refrain from giving a privileged status to SRI, and rather study the diversity of practices as such, without the use of predefined categories.

\subsection{Conclusion}

Rice farming in Morang is diverse, agro-ecologically, socio-economically and technically. Initially farmers had increased rice yield by the use of still abundant and fertile land, surplus labour with low production cost, and high profit. There were no alternative occupations so rice farming was a major occupation for most farmers for their livelihoods. After the introduction of improved cultivars and mineral fertilisers, rice productivity did increase for some years, after which it stagnated. Labour shortage, increased wage rates and input prices, increased production cost and decreased profits made rice farming less profitable. Nepal ended up as a rice-importing country, whereas formerly it exported a rice surplus. As a less profitable occupation rice cultivation became less attractive for small farmers for their livelihood. In the meantime SRI was introduced in Nepal as a means to increase rice production without increased production cost (no need for high costs for seed, fertilisers, irrigation and labour). SRI was proposed as a solution to address government priorities (food security) and farmer priorities (more food and more income for a better livelihood). But SRI was not everywhere the success that its proponents hoped it to be. It turned out that SRI is better regarded as one option for agricultural intensification and that farmers, 
depending on their agro-ecological and socio-economic circumstances, are in need of a basket of options for managing their livelihood strategies and crop fields.

During the rainy (monsoon) season rice is the dominant crop of the terai, as most farmers grow rice (for food security and income). But during the winter and spring season farmers use their land in diverse ways: not only for rice, but also (and even more so) for cash crops (such as high-value vegetables) and commercial farming. Intensification of these cropping systems demands different forms of management that may not necessarily be combinable with intensification of rice farming. Increased interest in cash crops might also be a driver for agricultural intensification that impacts on rice intensification, without any focus on SRI. As will become clear in the next chapters, all pathways for intensification are taken, in different ways, with or without privileging rice production or specific forms of rice intensification like SRI. My study therefore also revealed that for some farmers rice farming may not be attractive, even though it still remains the priority of the government for national food security. 


\section{Chapter 3}

Agricultural intensification and the livelihood strategies of rice farmers 


\begin{abstract}
Rice is an essential food crop for the people in the terai of Nepal. Intensification of rice cultivation is an objective of the Nepalese government to create food self-sufficiency. This chapter analyses if and how such national objectives coincide with farmer practices. We studied the diversity of livelihood strategies among these farmers. We used factor analysis to find out how various livelihood attributes correlate and how this pattern results in a typology of different livelihood strategies. We observed four major livelihood strategies. Farmers with relatively smaller areas appeared to be the most productive. These farmers (high-productive owners; high-productive tenants) invest in new techniques for agricultural intensification, including machinery, to reduce production costs and increase crop yields. For high-productive owners, rice is the dominant crop for home consumption. Highproductive tenants are mainly younger farmers, hiring and increasingly buying land where they grow vegetables for income and cultivate rice as a second source of income. Farmers of both groups lived significantly more often in Indrapur than in Jhorahat, possibly related to better irrigation facilities. However, even in Indrapur only $50 \%$ of the farmers belonged to the high-productive group. Intensification was observed for both land owners and tenants. Farmers in the other two groups (low-productive owners; low-productive tenants) grow rice but are less productive and engage less in intensification as their main income source is either from off-farm labour or non-agriculture occupations. For the majority of farmer families, rice farming is neither a main activity nor the main source of income.

An intensification pathway, as implied by the System of Rice Intensification (SRI), overlaps primarily with the livelihood strategies of both groups of high-productive farmers. Our analysis raises important questions on how new technologies like SRI are likely to fit with overall agricultural development and with farmer preferences of crop choice and farming strategies.
\end{abstract}




\subsection{Introduction}

Rice is an essential and the preferred staple food crop of the people of Nepal. Almost every farmer in the terai (the plain area at the foothills), river valleys in the hills and up to certain altitude grows rice. This chapter focuses on terai rice farming. Because rice is so commonly grown and so important in Nepal's national consumption, it is generally assumed that new farm methods or technical inputs to intensify rice production will be embraced by farmers (Awotide et al. 2012, 2015).The System of Rice Intensification (SRI - see Chapter 2) is a farming method that seems to fit this logic. It is claimed that with a number of simple practical adjustments, farmers can increase net returns because yields go up and input costs go down (Uphoff 2001; Stoop et al. 2002.The technical features of SRI and its capacity to produce 'more with less' have been questioned by researchers from leading institutes that are devoted to 'classical' rice cultivation, resulting in an acrimonious debate (see Berkhout and Glover 2011 for an overview of the arguments exchanged and a tentative explanation why this debate was and still is so heated).Given that SRI is a composite practice with considerable variation in application (rather than a specifically prescribed technology package), an analysis of SRI at farm level and plot level (see Chapter 4) has to include the specific agro-ecological and socio-economic conditions under which SRI is applied. Variations in availability of water, soil fertility, or field preparation practices, and farmers livelihood strategies and attitudes to agricultural intensification likely affect opportunities and constraints to apply SRI.

In this chapter we focus on variation in farm management strategies and explore connections with underlying variation in livelihood strategies, as a means of understanding processes of agricultural intensification in general and intensification of rice farming in particular. Mapping diversity in agricultural management strategies is important to find out if and how pathways of intensification as proposed by formal agricultural research and extension correspond with the reality of farming practice (Brookfield 2001; Richards 1985; Stone et al. 1990). Diversity in agricultural management strategies is an important element of agro-diversity (Brookfield 2001). Diversity in farm management and livelihood strategies is affected not only by local conditions but also by wider social, economic and political dynamics (Scoones 2009). The focus of this chapter is on an analysis of farm management strategies among terai farmers in Morang district, Nepal. Morang is the largest rice-growing 
district of Nepal. There is a good mixture of migrated and indigenous farmers. There are different types of big and small, government-managed and farmer-managed irrigation systems (Chapter 6). So there is wide diversity of socio-economic and agro-ecological conditions that affect overall agricultural dynamics. Based on a sample of 60 farmers, a statistical analysis of various characteristics of these farmers revealed that livelihood strategies can be clustered in four groups, representing four different livelihood strategies, ways of combining resources and opportunities in making a living. Moreover, each strategy suggests a different approach to intensification. Consequently, intensification of rice cultivation has different implications for these groups; intensification may also not be a priority for some farmers. These findings have major implications for the introduction of new technologies like SRI. A companion chapter will deal with variation in management strategies in individual rice plots, as most farmers grow rice on several plots that are partly under different management (Chapter 4). It has been debated whether the household or the plot level is more suitable to understand processes of intensification (Noltze et al. 2012, 2013). It is therefore important to address the question to what extent both approaches yield congruent answers.

\subsection{Dynamics in society and agriculture}

Agriculture is the backbone of the Nepalese economy. Rice is a crucial crop, gown by almost every farmer in the terai. However, average rice yield over the last decade remained just below $3 \mathrm{t} \mathrm{ha}^{-1}$ (MOAC 2011). Until 1973 Nepal was a rice-exporting country, but it has become a net importer of cheaper rice from neighbouring countries. National goals of increasing food self-sufficiency require increased production of major staple crops like rice. Yet, macro-economic developments show a pattern of diversification of income opportunities for rural households and a growing demand for more luxury food items. This puts pressure on the available labour for agriculture and diverts labour input from low-profit crops, like rice, to high-profit crops, like vegetables.

Nearly $80 \%$ of all Nepalese households are involved in farming in one way or another (Karkee 2008). Smallholders and marginal farmers dominate Nepalese agriculture with an average landholding size of 0.8 ha (Joshi et al. 2012). Most (87\%) farm holdings produce mainly for home consumption (CBS 2006). However, many farmers are also 
involved in production for local or regional markets. Cereal crops account for over $80 \%$ of annual cropped area, wherein rice alone occupies $40 \%$. Cropping intensity is low at $180 \%$ (that is slightly less than two harvests per year in this subtropical monsoon climate) (Karkee 2008).

The main organisation working for agricultural technology dissemination and support is the Department of Agriculture (DOA) under the Ministry of Agriculture Development (MOAD). The broad objective of DOA has been to support and help achieve food security and poverty alleviation by the transformation of agriculture through diversification and commercialisation. Specifically DOA's first objective is to achieve national food security by increasing production and maintaining the internal supply of food stuffs. To achieve these objectives, DOA established district offices, service centres and supporting laboratories (soil, seed, and plant protection) for technical support. For improved irrigation facilities the Department of Irrigation constructs and manages several irrigation systems throughout the country. Despite substantial funding on agricultural development by MOAD, the number of food-deficit districts has increased over the last decades.

The rural areas have changed significantly in recent decades in terms of composition of the rural population. A major reason for this change was the political contention. As Scott (2009) has shown for other regions, hill areas are a refuge to escape from malaria but also a refuge to hide in case of social conflict or political oppression. Likewise, the hills and mountains of Nepal form a hiding place for the Maoist rebel movement but the conflict also causes an outflow of people from the hills and mountains of the Himalaya (Upreti 2004; Murshed and Gates 2005; Joshi and Mason 2007, 2010; Lawoti and Pahari 2009).Overall, the control of malaria from the $1950 \mathrm{~s}$ and political (de)stabilisation affected migration flows between the terai and hills (KC 2003; Gurung et al. 1983).The lands of the terai form an ideal environment for rice farming.

The inflow of hill farmers to the terai resulted in an overall labour surplus. Working as agricultural labourer therefore is the main fall-back option when job opportunities outside agriculture cannot be found. Nevertheless, there has been a reduction in dependence on agriculture from $90 \%$ in 1981 to $65 \%$ in 2009 (MOAC 2010). The restoration of a multiparty democracy and liberalisation in the 1990s had a positive effect on the national economy, resulting in a growth of job opportunities in cities (Bohra and Massey 2009). 
There was an overall decline in poverty between 1995 and 2004 due to increases in remittances, agricultural wages, and mobility, which have created new opportunities for income diversification (CBS 2006). These changes also stimulated developments in agriculture, in particular a growing demand for vegetables, fruits and other high-value products, to which farmers have responded (Brown and Shrestha 2000; Brown and Kennedy 2005; Angood et al. 2002; Paudel 2002).

Vegetable crops are labour-intensive and provide year-round employment for farmers and hired labourers. The switch towards vegetable cultivation represents a general intensification of agricultural production, since vegetable farmers typically operate on small farms. On the other hand, rice farming is also labour-intensive but the demand for labour is seasonal and areas of rice cultivation are generally more extensive than vegetable farming. Rice farming in Nepal is the main traditional occupation before but has become less profitable in a later stage. The net income from producing vegetables and spice crops can be more than ten times higher than from selling rice and other cereals (APMDD 2014).

Besides this, opportunities outside agriculture have also increased, resulting in migration to urban centres and also foreign countries (especially in the Middle East and Malaysia).Migration towards urban and industrial areas created labour shortage in agriculture and increased labour wages, which, together with higher input prices, made cereal farming (including rice cultivation) less profitable. Many (big) farmers are currently leaving agriculture and renting out their land to share-croppers (Sugden and Gurung 2012), so the total area cultivated under share-cropping has increased.

These overall dynamics form the backdrop against which farmers in Morang district develop their livelihood strategies and opt for certain agricultural practices. Our analysis of farmer livelihood strategies in this paper helps to understand how such an overall pattern is expressed at local level.

\section{3. Methodology}

This study analysed the livelihood strategies of individual farm households. Livelihood is defined as the process by which rural families construct a diverse portfolio of activities and social support capabilities in their struggle for survival and in order to improve their standards of living (Ellis 2007). Livelihood is more than just income (Lipton and Maxwell 
1992).Farm families use their bodily capacity (knowledge, skills, and muscle power), tools and inputs in diversified ways for the betterment of their households. As explained in chapter 1 , the underlying mechanism is performance, i.e. farmers' capacity to improvise and adjust to changing and variable conditions through a combination of social and environmental learning (Richards 1989, Stone 2007). Household strategies are affected by societal dynamics. This study took individual households (families) as a unit of study and as a means to generalise to societal developments of agricultural intensification. Activities, works or occupational diversity within the family are internal factors and overall socioeconomic conditions are external factors responsible for diversification of livelihood strategies.

\subsubsection{Study area}

Morang district of eastern Nepal, situated between latitudes $26^{\circ} 20^{\prime}$ to $26^{\circ} 53^{\prime} \mathrm{N}$ and longitudes $87^{\circ} 16^{\prime}$ to $87^{\circ} 41^{\prime} \mathrm{E}$, has been selected for this study (Figure 1.1). It is the largest rice-growing district of Nepal. Total rice-growing area of this district is about 94, 000 ha and average rice yield is $3.1 \mathrm{t} \mathrm{ha}^{-1}$ (MOAC 2009). The district covers an area of $1,855 \mathrm{~km}^{2}$. It has a population size of 1,028,362 (2011). Biratnagar, the district headquarters, is the second largest city after Kathmandu and is the main industrial centre of Morang. Altitude varies from 100-2410 meters. The climate type is subtropical, of the monsoon type with more than $2000 \mathrm{~mm}$ average annual rainfall. Average annual maximum and minimum temperatures are $30.6^{\circ} \mathrm{C}$ and $14.2^{\circ} \mathrm{C}$ respectively (DADO 2008).

The study was conducted in two VDCs, namely Jhorahat and Indrapur from June 2008 to December 2009. Information on both VDCs is presented in Table 3.1.

Table 3.1. Details of the studied VDCs.

\begin{tabular}{|c|c|c|c|c|c|c|}
\hline VDC & $\begin{array}{c}\text { Area } \\
\left(\mathrm{km}^{2}\right)\end{array}$ & $\begin{array}{c}\text { Population } \\
(2007)\end{array}$ & $\begin{array}{c}\text { Distance }(\mathrm{km}) \\
\text { from Biratnagar }\end{array}$ & $\begin{array}{c}\text { No. of farm } \\
\text { households }\end{array}$ & $\begin{array}{c}\text { Cultivable } \\
\text { land (ha) }\end{array}$ & $\begin{array}{c}\text { Area under } \\
\text { rice (ha) }\end{array}$ \\
\hline Jhorahat & 13.17 & 5,414 & 10 & 788 & 1250 & 1180 \\
\hline Indrapur & 25.47 & 19,179 & 28 & 2650 & 2510 & 2250 \\
\hline
\end{tabular}


Indrapur VDC is situated in central Morang. It is more densely populated and rapidly urbanising VDC than Jhorahat. The majority of people living in this VDC are hill migrants and migration flow to this VDC has been very high. Irrigation sources of Indrapur are small perennial rivers. Irrigation systems are small and farmer-managed. Few farmers use ground water for irrigation. Due to manageable small irrigation systems and pumping ground water most of the agriculture fields have good irrigation facilities (see also Chapter 6).

Jhorahat is closer to Biratnagar and the majority of the farmers in this VDC are terai-indigenous Tharu, Jhagad and Sardar people. It is less densely populated than Indrapur. There was no migration flow to Jhorahat and population size is slowly decreasing. Sunsari Morang Irrigation System (SMIS) is the main source of irrigation for this VDC. Jhorahat is located at the middle part of SMIS. SMIS secondary and tertiary canals were constructed in Morang district but there was no good network of water courses to deliver water to all plots. Therefore rice plots close to irrigation canals get better irrigation and distant fields face water supply problems (see also Chapter 6).

\subsubsection{Sampling methods and data collection}

These two village development committees were selected purposively. Both have similar extension support systems, being close to an Agriculture Service Centre. However, social settings (migrants in Indrapur, indigenous people in Jhorahat) are different. In both VDCs SRI was introduced in 2004 (Uprety 2005).

We prepared a list of farmers in both VDCs. From the list 60 farmers (30 from each VDC), all growing rice, were randomly selected. We monitored their activities (management) in weekly intervals from seeding to harvesting. For this purpose information was collected about livelihood strategies, using as main indicators land size, tenure situation, labour within the family, use of hired labour for different agricultural activities, seed use, fertiliser use, land operating system, rice yield as related to family demand, income from rice and other sources, main and secondary occupation by farmer and family members inside and outside agriculture, family size, cattle number and availability of machines.

We calculated labour for rice cultivation. Both family labour, labour on an exchange basis, and hired labour was included. All labour data were converted to the same unit, 
number of 'person days'. A 'person day' equals eight hours. Work usually starts around 7 $\mathrm{AM}$ and ends at 5 PM, with a two-hours break from 12 AM-2 PM. Cost of a day's labour is calculated as the average wage for an eight-hour work day. In case machines were used, we counted labour on the basis of expenses for that particular work divided by the wage of one person day labour (equivalent labour number). Machine expenses have been fixed on the basis of rental rate of the study area. Incomes of share-cropper and tenants were calculated after deduction of production costs and land rent (the part of the yield given to the landowner). Other secondary data (irrigation facility, loans, poverty levels, demographic data concerning involvement in agriculture and non-agriculture occupations, etc.) were collected from District Agricultural Development Office (DADO), District Development Committee (DDC) Morang, and comparable relevant sources.

Instead of using a pre-conceived classification of farmers (using an a priori choice to classify farmers as SRI or non-SRI), we applied factor analysis to determine patterns in livelihood strategies and land management.

\subsubsection{Data analysis}

SPSS computer software has been used for data analysis. Factor analysis (Fabrigar et al. 1999) was applied to explore different farmer strategies and the main characteristics of these strategies. Factor analysis is used to reduce the number of variables and detect structure in the relationships between variables (Darlington 2012; StatSoft 2012). For factor analysis we used 12 variables related to livelihoods. These variables are: (1) total rice area (ha), (2) average rice yield $\left(\mathrm{t} \mathrm{ha}{ }^{-1}\right.$ in main-season rice; rice production in winter season and spring season are excluded), (3) cropping intensity (\%; 100\% implying one crop per year, 300\% implying a main-season crop (rice) plus winter-season and spring-season crop), (4) family demand for rice $\left(\mathrm{t}\right.$ year $\left.{ }^{-1}\right),(5)$ rented area (ha), (6) number of family members working in agriculture, (7) number of family members working outside agriculture, (8) number of different occupations by family, (9) percentage of hired labour, (10) availability of bullocks,(11) availability of tractors or power-tillers, and (12) presence of small animals (pigs, goat, etc.).

Rented area (5) is a proxy for landownership or tenure relations (if larger than zero). Number of working members inside (6) and outside (7) agriculture, and percentage of hired 
labour (9) represent labour availability and allocation. Bullock availability (10) and availability of tractors and power tillers (11) represent the means of land preparation, being the most costly operation of rice farming (Chapter 2). Small animals (12) are an alternative source of farmer income. Other variables assessed were not used for factor analysis, but subsequently used to test for further differences between the livelihoods categories that were recognised.

Next to factor analysis, we tested for differences between livelihood categories by one-way ANOVA or likelihood ratio test (G-test), which is approximately distributed as chi square. Data on rice area, family production, and family surplus were log-transformed to meet the assumptions for ANOVA. Correlations between different parameters were also calculated. Outcomes were considered significant at $P<0.05$.

\subsection{Results}

\subsubsection{Correlations between variables}

Correlations between the 12 variables that were used for factor analysis are shown in Table 3.2. There was a significant negative correlation between total rice area and cropping intensity. Total rice area was positively correlated with family demand, the amount of rented land, the number of family members outside agriculture, and the availability of bullocks. Rice area and rice yield per hectare (productivity) were not significantly correlated. Productivity and cropping intensity were significantly positively correlated, indicating a multiplier effect for total production and income. Productivity was also positively correlated with income diversification within the family. Cropping intensity followed the same pattern. The number of family members in agriculture was strongly negatively correlated with the percentage of hired labour. Hired labour was significantly negatively correlated with the possession of bullocks for land preparation, suggesting that farmers who possessed bullocks also have more family labour for agricultural work.

\subsubsection{Factor analysis}

The first axis of the factor analysis explained $21 \%$ of variation, the second axis $16 \%$, and the third axis $14 \%$. In all, these three axes explained $51 \%$ of the total variation. The first five axes explained $75 \%$ of variation. The first axis showed positive loadings for bullock 
availability $(+0.87)$, number of working members in agriculture $(+0.62)$ and the area of rented land $(+0.60)$, and negative loadings for percentage of hired labour $(-0.87)$. This axis separates landowners (who depend on hired labour and do not possess bullocks) from tenants (who rent part of land and prepare land by their own bullocks). The second axis showed positive loadings for productivity $(+0.84)$ and cropping intensity $(+0.79)$. This axis separates high-productive farmers (who engage in intensification) from low-productive farmers (who engage less in intensification). The third axis showed positive loading for total rice area $(+0.90)$. Occupational diversity had a high loading on the fourth axis $(+0.80)$ and the number of small animals on the fifth axis $(+0.83)$.

When plotted in a diagram the factor analysis showed four groups of farmers, characterised by different livelihood strategies. Each group roughly coincided with a quadrant of the factor analysis diagram with the first and second axis plotted (Figure 3.1). The first axis separates owner-producers (groups 1 and 2; left) from tenants (groups 3 and 4; right), whereas the second axis separates high-productive (and intensively farming) producers (groups 1 and 4; upper) from less productive and less intensively farming producers (groups 2 and 3; lower). Both factors (tenure, intensification) are independent.

In the final classification some minor manual adjustment were made: farmer 38 was moved from group 1 to 4 , and farmer 24 from group 2 to 3. Short-hand names for these four livelihood strategies plus acronyms and descriptions of these groups will be provided. The dynamic relationships between those groups will also be analysed.

Group 1: The first group (left upper quadrant) is called Strong Rice Focus and Ownership (SRFO). They work on farms of small size ( $0.5 \mathrm{ha})$. Their cropping intensity $(275 \%)$ and their yield of main-season rice $\left(4.9 \mathrm{tha}^{-1}\right)$ are very high. They depend more on hired labour, whereas family labour is invested in occupations outside agriculture. Land preparation is done by tractors, as they do not possess bullock (Table 3.3).

Group 2: The second group (left lower quadrant) is called Moderate Rice Focus and Ownership (MRFO). Like farmers of group 1 they own most of the land (85\%; table 3.3) and use hired labour for their agricultural operations. Their fields are larger than those of group 1 (1.4 ha), but they crop less intensively and also achieve lower yields of main-season rice. They also do not possess bullocks, and often do not possess tractors as well. Family labour is more invested in occupations outside agriculture and farm income depends on such 
income through remittances.

Table 3.2. Correlations between livelihood variables $(n=60)$. Values in bold are significant at $P<0.05$, values in bold and underlined are significant at $P<0.01$.

1. Total rice area $\quad \begin{array}{llllllllllll}\mathrm{X} & -.11 & \mathbf{. 0 2 9} & \underline{\mathbf{. 3 6}} & \underline{\mathbf{. 3 6}} & .04 & \underline{\mathbf{4 1}} & -.02 & .02 & \underline{\mathbf{. 3 3}} & .11 & .10\end{array}$ (ha)

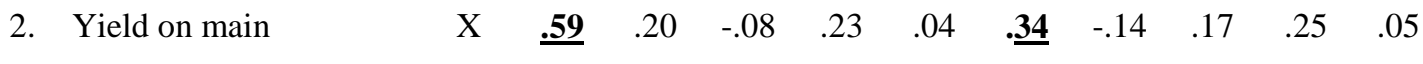
season rice $\left(\mathrm{t} \mathrm{ha}{ }^{-}\right.$ $\left.{ }^{1}\right)$

3. Cropping $\begin{array}{llllllllll}X & .27 & -.08 & \underline{.38} & -.02 & \underline{.36} & -.19 & .16 & .28 & -.09\end{array}$ intensity $(\%)$

4. Family demand $\begin{array}{lllllllll}X & .20 & \underline{.62} & \underline{.69} & .16 & -.24 & \underline{.34} & .12 & -.15\end{array}$ for rice $(\mathrm{kg})$

5. Rented area (ha) $\begin{array}{llllllll}X & .25 & .03 & -.15 & \underline{\mathbf{- . 3 5}} & \underline{\mathbf{. 5 8}} & -.21 & \mathbf{. 3 0}\end{array}$

6. Family members $\begin{array}{lllllll}\mathrm{X} & -.14 & .07 & \underline{\mathbf{- . 6 2}} & \underline{.58} & .10 & -.07\end{array}$ in agriculture

7. Members $\begin{array}{llllll}X & .13 & .27 & -.10 & -.02 & -.12\end{array}$ outside agriculture

8. Number of $\begin{array}{lllll}\mathrm{X} & -.11 & .04 & .21 & -.08\end{array}$ occupations

9. Percentage of $\begin{array}{llll}\mathrm{\mathbf {-.75 }} & .09 & \mathbf{- . 0 6}\end{array}$ hired labour

10. Availability of $\begin{array}{lll}\mathrm{X} & -.12 \quad .18\end{array}$ bullocks

11. Availability of X $\quad-.15$ tractors

12. Presence of X small animals 


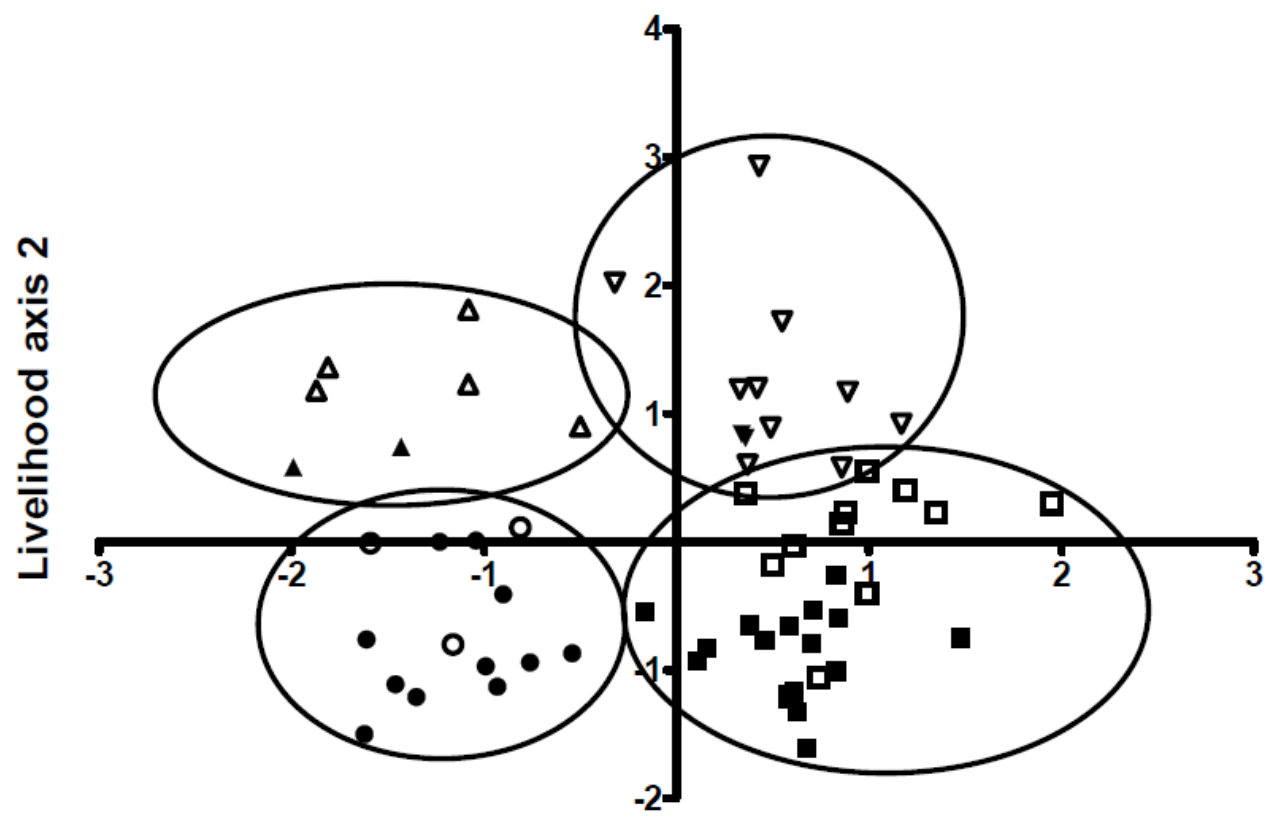

- MRFO Jho

- MRFT Jho

- SRFO Jho

V LRFT Jho

- MRFO Ind

口 MRFT Ind

$\Delta$ SRFO Ind

$\boldsymbol{\nabla}$ LRFT Ind

Livelihood axis 1

Figure 3.1. Farmer livelihood strategies. See text for abbreviations of livelihood strategies. Filled symbols refer to farmers in Jhoharat (Jho), open symbols to farmers in Indrapur (Ind).

Group 3: The third group third (right lower quadrant) is called Moderate Rice Focus and Tenancy (MRFT). They own only a small part of their land, and almost three quarters of their land is obtained through renting. Farm size is relatively large. Their cropping intensity is low, likewise rice yield of main-season rice is low. Tenants invest a larger part of family labour in agriculture than outside agriculture (Table 3.3). Therefore their use of hired labour is much lower than that of owners. However, income in the family still depends to a large extent on non-agricultural labour (remittances). Most of them possess bullocks, but tractors are absent.

Group 4: The fourth group (right upper quadrant) is called Low Rice Focus and Tenancy (LRFT). Like farmers of group 3, they rent land and work on it by their own labour. However, they possess relatively more own land than tenants of group 3, possibly related to the fact that average land size is smaller than that of that group. More family members work 
inside agriculture than outside. They possess bullocks or tractors. In terms of cropping intensity and rice yield in the main season they resemble the high-productive landowners of group 1. Yet, these farmers seem more focused on income sources from non-rice crops and non-agricultural labour.

We identified one outlier in group 2, a farmer who had a very large rice area (9 ha). If the data from this farmer are omitted, rice area for group 2 is reduced to 0.8 hectare, family production to 1.9 ton and food surplus to 0.5 tons. However, exclusion of these data as outlier does not affect the general conclusions regarding the differences between the various life styles, except that family production would then be significantly different between groups $(\mathrm{P}=0.03)$.

Table 3.3. Differences between four livelihood strategy groups for twelve variables used in the factor analysis. For acronyms of the groups, see text. P-values are based on on-way ANOVA or G-test. Values in bold indicate significant differences $(P<0.05)$.

$\begin{array}{lccccc}\text { Group number } & 1 & 2 & 3 & 4 & P \\ \text { Group name } & \text { SRFO } & \text { MRFO } & \text { MRFT } & \text { LRFT } & \\ \text { Group size } & 7 & 14 & 26 & 13 & \\ \text { Total rice area (ha) } & 0.5 & 1.4 & 1.6 & 1.0 & \mathbf{0 . 0 0 1} \\ \left.\text { Average yield (t ha }{ }^{-1}\right) & 4.9 & 3.0 & 3.5 & 5.1 & <\mathbf{0 . 0 0 1} \\ \text { Cropping intensity (\%) } & 275 & 196 & 223 & 289 & <\mathbf{0 . 0 0 1} \\ \text { Family demand for rice (t) } & 1.7 & 1.6 & 1.8 & 2.0 & 0.43 \\ \text { Rented area (ha) } & 0 & 0.1 & 1.1 & 0.6 & <\mathbf{0 . 0 0 1} \\ \text { Family members in agriculture } & 1.9 & 1.5 & 3.0 & 3.6 & <\mathbf{0 . 0 0 1} \\ \text { Members outside agriculture } & 3.4 & 3.2 & 2.5 & 2.2 & 0.31 \\ \text { Number of occupations } & 2.0 & 1.9 & 1.8 & 2.3 & 0.13 \\ \text { Percentage of hired labour } & 76 & 76 & 30 & 34 & <\mathbf{0 . 0 0 1} \\ \text { Availability of bullocks } & 0 & 1 & 26 & 13 & <\mathbf{0 . 0 0 1} \\ \text { Availability of tractors } & 5 & 2 & 0 & 5 & <\mathbf{0 . 0 0 1} \\ \text { Small animals (number) } & 2.6 & 2.0 & 3.2 & 3.5 & 0.40\end{array}$


Next to the differences between those four groups (based on the twelve factors that were used for factor analysis), we also tested for differences between livelihood strategies in other factors that were not part of the factor analysis and creation of the four groups. These are separately listed in Table 3.4

High-productive farmers, both landowners and tenants, were more common in Indrapur than in Jhorahat. However, only half of the farmers in Indrapur belonged to the high-productive categories. Some farmers in Jhoharat also managed to achieve highproductive agriculture, indicating that biophysical conditions (better irrigation facilities in Indrapur than in Jhorahat, see Chapter 6) do not fully explain processes of intensification. Other differences between high- and low-productivity farmers were noted in the use of highvalue crops (higher in Indrapur) and of pulses (higher in Jhorahat) in the off-season (winter season and spring season). This results in high-productive farmers obtaining far more net income than low-productive farmers. High-productive farmers also received significantly more SRI training than low-productive farmers; however even $40 \%$ of the latter category had received such training, but did not translate this training in high-productive agriculture.

Table 3.4. Differences between four livelihood strategy groups for variables not used in the factor analysis. For acronyms of the livelihood groups, see text. P-values are based on oneway ANOVA or G-test. Values in bold indicate significant differences $(P<0.05)$.

\begin{tabular}{|c|c|c|c|c|c|}
\hline Group name & SRFO & MRFO & MRFT & LRFT & $P$ \\
\hline Group size & 7 & 14 & 26 & 13 & \\
\hline Family production $(\mathrm{t})$ & 2.4 & 4.2 & 3.7 & 5.2 & 0.06 \\
\hline Fraction own land (\%) & 100 & 85 & 28 & 48 & $<0.001$ \\
\hline Family surplus (t) & 0.7 & 2.6 & 1.9 & 1.7 & 0.82 \\
\hline Family size & 5.3 & 4.7 & 5.6 & 5.8 & 0.49 \\
\hline $\begin{array}{l}\text { Land preparation (man days ha- } \\
{ }^{1} \text { ) }\end{array}$ & 36 & 33 & 31 & 27 & 0.006 \\
\hline Transplanting (man days ha $^{-1}$ ) & 35 & 31 & 30 & 26 & 0.06 \\
\hline Weeding (man days ha $^{-1}$ ) & 18 & 20 & 14 & 10 & 0.14 \\
\hline
\end{tabular}




$\begin{array}{lccccc}\text { Harvesting (man days ha }{ }^{-1} \text { ) } & 43 & 43 & 43 & 45 & 0.89 \\ \text { Total labour (man days ha }{ }^{-1)} & 131 & 128 & 118 & 108 & \mathbf{0 . 0 1} \\ \text { Land preparation (\% hired) } & 100 & 93 & 7 & 25 & <\mathbf{0 . 0 0 1} \\ \text { Transplanting (\% hired) } & 73 & 67 & 54 & 50 & 0.23 \\ \text { Weeding (\% hired) } & 50 & 53 & 20 & 12 & \mathbf{0 . 0 0 6} \\ \text { Use of high-value vegetables } & 5 & 0 & 6 & 11 & <\mathbf{0 . 0 0 1} \\ \text { (\#) } & & & & & \\ \text { Use of pulses (\#) } & 0 & 8 & 9 & 0 & <\mathbf{0 . 0 0 1} \\ \text { Food insufficiency (number) } & 3 & 7 & 2 & 2 & \mathbf{0 . 0 0 3} \\ \text { Foreign employment (number) } & 5 & 8 & 11 & 2 & 0.06 \\ \text { Production costs (Rs ha }{ }^{-1} \text { ) } & 22960 & 24262 & 21150 & 21675 & 0.40 \\ \text { Net income (Rs ha }{ }^{-1} \text { ) } & 57305 & 28642 & 17792 & 48610 & <\mathbf{0 . 0 0 1} \\ \text { Training participation (number) } & 7 & 8 & 18 & 11 & 0.14 \\ \text { SRI training (number) } & 7 & 5 & 11 & 11 & \mathbf{0 . 0 0 2} \\ \text { Group affiliation (number) } & 6 & 6 & 16 & 11 & 0.08 \\ \text { Living in Jhorahat (number) } & 2 & 11 & 15 & 2 & \mathbf{0 . 0 0 4}\end{array}$

Other elements of the agricultural system separated landowners from tenants, irrespective of productivity. Landowners, who depended more on hired labour, showed significantly higher numbers of man days for land preparation than tenants, suggesting differences in quality and / or intensity of the agricultural labour (preparation, transplanting, weeding) that is executed on own land (by tenants) and on land of landowners. Consequently labour expenditure (mainly hired labour) was significantly higher for landowners than for tenants.

\subsubsection{Livelihood dynamics}

Factor analysis, which is a static depiction of current livelihoods, separated four groups of farmers in Morang district. But such groups are not permanent, due to the changing socioeconomic and political environment in Nepal. Limits between groups can be fuzzy, and farmers may move from one group to another, through processes of agricultural intensification or extensification (Dorward 2009; Tittonell 2014). Farmers can shift to other groups through land acquisition, by which tenants become landowners. Farmers can leave 
agriculture in search for more profitable activities outside agriculture, and new farmers (hill migrants) establish themselves in Morang district and become agricultural labourers on land owned by other farmers.

Figure 3.2 links these four groups in a dynamic scheme. It indicates that moderate rice focus tenants (MRFT) might either intensify as tenants and enter LRFT, or use the agricultural surplus to acquire land and become moderate rice focus owners (MRFO). The majority of low rice focus tenants (LRFT) intend to acquire more land and further intensify their agriculture, but their focus is rather on vegetable and cash crops than on the conventional cereals. Some of that group do not intend to remain agriculturalists and diversify their jobs outside agriculture and leave farming, a pathway that is also followed by strong rice focus owners (SRFO). Apparently, agricultural intensification can be a pathway to intensification outside rice growing or even outside agriculture. As those high-productive farmers (SRFO and LRFT) have almost all received training in SRI, it is plausible that SRI contributes to that process. Moderate rice focus owners (MRFO) may not be in a position to intensify, and they are then bound to remain subsistence farmers who earn a major part of their income outside agriculture. They may also leave agriculture because of the low benefits rice-growing provides them with or because rice production falls below family demands. 


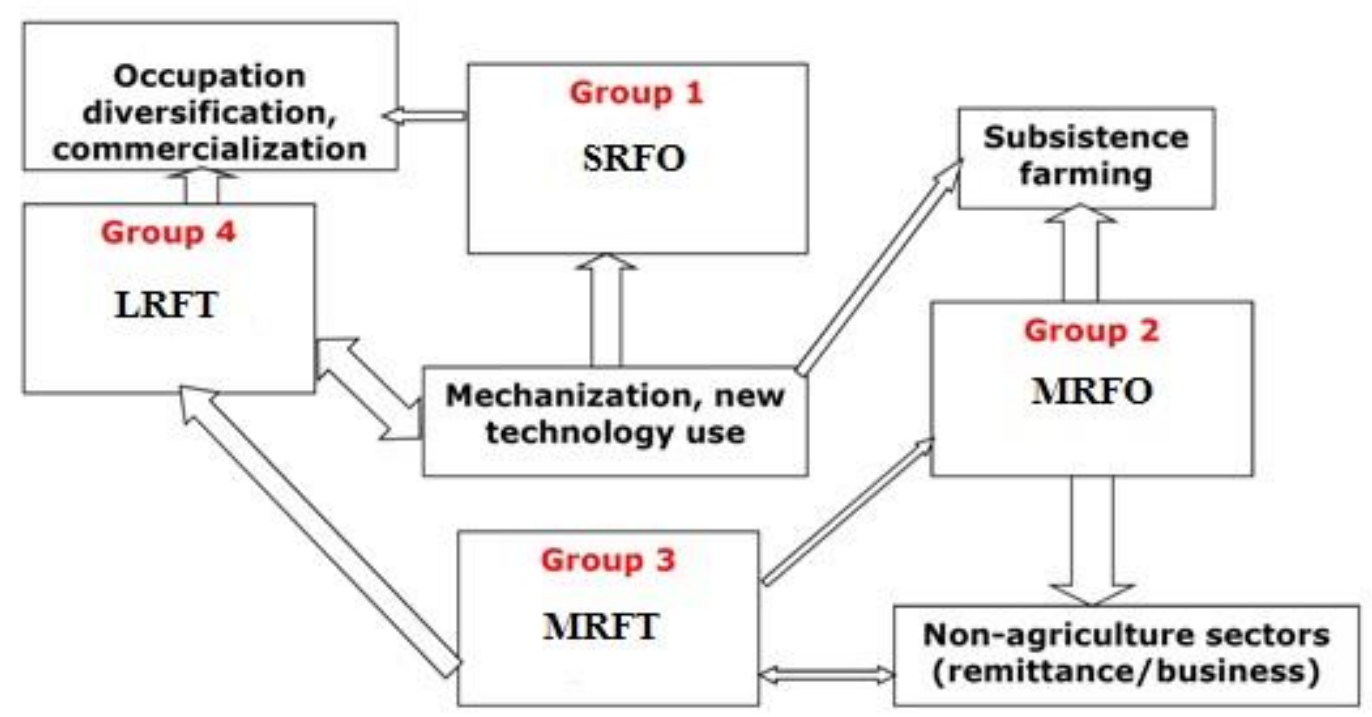

Fig 3.2. Dynamics of various livelihood strategies of rice farmers in Morang, Nepal. See text for explanation.

\subsection{Discussion}

Classifying farmers in different livelihood categories, rather than treating them as one homogeneous category, has been applied by several authors (Singah and Baruah 2011; Awotide et al. 2012; Noltze et al. 2013). Two different methods have been employed to classify farmer livelihood styles. One method starts with a priori classifications, based on extensive inventories, as shown by Van der Ploeg et al. (2009) and Monteiro Novo (2012). The other method, like ours, employs multivariate techniques (factor analysis, clustering) to a posteriori assign farmers to different groups. Several classificatory schemes have been introduced, notablybased on field work in eastern Africa (Tittonell et al. 2010; Kamanga et al. 2010; Pacini et al. 2014; Franke et al. 2014). These classifications were usually onedimensional, where all farmers categories could be listed along one axis of resource endowment. It is not clear whether this linear scheme is partly caused by the criteria used to recognise livelihood strategies (or resource endowment categories) or whether the situation in Nepal (where two dimensions of similar relevance were noted, viz., the contrast between landowners and tenants, and the contrast between high-productive and low-productive 
farmers) is very different from that in eastern Africa. Due to the multidimensional structure of livelihood strategies there are also multiple pathways to move from one category to the other (Figure 3.2) and to move outside rice growing or even outside agriculture.

Our study showed that landowners and tenants can engage in low-productive (and low-intensive) or high-productive (and high-intensive) agriculture. It should be noted that landowners and tenants are not absolute categories, as many farmers possess some land while also renting land and working on that land under a share-cropping regime. Among the 60 farmers investigated, 7 could be classified as landless tenants and 22 as landowners. About half of the farmers investigated ( 31 out of $60 ; 52 \%$ ) owned land and also rented land. Depending on their success in agriculture they may either increase land acquisition (move from tenants to landowners) or be forced to sell land and engage in share-cropping arrangements (move from landowners to tenants). The landowners are usually long-term inhabitants living in the terai, their family members seem to be more educated, and often earn income outside agriculture. They invest less family labour in farming. Currently, in Nepal land use is changing with tenants gradually cultivating more land than landowners (Table 3.3).This process indicates that tenure may be less important than labour availability (in relation to labour opportunities outside agriculture) for agricultural production (Huffman 1998).

On average, more productive farmers farm on smaller areas and show a higher cropping intensity. Bray (1986) has shown that increased productivity on the same (small) land size is a typical pattern of Asian rice economies. It is difficult to reconstruct the driving factor between that correlation - is low land size an inducement for intensification and higher productivity, as in the model of Boserup (1965)? Because labour costs are high, intensification would require the application of techniques that increase productivity without increasing and preferably even reducing, labour input. Or does agricultural intensification and productivity increase result in more options for income diversification by remunerative activities outside agriculture, which reduce labour available for agriculture and lead to smaller farm sizes? The fact that landowners spend more time to earn money outside agriculture and hire labour for their agricultural activities, even though the hired labour is of lower intensity or quality (to judge from higher labour demand for land preparation, transplanting, and weeding on land where landowners hired labour than on land owned by 
the tenants themselves), suggests that reducing farm sizes may be a response to increased intensification and higher yields (Raut et al. 2011; Rahut and Scharf 2012). As a likely future scenario, agricultural intensification results in diversification (whereby rice becomes less important and high-value crops such as vegetables become increasingly important, cf Dahal et al. 2009) and may ultimately lead to a situation where farmers intensify themselves out of agriculture as long as income-generating activities outside agriculture are more lucrative. Diversification towards vegetable crops outside the monsoon season (and its corollary that rice growing becomes less prominent) may put demands on farm management, including water management (see Chapter 6). To some extent patterns of rice intensification (especially the move towards aerobic rice and more generally towards practices that are part of SRI) should be analysed within a framework that transcends rice growing. That tentative conclusion does not only raise the question to what extent the interests of Nepal's agricultural policy are aligned with the interests, ambitions and livelihood strategies of farmers; but also raises the question what longer-term impacts of SRI on rice growing in Nepal could be.

While Tables 3.4 indicate significant differences in labour expenditure (and especially labour for land preparation, transplanting and weeding), it is also evident that there is no straightforward relation between labour expenditure and yield. Whereas highproductive landowners had highest labour needs, the high-productive tenants had lowest labour needs, and the low-productive farmers were intermediate. Landowners almost completely rely on hired labour, whereas tenants do almost all of the land preparation themselves. These data suggest important differences in the effectiveness (or quality) of own versus hired labour. While hired labour may be an attractive option for some farmers (if family members have more lucrative job opportunities outside agriculture), it is done less efficiently. The fraction of hired labour for transplanting was consistently high among all four livelihood strategy groups. The most likely explanation is that transplanting is specialised work that is done by specially trained labour gangs. Such specialised groups also make labour expensive.

Average cropping intensity in our study was $237 \%$ and ranged from $196-289 \%$ (that is on average two to three crops per year) depending on livelihood strategy. In my study area cropping intensity was much higher than what has been reported for Morang district, viz., 
$169 \%$ (DADO 2010). Cropping intensity in our study area was higher because of a more favourable irrigation situation (Chapter 6).

A number of different rotations in Morang district are practiced. The main cropping patterns (monsoon crop, winter crop, spring crop) are: (1) Rice-Pulses-Fallow; (2) RiceWheat-Fallow; (3) Rice-Wheat-Maize; (4) Rice-Wheat-Rice; (5) Rice-VegetablesVegetables; (6) Rice-Maize-Rice; (7) Rice-Mustard-Maize; (8) Rice-Fallow-Fallow; (9) Rice-Potato-Maize; (10) Rice-Wheat-Green manure. Choices for particular rotations correlate with livelihood strategies. Low-productive (and low-intensive) farmers (groups 2 and 3) often grow pulses off season. While pulses do not generate high prices on the market, they fix nitrogen and therefore contribute to soil fertility (Chapter 5). High-intensive and high-productive farmers grow more lucrative high-value crops such as vegetables. These crops are usually well-fertilised (Chapter 5), with likely residual effects on rice yields in the main cropping season.

Water availability plays a crucial role in affecting cropping intensity and possibilities for intensification. Average cropping intensity in Indrapur was $285 \%$ and in Jhorahat $190 \%$, a difference that was highly significant $(P<0.001)$. Water availability is more problematical in Jhorahat than in Indrapur (Chapter 6). In areas that in winter and spring are better irrigated, farmers cultivate more often vegetables, winter maize, wheat, and potatoes. But in areas of off-season water scarcity farmer grow pulses. Consequently, in Jhorahat in the winter of $2009,45 \%$ of the fields were covered by pulses (mainly lentil) followed by wheat and mustard, with only a small fraction by vegetables $(6 \%)$ or fallow land (7\%). In spring season almost $97 \%$ of the land was under fallow. Better irrigation facility in Indrapur encouraged farmers to grow more profitable crops (vegetables). In the winter of $2009,30 \%$ of the fields were covered by vegetables and potatoes, $58 \%$ by wheat and mustard, and only $12 \%$ by pulses. In spring $84 \%$ of the lands were covered by spring rice, maize and vegetables. Only $11 \%$ of the land was under fallow during spring season and $5 \%$ was covered by a green-manure crop. In water-scarce areas farmers prefer pulses, because they just broadcast pulse seed in fields before rice harvest. Pulse seedlings can benefit from residual soil moisture. There is no more labour demand afterwards for crop management before harvest. Farmers harvest these crops in March-April. In better irrigated areas farmers grow wheat (which demands land preparation but no weeding) or vegetables 
and maize (which demand both land preparation and weeding).

For the majority of farmers the main source of income comes from outside rice farming. This applied both to high-productive and low-productive farmers. However, net income was significantly higher for high-productive farmers than for low-productive farmers, a difference that is explained by income obtained by activities outside agriculture. Only 45\% of the farmers obtained their main livelihood from rice farming. A second important source of income (35\%) are remittances (often by family members working abroad). Five farmers obtained their main income from vegetable growing. Twenty-six households had family members in foreign employment. Landowners had more members in foreign employment than tenants. Tenants need family members to intensify agriculture, generate income in order to buy land (and reduce the amount of share cropping). If successful, they can continue as high-productive landowners and can also move out of agriculture (Figure 3.2). These data indicate that analysing livelihood strategies of farmers by looking at how remunerative agriculture might be, misses essential elements of their livelihoods and likely fails to capture the underlying dynamics of intensification, which allows an increasing income to be obtained from activities outside agriculture.

Low-productive landowners, who have most family members working outside agriculture, could be vulnerable, especially in cases where the husband has left for foreign employment leaving the wife, children and elderly household members to manage the farm. Such families are likely to move towards feminisation of agriculture (Tamang et al. 2014; Gartaula et al. 2010; Joshi 2000) or finally leave agriculture as it is not a remunerative activity anymore.

A consequence of employment outside agriculture (because that employment is more remunerative) is the increasing labour shortage, which increases labour wages resulting in increased production costs and decreased profits for landowners. They might finally change their occupation by renting out their available land to others. This trend is most visible in group two. Farmers who have sufficient resources to buy machines (tractor/power-tillers) use this option to reduce production cost (group one).

A large majority (75\%) of farmers had participated in agricultural training. Most of them participated in SRI, Integrated Pest Management (IPM), Farmers Field Schools (FFS), and training for vegetable production. Agricultural training is usually given to farmers who 
are members of farmer groups. Landless labourers generally do not get a chance to attain agricultural training. Because of high participation levels, there were no significant differences between groups (Table 3.4).The lower training participation among the lowproductive and low-intensive farmers might be related to the fact that agricultural intensification does not match their current livelihood ambitions (Gruning 1971).

Due to good accessibility of agricultural service centres (ASC), the majority of farmers were organised in farmer groups. Only $32 \%$ of the families were not organised in groups. The differences between high-productive and low-productive farmers with regard to group affiliation were marginally significant $(P=0.08)$. The Government of Nepal (through its Ministry of Agriculture Development) has emphasised group formation to promote agricultural development since 1989. Most non-governmental organisations (NGOs) also work with such farmer groups. Most groups organise monthly or bi-weekly meetings to discuss technical issues (seed arrangements, water distribution, saving and use). Some group members participate in meetings at district or regional levels, and such information is shared within the farmer group. Most active group members have good savings which was utilised to solve their farming and household needs.

Among the 60 respondents $34(57 \%)$ had participated in SRI training. Highproductive and high-intensive farmers had significantly more often participated in SRI training than farmers that were less productive and cropped less intensively (Table 3.4). However, in that latter category also $40 \%$ of the farmers had received SRI training, but they had apparently been unable to translate that training into more productive agricultural practices. Farmers applied SRI methods to varying degrees, depending on specific properties of the various fields (Chapter 4). Farmers were also not consistent in applying SRI between years. In 2009 the monsoon started later, so there was a water problem at the start of the growing season. Less farmers applied SRI in in 2009 than in 2008 (data not shown).

\subsection{Conclusion}

Rice farming in the terai of Nepal is not a main income source for the majority of the farmers, as most of them depend on income-generating activities outside agriculture. Highproductive farmers derive a larger income from outside agriculture, presumably because 
high-productive and high-intensive farmers save on labour for agricultural operations and rely more on hired labour, which allows them to spend their labour force on more remunerative activities. Their strategy of intensification results not only in more hired labour, but also in smaller areas for rice, a higher cropping intensity and a focus towards high-value vegetables in the off-seasons. The investments on these high-value vegetables results likely in further intensification. In that sense practices of rice intensification lead to more general processes of intensification and ultimately into processes whereby farmers intensify themselves out of agriculture. However, while farming is not any longer the main source of income, rice is still important as it secures food security at the household level. Low-productive farmers are faced with other constraints. When successful, a strategy more commonly found with low-productive tenants, they reinvest the money that they generate in agriculture, buying land and transforming themselves into landowners. However, when less successful, they also move out of agriculture. The role of SRI in Nepal is therefore complex: next to allowing intensification and higher yields on smaller fields, it also contributes to farmers leaving agriculture as they find activities outside agriculture more remunerative. In that sense these data also necessitate a reflection on agricultural policy of Nepal (which strives towards higher productivity and higher yields) in relation to the livelihood aspirations of the farmers (whose success in intensification enables them to diversify and to invest more in remunerative activities outside agriculture).

These dynamics imply that there is a contradiction between the objectives of the government and farmers. Whereas the government aims to increase rice productivity as a means of achieving national food security, farmers prefer to move out of uneconomical and unrewarding rice production towards more profitable crops in order to improve their livelihoods. 


\section{Chapter 4}

Variation in field management strategies among rice growers 


\begin{abstract}
This chapter, as a companion chapter to chapter 3, analyses differences in management between different types of fields in which rice is grown by 60 farmers in two VDCs in the terai area of Nepal. We used factor analysis to establish groups of fields with similar forms of management. Factor analysis indicated three groups of field management that were characterised by forms of nutrient management. There were two groups of rice fields were management was of low intensity. The first group of these fields was characterised by application of manure, while no urea was used for topdressing. The second group of these fields was characterised by application of mineral fertiliser (including urea for top dressing), with no or little application of manure. The third group consisted of fields with intensified management and consequently higher yield. Part of those fields conformed to the principles of SRI, however other fields with intensive management were observed, indicating a diversity of pathways for intensification. In more productive fields younger seedlings were used and interplant distance was wider. Fields with more intensive management were significantly smaller than fields that were managed less intensively. Ownership of the land, distance to the homestead and village (likely a proxy for different irrigation facilities) were also factors that correlated with different forms of field management. There was a significant association between farmer livelihood strategy and the forms of field management.
\end{abstract}




\subsection{Introduction}

There is large variation in rice yields in Nepal. Rice yield depends on the interaction between genotype (choice of rice cultivar), environment (soils, water, etc.) and management, including both the biophysical side (e.g., nutrient management, irrigation) and the socio-economic and cultural side (e.g., land tenure, labour allocation, market and cultural value of different cultivars). Cultivar selection (Chapter 7) and nutrient and water management (Chapters 5 and 6) are important management variables. Yield differences among rice farmers in the same locality and with the same cultivars indicate the effect of management by those farmers in their fields. Improving management leads almost always to increased yields. Richards (1985) suggested that small farmers prefer to minimise risks than maximise yield. In agreement with that suggestion, local cultivars and also local resourcebased methods perform often better during risky situations (Rijal and Synnevag 2005).

Rice development efforts in Nepal started 50 years ago when improved cultivars, irrigation facilities and mineral fertilisers were introduced (Chapter 2). Since then about 57 rice cultivars have been released (NARC 2014). The use of mineral fertiliser has increased as did the area under irrigation. Despite all these efforts, the productivity of rice in Nepal has remained the lowest within this region, just 2.7 tha $^{-1}$ (IRRI 2006; MOAC 2009) and been more or less stagnant in last decade (MOAC 2011).

The majority of Nepalese farmers (75\%) are smallholders with less than one hectare of land. The use of mineral fertiliser, improved varieties and other modern inputs (as part of the Green Revolution package) by small farmers continues to be low (CBS 2002). Agricultural research organisations focus mainly on cultivar development and cost effectiveness of external inputs (NARC 2014). Studies have shown that most of the benefits of research findings that accompanied the Green Revolution have gone to rich instead of poor farmers (Griffin 1976; Pearse 1980).Alternatives that rely on lower external inputs could be attractive to resource-poor farmers, especially if the lower inputs still result in higher yields. One such alternative option is the System of Rice Intensification (SRI). SRI was introduced in Morang district by the local district agriculture development office (DADO) in 2003 (Uprety 2005, 2006). Its introduction was inspired by a paper on SRI by Uphoff (2001). SRI is a farm-based method that has its origin in Madagascar for rice cultivation and is characterised amongst others by transplanting of younger single seedlings 
at wider spacing, alternate wetting and drying (AWD) system of irrigation and better weed management by use of a rotary weeder (De Laulanié 2003; Stoop et al. 2002; Uphoff 2001 see also chapter 2).

The claims that surround SRI have been contentious (see Box 1.1 for a brief overview of the so-called SRI controversy) and met with strong disbelief. Berkhout and Glover (2011) summarised official and grey literature about SRI and its global development. One interesting outcome that emerged from their analysis is that, whereas SRI as that particular set of practices is highly contentious, several underlying individual management practices have been accepted as contributing to more efficient and productive rice cultivation. Their study also highlighted a tension between location-specific claims of individual practices and generalised claims of a whole technology package. Finally, they argue for a shift in emphasis from controlled trials on-station or in farmers' field to analysis of actual use of cultivation techniques in farmers' fields.

A critical issue in studying the use of SRI practices is the unit of analysis. Should one analyse farmers as belonging to categories of SRI- or non-SRI farmers? Such a classification invites questions about early and late adopters, non-adopters and disadopters. Moreover, because SRI is not a fixed set of practices but a basket of techniques for intensification that may or may not work under specific agro-ecological and socio-economic conditions, it may be better to look at the practices on field level. A field-level analysis assumes that farmers apply SRI-like practices (or a subset of them) in some fields, whereas they apply different management practices (or discontinue earlier practices) in other fields. Such patterns may then subsequently be understood in the framework of larger-scale processes of agricultural intensification and the mechanisms shaping that intensification.

Berkhout and Glover (2011) recommended investigation at several levels. Certain questions, for example about dissemination strategies, can be studied by selecting different communities, villages and regions. Questions about implementation and diversification of practices are better studied at field level. Recently Noltze et al. (2012) conducted a study in Timor Leste on SRI. Because they regarded SRI as a location-specific (or even fieldspecific) package of practices, they took individual rice plots rather than the whole farm (or the farmer) as a unit of study. These authors took a core set of four SRI practices (intermittent irrigation, early transplanting, use of single seedlings, wide spacing) as 
standard benchmark to define SRI. By treating SRI as a standard package, their study could not address if individual components or specific combinations of components of intensification were adopted while others were not.

However, there is no need to consider either the farm level (expression of livelihood strategies by individual farmers) or the plot level (expression of specific forms of management based on the interaction between Genotype $\times$ Environment $\times$ Management) as the privileged level of analysis. A combination of both analytical approaches may be advantageous. In Chapter 3 we investigated livelihood strategies in Morang district. We identified four distinct livelihood strategies and these were associated with different likelihoods that farmers adopt strategies for rice intensification (or more general agricultural intensification). Intensification occurred both among landowners and tenants, and were partly driven by opportunities outside agriculture. While the high-production livelihood strategies fit in a pattern of adoption of SRI practices, we also noted that several farmers used intensification as a pathway to intensify out of rice farming towards the cultivation of high-yielding vegetables or even towards non-agricultural jobs.

In this chapter we therefore looked at the actual practices in individual plots. We explored which practices of more intensified rice farming occur together. Linking livelihood strategies of farmers with management strategies in their individual fields would then allow the best means to understand processes of agricultural intensification in the terai of Nepal. Using a quantitative approach, we explore the effect of different management practices in different fields on rice productivity. We were interested to what extent field management strategies could be grouped, because of regularly co-occurring sets of practices. We were also interested to explore how different forms of management of individual fields correlated with livelihood strategies of individual farmers (Chapter 3).

\subsection{Materials and methods}

\subsubsection{Study Area}

Morang district of eastern Nepal, situated between latitudes $26^{\circ} 20^{\prime}$ to $26^{\circ} 53^{\prime} \mathrm{N}$ and longitudes $87^{\circ} 16^{\prime}$ to $87^{\circ} 41^{\prime} \mathrm{E}$, has been selected for this study (Figure 1.1). It is the largest rice-growing district of Nepal. Total rice-growing area of this district is about 94, 000 ha and average rice yield of main-season rice is $3.1 \mathrm{t} \mathrm{ha}^{-1}$. The district covers an area of 1,855 
$\mathrm{km}^{2}$. It has a population size of 1,028,362 (2011). Biratnagar, the district headquarters, is the second largest city after Kathmandu and is the main industrial centre of Morang. Altitude varies from $100-2410 \mathrm{~m}$. The climate type is subtropical, of the monsoon type with more than $2000 \mathrm{~mm}$ average annual rainfall. Average annual maximum and minimum temperatures are $30.6^{\circ} \mathrm{C}$ and $14.2^{\circ} \mathrm{C}$ respectively.

The study was conducted in two VDCs, namely Jhorahat and Indrapur from June 2008 to December 2009. Information on both VDCs is presented in Table 4.1.

Table 4.1. Details of the studied VDCs

\begin{tabular}{|c|c|c|c|c|c|c|}
\hline VDC & $\begin{array}{c}\text { Area } \\
\left(\mathrm{km}^{2}\right)\end{array}$ & $\begin{array}{c}\text { Population } \\
(2007)\end{array}$ & $\begin{array}{c}\text { Distance }(\mathrm{km}) \\
\text { from Biratnagar }\end{array}$ & $\begin{array}{c}\text { No. of farm } \\
\text { households }\end{array}$ & $\begin{array}{c}\text { Cultivable } \\
\text { land (ha) }\end{array}$ & $\begin{array}{c}\text { Area under } \\
\text { rice (ha) }\end{array}$ \\
\hline Jhorahat & 13.17 & 5,414 & 10 & 788 & 1250 & 1180 \\
\hline Indrapur & 25.47 & 19,179 & 28 & 2650 & 2510 & 2250 \\
\hline
\end{tabular}

Both VDCs have similar extension support systems but different social settings (Chapter 3). In Indrapur VDC more farmers were engaged in agricultural intensification than in Jhoharat. In both VDCs SRI was introduced in 2004 (Uprety 2005). Of the 60 farmers studied for their livelihood strategies, we monitored their agricultural activities on individual plots. These plots are different in their biophysical, agro-ecological and ownership conditions and were differently managed by farmers because of agro-ecological and / or socio-economic differences. In all, 165 fields were analysed, 94 in Jhorahat and 71 in Indrapur. These 165 plots were kept on season-long observation. We collected information related to management practices by individual farmers in individual plots by interviews and observations.

Instead of using a pre-conceived classification of farmers' fields (using an a priori choice to classify plots as being under SRI or non-SRI), we applied factor analysis to determine patterns in field management strategies.

\subsubsection{Data analysis}

SPSS computer software has been used for data analysis. Factor analysis (Darlington 2012; 
StatSoft 2012) was applied to explore different plot management strategies. Factor analysis is used to reduce the number of variables and to detect structure in relationships between variables. For factor analysis we used 11 variables related to field management characteristics. These variables are: (1) seedling age at transplanting; (2) seedling density per hill; (3) density of hills per square meter (variables 2 and 3 then yield seedling density per area, which translates into seeding rate); (4) days after first transplanting in study area; (5) day of first weeding after transplanting; (6) day of application of topdressing nitrogen fertiliser after transplanting; (7) amounts of nitrogen fertiliser; (8) amounts of phosphorus fertiliser; (9) amounts of potassium fertiliser; (10) fraction of nitrogen fertiliser used for topdressing; (11) manure use. Other variables (field productivity, distance of field to village, ownership, cultivar choice, etc.) that were recorded were not used for factor analysis, but used subsequently to test for further differences between the plot management strategies that were recognised.

Next to factor analysis, we tested for differences between field management categories by one-way ANOVA or likelihood ratio test (G-test), which is approximately distributed as chi square. Correlations between different parameters were also calculated, to address the question to what extent individual management practices actually occur together and fitwith the general description of SRI. We also calculated correlations between the three main axes of the factor analysis for livelihood strategies and for plot management strategies. Differences were considered significant at $P<0.05$.

\subsection{Results}

\subsubsection{Correlations between practices}

The correlation matrix is given in Table 4.2. Four practices of planting (seedling age, seedling density, hill density, and seedling transplantation date) are significantly correlated. This significant correlation implies that the SRI practices of using young seedlings that are widely spaced and transplanted at an early date are usually combined. These practices were also significantly correlated with use of both organic amendments (manure) and nitrogen use.A more detailed analysis of nutrient management is provided in Chapter 5 .

Yield significantly correlated with seedling parameters (seedling age: $r=0.648$; seedlings per hill: $\mathrm{r}=-0.588$; hill density: $\mathrm{r}=-0.645 ; \mathrm{P}<0.001$ in all cases) and use of organic 
amendments $(\mathrm{r}=0.590 ; \mathrm{P}<0.001)$ and $\mathrm{K}(\mathrm{r}=0.220 ; \mathrm{P}=0.004)$, but not to total mineral $\mathrm{N}$ and $\mathrm{P}$ (see Chapter 5 for extended analysis).

\subsubsection{Factor analysis}

The first axis of the factor analysis explained $27 \%$ of variation, the second axis $17 \%$, and the third axis $16 \%$. These three axes explained $60 \%$ of the total data set. The fourth and fifth axis explained respectively $16 \%$ and $11 \%$, resulting in $78 \%$ of cumulative variation explained by the first five (out of eleven) axes. The first factor was positively correlated with seedling characteristics (0.80) and negatively with manure use (-0.71) and to a lesser extent nitrogen (0.47). The second factor correlated with nitrogen used for topdressing, both for timing of topdressing (0.86) and the fraction of $\mathrm{N}$ used for topdressing (0.91). The third axis correlated with other mineral nutrients, phosphorus (0.84) and potassium (0.82), while the fourth axis correlated with weeding days after transplanting (0.90). Figure 4.1 shows the results of the factor analysis whereby the first two axes are graphically depicted. In that figure we recognise three groups that represent three types of field management strategies in Morang. 
Table 4.2. Correlations between field variables $(\mathrm{n}=165)$. Values in bold are significant at $P<0.05$, values in bold and underlined are significant at $P<0.01$.

Variables

1. Seedling age at transplanting

2. Seedlings per hill

3. Hill density $\mathrm{m}^{-2}$.

4. Transplanting days (from first transplanting)

5. Weeding (days after transplanting)

6. Topdressing (days after transplanting)

7. Nitrogen $\left(\mathrm{kg} \mathrm{ha}^{-1}\right)$

8. Phosphorus $\left(\mathrm{kg} \mathrm{ha}^{-1}\right)$

9. Potassium $\left(\mathrm{kg} \mathrm{ha}^{-1}\right)$

10. Nitrogen used for topdressing (\%)

11. Manure use $\left(\mathrm{tha}^{-1}\right)$ $\begin{array}{lllllllllll}1 & 2 & 3 . & 4 & 5 & 6 & 7 & 8 & 9 & 10 & 11\end{array}$ $\begin{array}{lllllllllll}X & \underline{\mathbf{5 7}} & \underline{\mathbf{5 8}} & \underline{\mathbf{. 5 2}} & -.13 & \mathbf{. - 1 7} & \underline{-.41} & .04 & \mathbf{- . 1 9} & .01 & \underline{\mathbf{- . 4 5}}\end{array}$ $\begin{array}{llllllllll}X & \underline{\mathbf{6 5}} & \underline{\mathbf{. 2 6}} & -.03 & -.15 & \underline{\mathbf{. 3 9}} & .00 & \underline{\mathbf{- . 2 3}} & -11 & \underline{-.41}\end{array}$ $\begin{array}{llllllllll}X & \underline{.28} & .00 & \underline{\mathbf{- . 2 5}} & \underline{-.44} & -.00 & \mathbf{- . 1 9} & -.14 & \underline{\mathbf{- . 3 9}}\end{array}$ $\begin{array}{llllllll}X & \mathbf{- . 1 8} & \underline{\mathbf{- . 2 9}} & \underline{\mathbf{- . 2 3}} & .03 & -.05 & -.08 & \underline{\mathbf{- . 3 0}}\end{array}$ $\begin{array}{lllllll}\mathrm{X} & \mathbf{1 7} & .08 & -.13 & .14 & .05 & .13\end{array}$ $\begin{array}{llllll}X & \underline{. \mathbf{4 6}} & -.02 & .00 & .003 & .06\end{array}$ $X \quad \underline{.36} \quad \underline{.40} \quad \underline{.28} \quad \underline{.31}$ $\begin{array}{llll}\mathrm{X} & \underline{.44} & -.12 & -.16\end{array}$ $\begin{array}{lll}\mathrm{X} & -.04 & -.01\end{array}$ $\mathrm{X} \quad \underline{. .22}$ 
The first group (OM - organically managed; lower half of the diagram) comprised 33 plots $(20 \%)$ with the lowest amount of mineral fertilisers applied and no use of topdressing; however, use of manure, which was the main nutrient source, was higher than in the fields of group 2. In these fields seedling density was highest (Table 4.3). The second group (FM - mineral-fertiliser managed; upper left part of the diagram) comprised 90 plots (55\%) of conventional rice farming that have higher levels of mineral fertilisers, including urea for topdressing, but with very low manure use. Also seedling age is high. Both group 1 and 2 comprise plots where SRI practices are absent or scarce. The third group (RI - rice intensified) comprises 42 plots (25\%) characterised by forms of increased management. In these fields both high levels of mineral fertiliser and organic amendments are applied. Seedlings are very young to young when planted. Those fields are also significantly more productive than the fields of group 1 and 2 (Table 4.3).Further details of these three type management are given in Table 4.3 (based on factor analysis) and Table 4.4 (based on other recorded properties, not used for the factor analysis). Part of the plots are characterised by practices that fit SRI, other plots do not fit that system (in terms of spacing and seedlings per hill), but that are characterised by other forms intended to increase productivity. These plots were differentiated along the fourth axis of factor analysis (not shown); a few salient differences in management are shown in Table 4.5. Fields that were managed in conformity with SRI were characterised by transplanting younger seedlings, with less seedlings per hill and with less hills per area. These fields were also significantly smaller. Interestingly, use of area was marginally higher in these fields and that of compost significantly lower. Use of phosphorus and potassium was not different between both subtypes. Fields under SRI were also significantly more under fallow that those under other forms of intensification. Farmers also spent more time for field preparation and for transplanting when the field was managed according to SRI than when managed under other forms of intensification. Fields under SRI were also significantly more often owned and found significantly more in Jhoharat than in Indrapur, suggesting that VDC-specific factors were relevant for forms of intensification and increased productivity. 


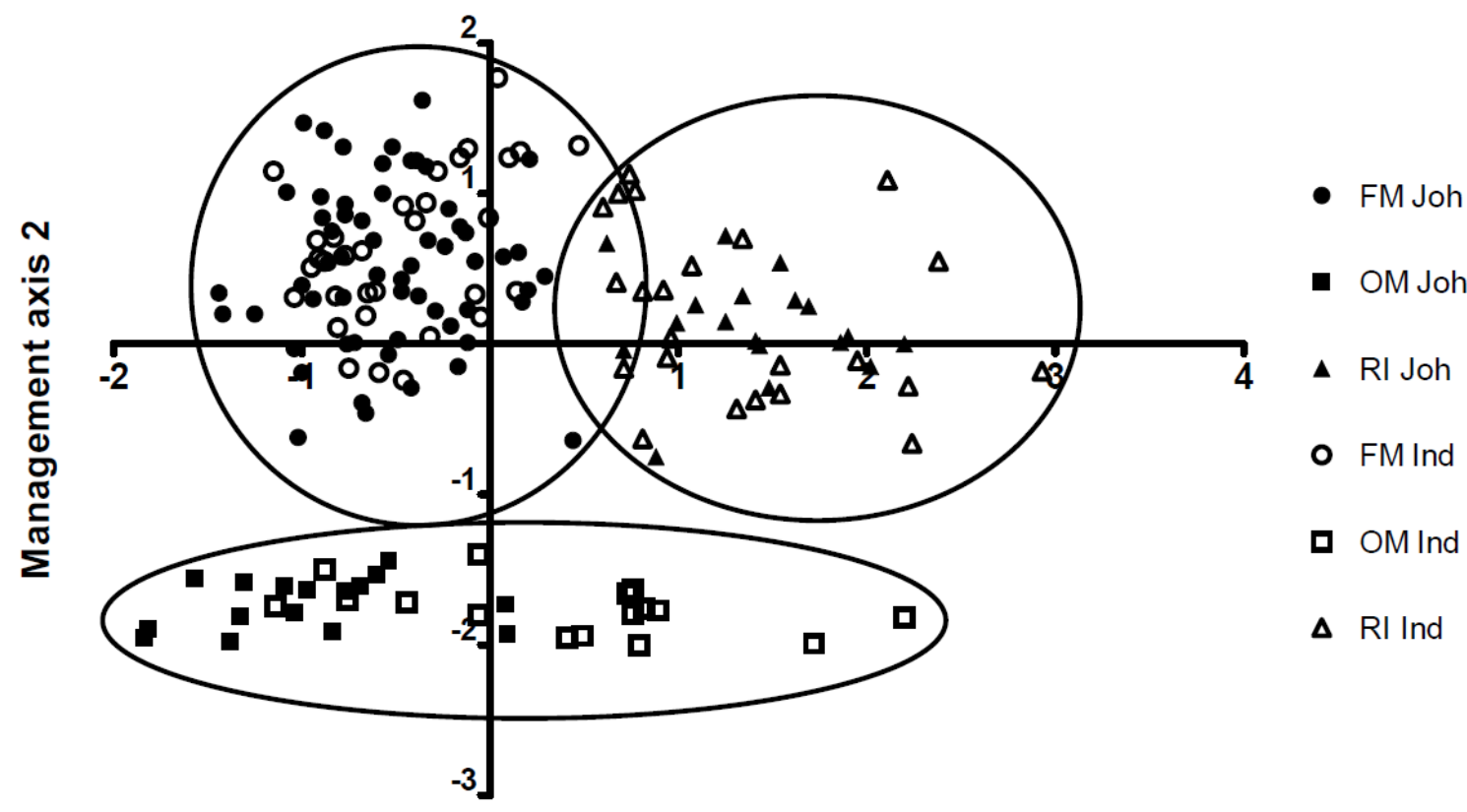

\section{Management axis 1}

Fig. 4.1 Pattern of farmers plots according to their management practices. See text for explanation of abbreviation of field management strategy. Closed symbols refer to Jhoharat (Jho), open symbols to Indrapur (Ind).

Table 4.3. Average of different categorical variables within different field management groups. For acronyms of the field management groups, see text. P-values are based on oneway ANOVA or on the G-test. Values in bold indicate significant differences between groups $(P<0.05)$.

$\begin{array}{lllll} & \text { OM } & \text { FM } & \text { RI } & \text { P } \\ \text { Seedling age (days) } & \mathrm{n}=33 & \mathrm{n}=91 & \mathrm{n}=41 & \\ \text { Seedling density (number per hill) } & 34.2 & 34.6 & 16.2 & <\mathbf{0 . 0 0 1} \\ \text { Hill density (number per } \mathrm{m}^{2} \text { ) } & 5.5 & 4.6 & 2.0 & <\mathbf{0 . 0 0 1} \\ \text { Days of transplanting } & 35 & 31 & 21 & <\mathbf{0 . 0 0 1} \\ \text { Weeding (days after transplantation) } & 31 & 29 & 27 & 0.10\end{array}$




$\begin{array}{lllll}\text { Top dressing (days after transplantation)* } & 0 & 34 & 35 & <\mathbf{0 . 0 0 1} \\ \text { Nitrogen }\left(\mathrm{kg} \mathrm{ha}^{-1}\right) & 12.0 & 39.8 & 40.7 & <\mathbf{0 . 0 0 1} \\ \text { Phosphorus }\left(\mathrm{kg} \mathrm{ha}^{-1}\right) & 22.2 & 24.5 & 24.3 & 0.56 \\ \text { Potassium }\left(\mathrm{kg} \mathrm{ha}^{-1}\right) & 7.0 & 9.6 & 13.1 & \mathbf{0 . 0 0 3} \\ \text { \% of N for topdressing* } & 0 & 60 & 46 & <\mathbf{0 . 0 0 1} \\ \text { Manure use }\left(\mathrm{t} \mathrm{ha}^{-1}\right) & 5.1 & 1.2 & 12.4 & <\mathbf{0 . 0 0 1} \\ \text { * Rank test applied } & & & & \end{array}$

Table 4.4. Yield and nutrient-related variables within different field management groups. For acronyms of the livelihood groups, see text. P-values are based on one-way ANOVA or on the G-test. Values in bold indicate significant differences between groups $(P<0.05)$.

$\begin{array}{lllll} & \text { OM } & \text { FM } & \text { RI } & \text { P } \\ \text { Yield }\left(\mathrm{t} \mathrm{ha}^{-1}\right) & 3.1 & 3.3 & 5.4 & <\mathbf{0 . 0 0 1} \\ \text { Field size }(\mathrm{ha}) & 0.4 & 0.6 & 0.3 & \mathbf{0 . 0 6} \\ \text { Seedling density }\left(\mathrm{m}^{-2}\right) & 205 & 148 & 45 & <\mathbf{0 . 0 0 1} \\ \text { Seed rate }\left(\mathrm{kg} \mathrm{ha}^{-1}\right) & 61.4 & 50.1 & 19.1 & <\mathbf{0 . 0 0 1} \\ \text { Urea-N }\left(\mathrm{kg} \mathrm{ha}^{-1}\right) & 3.3 & 30.0 & 31.8 & <\mathbf{0 . 0 0 1} \\ \text { Urea-N starter }\left(\mathrm{kg} \mathrm{ha}^{-1}\right) & 3.3 & 6.0 & 5.8 & 0.22 \\ \text { Urea N-top dress }\left(\mathrm{kg} \mathrm{ha}^{-1}\right)^{* *} & 0 & 24.2 & 25.3 & <\mathbf{0 . 0 0 1} \\ \text { Ammonium-N }\left(\mathrm{kg} \mathrm{ha}^{-1}\right)^{*} & 8.7 & 9.6 & 9.4 & 0.56 \\ \text { Total N }\left(\mathrm{kg} \mathrm{ha}^{-1}\right) & 19.8 & 41.6 & 58.8 & <\mathbf{0 . 0 0 1} \\ \text { Fallow outside main season } & 18 / 33 & 59 / 91 & 13 / 41 & \mathbf{0 . 0 0 2} \\ \text { Own field } & 17 / 33 & 48 / 91 & 33 / 41 & <\mathbf{0 . 0 0 1} \\ \text { Distance from home }(\mathrm{km}) & 2.1 & 2.2 & .4 & <\mathbf{0 . 0 0 1} \\ \text { Labour for field preparation } & 28 & 27 & 28 & 0.49 \\ \text { In Jhorahat } & 17 / 33 & 59 / 91 & 18 / 41 & 0.06 \\ { }^{*} \text { NH } & -\mathrm{N} \text { and P are simultaneously applied through } \mathrm{DAP} ;{ }^{* *} \text { Data do not fit ANOVA } \\ \text { assumptions (rank test was applied). } & & & & \end{array}$




\subsubsection{Correlations between livelihood strategies and plot management strategies}

In chapter 3 we applied factor analysis to recognise four livelihood categories of farmers. We therefore tested to what extent a classification of farmers and of fields are consistent or not, and whether they provide indications of underlying similarity. Table 4.6 provides correlations between the first three axes of the factor analysis of livelihood strategies and of fields. Results show that the first axis of the field management strategy (which is partly an intensification axis as it correlates with forms of SRI management livelihood analysis) and the second axis of the farmer livelihood strategy (which can also be equated with an intensification axis as it correlated with cropping intensity and productivity) were significantly correlated $(\mathrm{r}=0.34 ; \mathrm{n}=$ $165 ; \mathrm{P}<0.001)$. These data indicate that both a classification of livelihood strategies and of actual field management practices capture a similar underlying dynamic of intensification leading to more crops per year and higher yields.

Similarly, a chi-square test showed there was a significant association $(P=0.02)$ between farmer livelihood strategies and field management strategies (Table 4.7). SRI-like practices were mostly but not exclusively found among high-productive owners and tenants; but low-productive owners and tenants also owned fields with intensified management.

\subsubsection{Adaptive management of farmers in different plots}

Farmers used different strategies in different plots. Several factors correlated with and likely influenced farmers' management practices. Land type is one important factor associated with different crop management strategies. Results show that in 90\% SRI-like plots were upland where irrigation facility and drainage was better while $>73 \%$ lowland were under mineral-fertiliser management. But management in the other two groups of fields showed variation: farmers used slightly younger seedling and fewer seedlings in lowland. Regarding field distance most of the farmers used younger seedling and fewer seedlings in fields closer to the residence. 
Table 4.5. Differences in forms of intensification of rice farming, based on differentiation of farmers of group 3 (RI).P-values are based on one-way ANOVA or on the G-test. Values in bold indicate significant differences between groups $(P<0.05)$.

\begin{tabular}{|c|c|c|c|}
\hline & $\begin{array}{l}\text { SRI } \\
(\mathrm{n}=30)\end{array}$ & $\begin{array}{l}\text { Other } \\
\text { intensification } \\
(\mathrm{n}=11)\end{array}$ & $\mathrm{P}$ \\
\hline Yield $\left(\mathrm{t} \mathrm{ha}^{-1}\right)$ & 5.8 & 4.5 & 0.004 \\
\hline Field size (ha) & 0.2 & 0.4 & 0.005 \\
\hline Seedling age (days) & 13.7 & 23.0 & $<0.001$ \\
\hline Seedling density (number per hill) & 1.4 & 3.9 & $<0.001$ \\
\hline Hill density (number per m²) & 18.9 & 26.6 & $<0.001$ \\
\hline Seedling density $\left(\mathrm{m}^{-2}\right)$ & 27 & 96 & $<0.001$ \\
\hline Compost $\left(\mathrm{t} \mathrm{ha}^{-1}\right)$ & 14.3 & 21.2 & 0.05 \\
\hline Urea-N $\left(\mathrm{kg} \mathrm{ha}^{-1}\right)$ & 34.2 & 25.2 & 0.06 \\
\hline Labour for transplanting (days) & 29 & 23 & 0.04 \\
\hline Land preparation (days) & 29 & 24 & 0.01 \\
\hline Own field & $27 / 30$ & $6 / 11$ & 0.01 \\
\hline Fallow in previous period & $12 / 30$ & $1 / 11$ & 0.06 \\
\hline In Jhorahat & $18 / 30$ & $0 / 11$ & $<0.001$ \\
\hline
\end{tabular}

Table 4.6. Correlations between the main axes of both factor analyses.

Field axis 1

Livelihood axis 1

$-0.01$

Livelihood axis 2

$0.34^{* * *}$

$-0.22^{* * *}$

Livelihood axis 3

**: significant at $0.001<\mathrm{P}<0.01 ; * * *$ significant at $\mathrm{P}<0.001$
Field axis 2

Field axis 3

$-0.11$

$-0.13$

$0.20^{* * *}$ 
Table 4.7. Association between livelihood strategies and farmers' field management, based on 60 farmers and 165 fields.

$$
\text { Field management strategy } \quad \text { OM } \quad \text { FM } \quad \text { RI }
$$

Livelihood strategy

SRFO

MRFO

MRFT

LRFT

$\begin{array}{lll}3 & 4 & 6 \\ 7 & 25 & 6 \\ 18 & 48 & 14 \\ 5 & 14 & 15\end{array}$

\subsection{Discussion}

Rice farmers' livelihood strategies and their plot level crop management strategies were interrelated but crop management strategies were more influenced by contextual situations like irrigation facility, land type, previous crop, labour availability, land ownership, crop after rice harvesting, distance of fields from their residence, manure availability, etc. Both classifications of livelihood strategies and plot management strategies provided evidence for agricultural intensification, in agreement with the System of Rice Intensification. Individual farmers applied different forms crop management in different rice fields. In livelihood strategies farmers make decisions how to allocate their household resources (family labour, bullocks, land, and mineral fertilisers and manure) to improve income and ultimately their livelihoods (both within agriculture and non-agricultural occupations). Within such strategies farmers, who possess or have access to more plots, make decisions how to optimally use these plots with their given environmental context.

Considering this multi-level context a simple classification of farmers as SRI and non-SRI farmers (e.g., Anthofer 2004; Moser and Barrett 2003; Moser and Barrett 2006; Sinha and Tilati 2005; Barah 2010; Somaratne 2010) does not address the complexities of the environment in which they grow rice. Similarly, only classifying plot management strategies without the context of livelihood strategies misses part of that complexity. Certain plot management decisions (e.g., application of mineral fertilisers and manure, but also of rice varieties) are not only related to rice growing, but also to the different crops that are grown in their fields in other seasons (see Chapter 5 with regard to nutrient management). Farmers who intensify out of rice growing (as shown by important major marketable 
vegetable crops - Chapter 3) or even intensify out of agriculture, manage their plots in ways that could easily result in overestimating the importance of SRI as a rice-specific system. In fact, the study showed that next to a number of fields (in all 18\%) where management was in accordance of SRI, other fields, especially in Indrapur, showed clear signs of intensification, without conformity to the principles of SRI. A classification that would have listed fields as either managed as under SRI or managed conventionally would not only have missed the difference between fields with nutrient management through manure (OM) or through mineral fertiliser (FM), but would also have missed other forms of intensification where farmers apply both manure and mineral fertiliser under a very high cropping intensity. Intensification in such fields is also evident from the fact that transplanted seedlings in such fields are younger than in OM and FM fields that are also planted in a lower density.

The results of this study confirm findings regarding the positive effect of younger seedlings and lower seedling density on rice yield. With a seeding rate that is only $30-40 \%$ of that in other plots, the productivity was still $60-70 \%$ higher. However, several factors limit the use of younger seedlings, which is a prerequisite for the low seeding rate. Almost all rice farmers in Morang district use the transplanting method on puddled fields. There was no direct seeding of rice. Transplanting work is connected with land preparation and land preparation is only possible when there is sufficient water on such fields (Chapter 2). In other sites swampy lowlands were covered by water after heavy rainfall and such fields could only be prepared when water level has gone down to its minimum, usually at the end of the monsoon. Under such conditions farmers were unable to manage their transplanting dates. They need to wait till the situation is favourable for final land preparation (puddling and levelling) and transplanting. Most farmers in water-scarce areas start seeding their rice nurseries immediately after the beginning of the monsoon rains. But for transplanting they need to wait for favourable times when sufficient water is available on their fields. Timing of seeding in areas with better irrigation has larger windows of opportunity. Farmers can then adjust their nursery preparation and seeding according to possible transplanting dates. The importance of water reliability is further discussed in chapter 6. Seedling age was significantly positively correlated with seedling numbers per hill, spacing of hills, and hence total seedling density per unit area. So if transplanting is not possible at the expected or 
preferred date, seedlings become older at time of transplantation; and under such conditions farmers transplant more densely. The final consequence of that situation is that their field is less productive.

Land ownership and distance of rice plots from the residence were also very important for intensive management of the plots and therefore for higher yields (Table $4.4-$ see also Chapter 3). Depending on their livelihood aspirations some farmers who are landowners obtain high yields in their own fields. Also tenants can obtain high yields in fields that are closer to the residence. Rented land (especially under conditions of share cropping), unreliable irrigation (for timely execution of the various activities) and distance to the field (for intensive management) result in conditions where productive rice farming is vulnerable or risky, so these fields are less intensively managed and therefore lowproductive. Farmers transplanted the fields close to the residence, which are more suitable for intensive management, first and the fields at larger distance later. They also managed such fields less.

We repeatedly observed that in fields, which are far from the residence, land preparation and transplanting took place at the same time. Farmers have to combine both activities in order to protect their crops from freely grazing livestock. During the transplanting season farmers leave their animals free for grazing on fallow land during day time. If in that period fallow lands are scarce, animals might graze these rice fields. So this combined practice is an inevitable response in order to protect their crop in distant fields from grazing animals. In such cases, however, transplantation might be too early or too late (depending on water availability) for yield maximisation.

There were no significant differences in weeding time between the three groups of fields (Table 4.3).Similarly, there was no significant relationship between time spent on weed management and rice yield (data not shown). We hypothesise that labour and / or financial constraints force most farmers to weed less or spend less on weed management than what would be necessary for optimum yields. Farmers with limited family labour available (especially owners)face more problems for early weed management, the more so as labour investment (own labour and hired labour) is in transplanting, not in weeding. Farmers want to use the opportunity of water availability to finish their transplantation of rice seedlings. Weeding is only possible after (most of the) transplanting has been finished. 
Also labour spent on transplanting is considered less of a drudgery than labour spent on weeding.

The use of organic amendments is an important component of nutrient management in rice farming. However, its use was limited and plots of group 2 (FM) did not see the use of organic amendments. Only fields of group 1 and especially of group 3 received (substantial amounts of) (mainly animal) manure. Differential manure use is partly explained by land ownership and distance of fields to the residence. Farmers use most manure on their own land which is also closer to the residence. Differential use of manure as a function of distance is due to the bulkiness of manure, requiring substantial labour and transportation costs to far-away fields. Manure use is also related to livelihood strategies, as not all farmers possess bullocks (Chapter 3). However, we observed some notable exceptions: farmers, whose livelihood strategy is towards intensification and who cultivate vegetables after rice, use manure also in rented fields.

Most of the terai indigenous farmers do not use animal manure or vegetable organic matter on their rice fields. They use most of the farmyard manure for guitha (animal dung cake, used as fuel for cooking; Chapter 2). Most of these farmers live in the southern part of Morang district far from the forest, hence without good access to fire wood. Lack of firewood seems a major reason for using animal dung as fuel. Part of the animal manure is used for agricultural purposes. However, their second priority in manure use is garlic, which is a main income source for women during their weekly marketing, and vegetables, which are also high-value market crops. Consequently, manure use in rice fields is very limited.

Several studies (Barison 1997; Makarim et al. 2002; Menete et al. 2008; Pasuquin et al. 2008; Manjunatha et al. 2010; Deb et al. 2012) reported positive effect of younger seedlings on rice yield. Menete et al. (2008) reported about different level of effect of young seedlings on different cultivars. My study found positive effect of younger seedlings on rice yield. But other studies did not find effect of seedling age on rice yield (Thiyagarajan et al. 2002; Long et al. 2005; Latif et al. 2009).

Better weed management can increase rice yield (Anitha and Chellappan 2011). These authors reported that weeding by cono-weeder gave higher yields than manual weeding. My study results confirmed that finding. Importance of efficient weed management further increased for SRI due to its wider spacing and AWD system of 
irrigation. Several studies reported weed management as a critical part of SRI method (Yadao and Zamora 2007; Krupnik et al. 2010; Uprety 2011). That might be the reason that De Laulanié (1993) recommended early first weeding after transplanting.

Nutrient management is another important aspect of rice cultivation. Non-judicious use of chemical fertilisers has negative effects on crop yield. During a study conducted in Nepal Dhungana et al. (2004) found that less efficient farmers used more urea. To systematise use of rice nutrient management IRRI recommended location-specific nutrient management (Dobermann et al.1998, 2002). Several other studies reported about the benefits of organic manure on rice yields (Bhattacharya et al. 2003; Sahrawat 2004; He and Ma 2005; Nayak et al. 2009; Tsujimoto et al. 2009). My study results confirmed the findings of Dhungana et al. (2004) and positive effects of organic manure on rice yield when used combined with mineral fertilisers.

Finally water management is important and critical for rice production (rice cultivation is the largest user of fresh water) regarding rice yield, water productivity. IRRI researchers carried out extensive research on rice cultivation systems that could save water with increasing water productivity (Belder at al. 2004, 2005; Bouman et al. 2006). Regarding water management and SRI Vijayakumar et al. (2006), Zhang et al. (2007), Zhao et al. (2009), and Thakur et al. (2010) reported significant water saving with higher yield by SRI method. Further Krupnik et al. (2010) reported that water saving and water productivity were only possible with effective weed management. My observation is very close to Krupnik et al. (2010) findings, farmers tried to hold more water in their rice field if there was problem of weed management.

\subsection{Conclusion}

Livelihood and plot management strategies by rice farmers are interconnected. Livelihood strategies are more family resource-based strategies while field management strategies are more context-dependent. Relevant elements of this context include ownership of the land (tenure status), distance to the residence, availability of good irrigation practices, and competition for manure for cooking. Due to the wide diversity in agro-ecological conditions, it is evident that there is not one single solution that would fit all farmers and all fields. Intensification is not achievable as a general strategy. SRI is therefore more of a 
choice than an imperative. Solutions should be appropriate for local situations, and this location specificity includes both the agro-ecological and socio-economic context. Farmers try to modify or re-shape new technologies and incorporate appropriate parts of it to suit their situation. The poor correlations between fertiliser use (especially nitrogen use) and yield indicate low fertiliser use efficiency (see Chapter 5 for an extended analysis).

Training programmes should therefore be only directed towards farmers (both landowners and tenants) with a livelihood strategy that is compatible with agricultural intensification. The introduction of SRI in Morang district resulted in several changes in rice farming, but only part of the farmers adopted such technologies, and adoption was only in part of their fields. Other farmers incorporated some SRI practices in their conventional practices. Current rice growing practices in Morang district can therefore be described as hybrid practices, conforming neither to the concept of conventional practice nor to the ideal type of SRI. Introduction of SRI in the region therefore acted more as an additional factor in practices of intensification and de-intensification. After introduction of SRI farmers further tested, re-packaged or made hybrid SRI methods to make it suitable for their agroecological and socio-economic environment. Therefore, if SRI is promoted as a copy-paste practice type of intervention, it is bound to remain ineffective, not different from earlier attempts to introduce context-independent practices. In order to reform Nepalese rice farming we need to recognise that different farmers, with different livelihood strategies and with access to different kinds of fields, need different forms for agricultural intensification. 


\section{Chapter 5}

Nutrient management and its effects on rice yield 


\begin{abstract}
There is large variation in rice yield in the main rice-growing season in the terai of Nepal. This chapter analyses nutrient management (application of mineral fertiliser and animal manure) in 165 fields of 65 farmers in two VDCs of the terai. There were large differences in application of manure and urea and smaller differences in potassium application among the three groups of field management recognised in Chapter 4. Averaged over all plots, rice yield was significantly correlated with use of manure, urea and potassium. However, within each group of field management, the relations with nutrient management were weak or absent. Regression analysis indicated large differences in the intercept, the yield under conditions of no nutrient management, suggesting that intrinsic differences in soil fertility and differences in nutrient management outside the main rice-growing season were more important than actual nutrient management. Because of the poor regressions it was not possible to reliably estimate nutrient use efficiency in these fields. Data indicated that the amounts of nutrient applied were less than what would be needed to maintain soil fertility and productivity, which fits with data obtained from soil testing by soil labs that also indicated a decrease in soil fertility in many fields where rice is grown.
\end{abstract}




\subsection{Introduction}

Rice is the main staple food in Nepal and also the single largest contributor to GDP. Nepal grows rice on about 1.5 million hectare and produces about 4.0 million tons with an average yield of $2.7 \mathrm{t} \mathrm{ha}^{-1}$ (MOAC 2010). This average yield is the lowest for south Asia (IRRI 2006). Up to 2000 average rice yield in Nepal had been increasing. In 1984 it was $2.0 \mathrm{t} \mathrm{ha}^{-1}$ and it reached $2.7 \mathrm{t} \mathrm{ha}^{-1}$ in 2000 . Annual growth rate of total rice production was $2.9 \%$ in the 1990s, but after 2000 it declined to 1.7\% (IFPRI 2012).

The Agriculture Perspective Plan (APP) identified mineral fertiliser as a major driver for agricultural growth. Fertiliser was expected to contribute $64-75 \%$ of the total envisaged agricultural growth target set in the APP. To meet this target, high-yielding cultivars are promoted as a way to maximize the returns of increased use of fertilisers, from $25 \mathrm{~kg} \mathrm{ha}^{-1}$ to $131 \mathrm{~kg} \mathrm{ha}^{-1}$ at the end of planning period (Agricultural Projects Services Centre and John Mellor Associates 1995). A study by Thapa (2002) concluded that about half of agricultural growth during the $9^{\text {th }}$ plan period (1997/98-2002/2003) was caused by increased availability of fertilisers. During that period average nutrient (NPK) use in Nepal reached 58 $\mathrm{kg} \mathrm{ha}^{-1}$ (ANZDEC 2002; OPM 2003). Average fertiliser use in the terai (lowlands) was more than four times higher than that in the hill areas. In Chapter 4 we reported that mineral fertiliser application in rice fields ranged from 40 to $80 \mathrm{~kg} \mathrm{ha}^{-1}$, depending on plot management strategy. The causes for higher use of fertilisers in the terai are ease of transport in the lowlands, and lower fertiliser prices near the Indian border (IDL Group 2006). However, despite increases in fertiliser use, also after 2000 (Shresta 2010), rice productivity did not increase (MOAC 2010). The explanation for this stagnation has remained unclear.

No comprehensive surveys on fertiliser use have been conducted since 2000 . Shrestha (2010) presented an overview of the influences of different fertiliser policies by the government of Nepal on its supply system. He reported that the demand for mineral fertiliser in Nepal was 726,000 tons in 2010. However, supply from formal sources was less than $30 \%$ of that demand. This mismatch may be partly explained by trans-border trade in fertiliser between India and Nepal.

The declining growth rate of rice yield did not only happen in Nepal, but turned out to be a common phenomenon in rice-growing countries (Dawe and Dobermann 1999). 
Reduced (or even stagnant) yield growth rates were especially evident in those areas where farmers used modern high-yielding rice production technology under irrigated conditions (Cassman and Dobermann 2001). Resource degradation (soil quality decline) and declining fertiliser use efficiency were reported as causal factors for declining rice yield growth (Cassman and Pingali 1995; Cassman et al. 1997). The average yield of irrigated rice of about $5.3 \mathrm{t} \mathrm{ha}^{-1}$ was just $60 \%$ of climate-adjusted yield potential in Asia (Matthews et al. 1997). Low nitrogen-use efficiency by irrigated rice (Dobermann 2000) and a negative balance of potassium (Dobermann et al. 1998) were reported as major reasons for rice yield growth decline in intensive irrigated-rice farming.

Strategic research on rice is still focused on high-yielding rice cultivars, and improved plant resistance to pests or diseases, N-fixation ability of rice, or transforming rice into a C4 photosynthetic plant (Ladha and Reddy 2000; Peng et al. 1999; Sheehy et al. 2000). But inefficient crop management practices are unlikely to give measurable impact by such high-yielding cultivars. De Laulanié $(1993,2003)$ emphasised the need to master production techniques, before calling on genetic improvement. Improving management practices leads almost always to increased yields, until the yield gap has been substantially reduced.

A study conducted in Nepal (Sherchan and Karki 2005) demonstrated a large gap between rice yields in farmers' fields(less than $3 \mathrm{t} \mathrm{ha}^{-1}$ ) and on research stations (around 4.5 $\mathrm{t} \mathrm{ha}^{-1}$ ). One major way to increase rice yield is to increase nutrient use efficiency by better management (Wang et al. 2001; Barison 2002; Turmel et al. 2011). Several studies (Gami et al. 2001; Bhandari et al. 2002; Krupnik et al. 2012) noted the importance of the combined use of mineral fertiliser and organic amendments (manure) for positive yield effects on rice and for long-term sustainability of the system.

Organic matter plays an important role in improving biological, chemical and physical soil quality and in enhancing crop growth. Studies on the role of organic matter in rice cultivation noted positive effects on growth, development and yield (Eneji et al. 2001; Yang et al. 2004). Bhattacharyya et al. (2003) reported a higher nitrogen recovery and higher grain yield by the combined use of manure and fertilisers. The use of manure increased microbial biomass (Nayak et al. 2009), soil organic matter (Sahrawat 2004) and significantly improved soil fertility (Shindo et al. 2006). However, actual use of organic 
amendments in rice farming (manure, straw) depends on several factors, such as alternative uses for this material (fuel, fodder), distance between farm and field, transportation problems, priority crops, land ownership and tenure status (see also Chapter 4).

The government of Nepal still puts emphasis on increased fertiliser use rather than on crop and field management. Its strategy has been continued since the implementation of APP in 1995. At that time the government liberalised the fertiliser supply system and included the private sector for the improvement of fertiliser supply (Figure 5.1). Before the liberalisation only the governmental Agriculture Input Corporation (AIC) was responsible for fertiliser supply. The government expected that involvement of the private sector would ease supply constraints for fertilisers, and thereby bring higher agricultural growth. The data show that the private sector indeed replaced the AICL (Agriculture Input Company Limited - former AIC), even though total fertiliser volume remained constant. When the government removed fertiliser subsidies in 2003, imported volume declined. In 2000/2001 the formal fertiliser supply covered $34 \%$ of all fertilisers in Nepal, and this went down to $28 \%$ in $2005 / 2006$. Figure 5.1 suggests it has further declined rapidly since then and came to the lowest level in 2009. After that government started fertiliser subsidy again and improved the fertiliser availabilities. However, the data of last decade also suggests that the informal fertiliser supply has always been much more important than the formal supply.

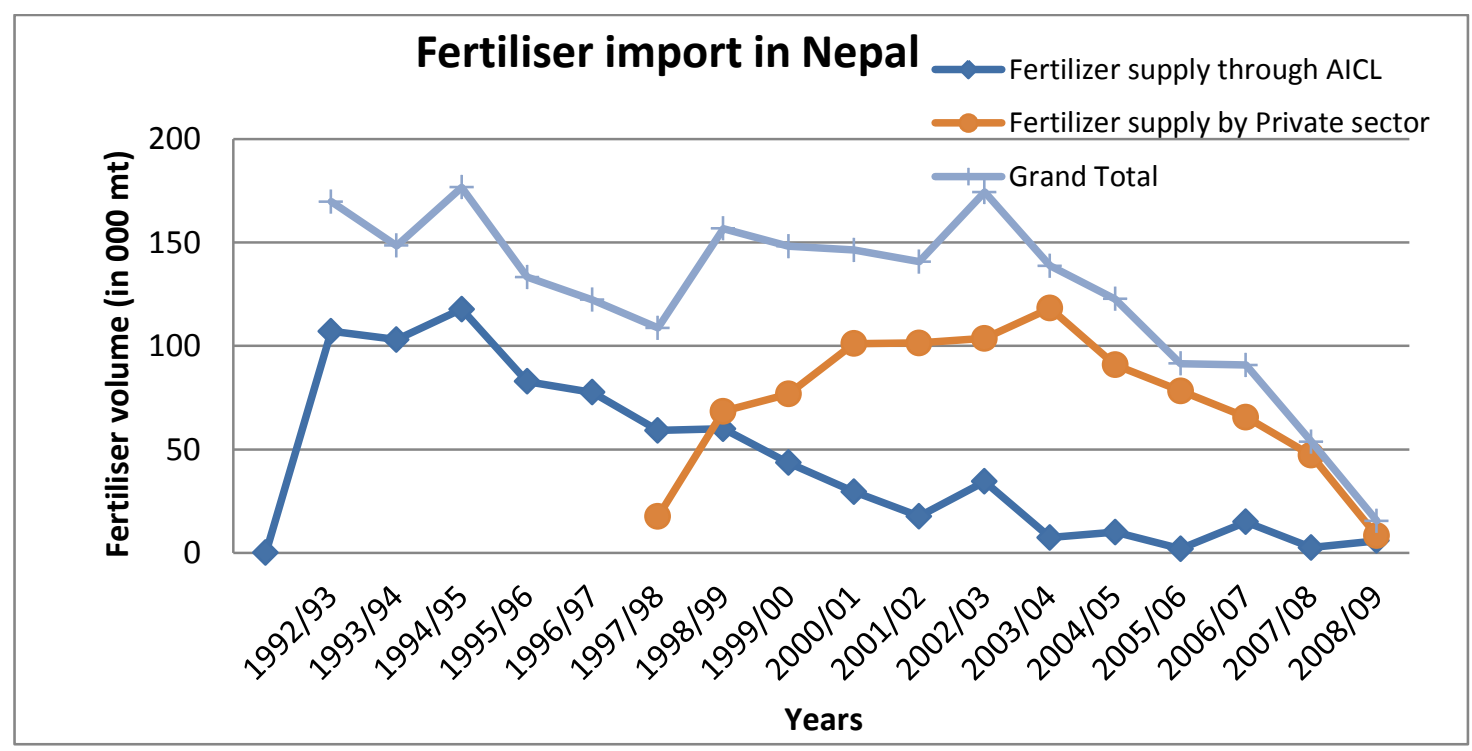


Figure 5.1. Fertiliser imported into the country by formal ways (MOAC, 2010).

Declining supplies made fertilisers more expensive, exacerbated after 2003. Fertiliser became expensive compared to fertilisers in the Indian border, as India maintained its fertiliser subsidies. The price of subsidised fertilisers in Nepal was more or less similar to that in India in 1999, but after liberalisation in Nepal prices diverged substantially (Table 5.1). Price differences opened the door to informal fertiliser trading in most of the terai areas connected to the Indian border. Because of informal fertiliser supply, Nepalese fertiliser importers face major problems in selling their products in local markets. Thapa (2002) estimated that about $2 / 3$ rd of the fertilisers used in Nepal came from informal ways from the Indian border.

From 2006 onward there were several new governments formed in Nepal within short intervals of time. Some governments received support from India, some did not. It was observed that fertiliser supply from the Indian border became easy when the Indian government was supportive, and very difficult when it was negative towards the government in Nepal. When the Indian government was supportive to the Nepalese government, the Indian border administration (security force) became liberal to allow fertilisers from India to Nepal. But it was very strict when it was less supportive to the ruling government in Nepal. The APP estimated that average use of NPK in Nepal was around $25 \mathrm{~kg} \mathrm{ha}^{-1}\left(31 \mathrm{~kg} \mathrm{ha}^{-1}\right.$ in the terai) in 1995. It also estimated that around $75 \%$ of imported fertilisers were used in the terai.

Table 5.1. Fertiliser prices in Nepalese Rupees per metric ton. After MOAC (2005).

\begin{tabular}{|l|c|c|c|}
\hline & $\begin{array}{c}\text { Nepal 1999 } \\
(\mathrm{NRs} / \mathrm{t})\end{array}$ & $\begin{array}{c}\text { Nepal 2004 } \\
(\mathrm{NRs} / \mathrm{t})\end{array}$ & $\begin{array}{c}\text { India 2004 } \\
(\mathrm{NRs} / \mathrm{t})\end{array}$ \\
\hline Urea & 7,400 & 15,560 & 7,442 \\
\hline Di-ammonium phosphate (DAP) & 10,000 & 20,860 & 14,960 \\
\hline $\begin{array}{l}\text { Complex fertiliser (NPK } \\
\text { mixture) }\end{array}$ & 18,570 & 19,300 & 12,776 \\
\hline
\end{tabular}


Next to insufficient supply of fertiliser there are several other problems. Timely availability of fertiliser was not guaranteed, thereby further restricting the use of fertiliser at the right time. It was also beyond the capacity of the majority of farmers to use recommended fertiliser doses due to high fertiliser prices. Furthermore, many farmers were of the opinion that these higher doses of fertilisers would not increase rice production.

Several decades ago only a limited number of farmers used fertiliser for rice in Nepal (Barker et al. 1985; Upadhyaya et al. 1993). Recycling of crop residues and use of manure were the main strategies that farmers applied to maintain soil fertility. Cropping intensity was low (mostly a single crop of rice per year; or rice followed by the nitrogenfixing legumes lentil [Lens culinaris] and grass pea [Lathyrus sativus]). That latter cropping pattern contributed to maintenance of soil fertility. After the introduction of new rice cultivars (see Chapter 7) farmers started using mineral fertiliser. Initially fertilisers increased rice yield of those improved cultivars. But gradually yields started to decline and high fertiliser prices and increased labour costs cut down the profit of rice growers. The majority of low-productive farmers, despite fertiliser use, did not get sufficient income from rice cultivation to sustain the livelihood of the family. But farmers who produce high yields still earn a good income from rice.

Many rice growers have been producing high rice yields without increasing fertilisers, by changing management practices. Farmers combined the use of organic amendments and mineral fertiliser, but did not use both on all rice fields. Sherchan and Karki (2005) reported that cropping pattern, water availability, market opportunities, fertiliser type, and crop species determine nutrient management in the terai. Use of farmyard manure depends on availability of farmyard manure (in terai region animal dung is used for fuel, see Chapter 2), labour availability, and adequate supply of composting materials.

The APP stated a strong research and extension system was needed to strengthen technical knowledge and skills of Nepalese farmers regarding crop and nutrient management. But there was no comprehensive study on economic aspects of fertilisers for various crops except Joshi and Deo (1976), who studied soil fertility status and recommended different fertiliser application doses for different crops.

Currently, the Department of Agriculture recommends two doses of fertilisers for rice farming as 100:30:30 kg NPK ha ${ }^{-1}$ for irrigated rice and 60:20:20 kg NPK ha ${ }^{-1}$ for rain- 
fed rice. In both cases the recommendation for organic amendments is $6 \mathrm{tha}^{-1}$ (Agriculture Diary 2011). On the basis of soil test results a refinement for rice cultivation is possible (Table 5.2). There are one central, five regional and several district-level soil laboratories under the Department of Agriculture. The main responsibility of those laboratories is to report on soil $\mathrm{pH}$, organic matter content, and NPK status of the soil. Furthermore they prescribe fertiliser dose to crops, when asked by farmers. There are also organised soil testing campaigns together with district agriculture development offices at the field level. Most soil-testing campaigns are free of cost; respective DADOs bear the cost for their farmers. But farmers who bring soil for testing at the laboratory need to pay the cost themselves.

Table 5.2. Recommended dose of fertiliser on the basis of soil testing in Nepal (RSTL 2010). Levels are defined as follows. For nitrogen: low $\left(<1 \mathrm{~g} \mathrm{~kg}^{-1}\right.$ soil $)$, medium $\left(1-2 \mathrm{~g} \mathrm{~kg}^{-1}\right.$ soil), high ( $>2 \mathrm{~g} \mathrm{~kg}^{-1}$ soil ; for phosphorus: low $\left(<26 \mathrm{~kg} \mathrm{ha}^{-1}\right)$, medium $\left(26-56 \mathrm{~kg} \mathrm{ha}^{-1}\right)$, high $\left(>56 \mathrm{~kg} \mathrm{ha}^{-1}\right)$; for potassium: low $\left(<112 \mathrm{~kg} \mathrm{ha}^{-1}\right)$, medium $\left(112-280 \mathrm{~kg} \mathrm{ha}^{-1}\right)$, high $(>280 \mathrm{~kg}$ $\left.\mathrm{ha}^{-1}\right)$.

\begin{tabular}{|l|c|c|c|}
\hline Soil nutrient availability & $\begin{array}{c}\text { Recommended N } \\
\left(\mathrm{kg} \mathrm{ha}^{-1}\right)\end{array}$ & $\begin{array}{c}\text { Recommended P } \\
\left(\mathrm{kg} \mathrm{ha}^{-1}\right)\end{array}$ & $\begin{array}{c}\text { Recommended K } \\
\left(\mathrm{kg} \mathrm{ha}^{-1}\right)\end{array}$ \\
\hline Low & 100 & 30 & 30 \\
\hline Medium & 50 & 15 & 20 \\
\hline High & 25 & 8 & 10 \\
\hline
\end{tabular}

To improve fertiliser use efficiency IRRI prepared on-line tutorials for nutrient management in rice. The recommendation for transplanted medium-duration (110-119 days) cultivars is three applications at the main field at early (0-14 days after transplanting), active tillering, and panicle initiation stages. At the early stage $20-25 \%$ of $\mathrm{N}$ should be applied, while the rest should be split equally over the tillering and panicle initiation stage. Use of $\mathrm{P}$ and $\mathrm{K}$ was recommended for basal application before transplanting, but in case of high yield 
expectation $\left(>6 \mathrm{t} \mathrm{ha}^{-1}\right)$ it is recommended to use $\mathrm{K}$ in two equal doses: first as basal application and second top-dress at panicle initiation stage.

Table 5.3. Recommended fertiliser dose for different yields for medium-duration cultivars of transplanted rice, with stubble remaining in the field. Source: http://webapps.irri.org/nm/nmtutorial/nmtutorial.php

$\begin{array}{cccc}\text { Yield level }\left(\mathrm{tha}^{-1}\right) & \mathrm{N}\left(\mathrm{kg} \mathrm{ha}^{-1}\right) & \mathrm{P}_{2} \mathrm{O}_{5}\left(\mathrm{~kg} \mathrm{ha}^{-1}\right) & \mathrm{K}_{2} \mathrm{O}\left(\mathrm{kg} \mathrm{ha}^{-1}\right) \\ 3 & 32 & 15 & 8 \\ 4 & 66 & 20 & 19 \\ 5 & 100 & 25 & 30 \\ 6 & 114 & 30 & 40 \\ 7 & 126 & 35 & 52 \\ 8 & 163 & 40 & 62 \\ 9 & 173 & 45 & 74\end{array}$

There are many reasons why farmers do not follow recommendations in a strict manner, if at all. Although this is a known phenomenon, few studies have investigated the actual use and application of manure by rice farmers in Nepal. Just looking at a direct relationship between the amounts of fertiliser and rice yield is not sufficient to understand nutrient management by rice farmers. We therefore need to go deeper to analyse specific nutrient management strategies applied by different farmers in different fields (Chapters 3 and 4) and their effects on rice yield. In this chapter, I explore the realities of contextspecific nutrient management strategies of Nepalese rice farmers and their effects on rice yield.

\subsection{Material and methods}

\subsubsection{Study area}

Morang district of eastern Nepal, situated between latitudes $26^{\circ} 20^{\prime}$ to $26^{\circ} 53^{\prime} \mathrm{N}$ and longitudes $87^{\circ} 16^{\prime}$ to $87^{\circ} 41^{\prime} \mathrm{E}$, has been selected for this study (Figure 1.1). It is the largest 
rice-growing district of Nepal. Total rice growing area of this district is about 94, 000 ha and average rice yield is $3.1 \mathrm{t} \mathrm{ha}^{-1}$. The district covers an area of $1,855 \mathrm{~km}^{2}$. It has a population size of 1,028,362 (2011). Biratnagar, the district headquarters, is the second largest city after Kathmandu and is the main industrial centre of Morang. Altitude varies from 100-2410m. The climate type is subtropical, of the monsoon type with more than $2000 \mathrm{~mm}$ average annual rainfall. Average annual maximum and minimum temperatures are $30.6^{\circ} \mathrm{C}$ and $14.2^{\circ} \mathrm{C}$ respectively.

The study was conducted in two VDCs, namely Jhorahat and Indrapur from June 2008 to December 2009. Information on both VDCs is presented in Table 5.4.

Table 5.4. Details of the studied VDCs

\begin{tabular}{|c|c|c|c|c|c|c|}
\hline VDC & $\begin{array}{c}\text { Area } \\
\left(\mathrm{km}^{2}\right)\end{array}$ & $\begin{array}{c}\text { Population } \\
(2007)\end{array}$ & $\begin{array}{c}\text { Distance (km) } \\
\text { from Biratnagar }\end{array}$ & $\begin{array}{c}\text { No. of farm } \\
\text { households }\end{array}$ & $\begin{array}{c}\text { Cultivable } \\
\text { land (ha) }\end{array}$ & $\begin{array}{c}\text { Area under } \\
\text { rice (ha) }\end{array}$ \\
\hline Jhorahat & 13.17 & 5,414 & 10 & 788 & 1250 & 1180 \\
\hline Indrapur & 25.47 & 19,179 & 28 & 2650 & 2510 & 2250 \\
\hline
\end{tabular}

Indrapur is the VDC situated around central Morang. It is a densely populated and rapidly urbanising VDC. The majority of people living in this VDC are hill migrants and migration flow to this VDC has been very high. Irrigation sources of Indrapur are small perennial rivers. Irrigation systems are small and farmer-managed. Few farmers use ground water for irrigation. Due to manageable small irrigation systems and pumping ground water most of the agricultural fields have good irrigation facility (see also Chapter 6).

Jhorahat is close to Biratnagar and the majority of the farmers in this VDC are teraiindigenous (Tharu, Jhagad and Sardar) people. Jhorahat is less densely populated than Indrapur. There was no migration flow in Jhorahat and population size is slowly decreasing. Sunsari Morang Irrigation System (SMIS) is the main source of irrigation for this VDC. Jhorahat is located at the middle part of SMIS. SMIS secondary and tertiary canals were constructed in Morang district but there was no good network of water courses to deliver water to all plots. Therefore rice plots close to irrigation canals get better irrigation and distant fields face problems for irrigation. 


\subsubsection{Sampling method and data collection}

These two village development committees were purposively selected. 60 Farmers (30 from each VDC) were randomly selected for the study. The rice fields of those farmers (165 in all; 94 in Jhorahat and 71 in Indrapur), their management and farmers activities were monitored from seeding to harvesting especially focusing on nutrient management. Those 165 plots (see Chapter 4 for analysis) were kept on season-long observation for the collection of nutrient management and yield data.

Secondary data of soil tests of Morang district (obtained from Regional Soil Testing Laboratory-RSTL, Jhumka, Sunsari and District Agriculture Development Office Morang) were used to understand soil fertility of the studied fields. RSTL is a regional soil testing laboratory under Department of Agriculture. RSTL test and report about soil $\mathrm{pH}$, organic matter, and N, P, K contents and collaborate with DADO. Together they organise field-level soil-testing campaigns to test $\mathrm{pH}$, and $\mathrm{N}, \mathrm{P}, \mathrm{K}$ contents. Soil tests form the basis for fertiliser recommendation for requested crops.

Actual amounts of nutrients used by farmers in particular fields were calculated based on the volume of used fertiliser. Main fertilisers in the study areas were urea $(46 \% \mathrm{~N})$; DAP-di-ammonium phosphate ( $18 \% \mathrm{~N}$ and $46 \% \mathrm{P})$, complex fertiliser $(20 \% \mathrm{~N}$ and $20 \% \mathrm{P})$ and $\mathrm{KCl}(60 \% \mathrm{~K})$. Farmers applied organic manure by using bamboo baskets (doko), so the volume of manure was calculated by counting the numbers of doko fora particular field multiplied by the average weight of one doko. The information on the amount of fertiliser and organic amendments was recorded by interviews and verified during field observations.

Different ethnic groups live together in the study area and they have their own ways of rice farming and nutrient management. Ethnic groups were categorised according to their differences in nutrient management practices (especially use of manure). Brahmin and Chhetry are hill migrants and use most of their manure in the agricultural fields. (However, our research concentrated on fertiliser use in rice fields during the main cropping season.) Terai-indigenous (Tharu and other) are those people originally from the terai or Indian migrants, living in southern Morang. Most of them use farmyard manure as fuel (guithasee Chapter 2) for cooking. Janajati are hill indigenous migrants to terai. They are similar to other migrant groups regarding manure use. 


\subsubsection{Data analysis}

We applied multiple regression to link rice yield to application of the different nutrients. We regressed yield against (1) amount of $\mathrm{N}$ applied at start (through DAP and urea); (ii) amount of urea applied at topdressing; (iii) amount of compost applied; (iv) amount of K; (v) amount of P. We did not look at nutrient interactions, so applied a simple linear multiple regression, and selected the best model. We regressed yields to nutrient application for all 165 fields, but also analysed the three plot management systems (Chapter 4) separately.

\subsection{Results}

\subsubsection{Soil fertility and $\mathrm{pH}$ in Morang district}

In 2010,144 soil sample were tested at regional soil-testing laboratory and 250 soil samples tested at field level during soil testing campaigns. The proportion of different ethnic groups who had their samples analysed was representative of the proportion of those groups in the Morang district.

The majority of soil samples $(63 \%)$ had a $\mathrm{pH}$ below 6.5. Past soil testing reported that only $33 \%$ of the soils had a $\mathrm{pH}$ lower than 6.5 , suggesting that soil $\mathrm{pH}$ has declined in the last decade(s). Soils cultivated by Janajati farmers had a lower $\mathrm{pH}$ than the soils that were cultivated by Terai indigenous people. Most soil samples contained less than $25 \mathrm{~g}$ organic matter $\mathrm{kg}^{-1}$ soil. Around $10 \%$ of the samples by the Brahman / Chhetry had more than $50 \mathrm{~g}$ organic matter $\mathrm{kg}^{-1}$ soil. None of the soil samples of the terai indigenous groups contained $50 \mathrm{~g}$ organic matter $\mathrm{kg}^{-1}$ soil.

Most soils contained low to medium amounts of nitrogen. Soil samples by the Brahman / Chhetry were on average richer than the samples by the terai indigenous groups, where no soils were classified as of high nitrogen. Phosphorus availability was also low in most fields. Again there were differences in soil P amounts between the groups, with the Brahmin / Chhetry having soils that contained more P than the soils of the terai indigenous people. A comparison with previous sampling suggested declining phosphorus contents in soil. In 1997, 51\% of the soils had high P contents and this was reduced to $24 \%$ in 2009. Low P contents were noted in 1997 in $19 \%$ of soils, and this increased in 2009 to $62 \%$. Potassium showed a similar pattern as phosphorus, with clear signs of losses over time. In 
$199721 \%$ of soils were classified as low-K soils, and this increased to $55 \%$ in 2009 . Again the terai indigenous groups had the poorest soils, whereas those of the Brahmin / Chhetry were somewhat richer.

\subsubsection{Use of mineral fertiliser and manure}

Farmers applied mineral fertiliser and organic manure separately or in combination. Out of 165 fields, $62 \%$ received only mineral fertiliser, 4\% only FYM, whereas the remaining fields (34\%) received both mineral fertiliser and FYM. There were significant differences in fertiliser use among the three categories of field management (Table 5.5).

Farmers reported that most swampy lowland fields already have high organic matter contents. In those fields farmers used (low doses of) mineral fertiliser (mostly for top dressing). They reported that the use of high amounts of fertiliser causes lodging of rice. I observed very good growth of swampy lowland rice plants at initial stage, but these plants lodged during flowering/milking stage resulting in yield loss.

In $41 \%$ of the rice fields in Jhorahat and 79\% in Indrapur farmers did not use urea for basal application. They used DAP and MOP (Muriateof Potash, $\mathrm{KCl}$ ) for basal application. Similarly $20 \%$ of the fields did not receive $\mathrm{N}$ as top dressing. Farmers did not apply $\mathrm{P}$ (DAP) in $10 \%$ of their fields and $\mathrm{K}$ in more than $30 \%$ of the fields. Manure was applied in $36 \%$ of the fields. Higher doses of manure were applied in smaller plots that were close to the farmer's residence. 
Table 5.5. Application of mineral fertiliser and organic amendments (manure) in different fields $(\mathrm{n}=165)$ in Jhorahat and Indrapur, main season 2008.P-values are based on one-way ANOVA. Values in bold indicate significant differences between groups $(P<0.05)$.

\begin{tabular}{|c|c|c|c|c|c|}
\hline & Total & Group & Group & Group & $\mathrm{P}$ \\
\hline & & 1 & 2 & 3 & \\
\hline & & $\mathrm{OM}$ & FM & RI & \\
\hline $\mathrm{N}$ & 165 & 33 & 91 & 41 & \\
\hline Yield $\left(\mathrm{tha}^{-1}\right)$ & 3.8 & 3.1 & 3.3 & 5.4 & $<0.001$ \\
\hline Urea-N $\left(\mathrm{kg} \mathrm{ha}^{-1}\right)$ & 25.1 & 3.3 & 30.0 & 31.8 & $<0.001$ \\
\hline Urea-N starter $\left(\mathrm{kg} \mathrm{ha}^{-1}\right)$ & 5.4 & 3.3 & 6.0 & 5.8 & 0.22 \\
\hline Urea N-top dress $\left(\mathrm{kg} \mathrm{ha}^{-1}\right)^{* *}$ & 19.6 & 0 & 24.2 & 25.3 & $<0.001$ \\
\hline Ammonium-N $\left(\mathrm{kg} \mathrm{ha}^{-1}\right)^{*}$ & 9.4 & 8.7 & 9.6 & 9.4 & 0.56 \\
\hline $\mathrm{N}$-mineral $\left(\mathrm{kg} \mathrm{ha}^{-1}\right)^{* *}$ & 34.5 & 12.0 & 39.8 & 40.7 & $<0.001$ \\
\hline $\mathrm{P}\left(\mathrm{kg} \mathrm{ha}^{-1}\right)^{*}$ & 24.0 & 22.2 & 24.5 & 24.3 & 0.56 \\
\hline $\mathrm{K}\left(\mathrm{kg} \mathrm{ha}^{-1}\right)$ & 9.9 & 7.0 & 9.6 & 13.1 & 0.003 \\
\hline Manure use $\left(\mathrm{t} \mathrm{ha}^{-1}\right)^{* *}$ & 4.8 & 5.1 & 1.2 & 12.4 & $<0.001$ \\
\hline
\end{tabular}

\subsubsection{The relation between rice yield and nutrient use}

Table 5.6 provides the results of the regressions between yield and nutrient applications. For both the total group of fields and for the three categories recognised in Chapter 4, we applied multiple regression to establish the relationship between nutrient application and rice yield. We considered the intercept as an indication of inherent soil fertility - possibly co-determined by the application of fertilisers outside the main growing season (see Discussion). In Table 5.6 the significant factors in each regression have been indicated.

When averaged over all fields manure and compost use explained $34 \%$ of the variation in yield. For every ton of manure applied per hectare, yields increased with $0.12 \mathrm{t}$. In the best model, to which the amount of urea at top dressing and the amount of $\mathrm{K}$ were added, the percentage explained variation increased to $42 \%$. Both the amount of starter $\mathrm{N}$ 
and the amount of $\mathrm{P}$ were not significantly different from zero in the regression. However, as these results may just reflect different field management strategies, we also tested these relations within each group of field management practices. In the group of organically managed fields, where farmers did not top dress their fields, only manure came out as a significant factor (with a yield increase of $0.09 \mathrm{t}$ for every ton of manure applied per hectare). For the fields that were managed with mineral fertilisers, only manure came out as a significant factor in the regression, with a yield increase of $0.06 \mathrm{t}$ for every ton of manure applied per hectare. None of the mineral nutrients had a regression coefficient significantly different from zero. But as many fields in this category did not receive manure (only 10 of 91 fields received manure), we would not attach too much importance to this significant factor. Surprisingly in the most productive fields, were management showed the most characteristics of the System of Rice Intensification, no factor in the regression was significantly different from zero, suggesting that variation in nutrient management was not the cause of variation in yield.

Table 5.6. The relation between yield and nutrient applications. In each column the data are provided for the best model. For each significant factor the regression coefficient is indicated. Significance of each factor is indicated as: * $0.01<\mathrm{P}<0.05$; $* * 0.001<\mathrm{P}<0.01$; *** $\mathrm{P}<0.001$

-: factor not part of best model; n.a.: not applicable, as in fields of OM not urea is used for top dressing

$\begin{array}{lllll} & \text { Total } & \text { OM } & \text { FM } & \text { RI } \\ \text { Intercept of full model } & 2.64 & 3.40 & 2.21 & 4.88 \\ \text { Adjusted } \mathrm{r}^{2} \text { (best model) } & 0.42 & 0.39 & 0.05 & - \\ \mathrm{N} \text { (start) } & - & - & - & - \\ \text { Urea (top dress) } & 0.02 * * & \text { n.a. } & - & - \\ \text { Manure } & 0.12^{* * *} & 0.09^{* *} & 0.06^{* *} & - \\ \mathrm{P} & - & - & - & - \\ \mathrm{K} & 0.03^{* *} & - & - & -\end{array}$


Inspection of the full models indicated that the intercept of the full model was highest in the RI fields $\left(4.9 \mathrm{tha}^{-1}\right)$ and lowest in the OM fields $\left(2.2 \mathrm{tha}^{-1}\right)$, indicating that there are large differences in intrinsic soil fertility and / or large differences in nutrient management outside the main season that cause the differences in yield between the three groups of field management.

As most of the regression coefficients for $\mathrm{P}, \mathrm{K}$ and total $\mathrm{N}$ were not significantly different from zero, it was not possible to calculate nutrient use efficiencies (kg biomass produced per kg nutrient applied).

\subsubsection{Manure use}

Use of organic amendments was correlated with land ownership status and distance of land from the residence. Manure was more often used ( $56 \%$ of all fields) on own land than on rented land (18\%). In the latter case, the fields were usually used for cultivation of vegetables, or the land was under fixed rent (see Chapter 2). The difference was highly significant (Fisher's exact test, $P<0.001$ ). Fields around the residence often received manure ( $75 \%$ of all fields), whereas those farther from the residence were rather unlikely to receive manure (16\%). The difference was also highly significant (Fisher's exact test, $P<$ $0.001)$.

\subsubsection{Cropping system and its effect on rice yield}

The effect of cropping system (the crops grown outside the main season) was significant on rice yield. Rice grown in fields where vegetables were grown in the previous season produced highest average rice yield $\left(6.6 \pm 1.3 \mathrm{tha}^{-1}\right)$, compared to green-manure fields (5.0土 $\left.0.8 \mathrm{tha}^{-1}\right)$,maize fields $\left(4.2 \pm 0.8 \mathrm{tha}^{-1}\right)$, spring rice $\left(3.9 \pm 1.3 \mathrm{t} \mathrm{ha}^{-1}\right)$, while fallow fields were least productive $\left(3.3 \pm 1.1 \mathrm{t} \mathrm{ha}^{-1}\right)$. These differences were highly significant $(\mathrm{F}=24.4$, $\mathrm{P}<0.001$ ), suggesting a major role for carry-over effects (through application of mineral fertilisers and manure). These data make evident that the application of fertiliser on rice fields cannot be evaluated in the context of rice cropping only. 


\subsection{Discussion}

In Nepal extension workers still provide general fertiliser recommendations to rice farmers. They apply two different fertiliser recommendations for irrigated and non-irrigated rice. But most farmers use fertilisers without knowing the fertility status of their soils and crop requirement. In agreement with this general conclusion we found very little evidence that the amount of either N, P or K applied correlated well with yields.

Field-based campaigns test soil samples and recommend appropriate dose of fertilisers for a particular crop; they also advise to use lime when the soil is acidic. But the difficulty to acquire lime in local markets creates problems for farmers. Although the cost of lime is not high, high transportation costs from the lime factory to farmers' field combined with high storage cost and low profit margin, make most agro-input traders rather unwilling to keep lime in their shop. If farmers demand at least one truck load (10 tons) agriculture lime then local suppliers order to the factory and supply to the farmers. Otherwise it is very difficult to use lime. For that reason the application of lime as soil amendment has not been included in our assessment.

Unavailability also extends to mineral fertilisers. Often appropriate kinds of fertilisers in the local market were unavailable. In 2008 during transplanting time of rainyseason rice there was plenty of urea available in the local market but no DAP and MOP. Farmers searched for DAP and MOP for basal application, before transplanting rice. The reverse situation occurred during topdressing time (one and half months after transplanting time) when farmers searched for urea but then there was only DAP available in local market and no urea. Such supply problems make it problematic to follow the results of soil testing and recommendation, especially for those farmers who are unable to stock fertilisers for future need. Unavailability issues could also have contributed to the lack of significant correlations between mineral fertiliser use and yield.

Some decades ago the majority of the farmers in Nepal used manure on their agricultural fields at times when there was no scarcity of fire wood. Large areas of the terai were covered by forest and rural people obtained sufficient firewood. Deforestation reduced the supply of firewood. Farmers then had to use alternatives for firewood, resulting in increased use of animal dung for fuel and hence had lower volumes of manure available for their fields. Similarly, at that time there were thousands of bullock carts to transport manure 
to the fields but the number of bullock carts decreased. Now it is difficult to find a bullock cart in every village. There was at least one in each farmer's house before. This change made it difficult to transport manure to distant fields. Most manure is therefore currently used in fields close to the residence.

Very few farmers of the terai-indigenous group use manure in their fields. As a consequence those field are generally low in organic matter, which confirms data from the soil testing laboratory showing that $84 \%$ fields of the terai-indigenous fields had less than $2.5 \%$ soil organic matter. Organic matter content was comparatively higher in the fields of farmers from other ethnic groups. Other possible mechanisms behind reduction of organic matter is long-term fertilisation with mineral fertiliser only (especially urea), which may have reduced soil organic matter stocks (Belay et al. 2002). Because more than $72 \%$ of terai-indigenous farmers used only chemical fertilisers in their fields, soil organic matter decline is a possible consequence.

Higher doses of fertilisers did generally not produce higher rice yields within each category of field management. This result shows that there are other factors (besides fertiliser amount) of the management that have a larger influence on rice yield. A comparison of yield data and nutrient application shows large discrepancies with the IRRI recommendations (Table 5.7). Most farmers use much smaller amounts of nitrogen and potassium than recommended, whereas the amounts of phosphorus seem to match demands. While it should be taken into account that there is variation in rice cultivars grown and that fertilisers are also applied outside the main rice-growing season, implying that we cannot straightforwardly compare actual application with recommended doses, it is evident that with such low doses annual removal of nutrients through rice harvest is often higher than fertiliser dose, even for the most productive farmers. These findings also suggest the need to reform the Nepalese agriculture extension support system with regard to nutrient management. 
Table 5.7. Recommended fertiliser dose (from IRRI Nutrient Manager) compared to actual fertiliser us.

\begin{tabular}{ccccccc} 
& \multicolumn{3}{c}{ Recommended dose } & \multicolumn{3}{c}{ Actual use } \\
Yield $\left(\mathrm{t} \mathrm{ha}^{-1}\right)$ & $\mathrm{N}\left(\mathrm{kg} \mathrm{ha}^{-}\right.$ & $\mathrm{P}\left(\mathrm{kg} \mathrm{ha}^{-1}\right)$ & $\mathrm{K}\left(\mathrm{kg} \mathrm{ha}^{-}\right.$ & $\mathrm{N}\left(\mathrm{kg} \mathrm{ha}^{-}\right.$ & $\mathrm{P}\left(\mathrm{kg} \mathrm{ha}^{-1}\right)$ & $\mathrm{K}\left(\mathrm{kg} \mathrm{ha}{ }^{-}\right.$ \\
& $\left.{ }^{1}\right)$ & & $\left.{ }^{1}\right)$ & $\left.{ }^{1}\right)$ & & 1 \\
$<4$ & 49 & 8 & 12 & 37 & 13 & 8 \\
$4-6$ & 93 & 11 & 25 & 47 & 12 & 9 \\
$6-8$ & 134 & 15 & 42 & 59 & 15 & 15
\end{tabular}

Several studies (Eneji et al. 2001; Gami et al. 2001; Bhandari et al. 2002; Yang et al. 2004) found positive effect of manure for higher rice yield. This study partly confirmed those findings. The general regression showed a major role for compost in raising yields; however, within the different groups of field management the relation between manure use and yield was weak at best. It is especially noteworthy that in fields that were managed in ways that showed most similarity to SRI principles there was no relation between manure use and yield. Our study did not allow assessing the causes of the effects of organic matter. Based on data by Gale et al. (2006) we calculated that manure addition made only a relatively small contribution to total $\mathrm{N}$ supply. Other effects of manure addition, such as addition of essential micronutrients like $\mathrm{Zn}$ and amelioration of physical soil quality are therefore likely more important. Farmers also knew this reality so they prefer to use manure and vegetable compost on their own fields and for the cultivation of high-value vegetable crops. This result confirmed the findings of Saleque et al. (2004) who noted that the dose of mineral fertilisers might be reduced by $33 \%$ by using cow dung and ash.

A major result from our study is the large difference in intrinsic soil fertility (as derived from the intercept in the full regression). Fields under SRI management showed a much higher intrinsic soil fertility than fields under other management. This issue is pertinent, as it has been debated whether the success stories of SRI might be related to differences in intrinsic soil fertility. Studies provided support both for claims that SRI was most successful in fields with low intrinsic fertility (Turmel et al. 2011) and for claims that 
SRI might be resulting in higher yields because these fields are already more fertile, as suggested by Berkhout et al. (2014). Our data clearly support the latter hypothesis.

\subsection{Conclusion}

Nutrient management is a very important aspect of rice farming in Nepal. Government policies (fertiliser subsidies) emphasised to increase fertilisers use. This study showed that higher amounts of fertiliser did not increase yields; neither did higher amounts of manure increase yields. Yield differences between different fields with different management strategies were rather caused by differences in intrinsic soil fertility (likely caused by nutrient management outside the main rice-growing season). More fertile fields received higher doses of mineral fertiliser and manure, however the amounts of $\mathrm{N}$ and $\mathrm{K}$ added to the fields were lower than the amounts harvested, which will result in nutrient depletion and declining yields over the longer term. The combination of organic manure and mineral fertilisers resulted in the highest rice production. Most farmers didn't have sufficient farmyard manure to use on their fields. Farmers used organic manure on their own fields, fields that were close from their residence and the fields used for the high-value crops (vegetables and spices). This study indicates that there should be a rethinking and revision of government policy to sustain long-term soil fertility and better rice yield in Nepal. 


\section{Chapter 6}

\section{Water availability and}

reliability and rice production in Nepal 


\begin{abstract}
This study explored effects of water availability and reliability on rice farming in Morang district in Nepal. Rice fields of 60 randomly selected rice farmers of two village development committees were monitored for two years. Water influenced most of the rice farming practices. Availability and reliability of water was more important than its volume for successful rice farming. Reliable water supply allowed early transplanting, use of younger seedling, mechanical weeding and alternate wetting and drying system of irrigation which were important components of more productive rice production systems. Irrigation policy should therefore focus more on availability and reliability of water supply than on its volume. Not all farmers did benefit from better irrigation facility.
\end{abstract}




\subsection{Introduction}

Nepal ranks among the 20 largest rice-producing countries in the world, with rice being cultivated in 73 of its 75 districts. The department of irrigation (DOI) claimed that the cropped area under irrigation has expanded substantially, reaching 600,000 ha in 1994, and 1,251,000 ha in 2007 (DOI 2007). It also reported that out of these 1,251,000 ha, more than $1,000,000$ ha are under year-round irrigation. Yet despite these facilities, rice yields in Nepal stagnated and have remained the lowest within the South Asian region, $2.7 \mathrm{t} \mathrm{ha}^{-1}$ (IRRI 2006; MOAC 2011). Thirty-five years ago, Nepal was a net exporter of rice, producing 500,000 metric tons more than domestic consumption needs. However, since then, despite the increases and improvements in inputs, production has failed to keep pace with population growth. Grain exports declined to just 100 metric tons in 1989/90, and the country is at present a net food importer. The average amount of rice imported from India in recent years has been around 500,000 metric tons, valued at about \$US 70 million annually (Bhandari 2007). As rice is the country's main food crop, the productivity of rice directly affects food security in Nepal. Given the important role of rice, it is necessary to increase rice productivity while reducing production costs.

Around $75 \%$ of Nepalese farmers are smallholders, with less than one hectare of land. The use of fertilisers (Chapter 5), improved seeds, and other purchased inputs remains low. Most smallholders are unable to produce sufficient food for their families (CBS 2002). Agricultural research organisations have focused on cultivar improvements and on the use and cost-effectiveness of external inputs. Resource-poor farmers have been left behind, not benefiting from these development initiatives. Small farmers are generally more concerned with minimising risks than with maximising output (Richards 1985). Consequently, the uptake of input-dependent technologies has been low and slow.

SRI-methods have been promoted as resource conservation technology especially to save water. Within the country different studies reported higher productivity with water saving by SRI over conventional methods (Bhatta and Tripathi 2005; Gairhe 2005; Gautam and Kovala 2005; Regmi 2005; NRM-PARDYP/ICIMOD 2005; Uprety 2006). Similarly Zhang et al. (2007) reported 34\% water saving and 7\% yield increment in China. In Andhra Pradesh, SRI saved water but did not increase grain yield (Reddy et al. 2005). Other researchers have reported higher yield with water saving by SRI like Zhao et al. (2009), who reported 21\% 
higher yield with $43 \%$ water saving. Similarly Vijayakumar et al. (2006) reported $23 \%$ more yield and water productivity and Thakur et al. (2010) reported 17\% more yield by SRI compared to recommended practice in field experiments in Tamil Nadu and Orissa respectively. Other studies also reported higher rice yield and water saving by SRI (Ceesay et al. 2006; Sato and Uphoff 2007; Turmel et al. 2011).

Effective control of water supply (McHugh et al. 2002) and reliability (Mushtaq et al. 2009) are reported as critical factors for SRI. But there is very little information on the influence of water availability and reliability on rice cultivation practices in farmers' fields, like in land preparation, transplanting, weed management, irrigation management and nutrient management. Researchers mentioned yield variation by water saving, but there is not sufficient information about context-specific farmer strategies. Studies (Moser and Barrett 2006; Berkhout and Glover 2011) mentioned partial adoption and disadoption of SRI and parallel use of conventional methods by the same farmer but both studies did not address why farmers use SRI and other methods side by side. My comparison of 165 rice fields, managed by 60 farmers, also showed that farmers applied different forms of management in different fields and a relationship with irrigation facilities was proposed (Chapter 4).

This chapter addresses the importance of water through a study in Nepal where SRI was introduced some years ago. This paper focuses on both availability and reliability and their effects on farmers' ability or willingness to adopt different practices of rice farming.

\subsection{Methodology and Data}

Two Village Development Committee (VDC) areas were purposively selected for this study, as they represent two different types of irrigation management. This made it possible to study the dynamics of rice farming under different types of water management: an agencymanaged irrigation system, and the other farmer-managed.

At one site, Indrapur, there are mostly migrant farmers from the hills. Their farms are served by farmer-managed irrigation facilities, with good drainage conditions. They use low to moderate amounts of mineral fertiliser and organic manure and utilise mostly improved rice cultivars. The other site, Jhorahat, is inhabited by an indigenous terai community, cultivating under moderate to poor drainage conditions. The community is served by an agency-managed system (Sunsari Morang Irrigation Project, the largest 
irrigation system of Nepal). They plant both local and improved rice cultivars, using moderate doses of fertiliser and very low organic manure for their rice cultivation.

The two locations represent different bio-physical and socio-economic conditions. Indrapur maintains and operates its irrigation system in a relatively autonomous and participatory manner; user groups decide on water rationing (volume and frequency of water availability for particular farmers). Jhorahat experiences disadvantages from having government personnel managing irrigation where there is less participation of farmers in decision of water scheduling and where repair and maintenance of irrigation canal were poor which affected the water flow. Most farmers do not know when water comes to their field. Lucky farmers, whose fields are close to the main canal or at the head part of canals, have more opportunity to access irrigation water, but it is very difficult to bring water to fields that are far from the main canal or located at the middle or tail part of the secondary canals. Other details about these VDCs are given in Table 6.1.

Table 6.1: Summary of agriculture-related characteristics of Jhorahat and Indrapur VDCs, 2009. Sources: DADO (2010).

Number of households

Cultivated land area (ha)

Average landholding size (ha)

Total rice area (ha)

Cropping intensity (\%)

Owner-operator farmers (\%)

Tenant/sharecropping farmers (\%)

Combined owner-tenant farmers (\%)

Agriculture loans (\$US 000)

$$
\text { Indrapur }
$$$$
2,650
$$$$
2,510
$$

0.95

2,036

290

23.3

20.0

56.7

416
Jhorahat 788

1,030

190

23.3

3.3

73.3

77

Thirty farmers from each VDC were randomly selected for the study. Their rice plots were observed and information from the plots was recorded in both 2008 and 2009 main seasons. In 
2008 there were 165 rice plots (94 in Jhorahat, and 71 in Indrapur); in 2009 these 60 farmers grew rice on 158 plots ( 85 in Jhorahat and 73 in Indrapur).

Farmers described their situation with respect to water availability and reliability in four categories: (1) reliable irrigation: controlled irrigation where farmers are able to irrigate their fields as and when they want; (2) unreliable irrigation: irrigation facility but outside control of farmers or farmers cannot schedule irrigation dates themselves and have to irrigate their fields when water is available in the canal; (3) swampy lowland: irrigation is not a main problem, but drainage is; (4) rain-fed fields: as and when rainfall comes those fields are supplied with water.

Season-long observations of farming activities and interviews with the selected farmers were the main sources of information. Information was also collected from keyinformant interviews and farmer group discussions.

SPSS statistical package was used to analysis the data. Chi-square tests, G-tests, ANOVA and Pearson correlations were used to identify kinds and degrees of difference.

\subsection{Results}

\subsubsection{Water availability and plot size}

Plot sizes of fields under different water availability were different. Where water availability was more secure, plots tended to be smaller (Table 6.2). Reliable water supply in Jhorahat and Indrapur was more or less similar, 35\% plots of Indrapur and 33\% plots of Jhorahat had reliable irrigation facility. Swampy low land percentage was also similar, it was $25 \%$ in Indrapur and $24 \%$ in Jhorahat. But rainfed rice plots were more in Jhorahat $(16 \%)$ as compared to that of Indrapur (1\%).

Table 6.2. Number of rice fields and fraction of land under four forms of water availability.

$$
\text { Number of fields (\%) }
$$

Area $(\%)$

Reliable irrigation

Unreliable irrigation

Swampy lowland 
Plots under better irrigation were somewhat smaller. Plots with reliable water supply were on average 0.38 ha (range: $0.29-0.47 \mathrm{ha}$ ), followed by swampy lowland with 0.45 ha (range: 0.33-0.58 ha), unreliable irrigated plots with 0.56 ha (range: 0.27-0.84 ha), while plots that were rain-fed were largest with 0.67 ha (range: 0.44-0.90 ha). However, these differences were not significant $(P>0.05)$.

\subsubsection{Water availability situations and rice production}

Rice productivity was related to water availability (Table 6.5). Fields with reliable irrigation were most productive, followed by fields with unreliable irrigation, and swampy lowland. Fields without irrigation (rain-fed) were least productive. The differences between these four categories was significant (ANOVA F-13.6, $\mathrm{P}<0.001$ ).

Table 6.5. Rice productivity in relation to reliability of water supply in Morang district, main season 2008 .

$$
\text { Productivity ( } \pm \text { S.D) in } \mathrm{tha}^{-1}
$$

Reliable irrigation $(\mathrm{n}=68)$

$$
4.5 \pm 1.5
$$

Unreliable irrigation $(\mathrm{n}=31)$

$$
3.5 \pm 1.3
$$

Swampy lowland $(\mathrm{n}=49)$

$$
3.3 \pm 0.8
$$

Rain-fed $(n=17)$

$$
3.0 \pm 0.8
$$

There were also large within-group differences in yield, due to field management differences. We observed three different type crop management practices in the study area (see Chapter 4); those are low productive conventional (FM), non-topdressing low productive $(\mathrm{OM})$ and high productive $(\mathrm{RI})$. Figures 6.1 and 6.2 present the relationship of those three crop management practices with four water availability situations and their effects on seedling variables and rice yield. 


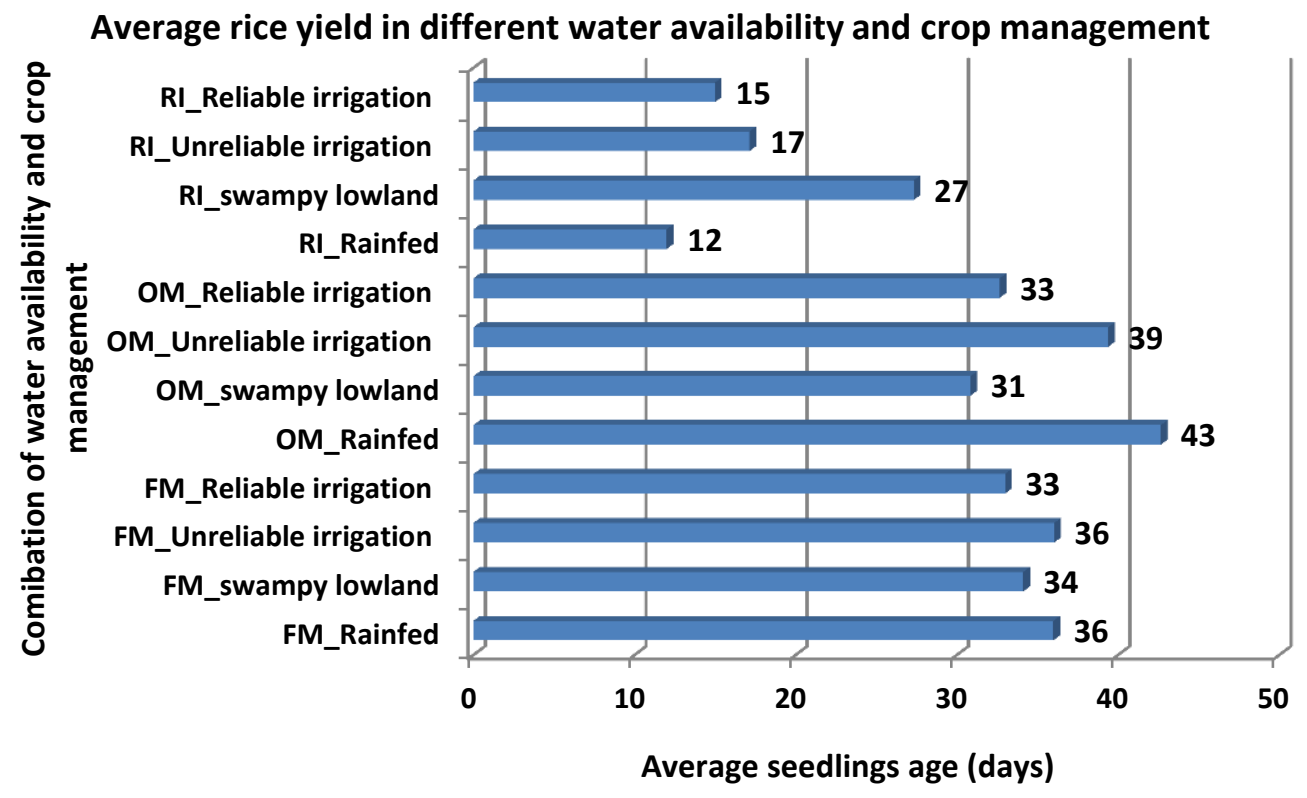

Figure 6.1. Relationship of three crop management practices with four water availability situations and seedling age.

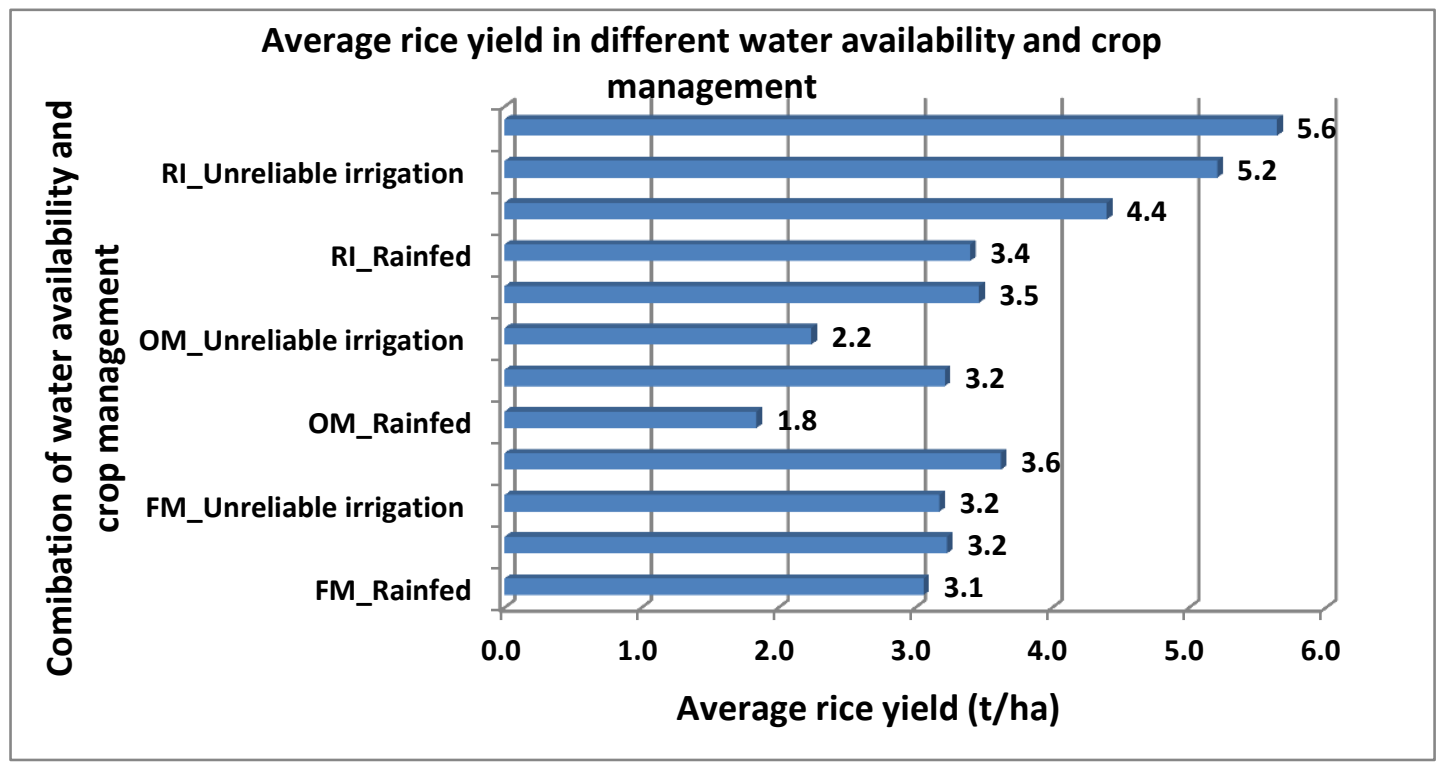

Figure 6.2. Relationship of three crop management practices with four water availability situations and rice yield. 


\subsubsection{Effect of transplanting date on rice yield}

Farmers in fields with better (more predictable) water supply are able to transplant younger seedlings and to complete their transplanting work in time. The association between transplanting data and crop yield was significant $\left(\chi^{2}=18.3 ; \mathrm{P}=0.03\right)$. This practice of earlier transplanting translates into higher yields (Table 6.3). Half of the fields that were transplanted in June yielded 4 or more $\mathrm{t}$ of rice $\mathrm{ha}^{-1}$. This was reduced to $41 \%$, when transplanted in the first half of July, 25\% when transplanted in the second half of July, and 17\% when transplanted in August. When transplanted in August, 75\% of these fields yield less than $3 \mathrm{t} \mathrm{ha}^{-1}$, whereas these low yields were only recorded of $22 \%$ of the fields where transplanting took place in June. With reliable irrigation facility, rice seedlings were transplanted to more than $66 \%$ of fields before first half of July.

Table 6.3: Rice yield and date of transplanting in Morang district, 2009 main season $(\mathrm{N}=158)$

\section{Crop yield tha ${ }^{-1}$}

$$
<3 \mathrm{t} / \text { ha }
$$

3-4 t/ha

4-5 t/ha

$>5 \mathrm{t} / \mathrm{ha}$

$\mathrm{N}$
Transplanting date

$\begin{array}{ccccc}\text { June } & \text { July } 1-15 & \text { July } 16-31 & \text { August } & \text { N } \\ 13 & 20 & 14 & 9 & 56 \\ 16 & 15 & 7 & 1 & 39 \\ 18 & 16 & 6 & 2 & 42 \\ 12 & 8 & 1 & 0 & 21 \\ 59 & 59 & 28 & 12 & 158\end{array}$

\subsubsection{Influence of water management on seedling age and rice yield}

Similarly, age of seedlings during transplanting had a major impact on rice yield (Table 6.4). The relationship was highly significant (chi square $=73.7 ; \mathrm{P}<0.0001$ ). More than $70 \%$ of the seedlings that were transplanted at an age of less than 15 days yielded more than $5 \mathrm{t} \mathrm{ha}^{-1}$. Productivity declined when transplanted seedlings were older: $12 \%$ of fields had similar yields with seedling age between 16 and 30 days, 6\% of the fields with seedling age between 31 and 45 days, whereas no seedlings that were older than 45 days at transplanting 
yielded more than $5 \mathrm{t} \mathrm{ha}^{-1} \mathrm{a}$. For the low-yield category $\left(<3 \mathrm{t} \mathrm{ha}^{-1}\right)$ the opposite pattern was noted: only $7 \%$ for the youngest seedlings ( $<15$ days), increasing to almost $20 \%$ for seedlings of 16-30 days, and more than 50\% of seedlings over 30 days. With reliable irrigation more than 35\% fields were transplanted younger seedling ( $<15$ days) and 69\% fields used $<30$ days seedlings. In other sides less than $6 \%$ rainfed and $2 \%$ of swampy lowland fields used less than 15 days older seedlings. And majority of the unreliably irrigated fields, swampy lowlands and rainfed fields used $>30$ days older seedlings.

Table 6.4.Rice yield and seedling age, Morang district, 2009 main season $(\mathrm{N}=158)$.

Crop yield category

$$
\text { tha }^{-1}<15 \text { days }
$$

$<3 \mathrm{tha}^{-1}$

$3-4 \mathrm{tha}^{-1}$

4-5 $\mathrm{t} \mathrm{ha}^{-1}$

$>5 \mathrm{tha}^{-1}$

$\mathrm{N}$

1

0

3

10

14
Seedling age category

$$
\text { 16-30 days }
$$

31-45 days $>45$ days

13

19

29

8

69
30

15

7

3

55
12

5

3

0

20

Due to lack of sufficient water for land preparation (see Chapter 2 for details), many farmers were unable to transplant seedlings at a young age. In 2009 more than 2/3rd majority of farmers' rice fields in Indrapur transplanted seedlings that were less than 30 days old, whereas it was the opposite in Jhorahat, where in the majority of fields transplanted seedlings were more than 30 days.

\subsection{Discussion}

Nepalese rice farming is dominated by the transplanting method (Chapter 2). There is very little direct-seeded rice in Nepal. So water reliability for rice farming is very important. As mentioned in chapter 2 there are mainly three types of rice cultivation methods in the study area: (1) Conventional method (where farmers use older seedlings, many seedlings in one 
place in close spacing and continuous flooded irrigation system), (2) double-transplanting (a conventional method popular among indigenous terai community where farmers transplant rice twice, especially when transplanting becomes delayed) and (3) SRI and its modifications (where farmers use younger seedlings, fewer seedlings in wider spacing and AWD irrigation system). In all cases farmers need to prepare fieldsbefore transplanting. Use of younger rice seedlings reportedly produces higher yield (Mishra and Salokhe 2008; Wagh et al. 1988; Thanunathan and Sivasubramanian 2002; Thiyagarajan et al. 2002; Pasuquin et al. 2008). Our study confirmed this relationship.

Reliably-irrigated plots and swampy lowland plots tended to be comparatively smaller in size than rain-fed and unreliably irrigated plots although the difference was not significant. Farmers tried to make small plots for uniform water distribution when water supply was reliable for intensive farming like SRI. As smaller plot size seems to be correlated with higher productivity, this link between plot size, labour investment, water reliability and rice productivity demands further study. Farmers in Jhorahat, who have relatively little control over water, seeded their nurseries and transplanted their seedlings in the sequential pattern, reflecting the influence of weather/rainfall. They seeded most of their nurseries between 15 May and 15 June. Many farmers in Indrapur, on the other hand, had planted a spring rice crop, which affected the timing for their rainy season crop operations. Having more water availability and better water control, a majority seeded their nurseries in June and also transplanted their main crop somewhat later.

In water-scarce or water-uncertain areas, farmers plough their field repeatedly, 3-4 times all within 3-4 days, and without any intervals for decomposition of weeds. Rice seedlings are transplanted after a good rainfall or whenever irrigation water is available. This practice contributes to severe weed problems subsequently, and farmers cannot harvest a good crop.

Transplanting work in Jhorahat, where most of the rice fields had been under fallow during the spring season, was spread out in something resembling a normal distribution. The pattern in 2008 was quite different in Indrapur, where transplanting work was done in two clusters -- the second half of June and mid-July making the distribution bimodal. Most of the rice fields in Indrapur that had been fallow or covered by maize and vegetables in the spring were transplanted in the first cluster, while those that previously grew spring rice 
were transplanted in the second cluster. In 2009 spring rice area was decreased and maize area increased. This difference between the two study sites was directly influenced by availability of irrigation water, as this enabled farmers in Indrapur to raise two crops of rice rather than just one. Jhorahat farmers had to depend largely on natural rainfall, relying on just one crop during the rainy season.

Wealthier farmers who are able to use a tractor or to hire more bullock ploughs for quicker land preparation find it possible to finish their transplanting work within this time period, provided that sufficient water is available. Consequently, they obtain higher yields. However, during the peak transplanting period, a majority of smaller and poorer farmers work as day-labourers to supplement their scarce income. Also the charges for bullocks and manual labour increase during this period when wealthier farmers try to finish their transplanting work as early as possible once water is available. Thus it becomes more expensive for small farmers to do their own transplanting, while their daily earnings are higher at this time. A bias in irrigation systems towards the more wealthy famers has also been shown for the Punjab (Ahmad et al., 2012).

But this problem of water limitation can ultimately have negative effects on poorer farmers, despite short-term gains. They can earn more immediate income during this time of labour scarcity by working on others' fields, but they are sacrificing some of their own potential yield. The majority of fields cultivated by poor farmers and share-croppers are rain-fed. So in any season of scanty rainfall and resulting water stress, these farmers are not able to harvest a good crop. By going into debt to meet consumption needs, they are perpetually dependent on wage labour opportunities. Short-term economic returns encourage these farmers to work in others' fields for immediate income, instead of investing labour on their own fields for a better crop, an effect reported also from Madagascar (Moser and Barrett 2003).

In Indrapur, an area of intensive cropping, the use of older-aged seedlings in the main season (June-November) was often due to farmers also cultivating in the spring season (February-July) before the main season. Otherwise, most of those farmers used seedlings less than 20 days old during the spring season. Jhorahat, as noted, is served by an agencymanaged irrigation system and is situated in the middle reaches of the Sunsari-Morang Irrigation system. Its farmers commonly face water shortages during rice-transplanting time 
because of poorly maintained canals and unreliable operation. The system's distribution capacity is reduced by silting up of channels, and its gross supply varies due to annual variations in rainfall and its distribution. What water is available at the head works does not get distributed efficiently or equitably. Uncertainty and fluctuation of water supply is a major bottleneck for transplanting younger seedlings in their area.

There should be 5-8 $\mathrm{cm}$ water on the field when farmers use mechanical weeders. Without water it is not possible to use mechanical weeders. Further mechanical weeders should be used when weed growth is at early stage (2-3 leaves stage).It is very laborious to use it when weed growth has progressed. Therefore for mechanical weeding assurance of water, male labour and time are very important. These realities show that availability of water influenced farmers' weeding practices. Adequate control over irrigation water facilitated timely (early) weeding and the use of mechanical weeders. Weeding becomes more difficult and problematic when it is done late or infrequently.

\subsection{Conclusion}

The predictability of water affects the type and management of rice farming systems. Predictable water availability makes land preparation easier and more efficient. Water scarcity, conversely, makes land preparation difficult, and later on weed control becomes problematic on fields that have not been well prepared. Water also affects timing for transplanting, as water availability provides opportunity for early transplanting and encourages the use of younger seedlings. Such use also encourages farmers to transplant fewer seedlings with wider spacing, which reduces seed and labour costs at the same time it enhances yield.

Younger seedlings and early transplanting are only possible if water is available for land preparation and for a favourable degree of muddiness when setting out the young seedlings. Farmers in Morang found the use of AWD irrigation to give positive results if water availability and reliability are good. But in spite of above-mentioned benefits many farmers are unable to capture those advantages. Several farmers keep water flooded in the fields to suppress weed growth and save labour for weeding.

Weed management can be done better where water reliability is assured because 
effective mechanical weeding depends on there being water available at field level. Not the amount of water, but reliability is key. Water availability and its management affect overall rice production system. But effects are different for different livelihood groups. 


\section{Chapter 7}

Rice cultivars recommended for and adopted in Nepal 


\begin{abstract}
Introduction of high-yielding new rice cultivars since 1966 is one of the main strategies of the Nepal government to increase rice production. But coverage of these recommended cultivars is limited and rice yield still remains low. This study was conducted among 60 farmers in two village development committees of Morang district of eastern Nepal, from June 2008-December 2009. Modern recommended cultivars performed better in better irrigated areas with better management practices. But those cultivars were very vulnerable or low productive with low management and under stress conditions. High-productive farmers preferred medium to short-duration cultivars to adjust their intensive cropping calendar but preference of low-productive farmers went to medium to long-duration cultivars. Basmati cultivars were popular among farmers who work under stressed/vulnerable conditions but not among intensive and productive farmers. In most of the time variation of farmers need and farming situations play an important role for cultivar decision. Nepalese researchers and extension systems are less successful in capturing and addressing the needs of rice farmers in Nepal.
\end{abstract}




\subsection{Introduction}

Rice has been cultivated in Nepal from times immemorial. Nepal is considered the centre of origin and diversity of Asian rice (Mallik 1981; Shrestha and Vaughann 1989; Upadhyaya et al. 2002; Niroula 2003; Joshi 2005; Niroula et al. 2005). Hundreds of indigenous rice cultivars are cultivated in Nepal. In 1966 six different new rice cultivars were released and recommended by the Department of Agriculture, Nepal (five cultivars for hills and one cultivar for terai and inner-terai) that should enhance yield. Since then, more than 50 new rice cultivars have been released and recommended for cultivation in different ecological regions. However, there has not been much increase in rice productivity (Joshi and Bauer 2006). Currently six spring-season and 38 main or rainy-season rice cultivars have been recommend by the national research system (NARC 2014). Among those 44 rice cultivars, six spring-season and 14 rainy-season cultivars have been released and recommended for the terai. Information on those recommended rice cultivars recorded during the process of cultivar release (CVT- Coordinated Varietal Trials, conducted at research stations; FFTFarmers Field Trials, conducted at farmers' fields before final release) are given in Table 7.1.

After release and recommendation of these new rice cultivars, the cultivar diversity on farm remained quite high. Joshi and Bauer (2006) and Bajracharya et al. (2010) observed that the majority of farmers cultivated modern cultivars and landraces simultaneously. The motivating factors for cultivar diversification were the heterogeneous production environment, spreading of risks, and farmers' participation in markets. Market mainly influenced the decisions of those farmers who produced rice for cash income generation (hence farmers that produced large surpluses). These farmers preferred to grow cultivars demanded by the rice industries (like Basdhan, Mansuli, Basmati). Several of these (especially Basmati cultivars) are not released and recommended by the formal research and extension system and therefore not listed in Table 7.1. But there were no market influences on those farmers who produced rice for home consumption. Joshi and Bauer (2006) concluded that the research system should develop a range of cultivars in order to meet the multiple concerns of the farmers as a single cultivar may not be able to fulfil all their concerns and livelihood strategies (see also Chapter 3). 
The origins of these modern cultivars released and recommended in Nepal are different (Table 7.1). Cultivars developed by the International Rice Research Institute (IRRI) are characterised by short stature, short growth period, high fertiliser use efficiency and high productivity under well-fertilised conditions. But they require reliable water supply (Barker et al. 1985; Upadhyaya et al. 1993) and for that reason are more vulnerable in rainfed or water-scarce areas. In Nepal about half of the rice area still depends on rainfall for water supply (rain-fed; see Chapter 6). Therefore adoption of modern cultivars of the IRRItype was generally low, even in irrigated areas. Modern cultivars that are more popular in Nepal are medium-statured, have a longer growth period, and are less responsive to fertiliser (Upadhyaya et al. 1993).

Table 7.1. Released and registered rice cultivars recommended for the terai (1966-2008). Data on average yield and days to maturation are according to NARC (2014).

$\begin{array}{ccccc}\begin{array}{c}\text { Name of the } \\ \text { cultivar }\end{array} & \begin{array}{c}\text { Year of } \\ \text { release }\end{array} & \text { Origin } & \begin{array}{c}\text { Average } \\ \text { yield t/ha }\end{array} & \begin{array}{c}\text { Maturity } \\ \text { (days) }\end{array}\end{array}$

$\begin{array}{lclccl}\text { Hardinath 1 } & 2004 & \text { Sri Lanka } & 5 & 120 & \text { Spring season } \\ \text { Chaite 6 } & 1991 & \text { IRRI } & 4.8 & 123 & \text { Spring season } \\ \text { Chaite 4 } & 1987 & \text { IRRI } & 4.5 & 118 & \text { Spring season } \\ \text { Chaite 2 } & 1987 & \text { IRRI } & 4.8 & 125 & \text { Spring season } \\ \text { Bindeshowori } & 1981 & \text { India } & 4 & 128 & \text { Spring season } \\ \text { CH-45 } & 1966 & \text { IRRI } & 3.5 & 118 & \text { Spring season } \\ \text { Sunaulo Sugndha } & 2008 & \text { Nepal } & 5.5 & 151 & \text { Main season } \\ \text { Loktantra } & 2006 & \text { Nepal } & 3.6 & 130 & \text { Main season } \\ \text { Mithila } & 2006 & \text { Philippines } & 5 & 145 & \text { Main season } \\ \text { Ram } & 2006 & \text { India } & 4.9 & 133 & \text { Main season } \\ \text { Barkhe 3004 } & 2006 & \text { Nepal } & 3.9 & 157 & \text { Main season } \\ \text { Rampur Mansuli } & 1999 & \text { Nepal } & 5.7 & 135 & \text { Main season } \\ \text { Radha 12 } & 1994 & \text { Nepal } & 4.6 & 155 & \text { Main season } \\ \text { Radha Krishna 9 } & 1991 & \text { Nepal } & 3.8 & 150 & \text { Main season }\end{array}$




$\begin{array}{lclccl}\text { Radha 7 } & 1991 & \text { Nepal } & 3.5 & 148 & \text { Main season } \\ \text { Ghaiya 2 } & 1987 & \text { India } & 3.4 & 113 & \text { Main season } \\ \text { Makwanpur 1 } & 1987 & \text { Sri Lanka } & 4.8 & 150 & \text { Main season } \\ \text { Sabitri } & 1979 & \text { IRRI } & 4 & 140 & \text { Main season } \\ \text { Mansuli } & 1973 & \text { Malaysia } & 3.5 & 155 & \text { Main season } \\ \text { Jaya } & 1973 & \text { India } & 4.3 & 130 & \text { Winter season }\end{array}$

During initial surveys of my study I observed that most cultivars used during the spring season were of dwarf stature and had a short growth period. These cultivars were released and recommended by the national research system. In the spring season there was assured irrigation for those farmers who grew rice; however, in the main season irrigation is not assured for many farmers (Chapter 6). In the main season these recommended cultivars were very scarce because these are more vulnerable to unfavourable conditions (Chapter 2). The majority of fields were covered by cultivars brought and disseminated by farmers to other farmers or farmer groups through their networks. For that reason Tables 7.1 and 7.3 list different cultivars. Most of the cultivars in Table 7.3 and not listed on 7.1 (like Basdhan, also known as Kanchhi, Ranjit, Rambilas, Sowarna) come from India. Ranjit is a comparatively new cultivar that spread very rapidly in the eastern terai. Basdhan and Sowarna have been cultivated for a longer time period. Basdhan covered the largest area but the government of Nepal did not register this cultivar for formal release due to its susceptibility to rice blast (Magnaporthe oryzae, formerly part of M. grisea). Similarly Sowarna was rejected for registration (and hence not formally released) due to its susceptibility to bacterial leaf blight (Xanthomonas oryzae pv. oryzae). But farmers like their characteristics and those cultivars spread rapidly and cover large areas of rice in eastern Nepal.

The adoption of different rice cultivars by different farmers may differ depending on the livelihood strategies (Chapter 3) of the farmers and the agro-ecological conditions (Chapter 4). Farmers assess a new cultivar in terms of a range of characters as grain yield, grain quality, straw yield, and input requirements (Traxler and Byerlee 1993). Farmers consider some rice traits as positive and others as negative, hence face inevitable trade-offs. 
For instance, several high-yielding cultivars are of dwarf stature and therefore produce low amounts of straw (and hence low amounts of fodder for livestock). While high grain yield is positive, low straw volume is negative for many farmers. Depending upon the preferences, resources, and constraints that individual farmers face, a favourable trait of a cultivar for one farmer may be unfavourable for another (Bellon 2001).

Most of the experimental research on rice yield improvement in Nepal evaluates rice cultivars, using yield as the (almost) exclusive criterion, while nutrient demand and use efficiency, and insect pest management are considered less important for evaluation purposes (NARC 2014). Because of the limited focus of the evaluation in comparison with the criteria that farmers deem important, most of the new cultivars(and technologies associated with those new cultivars) have either not been adopted, or adopted for short periods only (Joshi and Bauer 2006).

There are only few studies conducted on rice farming in Nepal. Joshi et al. (2011) studied the production economy of rice farming in different regions of Nepal and analysed the problems of low rice production. They provided recommendations to improve production efficiency. Dhungana et al. (2004) measured the economic efficiency of Nepalese rice farming and mentioned the low efficiency of farmers and agencies as major problems. Upadhyaya et al. (1993) studied adoption and productivity impact of modern rice cultivars. They studied modern cultivars developed at IRRI (dwarf cultivars) and other countries. Mansuli (a taller cultivar) was the most popular cultivar at that time and they observed that it was more tolerant to drought and performed more uniformly under a wider range of production environments than those IRRI cultivars. They concluded that uniform performance in a wide range of environments (yield stability) and tall size were the reasons for popularity of Mansuli. They also noted that poor irrigation facilities had further constrained the adoption of high-yielding modern cultivars developed by IRRI. Kafle et al. (2012) studied the diffusion of the high-yielding early-season Hardinath 1. The cultivar could meet the food demand of farmers (as a spring-season rice), which was the main reason for its diffusion. In general modern cultivars released and recommended for the spring season were more popular than cultivars recommended for the main season (see above). In the eastern terai most of the rice area during the spring season was covered by modern cultivars released by NARC, especially by Chaite 2 and Hardinath 1. Popularity of 
Hardinath 1 was due to its higher grain yield and disease resistance compared to older cultivars like CH 45 and Chaite 4 (Yadaw et al. 2005).

Most of the above-mentioned studies focused on performance of newly introduced rice cultivars and their dissemination. Rijal and Synnevag (2005) conducted a study in the western hills of Nepal about rice culture and on-farm management of rice diversity and found that most of the local cultivars or landraces were grown under marginal environments. Improved cultivars were also grown, but with high inputs under better agro-ecological conditions. There are very few studies on SRI methods with the performances of rice cultivars (Uprety 2005, 2011) in Nepal. During field observation some cultivars were more frequent under SRI than others.

Due to lack of in-depth information regarding rice cultivars in farmers' fields and context-specific appropriate strategies of rice cultivation, especially during the main (rainy) season when there is a larger variation of cultivation methods and cultivars, the public extension system provides a more or less similar technical package for all farmers (except cultivar differences for different ecological regions). This is not very effective and reported as one important reason of the inefficient rice production system of Nepal (Joshi et al. 2011). Therefore this study investigated the context specificity of choice for certain rice cultivars for main-season rice and the strategies used by the farmers to cultivate those cultivars in the terai of eastern Nepal.

\subsection{Methodology}

\subsubsection{Study Area}

Morang district of eastern Nepal, situated between latitudes $26^{\circ} 20^{\prime}$ to $26^{\circ} 53^{\prime} \mathrm{N}$ and longitudes $87^{\circ} 16^{\prime}$ to $87^{\circ} 41^{\prime} \mathrm{E}$, has been selected for this study (Figure 1.1). It is the largest rice-growing district of Nepal. Total rice growing area of this district is about 94, 000 ha and average rice yield is $3.1 \mathrm{t} \mathrm{ha}^{-1}$. The district covers an area of $1,855 \mathrm{~km}^{2}$. It has a population size of 1,028,362 (2011). Biratnagar, the district headquarter, is the second largest city after Kathmandu and is the main industrial centre of Morang. Altitude varies from 100-2410m. The climate type is subtropical, of the monsoon type with more than $2000 \mathrm{~mm}$ average annual rainfall. Average annual maximum and minimum temperatures are $30.6^{\circ} \mathrm{C}$ and $14.2^{\circ} \mathrm{C}$ respectively. 
The study was conducted in two VDCs, namely Jhorahat and Indrapur from June 2008 to December 2009. Information on both VDCs is presented in Table 7.2 and further information can be found in Chapter 3.

Table 7.2. Details of the studied VDCs

\begin{tabular}{|c|c|c|c|c|c|c|}
\hline VDC & $\begin{array}{c}\text { Area } \\
\left(\mathrm{km}^{2}\right)\end{array}$ & $\begin{array}{c}\text { Population } \\
(2007)\end{array}$ & $\begin{array}{c}\text { Distance }(\mathrm{km}) \\
\text { from Biratnagar }\end{array}$ & $\begin{array}{c}\text { No. of farm } \\
\text { households }\end{array}$ & $\begin{array}{c}\text { Cultivable } \\
\text { land (ha) }\end{array}$ & $\begin{array}{c}\text { Area under } \\
\text { rice (ha) }\end{array}$ \\
\hline Jhorahat & 13.17 & 5,414 & 10 & 788 & 1250 & 1180 \\
\hline Indrapur & 25.47 & 19,179 & 28 & 2650 & 2510 & 2250 \\
\hline
\end{tabular}

Both VDCs were selected purposively. Both have similar extension support systems but different social settings. In both VDCs SRI was introduced in 2004 (Uprety 2005).

\subsubsection{Sampling method and data collection}

The information for this study was collected from 60 randomly selected farmers through interview and season-long monitoring (main seasons of 2008 and 2009) of their entire rice field activities from seeding to harvesting. Besides detailed information regarding farming strategies of these 60 farmers, additional information of surroundings farmers was also collected to verify the information provided by the respondents. Rice farming situation of Morang was different and diversified. Regular weekly monitoring was therefore necessary to capture details of cultivar use. We also tried to explore cultivar coverage and production economy of particular cultivars. We monitored their agricultural activities on individual plots. These plots are different because of their biophysical and agro-ecological conditions and are often differently managed by farmers because of these agro-ecological and socioeconomic conditions (Chapters 3 and 4). In all, 165 plots (94 in Jhorahat and 71 in Indrapur) were monitored in 2008 and 158 plots (85 in Jhorahat and 73 in Indrapur) in 2009. These plots (which were different by topography, ownership, water accessibility and intensity of crop management) were kept on season-long observation. We collected information related to management practices by individual farmers in individual plots by interviews and observations. 
For data analysis SPSS software has been used. To find out common patterns of livelihood strategies and field management strategies factor analysis was used. The classifications of Chapters 3 and 4 (four livelihood strategies; three field management strategies) were used as a basis of addressing questions about cultivar choices. Rice cultivars were grouped under recommended cultivars, farmer-to-farmer (FTF) disseminated cultivars, and Basmati cultivars. I analysed their performance under different management systems. I used likelihood ratio test (G-test) to test for preferences for rice cultivars among livelihood and field management strategies. The relation between rice productivity and price was based on Pearson correlation.

\subsection{Results}

\subsubsection{Rice cultivars coverage}

Different local and improved main-reason rice cultivars were cultivated in Morang district. In all 13 cultivars were cultivated of which four were different Basmati cultivars that were not recommended. Out of the nine non-Basmati cultivars, four were recommended by the national agriculture research and extension system, whereas five cultivars were local cultivars, used traditionally or disseminated from farmer to farmer (without being registered and recommended). The percentage of total area covered by those cultivars is shown in Table 7.3.

In 2008 recommended cultivars covered about 22\% (30\% of the area in Jhorahat and $5 \%$ in Indrapur). Local cultivars (Basmati) covered $4.6 \%$, and $2.3 \%$ in Jhorahat and Indrapur respectively. Several cultivars (improved or imported from neighbouring countries like India) were not registered and recommended by national research system but spread from farmer to farmer. Such cultivars spread rapidly. These cultivars and Mansuli, a cultivar that has been de-notified, covered more than $70 \%$ of the area (about $64 \%$ in Jhorahat and $>90 \%$ in Indrapur) in 2008. The situation in 2009 was slightly different than 2008. Ranjit (a farmer-to-farmer cultivar) increased its covered area. This cultivar has been spreading in Morang and other neighbouring districts (table 7.3).

Basdhan (also known as Kanchhi) was the most popular cultivar followed by Mansuli and Radha 12. Basdhan was much more common in Indrapur, whereas Radha 12, a long-duration coarse-seed cultivar suitable for lowland cultivation, was almost exclusively 
used in Jhorahat. There were some differences between years, for instance Mansuli became almost twice as common in Indrapur in 2009 compared to 2008. This increase went at the expense of Basdhan. Mithila was a newly released and recommended rice cultivar by Nepal Agriculture Research Council (NARC), introduced in Morang by DADO in 2007. Its area already decreased in 2009 compared to 2008. Coverage of other cultivars was small. Two short-duration dwarf cultivars (Chaite 2 and Hardinath 1) covered total spring-season rice area in spring 2009 (results not shown).

Table 7.3. Percentage of area covered by different rice cultivars in two VDCs of Morang District in 2008 and 2009. For local cultivars it was not possible to assess since when they have been available.

\begin{tabular}{lccccll} 
& Jhorahat & Jhorahat & Indrapur & Indrapur & Available & \multicolumn{1}{c}{ Remarks } \\
Cultivar & 08 & 09 & 08 & 09 & since & \\
Basdhan & 32.2 & 30.9 & 70.2 & 56.5 & $>30$ years & Farmer to farmer \\
Mansuli & 29.3 & 24.8 & 18.1 & 32.6 & $>35$ years & De-notified \\
Radha 12 & 27.0 & 24.0 & 2.8 & 2.6 & $>15$ years & Recommended \\
Mithila & 2.9 & 0.7 & 2.3 & 0.5 & From 2008 & Recommended \\
Basmati* & 2.6 & 4.9 & 2.0 & 1.7 & Local & Local cultivar \\
Ranjit & 2.1 & 9.5 & 0.2 & 3.0 & $2-3$ years & Farmer to farmer \\
Chanachur* & 0.6 & 1.7 & 0.3 & 0.4 & Local & Local cultivar \\
Ashoka & 0.7 & 0 & 0.2 & 0 & 3 years & Farmer to farmer \\
Assame* & 0.6 & 0.4 & 0 & 0 & Local & Local cultivar \\
Anadi* & 0.1 & 0.1 & 0 & 0 & Local & Local cultivar \\
B44 & 0.7 & 0 & 0 & 0 & $>35$ years & Farmer to farmer \\
Rambilas & 1.1 & 2.9 & 1.6 & 0.6 & 3 years & Farmer to farmer \\
Hardinath 1 & 0.0 & 0.1 & 2.1 & 2.3 & 4 years & Recommended \\
Total & 100 & 100 & 100 & 100 & & \\
* Basmati cultivars & & & & &
\end{tabular}




\subsubsection{Productivity of rice cultivars}

Table 7.4 lists the average productivity of the different rice cultivars in 2008 and 2009 . Improved cultivars (recommended rice cultivars and those cultivars spread from farmer to farmer) were more productive than local cultivars. Yield variation was also higher among higher-yielding cultivars. Yield variation (coefficient of variation) was 0.33 for improved cultivars and only 0.20 for Basmati cultivars. In 2008 Hardinath 1 was most productive (6.3 t/ha) followed by Mithila (5.0 t/ha), and Ashoka (4.9 t/ha). Anadi (an aromatic cultivar valuable in Tharu community due to its religious function) was least productive (1.2/ha).

Table 7.4. Average yield of different rice cultivars, 2008 and 2009. $\mathrm{N}$ denotes the number of plots on which these cultivar was grown.

Cultivar

Basdhan (Kanchi)

Mansuli

Radha 12

Mithila

Hardinath 1

Basmati

Chanachur

Assame

Rambilas

Ashoka

B 44

Anadi

Ranjit
$\mathrm{N}$

$$
\begin{aligned}
& \text { Average rice yield plus } \\
& \text { minimum - maximum } \\
& \text { (t/ha) in } 2008
\end{aligned}
$$$$
4.1 \text { (2.4-8.0) }
$$$$
3.4(1.3-6.0)
$$$$
4.0(2.4-8.4)
$$$$
5.0(3.0-7.2)
$$$$
6.3(4.2-8.4)
$$$$
2.1(1.6-2.4)
$$$$
1.9(1.6-2.4)
$$$$
1.7(1.6-1.8)
$$$$
3.3(2.7-4.0)
$$$$
4.9(2.4-7.4)
$$$$
4.2
$$$$
1.2
$$

$3.3(3.0-3.6)$
N

Average rice yield plus minimum - maximum

(t/ha) in 2009

3.9 (2.4-7.2)

$4.0(1.8-6.0)$

$3.7(3.0-5.6)$

$4.5(4.2-4.8)$

$6.1(3.6-7.5)$

$2.5(1.8-3.4)$

$2.6(2.4-3.0)$

2.4

$2.6(1.8-3.0)$

3

1.8

$4.2(2.4-7.2)$ 
Productivity of most cultivars did not show differences between years, although the more productive cultivars tended to be slightly less productive in 2009. The four Basmati cultivars were more productive in 2009, which was a drought year. Most Basmati cultivars grow in swampy lowland and therefore perform better in drier years because of a more favourable water level on those lands. In wetter years there cultivars can be flooded.

\subsubsection{Growth duration and plant height of rice cultivars used by Morang farmers}

Basmati cultivars (Basmati, Chanachur, Assame, Anadi) were long-duration (on average between 158-167 days). These cultivars were harvested at the end of November or early December. Basmati cultivars flower at the same time (around late October and early November) when most other cultivars are at the harvesting stage.

Table 7.5. Growth duration and plant height of rice cultivars cultivated in Morang district, main season 2008.

\begin{tabular}{|c|c|c|c|c|}
\hline Rice cultivar & $\begin{array}{l}\text { Number } \\
\text { of } \\
\text { fields }\end{array}$ & $\begin{array}{l}\text { Average } \\
\text { duration } \\
\text { (days) }\end{array}$ & $\begin{array}{l}\text { Minimum - } \\
\text { Maximum duration } \\
\text { (days) }\end{array}$ & $\begin{array}{l}\text { Plant height }(\mathrm{cm}) \\
\text { Average (minimum - } \\
\text { maximum) }\end{array}$ \\
\hline Basdhan & 55 & 138 & $117-160$ & $128(90-135)$ \\
\hline Mansuli & 29 & 154 & $136-176$ & $129(100-145)$ \\
\hline Radha 12 & 19 & 158 & $136-172$ & $125(110-143)$ \\
\hline Mithila & 9 & 126 & $105-136$ & $118(100-130)$ \\
\hline Hardinath 1 & 2 & 117 & $107-127$ & $120(110-125)$ \\
\hline Basmati & 5 & 158 & $139-174$ & $152(149-155)$ \\
\hline Chanachur & 2 & 166 & $157-175$ & 157 \\
\hline Assame & 2 & 167 & $155-178$ & 146 \\
\hline Rambilas & 3 & 157 & $155-160$ & $113(100-120)$ \\
\hline Ashoka & 2 & 84 & $74-93$ & 138 \\
\hline B 44 & 1 & 147 & 147 & 118 \\
\hline Anadi & 1 & 165 & 165 & 140 \\
\hline Ranjit & 2 & 156 & $155-157$ & 130 \\
\hline
\end{tabular}




\subsubsection{Cooking quality and price of rice}

Rice cultivars were also categorised according to cooking quality, which is reflected in market demand and price. The price of different cultivars is also dependent on its fineness, aroma and consumer preference. There are three quality categories of milled rice available in the market and three main cultivars represented those three categories as Basmati (fine grain, aromatic), Mansuli (medium-fine grain) and Basdhan and Radha 12 (coarse grain). Next to milled rice another use of rice is for chiura (flattened rice). Chiura (or Baji) is popular in Nepal and India for breakfast. The suitability of particular cultivars for chiura making is an important trait that influences cultivar selection. Radha 12 is popular for chiura making followed by Basdhan.

Price range of the three groups is given in Table 7.6. Actual selling prices in 2009 were around 14-16 $\mathrm{NRs} \mathrm{kg}^{-1}$ for all cultivars, only Basmati fetched higher prices (25 NRs $\mathrm{kg}^{-1}$ ). This price indicates that lower productivity is (partially) compensated by higher prices.

Table 7.6. Prices of different brands of milled rice in Morang, Nepal, 2008.

Rice cultivars Average price $\left(\mathrm{NRs} \mathrm{kg}^{-1}\right) \quad$ Range $\left(\mathrm{NRs} \mathrm{kg}^{-1}\right)$

Coarse (Radha 12, Basdhan)

Medium (Mansuli, Sworna)

Fine (Basmati, different cultivars) 35

Flattened rice

22

Source: DADO Morang 2009. Note: 1 US $\$=96$ NRs

\subsubsection{Summary of traits used by farmers for cultivar selection}

Farmers in Moran district apply different criteria for cultivar selection. Based on their responses we qualitatively evaluated the different rice cultivars according to five criteria (Table 7.7).We did not rank cultivars, recognising that preferences are context dependent and correlated with livelihood strategies and field management strategies. 
Table 7.7. Evaluation of rice cultivars by farmers. $\mathrm{H}=$ High, $\mathrm{M}=$ Medium, $\mathrm{L}=$ Low.

$\begin{array}{lccccc}\text { Rice cultivar } & \text { Productivity } & \begin{array}{l}\text { Price } \\ \text { category }\end{array} & \begin{array}{l}\text { Cooking } \\ \text { quality }\end{array} & \begin{array}{l}\text { Straw } \\ \text { volume }\end{array} & \begin{array}{c}\text { Suitable for } \\ \text { double } \\ \text { transplanting }\end{array} \\ \text { Basdhan } & \text { H } & \text { L } & \text { M } & \text { M } & \text { M } \\ \text { Mansuli } & \text { M } & \text { M } & \text { M } & \text { H } & \text { H } \\ \text { Radha 12 } & \text { H } & \text { L } & \text { M } & \text { H } & \text { L } \\ \text { Mithila } & \text { H } & \text { L } & \text { L } & \text { L } & \text { L } \\ \text { Hardinath 1 } & \text { H } & \text { M } & \text { M } & \text { L } & \text { L } \\ \text { Basmati } & \text { L } & \text { H } & \text { H } & \text { H } & \text { H } \\ \text { Chanachur } & \text { L } & \text { H } & \text { H } & \text { H } & \text { H } \\ \text { Assame } & \text { L } & \text { H } & \text { H } & \text { L } & \text { M } \\ \text { Rambilas } & \text { M } & \text { L } & \text { L } & \text { M } & \text { L } \\ \text { Ashoka } & \text { M } & \text { L } & \text { L } & \text { H } & \text { L } \\ \text { B 44 } & \text { M } & \text { L } & \text { L } & \text { L } & \text { L } \\ \text { Anadi } & \text { L } & \text { H } & \text { H } & \text { M } & \text { M } \\ \text { Ranjit } & \text { H } & \text { L } & \text { M } & \text { L } & \text { L } \\ \text { * Double transplanting: see Chapter 2 for further details } & & \end{array}$

Farmers who grow vegetables and farmers who adopt intensive cropping systems generally prefer short to medium-duration cultivars. Farmers who also keep livestock in majority prefer medium-sized to tall cultivars. Therefore Basdhan, Mansuli and Radha 12 are popular among the majority of the farmers. In case where double transplanting is a common practice, farmers prefer Mansuli and Basmati, because of its photosensitive nature and its ability to be transplanted late.

\subsubsection{Crop management systems and cultivar performance}

As shown in Chapter 4 the majority (73\%) of the farmers used more than one rice cultivar in their fields, related to diversity of their land properties and ownership situation. Decisions to grow certain cultivars were also guided by factors like family preference for home 
consumption (coarse-grain high-productive cultivars), landlord demand (for Basmati cultivars for their home consumption), and crop duration of cultivars (short-duration cultivars for vegetable farmers or those with intensive cropping systems, see also Chapter 3 ), as cultivar choice should match the demands of the next crop.

Such differences are reflected in the choice for cultivars. For Basmati the number of plots was too small to apply a formal statistical test, although the lack of fields with Basmati (because of photo-sensitivity) among the fields where SRI-like practices were found, is striking. For long-duration cultivars, there were no significant differences between livelihood strategies $(\mathrm{P}=0.07)$, whereas the difference between crop management strategies was significant $(\mathrm{P}=0.02$; Table 7.8$)$.

As noted in chapter 4 average yield was highest is intensively managed fields. Rice yields were comparable in fields where the other crop management strategies were found. In all fields performance of recommended cultivars and farmer-to-farmer cultivars was comparable and around $2 \mathrm{t} \mathrm{ha}^{-1}$ less (Fig. 7.1). Management also impacted on productivity, with earlier transplants resulting in higher average yield. Again there was no difference between recommended cultivars and farmer-to-farmer cultivars (Fig. 7.2). Recommended cultivars were always transplanted with 45 days; farmer-to-farmer cultivars were sometimes transplanted later and then yielded around $3 \mathrm{tha}^{-1}$. Only at the best management conditions did recommended cultivars slightly outperform farmer-to-farmer cultivars. That conclusion is reinforced by Fig. 7.3: with reliable water supply recommended cultivars greatly outperform farmer-to-farmer cultivars (a difference of almost $2 \mathrm{t} \mathrm{ha}^{-1}$ ), but in other conditions both groups of cultivars perform similarly. Basmati cultivars are far less productive (cf Table 7.6), but show higher yield stability, that is their performance shows little relation to water availability. 
Table 7.8a. Inclusion of Basmati cultivars among different livelihood strategies. Data from 2008.

$\begin{array}{cccc}\text { Livelihood strategy } & \text { Fields with Basmati } & \begin{array}{c}\text { Fields with long- } \\ \text { duration cultivars }\end{array} & \begin{array}{c}\text { Total number of } \\ \text { fields }\end{array} \\ \text { SRFO } & 1 & 2 & 13 \\ \text { MRFO } & 5 & 19 & 38 \\ \text { MRFT } & 7 & 42 & 80 \\ \text { LFRT } & 1 & 12 & 34\end{array}$

Table 7.8b. Inclusion of Basmati cultivars among different crop management strategies. Data from 2008.

Crop management strategy

FM

$\mathrm{OM}$

RI
Fields with

Basmati

7

7

0
Fields with Total number of long-duration fields cultivars

46

91

20

33

41 


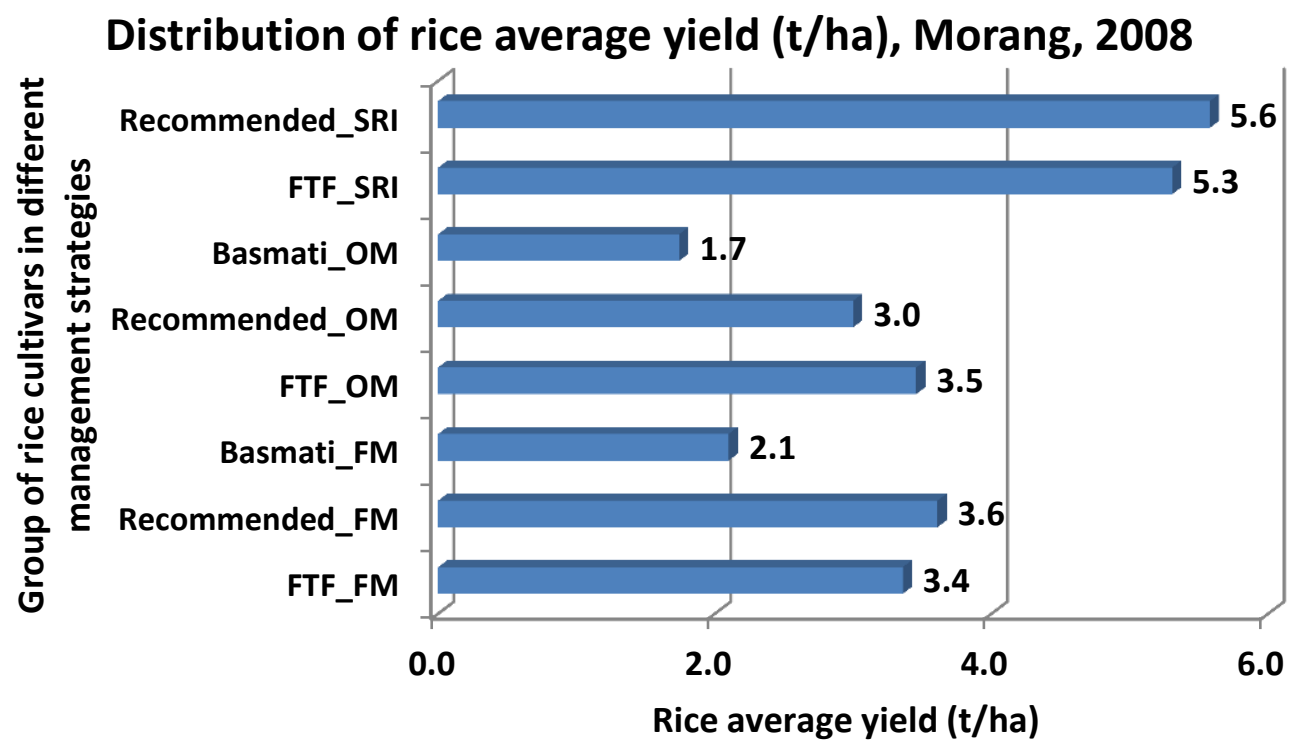

Fig 7.1. Average yields of three groups of rice cultivars: Basmati, Recommended cultivars, farmer-to-farmer (FTF) cultivars in three different crop management systems.

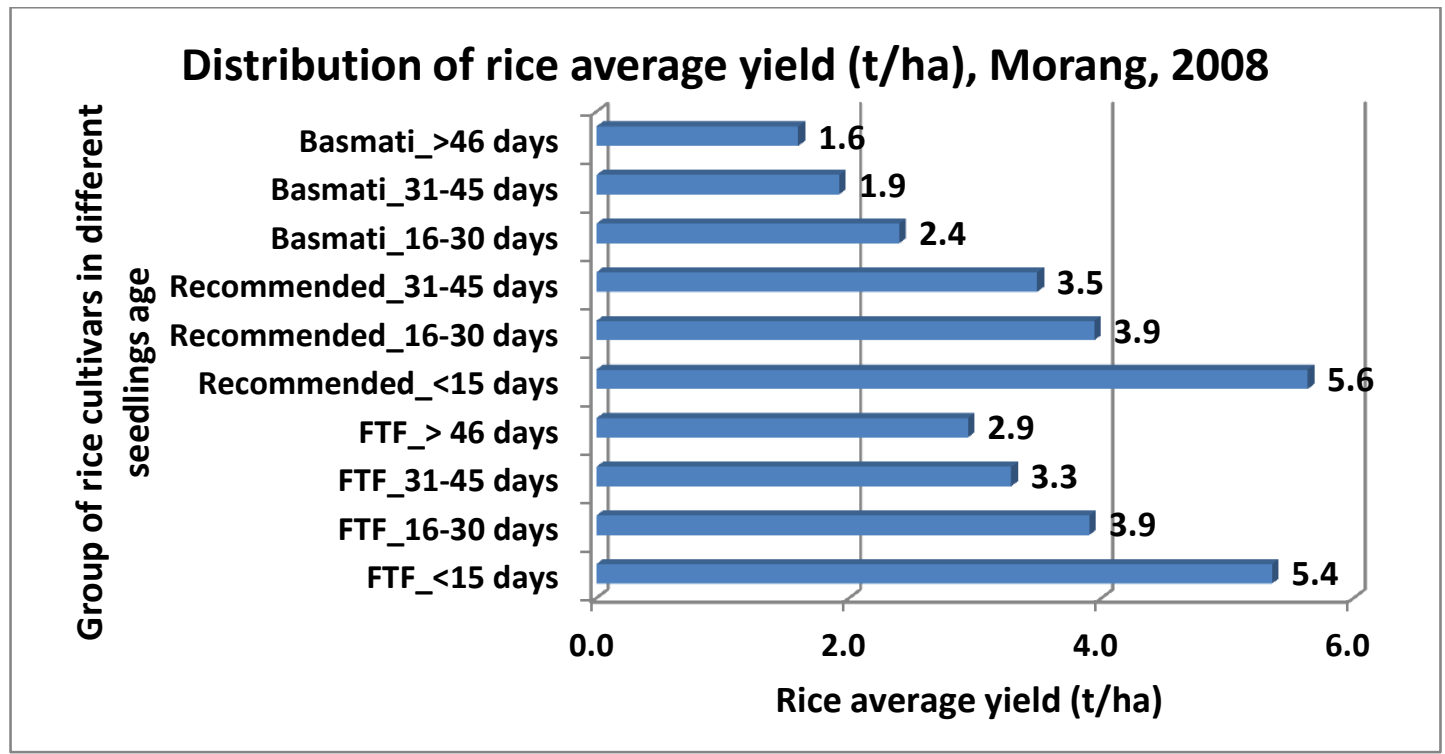

Fig 7.2. Average yields of three groups of rice cultivars (Basmati, recommended cultivars, farmer-to-farmer cultivars) as a function of age at transplanting. 


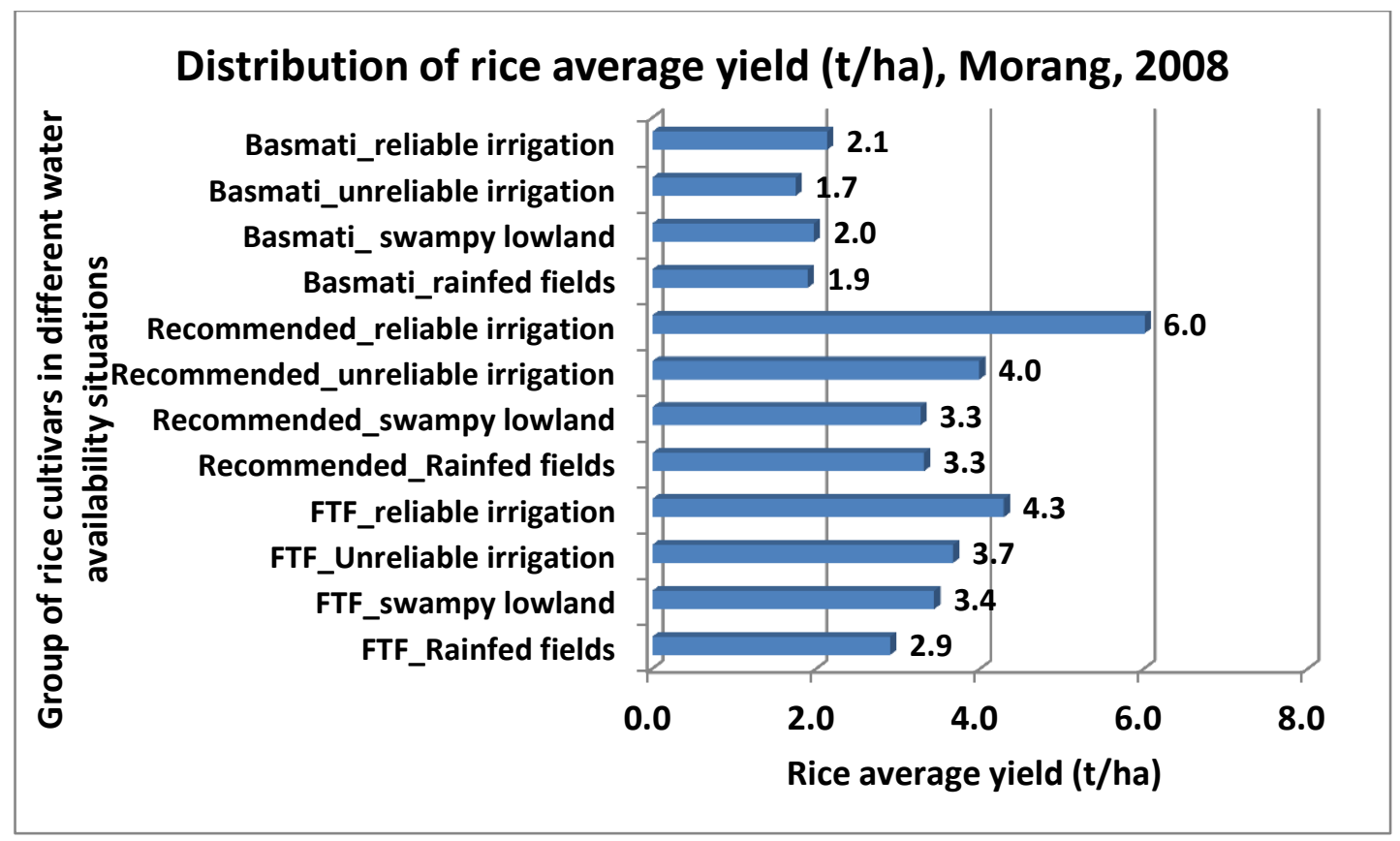

Fig 7.3. Average yields of three groups of rice cultivars (Basmati, recommended cultivars, farmer-to-farmer cultivars) as a function of water management.

\subsubsection{Average yield of different groups' rice cultivars}

Averaged over plots, recommended cultivars were more productive $\left(4.4 \pm 1.4 \mathrm{tha}^{-1}\right)$ than non-recommended cultivars spread from farmer to farmer $\left(3.8 \pm 1.2 \mathrm{t} \mathrm{ha}^{-1}\right)$. The difference was significant $(\mathrm{P}=0.002)$, and caused by recommended cultivars outperforming farmer-tofarmer cultivars at best management practices. Basmati and other local cultivars were least productive $\left(1.9 \pm 0.4 \mathrm{t} \mathrm{ha}^{-1}\right)$.

The majority of the farmers used their own seeds (produced and kept by them), but I repeatedly observed that seeds (especially of recommended cultivars) lost their potential after several years without selection and care. Very few farmers used new seeds produced from quality-seed producers and research centres. Most of the time nearby research stations did not produce and supply sufficient high-quality seeds to fulfil the demands of seed growers and farmers. This malfunctioning of the formal seed system made it difficult to stimulate rice farmers to replace their seeds rather than to rely on recycling of their own seeds. Some farmers replaced old seed by new seed after 2-3 years. But most of the farmers 
continuously used their own seed for several years. It is possible that differential seed recycling and seed use contributed to high variation of yield levels in recommended cultivars.

\subsection{Discussion}

Basdhan is the most popular cultivar in Morang and neighbouring districts. Its popularity has decreased somewhat (see Table 7.3) in recent years. Decreased interest is probably due to lower yields, caused by increased susceptibility to rice blast disease (neck and leaf blast). But as this (non-recommended) cultivar has wide adaptability (better than recommended cultivars), good productivity with relatively high yield stability, and acceptable straw yield, it is still the first choice for many farmers. Farmers therefore compare new cultivars with Basdhan. Research stations also use it as the standard against which they check new cultivars. Mansuli was considered as an attractive cultivar in eastern Nepal and south Asia for more than three decades (Barker et al. 1985), but is has currently been removed from (de-notified as) recommended cultivar. This cultivar of medium stature yielded more than traditional cultivars at low doses of fertilisers, had better grain quality and performed better in a wide range of agro-ecological conditions (Upadhyaya et al. 1993). The area of Mansuli seems to be gradually decreasing (although this is not evident from a comparison between 2008 and 2009) due to lower yields and disease susceptibility. But its higher selling price (it is still preferred by the rice industry and it is also a popular brand for middle-income families), good cooking quality, high volume of straw, and its suitability for single and double transplanting (table 7.7; see also chapter 2) makes it still very attractive for several farmers. Radha 12 is a coarse-grain cultivar, which is popular among working class families; it is also suitable for chiura making. High yield under conditions of good management and high straw production contribute to the popularity of Radha 12 in Morang district, but only in Jhorahat. Hardinath 1 is a popular cultivar of spring-season rice. Its popularity is gradually increasing in the main season, especially among vegetable growers and among farmers with more intensive cropping systems, due to its short life cycle and high-productive nature. Farmers also reported that straw of Hardinath 1 decomposes quickly after incorporation in soil; the cultivar therefore contributes to easier and faster land preparation and subsequent transplantation of next main-season rice. 
Ranjit is a newly introduced modern cultivar, spread through farmer-to-farmer networks. It shows high tillering ability, it is highly responsive to fertiliser and under such conditions very productive. It's fit well with intensification of rice-growing practices. Its popularity rapidly increased from 2008 to 2009 (Table 7.3). During my study period farmers from Jhapa district reported a decline of Ranjit yield (personal observations). After repeated use of Ranjit for 2-3 seasons in the same field, its yield decreased rapidly at the same input level. Several farmers from Morang and Jhapa districts reported that Ranjit seems to need increasing doses of mineral fertiliser every year to maintain its yield. The causes for this observation have not yet been understood. The observation is consistent with findings of Rijal and Synnevag (2005) regarding long-term better performance of modern cultivars only at high (and sometimes increasing) input levels. Mithila is another newly released, recommended rice cultivar. It was introduced by DADO Morang in 2007 through distribution of an improved seed kit. Several farmers tested this cultivar and the cultivar produced higher yield within a short duration (Table 7.6). But most farmers discontinued with this cultivar in 2009 (Table 7-3). The main reason to discontinue was its low market price (due to a low percentage of milling whole grain), its low quality for cooking purposes, and short straw length (resulting in less straw for livestock).

An important factor related to preferences for and subsequent adoption of rice cultivars is height. In spring season dwarf cultivars are popular among farmers. In that period it is very difficult to dry rice straw (due to heavy rainfall during harvesting) for longterm storage as fodder for animals. So in spring season farmers do not care about rice height (straw volume).But in the main season most farmers want medium to tall rice cultivars because of its straw volume. This preference (or rather the need) for cultivars that produce sufficient straw might be the reason dwarf cultivars in Morang covered only a minor area during the rainy season.

All Basmati cultivars are of long duration, but flower at the same time (they are photo-sensitive). When farmers seed this cultivar earlier, it takes more time for vegetative growth. Farmers are aware about this character of Basmati so they use these cultivars in areas where transplanting becomes delayed (due to land cover by previous crops like spring rice or jute; or where water is not yet available). Due to these physiological characteristics, crop duration of those cultivars is more variable than for other cultivars, as there is more 
variation in seedling age. Crops take more time to complete their life cycle when farmers use older seedlings. Sometimes photo-insensitive cultivars are unable to produce panicles in very late transplanting condition. Such cultivars need sufficient vegetative growth period before flowering. That is the main reason behind farmers' strategy to use older seedlings of Basmati or use double transplanting with long-duration cultivars (Mansuli and Basdhan) when transplanting is delayed. Farmers generally used high-tillering cultivars (like Chaite 2, Mansuli, Basdhan, Radha 12 and Ranjit) for (modified) SRI methods; the low-tillering cultivar Hardinath 1 was not popular because of wider spacing in SRI methodology where low-tillering cultivars are unable to cover space between hills and weed management becomes problematic, ultimately bringing low yield.

The majority of farmers grow rice for family consumption and fodder for livestock. So, not only cooking quality of rice, but also quality and volume of straw are important traits for cultivar selection. The people who are involved in physically hard work prefer bold grain cultivars like Radha 12 and Basdhan. Such cultivars are bulky, digest slowly and provide power for longer period of time. Radha 12 is also popular for chiura making. Basdhan is a popular brand for home consumption among lower and lower-middle class families. Mansuli is popular among middle-class families. Basmati cultivars are popular among high-income families (status symbol).It serves special religious functions as well.

Grain quality and market price are important traits for big farmers or those who cultivate rice for main income. But it is not very important for small farmers who want to produce more for home consumption. The latter group prefers high-yielding cultivars like Radha 12 and Basdhan. Dwarf cultivars (like Hardinath 1, Mithila) are not preferred by a majority of the farmers because of poor straw yield.

My results agree with the findings of Traxler and Byerlee (1993) and Rana et al. (2007) that farmers choose rice cultivars based on a range of characters like yield, straw volume, grain quality and input requirements. The diversity of criteria that Nepalese farmers apply, depending also on their livelihood strategies and crop management strategies, explains why very few modern rice cultivars (dwarf) developed at IRRI have become popular in Nepal, especially in the main season.

Large areas in Morang were covered by non-recommended cultivars, with only $22 \%$ of the area being covered by recommended cultivars. Coverage of Basmati was about $3 \%$. 
These result confirm that cultivar selection criteria by scientists and farmers are different, especially in the main season. (In Nepal spring-season rice is cultivated only in reliably irrigated areas, and in that season most rice cultivars (Chaite 2 and Hardinath 1) are recommended cultivars.)The mismatch between recommendations by research stations and actual use by farmers also suggests that testing and subsequent recommendation is more based on better irrigated areas. This suggestion is in agreement with the findings of Upadhyaya et al. (1993).However, not in all cases may a strong distinction between recommended and non-recommended cultivars be made. Steele et al. (2009) noted that there was substantial integration between local cultivars and modern cultivars.

Basmati cultivars are popular in rain-fed areas and in swampy lowland where transplanting is always delayed to the end of transplanting season. Basmati cultivars are low productive but highly priced, so net return is comparable with more productive cultivars. However, harvesting time is at the end of November or early December, so farmers cannot combine Basmati cultivars with land use intensification for vegetable cultivation. Small and marginal farmers who cultivate rice for home consumption cannot use Basmati cultivars due to its low production. This result confirms the findings of Bellon (2001) that diversity of farmer livelihood strategies and crop management strategies determine and is determined by rice cultivar choice.

The situation of Indrapur was different from that of Jhorahat with regard to use of rice cultivars. Jhorahat farmers used Radha 12 (recommended cultivar) over a larger area than Indrapur. The difference might be due to residential position of most landlords in Biratnagar who rent out their land to share-cropping. Biratnagar, the second largest town of Nepal, is a major centre for new seeds, agro-inputs and some popular Chiura mills/industries are located close to Jhorahat which provide better price to Radha 12 for Chiura making. Arrangement of seeds and fertilisers at the start of crop cultivation is the responsibility of the landlord especially under share-cropping arrangements. So landlords are responsible for bringing new seeds (of recommended cultivars) and inputs from the district headquarter. That might be the reason that coverage of recommended cultivars is higher in Jhorahat. In Indrapur a larger area was covered by cultivars introduced by farmers themselves. The higher percentage of such FTF cultivars was due to social networks (the majority of them are affiliated with farmer groups). However, the role of farmer networks on cultivar choice 
and other farming decisions was not addressed in this study. It will be a valuable area for future study.

\subsection{Conclusion}

Cultivar choice for rice cultivation by scientists and farmers was different in eastern Nepal. Scientists of the national research system recommended 14 rainy-season cultivars for the eastern terai, but only three of those were found in larger areas in Morang. Other recommended cultivars were not adopted by the farmers. High yield, high fertiliser use efficiency, and disease resistance are important traits for scientists for cultivar selection. Only high-productive farmers applied similar criteria. Farmers with other livelihood strategies and crop management strategies prefer long-duration cultivars that produce large volumes of straw (for fodder), but that are less responsive to fertiliser. However, such cultivars also show higher yield stability. Farmers' preferences of high-tillering and shorterduration cultivars for SRI methods is related with wider plant spacing and their intensive cropping system. Therefore, they preferred high-tillering but photo-insensitive cultivar over photo-sensitive Basmati cultivars. High- and low-productive farmers are confronted with the negative correlation between yield and market price for their cultivars. Because local cultivars perform better in more risk-prone conditions (drought, low soil fertility, labour scarcity -conditions that cause delayed transplanting), most farmers continue the use of (non-recommended) cultivars. For Basmati cultivars, high prices also compensate for low yields, and there is a clear niche for such cultivars. However, that niche prevents agricultural intensification, including intensification towards economically attractive vegetable crops. Other long-duration cultivars may equally hamper intensification. 


\section{Chapter 8}

\section{General Discussion and}

\section{Conclusion}




\subsection{Introduction}

Rice is the main staple food crop and the single largest contributor of agricultural GDP in Nepal. Several decades ago, rice was a main source of income for Nepal as an export commodity, but gradually Nepal became a rice importer (Khadka 2010; Bhandari 2011; MOAC 2011). In the 1960s and 1970s, rice production was increased by the expansion of cultivated area, irrigation, and by use of improved cultivars and mineral fertiliser (Barker et al. 1985; MOAC 2011; DOI 2007). However, in the last decade rice productivity and production have been more or less stagnant (MOAC 2011), while demand for rice has been increasing. A World Food Program study in Nepal of 2008 indicated that $75 \%$ of poor households did not produce sufficient food to meet their needs, and more than $95 \%$ of very poor households had insufficient access to food (WFP 2008; Khadka 2010). This unfavourable situation was because rice production fell by $30 \%$ while rice prices rose by the same proportion (WFP 2008). Insufficient access mainly stems from household financial problems. In this situation, improved earning is the main concern for the majority of poor households to have sufficient food for their family.

On average, more than $60 \%$ of income of the poor and very poor households in Nepal is spent on food (Khadka 2010; NPC 2010).Growing their own rice, with possibly some surplus to sell, is one strategy for small farmers to increase food security, especially when they do not have good alternatives for their earnings. Therefore, food crop productivity and production (especially of rice, the main staple food)is the main concern for the government of Nepal (MOAC 2011; NPC 2010) to improve food security. In order to achieve that objective, the government emphasised increased food production through the use of improved seeds, mineral fertilisers, and modern production technologies (MOAC 2011). However, the priorities of Nepalese farmers do not seem to fit with those of the government. Still, rice farming is important to them for food security purposes. But rice is no longer an important source for livelihood as it was in the past, when rice farming was the main source of income and employment for the majority of the farmers, not only in Nepal but in most rice-growing areas of South Asia (Samal et al. 2006; Paris et al. 2005).

Currently, in the area, where my PhD study took place, the eastern terai in Morang district, there were only $18 \%$ of families who depend exclusively on cereal-based (rice) agriculture. Of the $18 \%$ cereal-based farmers, $11 \%$ were tenant farmers or mixed farmers 
and 7\% were owner-operators (Chapter 3). The rest of the families (82\%) diversified their income sources and involved family members in high-value-crop farming and in nonagriculture occupations as also is occurring in other rice-growing countries (Deshingkar and Anderson 2004; Paris et al. 2005, 2007, 2010). According to their livelihood opportunities and ambitions, influenced by geographic location (proximity to towns), educational levels and other factors, different farmers applied different strategies at the household level and at the field level. Household-level strategies were more focused on the utilisation of available family resources given available occupational opportunities (Chapter 3). For better livelihood opportunities, a majority of farmers' families sent family members to foreign employment (remittances, especially from India), to non-agricultural work, or involved them in high-value vegetable farming. Field-level strategies (Chapter 4) were more focused on the utilisation of existing agro-ecological situations of rice farming.

My study explored constraints and opportunities for (intensification of) rice farming in Nepal and the strategies of rice farmers at household and field level by conducting a study among 60 randomly-selected farmers from two Village Development Committees (VDC) areas of Morang, the largest rice-growing district of Nepal, from June 2008November 2009. Intensification of rice farming is often brought into connection with the System of Rice Intensification (SRI; see Uphoff 2001; Stoop et al. 2002; Doberman 2004; Berkhout and Glover 2011; Glover 2011, 2013), but I took a broader perspective. The general discussion is based on five primary research chapters: (1) on household-level livelihood strategies of the rice farmers (Chapter 3); (2) on field-level crop management strategies (Chapter 4); (3) on nutrient management by rice farmers (Chapter 5) (4) on water availability and management (Chapter 6); and (5) on the dynamics of cultivar use (Chapter 7). In these section I will provide recommendations how to increase rice productivity. I will end this chapter with some suggestions for future research.

\subsection{Livelihood Strategies}

Four different types of livelihood strategies were identified. Two strategies can be characterised as more intensive and more productive; the other two are less intensive and less productive. The first group Strong Rice Focus Ownership (12\% of the farmers) consists of high-intensive and high-productive cultivator farmers possessing small land sizes, who 
depend on external labour for land preparation and the rest of the work. The second group Moderate Rice Focus Ownership (25\%) also consists of owner cultivators and is equally dependent on hired labour; however, they possess larger land sizes and their agriculture is of low intensity and productivity. The majority of the third group of farmers Moderate Rice Focus Tenancy (42\%) are tenants or mixed-type farmers, using more land and more family labour for rice farming. Like the second group their agriculture is of low productivity. The fourth group Low Rice Focus Tenancy (22\%) also is composed of tenants or mixed-type farmers, but they are working on smaller land sizes. They use more family labour, but like the first group their agriculture is intensive and productive. The majority of them are vegetable farmers. Those four groups work on, respectively, on $6 \%, 26 \%, 52 \%$ and $16 \%$ of the land, showing that more productive farmers possess less land (similar as for fields, as more productive fields were smaller). Average land size distributions of those four are significantly different. A majority of pure owner-cultivators work on less than one ha land (small farmers); the situation is the opposite in mixed farming and among tenant farmers who work comparatively larger areas.

Combining farmer groups (group 1 plus group 4; versus groups 2 and 3), I conclude that $34 \%$ high-productivity farmers cultivate $22 \%$ of the land, while the rest (two-thirds of the households) cultivate $78 \%$ of the land, with lower productivity. A classification in terms of productivity was independent of a classification of ownership status: more and less productive groups were found among owner-cultivators (groups 1 and 2) and tenants (groups 3 and 4). Farmers with relatively smaller plots are more productive in terms of output per unit of land. Those farmers who invest in intensification (or in a new technique like SRI, including the purchase or rental of machinery to reduce their production costs) increase their crop yield. For group 1, rice is the dominant crop for home consumption. Group 4 works on leased-in land, increasingly buying land where possible to grow vegetables for a main income and cultivating rice as a secondary source of income. Farmers in the other two groups grow rice but less extensively, as their main source of income is either off-farm labour or non-agriculture occupations. Details of intergroup dynamics and possible future changes within farmers' livelihood strategies at micro-level and Nepalese agriculture at macro-level suggest various pathways of intensification, including intensification out of rice cultivation. It seems that SRI, as one specific form of 
intensification, is not necessarily a fixed end point in a trajectory of increasing productivity. It is also clear that any simplistic dichotomy in terms of farmers versus non-farmers fails to capture the dynamics of intensification by some (but not all) farmers in Nepal.

Share-cropping is the entry point for landless farmers and also the main existing character of the land use of Nepalese agriculture especially in terai. This is a less-efficient but a good option for a resource-poor sharecropper. The landlord generally provides the cost of seeds and fertilisers at the beginning of the season, so this is attractive to resource-poor farmers, and the landlord can have his land protected against "land-to-the-tiller legislation", as the tenant cannot claim to have cultivated the land. Successful farmers who started their profession as sharecroppers after some years of experience move towards the more intensive and productive group (productive tenants or tenants with a fixed-rent system), but unsuccessful or less-successful families remain subsistence sharecroppers, agriculture labourers, or ultimately leave agriculture.

Another important reality of Nepalese agriculture is for farmers to start with a cereal-dominant, fairly simple farming system and to move to cultivation systems that require more knowledge (about cultivars, market demand and competitive prices, nutrient management, plant protection measures, etc.) and skills (marketing, cultivation, and postharvest). Such knowledge and skills are required for high-value vegetable farming. The successful farmers who have more family labourers start to invest in land. I predict that two types of farming strategies will be successful in the future in the eastern terai. One is familylabour-centred, intensive and diversified small-scale farming where productivity and intensity will be high, and the other is hired-labour-based or high-investment, mechanised, large-scale farming with high volume production and low production costs. Neither system is likely to become superior, and both pathways are likely to co-exist. The implication, then, is that a certain amount (but in all likelihood a minority) of farmers will practice what is like SRI (although it is also used as a way out of farming); but that the second, alternative option is equally viable.

Tenants will buy the lands that have been cultivated by them (as tenant) for the past several years. Under this practice they will use manure on rented land to maintain soil fertility for the long run. Those farmers families, who will be the future farmers, remain in agriculture. But smaller family farmers with less family labour leave agriculture, after 
accumulating enough wealth for investment in other occupations outside agriculture. But also in those situations farmers intend to hold some cultivated land for food security purpose. Figure 8.1 illustrates the pathway of rice farmers' dynamics in Morang (figure 8.1).

Although rice production is a main priority for the Nepal government, the majority of the farmers don't agree with it (chapter 3). Over $50 \%$ of lands were cultivated by tenants and the productivity of such lands was usually low. Similarly, most of the big farmers' (who depend on hired labour for their farming) rice productivity was also low and these farmers were less interested in labour-intensive technology like SRI due to high wage rate and scarcity of workers as well as low return from rice farming. They continue farming, not for the sake of return, but for maintaining their social status as well as for increasing value of lands overtime. The wealthy farmers who have already shifted from rural to urban centre have educated family members engaged in mostly non-agriculture professions. Older members of the family (who earn the land and think their status is attached with their land) still continue to farm. It is urgent to provide cost effective production strategy for this group of farmers, like mechanisation (Goodrich et al. 2008; Nepal and Thapa 2009; Uprety 2010) to reduce production costs and increase profit. Otherwise, the new generation (those grown up in urban area) is not willing to return to farming (a low-profit profession). 


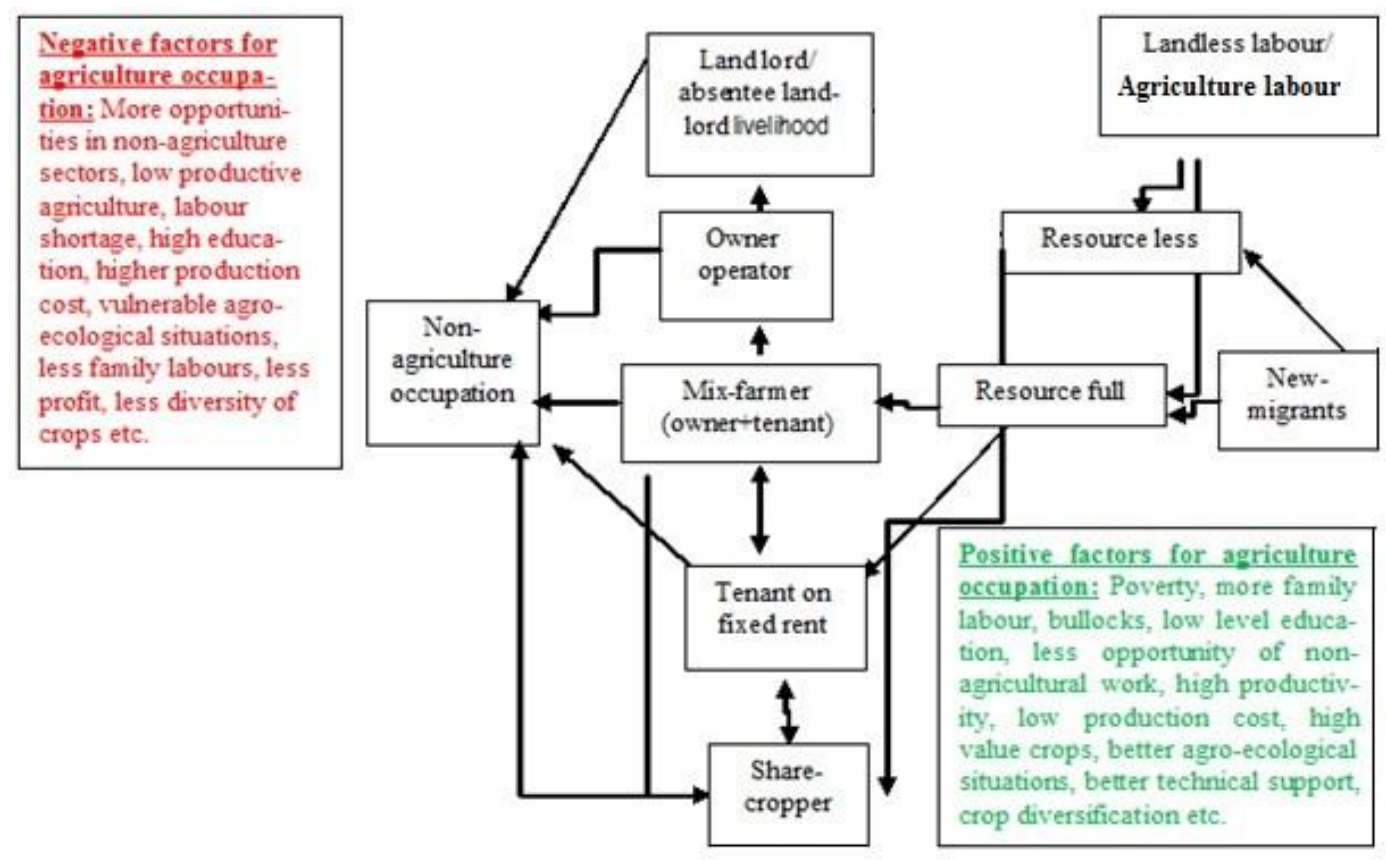

Fig 8.1. Rice farmers pathways and dynamics in Morang district, Nepal.

Educated farmers of the new generation increase their participation in agriculture profession but they are more focused on high-value vegetables, fruits and cash crops. As a main profession, very few farmers are attached with cereal-based conventional agriculture in Nepal. However, in the rainy season, rice is the only crop suitable for cultivation in lowland (Haefele et al. 2005); other crops will not perform well due to heavy rain and water stagnation. Second group of the farmers were of mixed type; most of them have their own land but also work on the rented land. They were comparatively new migrants or farmers improving their economic standard. They are the backbone of Nepalese agriculture at present (group 3 and 4 of chapter 3, they work on more than 2/3rd portion of cultivated land). Due to low standard of education and abundant family labour, they have fewer options in non-agricultural sectors. The majority of such families diversify their livelihood options (intensified agriculture, vegetables farming, dairy and remittances/foreign employment) and improve their living standard through investments in agricultural land or intensified fixed rent system. Most of the fixed-rent tenants were under this group.

However, not all such families have successful pathways. Less successful families 
continued subsistence farming for their living. Some of the small nuclear families, those having less family labour and previous migrants in the rural areas now shift towards urban centres after having their land rented to others. That is a common trend especially among younger-aged nuclear families who get their main income from remittance. Similar case was found by Gartaula et al. (2012) in Jhapa, a neighbouring district of Morang. Trained and organised farmers of this group produced higher rice yields by using (modified) SRI methods or by improving their crop and nutrient management system, thereby earning more profit from their farming. High productivity is the best option to increase income from rice farming because there was no significant difference between the production costs of high and low productive farmers but very high difference in net profit. High-productive farmers have intensified and diversified their farming by integrating vegetables, cash crop farming and livestock but less trained and less organised famers are left behind to run their farming inefficiently. Here, better agriculture training and group mobilisation workshops for such farmers from supporting organisations (department of agriculture and NGOs) will be more useful (Aveno et al. 2006; Ulimwengu and Badiane 2011).

Landless pure share-croppers are the third group of farmers found in Morang. Those families lack resources to invest in intensive farming. They were mostly cereal farmers because they don't have sufficient knowledge, skills and investment for high returns (but riskier) vegetable farming. On the other hand, landlords are less willing to invest in vegetable farming (which are harvested and sold in small volumes, making it difficult to share product) under share-cropping system. In this way, rice-based farming (which is easy to harvest, thresh and divide) is the only doable option for landless farmers, agricultural workers and landlords. Landlords favour this system to save their land against "land-to-thetiller legislation" and return (net-income) from share-cropping was more or less similar to low-productive owner-operators. Landless share-croppers were engaged in several other works to strengthen their livelihood like tailors, agricultural workers, watchmen in the nearby factories, and construction workers. It shows that they don't have sufficient money to invest in intensified farming and for better opportunities outside farming. Rice farming is a strategy to strengthen their family food security for this group.

Besides the above-mentioned three farmers groups, at the end there were landless agricultural workers living in every village who are not farmers but work as workers for 
transplanting, weeding and harvesting of rice. Such agricultural workers are an important part of Nepalese farming. Skilful or trained labour force will be useful to increase crop productivity (or rice yield). But existing training priority of the government agriculture training program didn't involve such landless workers. Some programs are trying to include such landless labours in training and income generating agriculture activities (like Community Managed Irrigation Agriculture Support Project). However, most of the time landless workers were less willing to attain those agriculture trainings. To attain such training they need to trade off their daily earning (of training days because they didn't go for work) and their agriculture-labour-wage-rate is not dependent on training skill (every farm worker, whether trained or untrained, gets similar wage rate). Most of agricultural workers were female because male members were more engaged in the non-agriculture work (industry, construction work, rickshaw pullers, etc.). Training will be effective to increase the skill of landless labours but there should be especial allowance/compensation for them during their participation in agriculture training. Such trained workers can be organised in a group and they can work collectively for better earning as in several parts of south India and Punjab. This arrangement could improve the working situation of hired-labour-based farming and earning of the landless workers.

The main lesson to be drawn is, variation in occupations and strategies provide doable solutions to the farmers which are guided by various socio-economic factors. Farmers belong to the SRFO group have a strategy based on a wage-labour-based intensified rice farming strategy to fulfil their family food needs and use family labour in non-agriculture occupations where earning is more easy. In this way, they maximize their rice yield by incorporating SRI practices in their conventional rice farming and earn more money from non-agricultural work. MRFO farmers have more land and less labour. While their existing production is sufficient to fulfil their family needs, they don't bother to increase rice yield by use of expensive labourers. They follow conventional rice farming, profit-yielding double transplanting method and earn major income from outside. MRFT farmers are resource poor but have more family labour (as main production factor) so they choose family-labour-based intensive share-cropping (where landlord provides seeds and fertilisers at the beginning thereby creating no need of investment initially) as main strategy to sustain their livelihood. Last group LRFT farmers are more experienced and trained 
farmers, have more family labour and work in smaller land size. They choose intensive farming incorporating SRI practices in rice production and more profitable vegetables and cash crop production as their main strategy to improve their livelihood.

\subsection{Field management strategies}

In 2004 the System of Rice Intensification (SRI) was introduced in Morang district in an attempt to increase rice production. It was considered as a system that requires low external inputs, is cultivar-neutral, which therefore fits well with the existing conditions for resourcepoor farmers with scarcity of fertilisers who use a diversity of rice cultivars. The system was considered suitable for the majority of rice farmers. However, it did not take the different livelihood strategies, as analysed in Chapter 3, into account. I therefore did study both livelihood strategies of individuals farmers and the actual practices in their individual fields, as most farmers access more than one field for growing rice. I consider neither a method that classifies farmers as SRI or non-SRI farmers, nor a classification of rice fields as SRI or non-SRI fields, as inherently superior. It is by comparing both classification that a better perspective can be obtained on the realities of rice farming in the eastern terai, and the possibilities for intensification. A classification of rice farming practices in their fields led to recognition of three field management strategies, one of which partly fitted the description of SRI. While (modified) SRI-practices were observed in 18\% of the fields (belonging to around $30 \%$ of the households), I furthermore noted other forms of intensification in a further 7\% of the fields (but only in Indrapur). I observed that some farmers, who belonged to low-productive, non-intensifying livelihood strategies, still had at least one field where intensification took place. I also noted that only part of their fields fitted the description of management according to the principles of SRI. Only in $15 \%$ of the fields were SRI practices observed.

The second group of field management (OM) consisted of 33 plots (20\%) and in those plots top-dress by nitrogen fertiliser was not applied. Nutrients came through manure. The conventional management group (FM) contained 91 fields (55\%). This group practiced conventional rice farming using older seedlings, many seedlings per hill, close spacing, flooded irrigation and mineral fertilisers with topdressing without the use of manure. Because of the smaller field areas for more intensive practices, especially when management was 
according to the principles of SRI, the total area covered by intensified agriculture was $15 \%$ and the total field area covered by those practices $8 \%$.

While my study therefore seems to confirm that SRI methods can increase rice production, it is also evident that a straightforward application of SRI has limited use for intensification of rice cultivation in the terai. Apparently agro-ecological and socioeconomic factors (livelihood strategies, water reliability, land type, field distance from the residence, land ownership status, scarcity of labour or availability of family labour, and training) are major constraints for SRI. The requirements for intensive and time-bound management required for SRI cannot be fulfilled by them, and shortage of labour will keep them with extensive and low-productive forms of rice cultivation.

Variation in rice yield is very high due to variation of their field management. High productive fields used younger seedlings, fewer seedlings in wider spacing. They used nonBasmati and photo-insensitive cultivars, more organic matter and higher dose of chemical fertilisers. Seedling variables were influenced a lot by the land type and water availability. Farmers used younger seedling in upland fields where irrigation is reliable. In the waterscarce areas transplanting was uncertain and depended on the rainfall volume. So even with good knowledge and interest to use younger seedlings farmers were unable to apply it in rain-fed areas. Similarly in the swampy lowland farmers need to wait for the land preparation and transplanting until water level has gone down. Several times seedlings were washed away from the transplanted fields immediately after transplanting due to heavy rainfall. Sometimes farmers need to transplant such fields 2-3 times due to flood damage. Therefore many farmers transplant flood-prone fields with older seedlings, Basmati cultivars or double-transplanting method at the end of the monsoon (late July or August). These are some important agro-ecological hurdles for intensified rice farming methods like SRI.

In better irrigated area several farmers used modified SRI method and they were able to obtain good yields. There are several modifications/variations in the SRI method used by the farmers. Few farmers used all six practices (young seedlings, single seedling, wider spacing, AWD irrigation, mechanical weeding and use of manure) introduced at those areas in the beginning (Uprety 2011 and chapter 4). But majority of the SRI users used it in the parts of their fields which is suitable for the SRI (better irrigated upland). 
After having obtained experience with SRI during several seasons, farmers used fewer seedlings and wider spacing but they were less careful about straight lining and perfect square patterns of transplanting. Farmers reported that straight line and square pattern are useful for the mechanical weeder but not necessary for the manual weeding. Main changes observed in the study areas after SRI introduction are use of younger seedlings, fewer seedlings, wider spacing, AWD irrigation and use of combined (manure and mineral fertilisers) nutrient management. Weed management was a less prioritised practice in the majority of fields. It might be due to scarcity of labour. It seems some farmers also lack knowledge about appropriate weed management.

Mechanical weeding was considered the best method of weed management for higher yield and labour saving but its use was limited. Most of the farmers complained about the efficiency of locally fabricated weeders. It was very heavy and therefore was in need of powerful (male) labour to operate it. Only a few farmers prepared their own weeders and used it effectively. It is therefore important to improve the efficiency of mechanical weeder and to make it labour-friendly (mostly for female workers) in order to increase the use of mechanical weeding and hence rice yield, while at the same time saving labour.

The overall insight taken from here is that the rice fields with unreliable water supply and fields in swampy lowland are not suitable for the intensive and time-bound management, as required for SRI. Farmers do not use SRI methods in rented land (under share-cropping) and in those fields that are far from their homes. Almost all fields under SRI cultivation are therefore privately owned land, close to the residence and with reliable water supply. In order to apply SRI, farmers need sufficient (family) labour; the alternative would be to use more trained labour for SRI. Big farmers are generally not interested to use SRI methods.

\subsection{Linking livelihood strategies with crop management strategies}

Livelihood and crop management strategies by rice farmers are interconnected. Livelihood strategies are more family resource-based strategies while field management strategies are more context-dependent. Relevant elements of this context include ownership of the land (tenure status), distance to the residence, availability of good irrigation practices, and using 
manure as fuel for cooking. Due to the wide diversity in agro-ecological conditions, it is evident that there is not one single solution that would fit all farmers and all fields. A single format for intensification is therefore not a good starting point for a general intensification strategy. SRI is more of a choice appropriate for local situations, and this location specificity includes both the agro-ecological and socio-economic context. Farmers try to modify or re-shape new technologies and incorporate appropriate parts of it to suit their situation, referred to in chapter 1 as a combination of social and environmental learning. The poor correlations between fertiliser use (especially nitrogen use) and yield indicate low fertiliser use efficiency (see Chapter 5 for an extended discussion).It depends on their livelihood strategies (investment of family labour within and outside agriculture) whether farmers have an interest in labour-intensive technologies that increase yields.

The introduction of SRI in Morang district resulted in several changes in rice farming, many farmers incorporated part of SRI practices in their conventional practices. Current rice growing practices in Morang district can therefore be described as hybrid practices (Richards 2010; Uprety 2013), conforming neither to the concept of conventional practice nor to the ideal type of SRI. Therefore, if SRI is promoted as a copy-paste practice type of intervention, it is bound to remain ineffective, not different from earlier attempts to introduce context-independent practices. In order to reform Nepalese rice farming we need to recognize that different farmers, with different livelihood strategies and with access to different kinds of fields, need different forms for agricultural intensifications.

\subsection{Fertiliser use}

Manure and fertilisers combination produced higher average yields than use of manure and fertilisers separately. It shows complementary effect of manure and fertilisers. Manure may improve soil structure and supplement parts of nutrients to the plants and mineral fertilisers supply required nutrients in bulk quantity for quick response. But use of manure or vegetable amendments was limited because some farmers use animal dung as fuel (see chapters 2 and 5). It was more common among the terai indigenous community. But majority of the hill migrants used most of their manure in their fields. Majority of hill migrant families had bio-gas plants for energy supply to their kitchen. So they used the biogas slurry for the manure making or used directly in the fields. 
Manure use in the study areas is influenced by different factors like its availability (after use as fuel for many families), field distance, land ownership and intended crops and its expected return. In the past almost all farm families had bullock carts for the transportation of manure to the fields and farm produce to the residence. But currently the number of bullock carts is only around $10-15 \%$ of what it used to be. After the increase in the number of tractors (making transportation easy) and a decrease grazing area (due to the increased cropping intensity of cultivated land, leaving less land as fallow for grazing animals) people started to keep less bullocks (use of bullock is restricted to a limited period of time during land preparation and transportation while there is a need to care for it during the whole year, which is very costly). This situation affects manure transportation and its use severely. Further farmers used manure more on vegetable fields and high-value spices crop like garlic and onion especially in Tharu community. Some farmers use green-manuring crop like Dhaincha (Sesbaniaaculeata) to improve their soil organic matter status and supplement nitrogen (Ladha et al. 1992; Choudhury and Kennedy 2004). But the use of green-manure crops is also limited to better irrigated areas for its proper decomposition before rice transplanting.

Non-judicious application of fertilisers was another remarkable observation and findings in Nepalese rice farming (chapter 4 and 5). Some farmers used nitrogen fertilisers one to two weeks before weeding (less useful for rice growth and development) to promote weed growth. Such use of nitrogen fertiliser was observed in low-productive fields, especially within terai-indigenous communities. Similarly some other farmers used nitrogen (mostly urea) fertilisers at flowering stage, which is also not useful to increase rice production. But high-productive farmers use fertilisers more efficiently, in combination with organic manure at tillering and panicle initiation stages. But even in those fields there was no correlation between rice yield and fertiliser and manure use in the main growing season. Fertiliser and manure use in swampy lowland is not very effective, due to the short vegetative period of older seedlings and double-transplanted rice plants (double-transplanted plants don't tiller much and their vegetative growth time is very short). The application of mineral fertilisers was more judicious among trained farmers.

Fertiliser volume and the time of its use were also influenced by fertiliser availability (supply system) and its price. Because the formal system supplies only one third of farmer 
demand, the remainder of the fertilisers came from informal ways from the Indian open border. However, such supply was uncertain. To improve appropriate use (type, volume and time) of mineral fertilisers, it is necessary to reform the current supply system. For that arrangement it is necessary to provide sufficient subsidies for required fertilisers (as in Indian border) and to open the market for competitive suppliers (both from the public and private sphere), for timely supply of fertilisers. Use of organic manure will be useful to improve the nutrient management situation of the rice farmers in Nepal.

These insights give an answer to research question no. 4 regarding farmers' nutrient management strategy as influenced by several factors. In my study area, inadequate knowledge of efficient nutrient management, unavailability of mineral fertilisers and manure (by use as fuel)and profit from products has been found as most important factors influencing nutrient management practices of rice growers in Nepal.

\subsection{Water availability and reliability and management}

Water availability strongly influenced land preparation and transplanting. Water availability, and, even more so, water reliability depended on the volume of water in the canals and its proper management. Farmer-managed small irrigation systems were more efficient for water distribution than public-managed big irrigation systems. My results show that it is imperative to reform the existing water management and distribution system to improve water reliability. Improper canal maintenance and its distribution system was the main problem why water could not be delivered to the majority of the fields managed by the public-managed irrigation system. This decreased reliability of water supply and most of the time farmers did not have the information about water availability schedule of irrigation canals which affected their planning.

To improve water management and its distribution, the government of Nepal emphasised to involve water users associations (WUA) in management committees, and to handover the management of several irrigation systems to WUA (DOI 2004; Howarth et al. 2012; Pradhan 2012).Because of the existence of double-management systems (repair and maintenance of the main canal and the secondary and tertiary canals by the government department and WUA), it is still insufficient to improve the water distribution system and its reliability in public-managed big irrigation systems. In small irrigation systems all decisions 
were taken at local level, so local water users associations can manage water distribution according to local needs. Achieving the same result was difficult in larger irrigation systems, due to the larger command areas, insufficient water supply, and centralised decision-making system. Water supply therefore has a direct effect on the options for intensification, including options to apply SRI.

As a reply, to research question no. five, we can wrap up by concluding that we can enhance crop intensity and productivity of agriculture by improving reliability of irrigation. It could be achieved by involvement of farmers/water users in decision-making processes (water scheduling) and better repair and maintenance of irrigation canals.

\subsection{Rice cultivars}

Rice farmers use a number of different rice cultivars as part of their strategy to respond to the diversity of agro-ecological and socio-economic conditions, trying to fit cultivar choice in their livelihood and crop management strategies. I recognise three broad groups of rice cultivars: (1) improved cultivars recommended by the official system; (2) local and improved cultivars that are not recommended and approved by the official system but that have spread through farmer-to-farmer networks; (3) Basmati cultivars. I demonstrated that farmers use selected and recommended rice cultivars (Chaite 2 and Hardinath 1) during spring season, when there is assured irrigation facility and when agro-ecological conditions are relatively uniform. In the main season, the majority of farmer fields were covered by non-recommended rice cultivars. The reason for this apparent mismatch is found in the criteria for cultivar selection. Whereas the official system assesses rice cultivars for its productivity, especially under conditions of good water supply and with ample availability of mineral fertilisers, farmers use a wider set of criteria. These include yield stability (the ability to also produce sufficient grain under less favourable conditions - see Ghritlahre and Sarial (2011) for a comparison for yield stability of different cultivars under SRI and conventional production systems), plant height and the volume of straw (for fodder), cooking quality and market prices. Finally several farmers use Basmati cultivars, which, despite their low yield, are much prised. Because of high prices it seems there is a distinct socio-economic niche (Ojiem et al. 2006; Sthapit et al. 2008) for Basmati.

A further criterion for farmer choice is the duration of the crop, as this directly 
translates into the number of possible harvests per year (an important determinant of livelihood strategies, see Chapter 3) and hence into possibilities for intensification. Farmers prefer medium to tall cultivars during the main season, but in spring they prefer shortduration and dwarf cultivars. Basmati cultivars and the double-transplanting method of rice cultivation were popular among the Tharu community. The choice for such cultivars seems the best option under conditions where there is a risk that transplanting becomes delayed. Therefore, Basmati cultivars and the double-transplanting method were not common among intensive and productive farmers.

Basmati cultivars and the double-transplanting method of rice cultivation were popular among the Tharu community. The choice for such cultivars seems the best option under conditions where there is a risk that transplanting becomes delayed especially in the rain-fed and swampy lowland. Basmaties are long-duration but photo-sensitive cultivars, they were low-productive but high-priced (Table 7.4), so net return of Basmati cultivar is more or less similar to medium to high-productive cultivars. But its harvesting time is at the end of November so farmers who used their land more intensively or for vegetable cultivation didn't use Basmati. Similarly those small and marginal farmers who cultivate rice for home consumption didn't use Basmati due to its low production (volume). Therefore, Basmati cultivars and the double-transplanting method were not common among intensive and productive farmers.

A large rice areas was covered by the non-recommended rice cultivars in Morang district. Only $22 \%$ areas were covered by the recommended (by national research system) cultivars and the coverage of the Basmati cultivar was about $3 \%$. This result shows that cultivar selection criteria of the scientist and the farmers are quite different (Chapter 7). Therefore involvement of the rice farmers in the cultivar selection process will be useful to select and recommend appropriate cultivars. But the situation in the spring season was different, when farmers used few cultivars and most of them were recommended. It shows that in the better irrigated (less vulnerable working situation) area recommended cultivars performed better with good management system and its adoption rate will be high. This result confirmed the findings of Upadhyaya et al. (1993).

Regarding the final research question, here the diversity of cultivars is necessary to utilize available agro-ecological situations (like long duration and photo-sensitive cultivar 
for double transplanting and late planting)and fulfil socio-cultural (Anadi is a valuable during Tharu festival) and socio-economic needs (double transplanting of Basmati needs less fertilisers but give more profit for wealthy farmers). Farmers know their situations and needs better than outsider/scientist so their variety choice is appropriate for their situation. In this context, participatory variety selection approach would be useful to introduce new varieties.

\subsection{Conclusion and suggestions for further research}

Rice demand has been increasing year after year in Nepal because of population growth, improving accessibility of rice in the different geographical areas of the country due to improving road network and transportation facility, purchasing power of the people by nonagricultural income. That's why government priority is on more production of rice and other food crops by increased crop productivity. But the priorities of the farmers are changing because of low profit margin of rice farming, which resulted in decreases of national rice production year after year due to high production cost and low productivity. In the meantime there are several other livelihood options available for better income. So the majority of the farmers keep their cereal-based conventional farming only for food security of the family and diversify their occupations (vegetable farming and non-agricultural occupations). Foreign employment (remittance) has become and remains a very important source of income for the majority of the rural-farmer families. Remittances affect farmer families in two ways. Some families use remittances to invest in (to purchase) cultivated land, while other families use the remittance to leave agriculture.

Profitable production and its sustainability are the key issues of agricultural intensification in Nepal. Rice is the main staple food and growing rice is the only possible crop during rainy season in most of the terai areas. Its demand has been increasing every year but the average yield in the majority of fields is low. During my study, I found that yield of most SRI and modified SRI fields was significantly higher with similar production costs. It shows that SRI can be useful to increase profit of rice farming. In other ways, an orientation towards intensification improves nutrient management of rice farming and increases the use of manures. Similarly, SRI interventions make farmers more experimental and thereby farmers try SRI in different ways according to their socio-economic and agro- 
ecological situation. Few farmers used complete SRI package but many other incorporated suitable parts in their conventional rice farming thereby increasing production as well as intensifying their farming. In this way, SRI intervention plays a creative role to intensify agriculture in Nepal.

To increase the productivity and production of rice, SRI was effective but it wasn't suitable for all farmers and agro-ecological conditions. Another important finding is related with partial adoption and variations of the SRI. It was observed that farmers tested and tried to re-shape any new technology according to their agro-ecological and socio-economic situations. They choose doable part of any package of practices/technology for their regular use. High-intensive farmers preferred to use modified SRI methods where there is good irrigation and drainage facility. But most of the big farmers who depend on hired labour were not interested in SRI. Therefore the medium to small farmers those have suitable land, reliable irrigation facility and more family labour for farm work will be the main target for SRI.

Extension agencies need to facilitate (not teach) technology dissemination process in order to provide all possibilities and alternatives of improvement. However, our existing extension system is still guided by conventional methods and farmers are treated as passive recipients of technology delivered by extension workers (source of information). We were working in same manner; however during initial days of SRI testing and dissemination, we took SRI as a fixed package of practice. Later, DADO Morang received Nepal Development Marketplace Award 2005 for SRI promotion and we worked intensively. Introduction of SRI during the DADO training sessions helped both farmers and extension workers to learn from the rice fields as well as from each other. Extension workers saw that their own recommendations were not followed, and started a process of reviewing the techniques with the farmers. This broke the traditional one-way-delivered recipient system of learning. After joint trials and learnings, mutual interactions became more common. Such interactions helped to re-shape the general recommendations of the extension staff. When DADO began making recommendations based on farmers' suggestions, other farmers became more interested in testing and disseminating the new approaches (Uprety 2013a), resulting in the availability of several hybrid-SRI (Uprety 2013b) which are more doable in diversified situations. 
There is a lot of possibility for improvement of the existing nutrient management practices of rice farmers in Nepal. Nutrient management will be useful to increase rice production but the majority of the farmers use fertilisers non-judiciously. Two things will be important to improve nutrient management. One is to strengthen the fertiliser supply mechanism and another is to provide intensive regular training on nutrient management. SRI package (younger seedling, early weeding, use of organic manure and AWD irrigation) will be useful to improve the nutrient use efficiency of rice farmers. But the training package should be designed according to local need; it should focus on appropriate farmers because training is not useful for all type farmers.

Improving water distribution systems and maintaining its reliability will be a positive intervention to improve cropping intensity of irrigated land, rice productivity and technology dissemination. In the current situation cultivar diversity and diversification in cultivation methods are essential components of rice farming to capture possibilities of the diverse agro-ecological and socio-economic conditions, especially in the countries like Nepal where the majority of rice farming is still rain-fed.

Cost-reduction strategies and less-labour-intensive cultivation practices will be appropriate options to improve existing rice farming system of Nepal. Mechanisation especially for land preparation (male-dependent work) will be a better option for the cost reduction and labour saving. Participatory cultivar selection and dissemination will be better strategies to introduce new promising rice cultivars among rice farmers. Currently the majority of the cultivars used by the farmers in the study areas are non-recommended and disseminated by farmers to farmers. It shows farmers will be the best selector of the cultivars, suitable for their land and their socio-economic condition.

Finally, this study was conducted in a limited area and in a limited time for the specific objectives. It wasn't sufficient to understand all causes and consequences of rice farming of Nepal. Therefore further study should cover wider geographical areas and focus on several other unexplained variables like effect of farmers networking, credit support, and marketing. These new studies will be essential to understand in-depth dynamics of rice farming system of Nepal and the options for intensification. 


\section{References}

ABTRACO (2008). Country report on the state of plant genetic resources for food and agriculture. Anamnagar, Kathmandu.

http://www.fao.org/docrep/013/i1500e/Nepal.pdf - accessed 13.10.2015.

Agricultural Projects Services Centre and John Mellor Associates (1995). Nepal Agriculture Perspective Plan Main Document (Final Report). http://lib.icimod.org/record/4168/files/APROSC\%20Nepalagricultureperspect iveplan630AGN.pdf - accessed 13.10.2015

Agriculture Diary (2011). Published by Agriculture Information and Communication Center, Ministry of Agriculture Development, Hariharbhawan, Lalitpur, Nepal.

Ahmad, A., S.R. Perret, R. Nawaz and G.P. Shivakoti (2012). Relationships between farm size and operational performances in irrigated cropping systems under contrasted governance systems in Punjab (Pakistan). Journal of Food, Agriculture and Environment 10: 463-467.

Angood, C., F. Chancellor, N. Hasnip, J. Morrison and L. Smith (2002). Contribution of Irrigation to Sustaining Rural Livelihoods: Nepal case study, Report OD/TN 113, Wallingford: HR Wallingford Ltd. http://books.hrwallingford.co.uk/acatalog/od_downloads/odtn113.pdf accessed 13.10.2015

Anitha, S. and M. Chellappan (2011). Comparison of the system of rice intensification (SRI), recommended practices, and farmers' methods of rice (Oryza sativa L.) production in the humid tropics of Kerala, India. Journal of Tropical Agriculture 49(1-2): 64-71.

Anthofer, J. (2004). The potential of the System of Rice Intensification (SRI) for poverty reduction in Cambodia. Paper presented at the 2004 Deutscher Tropentag, Berlin. http://www.tropentag.de/2004/abstracts/full/399.pdf accessed 11.10.2015.

ANZDEC (2002). Nepal: Agriculture sector performance review (ADB TA No.3536-NEP), main report prepared for MOAC and Asian Development Bank. ANZDEC Limited: New Zealand. http://www.moadwto.gov.np/downloadfile/finalreport_vol1_1322220998.pdf - accessed 13.10.2015

APMDD (2014). Cost of production and marketing margin of cereal, cash, vegatable and spices crops in Nepal (2013/14). Agribusiness Promotion and Marketing Development Directorate, Department of Agriculture, Hariharbhawan, Lalitpur, Nepal.

Aveno, J.L., T.T. Battad, M.E.M. Orden and A.S. Paderes (2006). Impact Assessment of Philrice Season-Long Rice Specialists Training Courses (RSTC). Research paper published at Socio-economic research portal for the Philippines.

http://serp- 
.pids.gov.ph/details.php?pid=4397andparam=Aveno\%2C+Jocelyn+L.accessed 13.10.2015

Awotide, B.A., A. Diagne, A.N. Wiredu, Alexander and V.E. Ojehomon (2012) Wealth status and agricultural technology adoption among smallholder rice farmers in Nigeria. International Journal of Sustainable Development, Vol. 5(2): 97-108.

Awotide, B.A., A.D. Alene, T. Abdoulaye and V.M. Manyong (2015). Impact of agricultural technology adoption on asset ownership: the case of improved cassava varieties in Nigeria. Food Security (in press), DOI 10.1007/s12571015-0500-7.

Bajracharya, J., R.B. rana, D. Gauchan, B.R. Sthapit, D.I. Jarvis and J.R. Witcome (2010). Rice landrace diversity in Nepal. Socio-economic and ecological factors determining rice landrace diversity in three agro-ecozones of Nepal based on farm surveys. Genetic Resources and Crop Evolution 57: 1013-1022.

Barah, B.C. (2010). System of Rice Intensification (SRI): Economic and ecological benefits of improved production practice for food security and resource conservation. https://hal.archives-ouvertes.fr/hal-00532992/document accessed 13.10.2015.

Barison, J. (1997). Perspective de développement de la région de Ranomafana: Les mecanismes physiologiques du riz sur sols de basfonds, Cas du Système de Riziculture Intensive [Development perspective for the Ranomafana region: The physiological mechanisms of rice on irrigated soils, The case of the System of Rice Intensification]. Promotion Sedra dissertation, Department of Agriculture, Faculty of Agronomy, University of Antananarivo.

Barison, J. (2003). Nutrient-use efficiency and nutrient uptake in conventional and intensive (SRI) rice cultivation system in Madagascar. Master thesis, Department of Crop and Soil Science, Cornell University, Ithaca NY, USA.

Barker R., R.W. Herdt and B. Rose. (1985). The Rice Economy of Asia. Resources for the Future. Washington, D.C.

Barrett, C.B., C.M. Moser, O.V. McHugh and J. Barison (2004). Better technology, better plots, or better farmers? Identifying changes in productivity and risk among Malagasy rice farmers. American Journal of Agricultural Economics 86: 869-888.

Basu, S. and C. Leeuwis (2012). Understanding the raid spread of System of Rice Intensification (SRI) in Andhra Pradesh: exploring the building of support networks and media representation. Agricultural Systems 111: 34-44.

Belay A., A. Claassens and F. Wehner (2002). Effect of direct nitrogen and potassium and residual phosphorus fertilisers on soil chemical properties, microbial components and maize yield under long-term crop rotation. Biology and Fertility of Soils 35:420-427.

Belder, P., B.A.M. Bouman, R. Cabangon, L. Guoan, E.J.P. Quilang, Y. Li, J.H.J. Spiertz and T.P. Tuong (2004). Effect of water-saving irrigation on rice yield 
and water use in typical lowland conditions in Asia. Agricultural Water Management 65: 193-210.

Belder, P., J.H.J. Spiertz, B.A.M. Bouman, G. Lu and T.P. Tuong (2005). Nitrogen economy and water productivity of lowland rice under water-saving irrigation. Field Crops Research 93: 169-185.

Bellon, M.R. (2001). Participatory Research Methods for Technology Evaluation: A Manual for Scientists Working with Farmers; CIMMYT, Mexico. http://libcatalog.cimmyt.org/download/cim/74275.pdf - accessed 13.10.2015.

Berkhout, E. and D. Glover (2011). The Evolution of the System of Rice Intensification as a Socio-Technical Phenomenon: A Report to the Bill and Melinda Gates Foundation; 205 pp.

Berkhout, E., D. Glover and A. Kuyvenhoven (2015). On-farm impact of the System of Rice Intensification (SRI): Evidence and knowledge gaps. Agricultural Systems 132: 157-166.

Bhandari B. (2011). Cheaper Indian paddy draws Nepali traders. www.ekantipur.com/2011/10/10/headlines/Cheaper-Indian-paddy-drawsNepalitraders/341964. Accessed 21 November 2011.FAO Food Security Information

Bhandari, A.L. J.K. Ladha, H. Pathak, A.T. Padre, D. Dawe and R.K. Gupta (2002). Yield and soil nutrient changes in long-term rice-wheat rotation in India. Soil Science Society of America Journal 66: 162-170.

Bhandari, B. (2007). India stops rice export to Nepal: Problems in rice supply for Bhutanese refugee. Kantipur National Daily, 27 October, Kathmandu.

Bhatta M.R. and J. Tripathi (2005). On-station and on-farm studies of System on Rice Intensification (SRI). Paper presented in the SRI Workshop, organised by ICIMOD, 19 December, Kathmandu. http://sri.ciifad.cornell.edu/countries/nepal/icimod/icrupandehi.pdf - accessed 13.10.2015

Bhattacharyya P., A. Chakraborty, B. Bhattacharyya and K. Chakrabarti (2003). Evaluation of MSW manure as a component of integrated nutrient management in wetland rice. Manure Science and Utilisation 11(4): 343-350.

Bhattarai D. (1998). Panoramic indicators of Nepalese agriculture. Tribhuvan University Journal, 21: 69-77. http://www.nepjol.info/index.php/TUJ/article/view/4579/3801 - accessed 13.10.2015.

Bhusal, L.N. and P. Singh (2011). Externally Determined Development: Does IndoChina Rivalry Explain Nepal's Underdevelopment? Millennial Asia 2(2): 163-186.

Biggs, S. (2008). Learning from the positive to reduce rural poverty and increase social justice: institutional innovations in agricultural and natural resources research and development. Experimental Agriculture 44: 37-60. 
Bindraban, P.S., H. Hengstdijk, W. Cao, Q. Shi, T.M. Thiyagarajan, W. Van Der Krogt and P.I. Wardana (2006). Transforming inundated rice cultivation. International Journal of Water Resources Development 22: 87-100.

Bohra, P. and D.S. Massey (2009). Processes of internal and international migration from Chitwan, Nepal. International Migration Review 43: 621-651.

Boling, A., T.P. Tuong, S.Y. Jatmika and M.A. Burac (2004). Yield constraints of rainfed lowland rice in Central Java, Indonesia. Field Crops Research 90: 351-360.

Boserup, E. (1965). The conditions of agricultural growth: the economics of agrarian change under population pressure. London: Allen and Unwin.

Bouman, B.A.M., E. Humphreys, T.P. Tuong and R. Barker (2006). Rice and water. Advances in Agronomy 92: 187-237.

Bray, F. (1994). The rice economies. Technology and development in Asian societies. University of California Press.

Brookfield, H. (2001). Exploring agrobiodiversity. Columbia University press, New York, USA.

Brown, S. and B. Shrestha (2000) Market-driven land use dynamics in the middle mountains of Nepal. Journal of Environmental Management 59 (3): 217-225.

Brown, S. and G. Kennedy (2005). A case study of cash cropping in Nepal: Poverty alleviation or inequity. Agriculture and Human Values 22: 105-116.

Cassman, K.G. and A. Dobermann (2001). Evolving rice production systems to meet global demand. In: Rice Research and Production in the 21st Century: Proceedings of a Symposium Honoring Robert F. Chandler Jr., 15-16 June 2000, International Rice Research Institute, Manila. Cornell University Press, Ithaca, NY, pp. 79-100.

Cassman, K.G. and P.L. Pingali (1995). Extrapolating trends from long-term experiments to farmers fields: the case of irrigated rice systems in Asia. In: Barnett, V., Payne, R., Steiner, R. (Eds.), Agricultural Sustainability in Economic, Environmental, and Statistical Terms. Wiley, London, pp. 64-84.

Cassman, K.G., S. Peng and A. Dobermann (1997). Nutritional physiology of the rice plant and productivity decline of irrigated lowland rice systems in the tropics. Soil Science and Plant Nutrition 43: 1111-1116.

CBS (1993). National Sample Census of Agricultural (1991/92) Central Bureau of Statistics, Kathmandu, Nepal.

CBS (1997). Nepal Living Standard Survey Report 1996 (Volume I and II), Central Bureau of Statistics, Kathmandu, Nepal.

CBS (2002). National Sample Census of Agricultural (2001/02) Central Bureau of Statistics, Kathmandu, Nepal.

CBS (2006). Monograph Agriculture Census Nepal, 2001/02. Kathmandu: CBS. http://cbs.gov.np/nada/index.php/catalog/8 - accessed 13.10.2015

Ceesay, M., W.S. Reid, E.C.M. Fernandes and N.T. Uphoff (2006). The effects of repeated soil wetting and drying on lowland rice yield with System of Rice 
Intensification (SRI) methods. International Journal of Agricultural Sustainability 4: 5-14.

Chapagain, D. (2000).Land tenure and poverty: Status and trends in land systems in the hills and mountains of Nepal. In: M. Banskota, T. S. Papola and J. Richter (eds.), Growth, Poverty Alleviation and Sustainable Resource Management in the Mountain Areas of South Asia, p. 407-432. Proceedings of the International Conference held from 31 January - 4 February 2000 in Kathmandu, Nepal. ZEL, Feldafing.

Chikowo, R., S. Zingore, S. Snapp and A. Johnston (2014). Farm typologies, soil fertility variability and nutrient management in smallholder farming in SubSaharan Africa (Review). Nutrient Cycling in Agroecosystems 100: 1-18.

Choudhury, A.T.M.A. and I.R. Kennedy (2004). Prospects and potentials for systems of biological nitrogen fixation in sustainable rice production. Biology and Fertility of Soils 39: 219-227.

CSRC (2009). Land and Land Tenure Security in Nepal (Country Study: Nepal). Community Self Reliance Centre (CSRC). Kathmandu, Nepal.

DADO (2008). Annual Progress Report 2008. District Agriculture Development Office, Morang, Nepal.

DADO (2010). Annual Progress Report 2009/10. District Agriculture Development Office, Morang, Nepal.

DADO (2012). Annual Progress Report 2011/12. District Agriculture Development Office, Morang, Nepal.

Dahal H. (2010). National Agriculture Extension System: A country report-Nepal presented in the workshop on Rural Development for high-level officers of AFACI members' countries held on August 7-14, in Suwon, Republic of Korea.

Dahal, B.M., I. Nyborg, B.K. Sitaula and R.M. Bajracharya (2009). Agricultural intensification: food insecurity to income security in a mid-hill watershed of Nepal. International Journal of Agricultural Sustainability 7: 249-260.

Dahal, K.R. (2014). System of Rice Intensification (SRI): A Potential Approach to Enhance Rice Productivity and Food Security. Journal of Forest and Livelihood 12(1): 75-81.

Darlington, R.B. (2012). Factor Analysis. http://www.psych.cornell.edu/Darlington/factor.htm (accessed on 23.2012)

Dawe, D. and A. Dobermann (1999). Defining productivity and yield. IRRI Discussion Papers Series No. 33. International Rice Research Institute, Makati City, Philippines.

De Laulanié, H. (1993). Le système de riziculture intensive Malgache [The Malagasy system of intensive riziculture], Tropicultura 11: 1-19.

De Laulanié, H. (2003). Le Riz à Madagascar: Un développement en dialogue avec les paysans [Rice in Madagascar: A development in dialogue with the peasants], Antananarivo, MG: Editions Ambozontany/Editions Karthala. 
Deb, D., J. Lässig and M. Kloft (2012). A critical assessment of the importance of seedling age in the System of Rice Intensification (SRI) in eastern India. Experimental Agriculture 48: 326-346.

Deshingkar P. and E. Anderson (2004). People on move: new policy challenges for increasingly mobile populations. DFID, The Overseas Development Institute, London, UK. $\quad$ http://www.odi.org/sites/odi.org.uk/files/odiassets/publications-opinion-files/72.pdf - accessed 13.10.2015

Dhakal M.P. (2005).Farmers' evaluation of the System of Rice Intensification in the middle mountains of Nepal.System of Rice Intensification. Article for People and Resource Dynamics in Mountain Watersheds of the HKH (PARDYP) /International Centre for Integrated Mountain Development (ICIMOD), Khumaltar, Kathmandu, Nepal. http://sri.ciifad.cornell.edu/countries/nepal/neppardyp05.pdf $\quad-\quad$ accessed 13.10 .2015

Dhital, R. (2004). Rural Urban Agriculture Market System: Challenges and Opportunities - A Case Study: Eastern Nepal. MSc thesis, Yale University.

Dhungana, B.R., P.L. Nuthall and G.V. Nartea. (2004) Measuring the economic inefficiency of Nepalese rice farms using data envelopment analysis. Australian Journal of Agricultural and Resource Economics 48(2): 347-369.

Dixit, Kunda. 2005. The miracle is it's no miracle. Nepali Times, July 15 - 21, Nation section, Issue 256.

Dobermann, A. (2000). Future intensification of irrigated rice systems. In: Sheehy, J.E., Mitchell, P.L., Hardy, B. (Eds.), Redesigning Rice Photosynthesis to Increase Yield. International Rice Research Institute/Elsevier, Makati City, Philippines/Amsterdam, pp. 229-247.

Dobermann, A. (2004). A critical assessment of the system of rice intensification (SRI). Agricultural Systems 79: 261-281.

Dobermann, A., C. Witt, D. Dawe, S. Abdulrachman, H.C. Gines, R. Nagarajan, S. Satawathananont, T.T. Son, P.S. Tan, G.H. Wang, N.V. Chien, V.T.K. Thoa, C.V. Phung, P. Stalin, P. Muthukrishnan, V. Ravi, M. Babu, S. Chatuporn, J. Sookthongsa, Q. Sun, R. Fu, G.C. Simbahanand M.A.A. Adviento(2002). Site-specific nutrient management for intensive rice cropping systems in Asia. Field Crops Research 74: 37-66.

Dobermann, A., K.G. Cassman, C.P. Mamaril and J.E. Sheehy. (1998). Management of phosphorus, potassium and sulfur in intensive, irrigated lowland rice. Field Crops Research 56: 113-138.

DOI (2004). Irrigation policy-2060. Department of Irrigation, Nepal. http://www.doi.gov.np/pdf/policy/Irrigation\%20Policy\%202060\%20$\% 20$ English\%20Final.pdf

DOI (2007). Development of database for irrigation development in Nepal. Department of Irrigation (DOI), Nepal. 
http://www.doi.gov.np/pdf/irrigation/Irrigation\%20Database\%20Final\%20Re port.pdf - accessed 13.10.2015

Dorward, A. (2009). Integrating contested aspirations, processes and policy: development as hanging in, stepping up and stepping out. Development Policy Review 27(2): 131-146.

Ellis, F. (2007). Rural livelihood diversity in developing countries: evidence and policy implications. ODI Natural Resources Perspectives 40: 1-10. http://www.odi.org/sites/odi.org.uk/files/odi-assets/publications-opinionfiles/2881.pdf accessed 13.10.2015

Eneji A.E., S. Yamamoto and T. Honna (2001). Rice growth and nutrient uptake as affected by livestock manure in four Japanese soils. Journal of Plant Nutrition 24: 333-343.

Fabrigar, L.R., R.C. MacCallum, D.T. Wegener and E.J. Strahan (1999). Evaluating the use of exploratory factor analysis in psychological research. Psychological Methods 4: 272-299.

Fageria, N.K. (2001). Nutrient management for improving upland rice productivity and sustainability. Communications in Soil Science and Plant Analysis 32: 2603-2629.

FAO (2010). Agricultural Extension Services Delivery System in Nepal. ftp://ftp.fao.org/OSD/CPF/Country\%20NMTPF/Nepal/AgExtServDelSysNep al.pdf - accessed 13.10.2015

Farooq, M., N. Kobayashi, A. Wahid, O. Ito and S.M.A. Basra (2009). Strategies for producing more rice with less water. Advances in Agronomy 101: 351-388.

Franke, A.C., G.J. Van den Brand and K.E. Giller (2014). Which farmers benefit most from sustainable intensification? An ex-ante impact assessment of expanding grain legume production in Malawi. European Journal of Agronomy 58: 28-38.

Gairhe J (2005). System of Rice Intensification: Researcher to farmers -- An adaptive perspective view of Nepal. Paper presented in the SRI Workshop, organised by ICIMOD, 19 December, Kathmandu.

Gale, E.S., D.M. Sullivan, C.G. Cogger, A.I. Bary, D.D. Hemphill and E.A. Myhre (2006). Estimating plant-available nitrogen release from manures, composts, and specialty products. Journal of environmental Quality 35: 2321-2332.

Gami, S.K., J.K. Ladha, H. Pathak, M.P. Shah, E. Pasuquin, S.P. Pandey, P.R. Hobbs, D. Joshy and R. Mishra (2001) Long-term changes in yield and soil fertility in a twenty-year rice-wheat experiment in Nepal. Biology and Fertility of Soils 34: 73-78.

Gartaula, H.N., A. Niehof and L. Visser (2010). Feminisation of Agriculture as an Effect of Male Out-migration: Unexpected Outcomes from Jhapa District, Eastern Nepal. International Journal of Interdisciplinary Social Sciences 5(2): 565-577. 
Gartaula, H., A. Niehof and L. Visser (2012). Shifting perceptions of food security and land in the context of labour out-migration in rural Nepal. Food Security 41: 181-194.

Gautam, D.D. and G.P. Kovala (2005). System of Rice Intensification (SRI). Paper presented in the SRI Workshop, organised by ICIMOD, 19 December, Kathmandu.

Ghritlahre, S.K. and A.K. Sarial (2011). G x E interaction and adaptability of rice cultivars in SRI and normal production systems. Cereal Research Communications 39: 589-597.

Glover, D. (2011a). Science, practice and the System of Rice Intensification in Indian agriculture. Food Policy 36: 749-755.

Glover, D. (2011b). The System of Rice Intensification: time for an empirical turn. NJAS - Wageningen Journal of Life Sciences 57: 217-224.

Glover, D. (2014). Of yield gaps and yield ceilings: making plants grow in particular places. Geoforum 53: 184-194.

Goodrich, C.G., S. Justice, S. Biggs and G. Sah (2008). Participatory technology development $\mathrm{i}$ agricultural mechanisation in Nepal: how it happened and lessons learned. Development in Practice 18: 643-649.

Griffin, K. (1976). The political economy of agrarian change: an essay on the Green Revolution, Macmillan, London.

Grunig, J.E. (1971). Communication and the economic decision-making processes of Colombian peasant. Economic Development and Cultural Change 19 (4): 580-597.

Gumma, M.K., D. Gauchan, A. Nelson, S. Pandey and A. Rala (2011). Temporal changes in rice-growing area and their impact on livelihood over a decade: a case study of Nepal. Agriculture, Ecosystems and Environment 142: 382-392.

Gurung, H. et al. (1983). Internal and International Migration in Nepal (in Nepali) (Kathmandu: National commission on Population).

Haefele S.M., G. Atlin and S.P. Johnson (2004). Improving farmers' livelihood in rain-fed rice-based lowland of Asia. IRRI, Metro Manila, Philippines. www.tropentag.de/2004/abstracts/full/128.pdf - accessed 13.10.2015

Haefele, S.M., G. Atlin, S.P. Kam and D.E. Johnson (2005). Improving farmers' livelihood in rainfed rice-based lowlands of Asia. http://www.tropentag.de/2004/abstracts/full/128.pdf - accessed 13.10.2015

Haviland, C. (2005). Nepal farmers reap bumper harvest. BBC News, Friday, 2 September 2005. http://news.bbc.co.uk/2/hi/south_asia/4200688.stm

He, Y. and J. Ma (2005). Effect of different kinds of fertilizers on the yield and physical and chemical status of soil in SRI. Southwest china Journal of Agricultural Sciences 18: 315-320.

Howarth S.E., U.N. Parajuli, J.R. Baral, G.A. Nott, B.R. Adhikari, D.R. Gautam and K.C. Menuka (2012). Promoting Good Governance of Water Users' 
Associations in Nepal. http://www.dfid.gov.uk/r4d/pdf/outputs/R80233.pdf accessed 13.10.2015

Huffman, W.E. (1998). Modernizing Agriculture: A Continuing Process. Daedalus 127: $159-186$.

ICIMOD (2007). System of Rice Intensification (SRI) A method for increasing the productivity of rice by changing the management of plants, soil, water, and nutrients. http://lib.icimod.org/record/28241/files/15.pdf - accessed 13.10.2015

IDL Group (2006). APP Implementation status report (vol. I): Main Report prepared by NARMA Consultancy Pvt. Ltd. and SEEPORT Consultancy Pvt. Ltd. Nepal for the Government of Nepal.

IFPRI (2012). Extension and Advisory Services in Nepal: A brief history of public extension policies, resources and advisory activities in Nepal. http://www.worldwide-extension.org/asia/nepal/s-nepal - accessed 13.10.2015

IRRI (2006). Bringing Hope, Improving Lives: Strategic Plan 2007-2015. International Rice Research Institute, Los Baños, Philippines.

IRRI (2010). Nutrient management tutorial. http://webapps.irri.org/nm/nmtutorial/nmtutorial.php accessed 13.10.2015

Jansen, K. and S. Vellema (2011). What is technography? NJAS - Wageningen Journal of Life Sciences 57: 169-177.

Joshi, B.K. (2005). Rice Gene Pool for Tarai and Inner Tarai Areas of Nepal. Nepal Agriculture Research Journal 6: 10-22.

Joshi, D. and G.P. Deo (1976). Fertilisers Recommendations for Major crops of Nepal. Division of Soil Science and Agricultural Chemistry, Department of Agriculture, HMG/Nepal.

Joshi, G. and S. Bauer (2006). Farmers' choice of the modern rice varieties in the rainfed ecosystem of Nepal. Journal of Agriculture and Rural Development in the Tropics and Subtropics 107: 129-138.

Joshi, K.D., C. Conroy and J.R. Witcombe (2012). Agriculture, seed, and innovation in Nepal: Industry and policy issues for the future. IFPRI project paper. http://cdm15738.contentdm.oclc.org/utils/getfile/collection/p15738coll2/id/12 7311/filename/127522.pdf - accessed 13.20.2015

Joshi, M. and T.D. Mason (2007). Land tenure, democracy, and insurgency in Nepal. Asian Survey 47: 393-414.

Joshi, M. and T.D. Mason (2010). Land tenure, democracy, and patterns of violence during the Maoist insurgency in Nepal, 1996-2005. Social Science Quarterly 91: 984-1006.

Joshi, N.P., K.L. Maharjan and L. Piya (2011). Production economics of rice in different development regions of Nepal. Journal of International Development and Cooperation. Vol. 17(1): 103-112.

Joshi, S. (2000). Counting women's work in the Agricultural census of Nepal: A report. Gender Technology and Development 4(2): 255-270. 
Kabir, H. (2006). Adaptation and Adoption of the System of Rice Intensification (SRI) in Myanmar using the Farmer Field School (FFS) approach. PhD Thesis, Honolulu University, USA.

Kafle, B., M.N. Paudel, and R.C. Ghimire (2012). Assessing current status of early rice cultivars in river basin area of Nepal: a concern to diffusion. International Journal of Agriculture: Research and Review, 2(2): 59-61.

Kaini, B.R. (2004). Increasing crops production in Nepal. in: D. P. Sherchan, K. Adhikari, B. K. Basta, D. Sharma (eds), Proceedings of the 24th National Summer Crops Research Workshop on Maize Research and Production in Nepal, 28-30 June 2004, NMRP and NARC, Kathmandu, Nepal, 15-19.

Kamanga, B.C.G., S.R. Waddington, M.J. Robertson and K.E. Giller (2010). Risk analysis of maize-legume crop combinations with smallholder farmers varying in resource endowment in central Malawi. Experimental Agriculture 46: $1-21$.

Karkee, M. (2008). Nepal Economic growth Assessment-Agriculture. Submitted to USAID Kathmandu, Nepal. http://pdf.usaid.gov/pdf_docs/Pnadn016.pdf accessed 13.10.2015

Kassam, A.and H. Brammer (2012a).Combining sustainable agricultural production with economic and environmental benefits. The Geographical Journal179:1118.

Kassam, A. and H. Brammer (2012b). Reply to Sumberg et al. The Geographic Journal 179: 186-187.

Kassam, A., W. Stoop and N. Uphoff (2011). Review of SRI modifications in rice crop and water management and research issues for making further improvements in agricultural and water productivity. Paddy and Water Environment 9: 163-180.

KC G.K., D. Pradhan, B.P. Upadhayay, S. Upadhyay (2003). Nepal: Agricultural extension experiences, challenges and opportunities. Country paper presented at Regional Workshop on operationalising agriculture extension reform in south Asia, New Delhi, India, 6 May 2003. http://info.worldbank.org/etools/docs/library/51025/ZipAgExtension1/ag_ext ension1/Materials/Plenary/Nepal.pdf - accessed 13.10.2015

KC, B.K. (2003). Migration, poverty and development in Nepal. Asian and Pacific Migration Journal 13(2): 205-232.

Khadka, S.B. (2010). Assessment of Food Security and Nutrition Situation in Nepal (An input for the preparation of NMTPF for FAO in Nepal), Food and Agriculture Organization of the United Nations UN Complex, Pulchowk, Nepal June 2010. ftp://ftp.fao.org/TC/CPF/Country\%20NMTPF/Nepal/thematic\%20studies/Foo d\%20Security\%20_Final_.pdf - accessed 13.10.2015

Koma, Y.S. (2002). Experiences with the SRI in Cambodia. Paper presented at the international conference on Assessments of the System of Rice 
Intensification (SRI), April 1-4, in Sanya, China.

Krupnik, T.J., C. Shennan and J. Rodenburg (2012). Yield, water productivity and nutrient balances under the System of Rice Intensification and Recommended Management Practices in the Sahel. Field Crops Research 130: $155-167$.

Krupnik, T.J., J. Rodenburg, C. Shennan, D. Mbaye and V.R. Haden (2010). Risky trade-offs: Comparing yield, water productivity, and weed competition under the System of Rice Intensification and best management practices in the Sahel. Paper presented at the Africa Rice Congress, Bamako, Mali, 22-26 March.

Ladha, J.K., and P.M. Reddy (Eds.). (2000). The Quest for Nitrogen Fixation in Rice. International Rice Research Institute, Makati City.

Ladha, J.K., R.P. Pareek and M. Becker (1992). Stem-nodulating legume-Rhizobium symbiosis and its agronomic use in lowland rice. Advances in Soil Science 20: 147-192.

Laha, J.K., D. Dawe, H. Pathak, A.T. Padre, R.L. Yadav, B. Singh, Y. Singh, Y. Singh, P. Singh, A.L. Kundu, R. Sakal, N. Ram, A.P. Regmi, S.K. Gami, A.L. Bhandari, R. Amin, C.R. Yadav, E.M. Bhattarai, S. Das, H.P. Agarwal, R.K. Gupta and P.R. Hobbs (2003). How extensive are yield declines in long-term rice-wheat experiments in Asia? Field Crops Research 81: 159-180.

Latif, M.A., M.R. Islam, Y.R. Ali and M.A. Saleque (2005). Validation of the system of rice intensification (SRI) in Bangladesh. Field Crops Research 93: 281-292.

Latif, M.A., M.Y. Ali, M.R. Islam, M.A. Badshah and M.S. Hasan (2009). Evaluation of management principles and performance of the System of Rice Intensification (SRI) in Bangladesh. Field Crops Research 114: 255-262.

Lawoti, M. and A.K. Pahari (2009). The Maoist Insurgency in Nepal:Revolution in the 21st Century. Routledge, London.

Lipton, M. and S. Maxwell. 1992. The new poverty agenda: An overview. IDS Discussion Paper 306. Brighton, U.K.: Institute of Development Studies, University of Sussex.

Long, X., J. Ma, F. Xu, H. Wang, Q. Huang and Z. Yuan (2005). Study on the Seedling-age and Planting Density in SRI, Journal of Sichuan Agricultural University 23(3): 368-373.

Maat, H. and D. Glover (2012). Alternative Configurations of Agronomic Experimentation. In: J. Sumberg and J. Thompson (eds), Contested Agronomy: Agricultural Research in a Changing World. Earthscan Abingdon.

Mahato, R. (2011). Nepal's hunger solution: New method of rice cultivation doubles harvests with less water and less seeds. Nepali Times, Issue 559, 24-30 June 2011, Kathmandu, http://www.nepalitimes.com/issue/2011/06/27/Nation/18312

Makarim, A.K., V. Balasubramanian, Z. Zaini, I. Syamsiah, I.G.P.A. Diratmadja, A. Handoko, I.P. Wardana and A. Gani (2002). System of Rice Intensification 
(SRI): evaluation of seedling age and selected components in Indonesia, in Water-wise Rice Production, eds. B.A.M. Bouman, H. Hengsdijk, B. Hardy, P.S. Bindraban, T.P. Tuong and J.K. Ladha, Los Baños, the Philippines: IRRI.

Mallik, R.N. (1981). Kheti-Bali (in Nepali). Curriculum Development Center, Tribhuwan University, Nepal.

Manjunatha, B.N., R. Basavarajappa and B.T. Pujari (2010). Effect of age of seedlings on growth, yield and water requirement by different system of rice intensification. Karnataka Journal of Agricultural Sciences 23 (2): 231-234.

Matthews, R.B., M.J. Kropff, T. Horie and D. Bachelet (1997). Simulating the impact of climate change on rice production in Asia and evaluating options for adaptation. Agricultural Systems 54: 399-425.

McDonald, A.J., P.R. Hobbs and S.J. Riha (2006). Does the system of rice intensification outperform best conventional management? A synopsis of the empirical record. Field Crops Research 96: 31-36.

McDonald, A.J., P.R. Hobbs and S.J. Riha (2008). Stubborn facts: stil no evidence that the System of Rice Intensification out-yields Best management Practices (BMPs) beyond Madagascar. Filed Crops Research 108: 188-191.

McHugh, O., T.S. Steenhuis, J. Barison, E. Fernandes and N. Uphoff (2002). Farmer implementation of alternate wet-dry and non-flooded irrigation practices in the System of Rice Intensification (SRI). In: B.A.M. Bouman, H. Hengstdijk, B. Hardy, P.S. Bindraban, T.P. Tuong and J.K. Ladha (eds), Water-wise rice production. IIRI, Los Baños, Philippines.

Mehta, R., R. Pudasaini and J. Zucker (2014). Nutrition from innovation and taste from waste. Farmer Matters 30(4): 12-15

Menete, M.Z.L., H.M. van Es, R.M.L. Brito, S.D. DeGloria and S. Famba (2008). Evaluation of system of rice intensification (SRI) component practices and their synergies on salt-affected soils. Field Crops Research 109: 34-44.

Mishra, A. and V.M. Salokhe (2008). Seedling characteristics and early growth of transplanted rice under different water regimes. Experimental Agriculture 44: $1-19$.

Mishra, A., M. Whitten, J.W. Ketelaar and V.M. Salokhe (2006). The System of Rice Intensification (SRI): a challenge for science, and an opportunity for farmer empowerment towards sustainable agriculture. International Journal of agricultural Sustainability 4: 193-212.

MOAC (2005). Statistical Information on Nepalese Agriculture. Ministry of Agriculture and Cooperatives, 2004/20. Kathmandu, Nepal.

MOAC (2009). Statistical Information on Nepalese Agriculture, 2008/2009. Agribusiness Promotion and Statistical Division, Ministry of Agriculture and Cooperatives, Kathmandu.

MOAC (2010). Statistical Information on Nepalese Agriculture. Ministry of Agriculture and Cooperatives, 2009/2010. Kathmandu, Nepal. 
MOAC (2011). Statistical Information on Nepalese Agriculture. Ministry of Agriculture and Cooperatives, 2010/2011. Kathmandu, Nepal.

Monteiro Novo, A.L. (2012). Islands of dairy in a sea of sugarcane: the future of family dairy farming in Brazil. PhD thesis, Wageningen University.

Moser C.M. and C.B. Barrett (2003). The disappointing adoption dynamics of a yield-increasing, low external-input technology: The case of SRI in Madagascar. Agricultural Systems 76: 1085-1100.

Moser C.M. and C.B. Barrett (2006). The complex dynamics of smallholder technology adaoption: the case of SRI in Madagascar. Agricultural Economics 35: 373-388.

Murshed, S.M. and S. Gates (2005). Spatial-Horizontal Inequality and the Maoist Insurgency in Nepal. Review of Development Economics 9(1): 121-134.

Mushtaq S., S. Khan, M. Hafeez and M.A. Hanjra (2009). Does reliability of water resources matter in the adoption of water-saving irrigation practices? A case study in the Zhanghe irrigation system, China. Water Policy 11: 661-679.

NARC (2014). Released and registered crop varieties on Nepal (1960-2013). Nepal agricultural research council (NARC). Communication, Publication and Documentation Division. Khumaltar, Lalitpur. http://www.narc.gov.np/publicaton/pdf/varieties_released/RecoVar.Eng\%20updated.pdf - accesses 13.10.2015.

Nayak P., D. Patel, B. Ramakrishnan, A. K. Mishra and R.N. Samantaray (2009). Long-term application effects of chemical fertiliser and manure on soil carbon under intensive rice-rice cultivation. Nutrient Cycling in Agroecosystems 83:259-269.

Nepal, R. and G.B. Thapa (2009). Determinants of agricultural commercialization and mechanization in the hinterland of a city in Nepal. Applied Geography 29: 377389.

Niroula R.K. (2003). Cytogenetic relationship between cultivated and Nepalese wild species of rice [M.Sc. Thesis]. Submitted at Department of Plant Breeding, Tribhuwan University, IAAS, Rampur, Chitwan, Nepal. $36 \mathrm{p}$

Niroula R.K., L.P. Subedi, R.C. Sharma and M. Upadhyaya (2005). Ploidy level and phenotypic dissection of Nepalese wild species of rice. Scientific World 3(3): 78-84.

Noltze, M., S. Schwarze and M. Qaim (2012). Understanding the adoption of system technologies in smallholder agriculture: the system of rice intensification in Timor Leste. Agricultural Systems 108: 64-73.

Noltze, M., S. Schwarze and M. Qaim (2013). Impacts of natural resource management technologies on agricultural yield and household income: the System of Rice Intensification in Timor Leste. Ecological Economics 85: 5968.

NPC (1997). Ninth Plan (1997-2002). Government of Nepal, National Planning Commission, Nepal. 
NPC (2010). Thirteenth Plan. Government of Nepal, National Planning Commission, Nepal.

NRM-PARDYP/ICIMOD (2005). System of Rice Intensification in PARDYPNepal watershed. Paper presented in the SRI Workshop, organised by ICIMOD, 19 December, Kathmandu.

Ojiem, J.O., N. De Ridder, B. Vanlauwe and K.E. Giller (2006). Socio-ecological niche: A conceptual framework for integration of legumes in smallholder farming systems. International Journal of Agricultural Sustainability 4: 79-93.

OPM (2003). Nepal fertiliser use study. A study funded by the UK Department for International

Pacini, G.C., D. Colucci, F. Baudron, E. Righi, M. Corbeels, P. Tittonell, P. and F.M. Stefanini (2014). Combining multi-dimensional scaling and cluster analysis to describe the diversity of the rural households. Experimental Agriculture 50: 376-397.

Paris T.R., A. Singh, J.S. Luis and M. Hossain (2005). Labour migration, livelihood of rice farming households and women left behind: a case study in eastern Uttar Pradesh. Economy and Politics Weekly XL (25): 18 June 2005.

Paris T.R., A. Singh, R.K. Singh, N.K. Saha, V. Lakra, J.S. Luis and M. Hossain (2007). Labour outmigration, livelihood, and gender roles: Synthesis of empirical findings in eastern India. In P.K Aggarwal, J.K. Ladha, R.K. Singh. C. Devakumar and B. Hardy (eds), Science, Technology and Trade for peace and prosperity, IRRI.

Paris T.R., M.F. Rola_Rubzen, J.S. Luis, T. Thi Ngoc Chi, C. Wongsamun and D. Villanueva (2010). Interrelationships between labour outmigration, livelihoods, rice productivity and gender roles. IFAD Occasional papers 11. http://www.ifad.org/operations/projects/regions/pi/paper/11.pdf - accessed 13.10.2015

Pasuquin, E., T. Lafarge and B. Tubana. (2008). Transplanting young seedlings in irrigated rice fields: Early and high tiller production enhanced grain yield. Field Crops Research 105: 141-155.

Paudel, G.S. (2002). Coping with land scarcity. Farmers' changing land-use and management practices in two mountain watershed of Nepal. Norwegian Journal of Geography 56: 21-31.

Pawson, R. and N. Tilley (1997). Realistic evaluation. SAGE, London.

Pearse, A. (1980). Seeds of plenty, seeds of want: social and economic implications of the Green Revolution, Clarendon Press, Oxford.

Peng, S.K., K.G. Cassman, S.S. Virmani, J.E. Sheehy and G.S. Khush. (1999). Yield potential trends of tropical rice since the release of IR8 and the challenge of increasing rice yield potential. Crop Science 39: 1552-1559.

Pokhrel T.P. (1995). Rice Development Programme in Nepal. International Rice Commission

Newsletter,

FAO http://www.fao.org/docrep/v6017t/V6017T04.htm - accessed 13.10.2015 
Pradhan, P. (2012). Water Users Associations (WUAs) for the Implementation of Irrigation Management Transfer (IMT) in Nepal. ftp://ftp.fao.org/agl/aglw/imt/WUANepal.pdf - accesed 13.10.2015

Rahija M., H.K. Shrestha, G. Stads and R.B. Bhujel (2011). Nepal: Recent developments in public agricultural research. IFPRI. http://www.asti.cgiar.org/pdf/Nepal-Note.pdf - accessed 13.10.2015

Rahut, D.B. and M.M. Scharft (2012). Livelihood diversification strategies in the Himalayas. Australian Journal of Agricultural and Resource Economics 56: 558-582.

Rana, R.B., C. Garforth, B. Sthapit and D. Jarvis (2007). Influence of socio-economic and cultural factors in rice varietal diversity management on-farm in Nepal. Agriculture and Human Values 24: 461-472.

Randriamiharisoa, R., J. Barison and N. Uphoff (2006). Soil biological contribution to the System of Rice Intensification. in N. Uphoff, A. Ball, E. Fernandes, H. Herren, O. Husson, M. Laing, C. Palm, J. Pretty, P.A. Sanchez, N. Sanginga and J. Thies (eds), Biological Strategies for Sustainable Soil Systems CRC Press, Boca Raton, FL, pp. 409-424.

Raut, N., B.K. Sitaula, J.B. Aune and R.M. Bajracharya (2011). Evolution and future directions of intensified agriculture in the central mid-hills of Nepal. International Journal of Agricultural Sustainability 9: 537-550.

Reddy, V.R., P.P. Reddy, M.S. Reddy and D.S. R. Raju (2005). Water use efficiency: a study of system of rice intensification (SRI) adoption in Andhra Pradesh. Indian Journal of Agricultural Economics 60: 458-472.

Regmi, M. (2005). System of Rice Intensification trials in Dang district: Method and approach. Paper presented in the SRI Workshop, organised by ICIMOD, 19 December, Kathmandu.

Richards P (1985). Indigenous Agriculture Revolution: Ecology and food production in West Africa. Westview Press, Colorado.

Richards, P. (1989). Agriculture as a performance. In: R. Chambers, A. Pacey and L.A. Thrupp (eds.), Farmer First. Farmer Innovation and Agricultural Research, p. 39-43. Intermediate Technology Publications, London.

Richards, P. (2001). Technography: Notes on methods. Unpublished project document for the Convergence of Sciences Programme, International Research and Education Fund (INREF), Wageningen University.

Richards, P. (2010). A green revolution from below. Farwell address, Wageningen University. http://edepot.wur.nl/165231 - accessed 13.10.2015

Rijal D. and G. Synnevag (2005). Contribution of 'Rice Culture' to On-Farm Management of Diversity and Knowledge in Nepal. Noragric Working Paper No. 38 May 2005, Noragric Norwegian University of Life Sciences. http://www.umb.no/statisk/noragric/publications/working_papers/2005_wp_3 8.pdf - accessed 13.10.2015 
RSTL (2011). Annual Progress Report 2011. Regional Soil Testing Laboratory, Jhumka, Sunsari, Nepal.

Sahrawat, K.L. (2004). Organic matter accumulation in submerged soils. Advances in Agronomy 81:169-201.

Saleque, M.A., M.J. Abedin, N.I. Bhuiyan, S.K. Zaman and G.M. Panaullah (2004). Long term effects of inorganic and organic fertiliser sources on yield and nutrient accumulation of lowland rice. Field Crops Research 86: 53-65.

Samal P., B.C. Barah and S. Pandey (2006). An analysis of rural livelihood systems in rain-fed rice-based farming systems of costal Orissa. Agricultural Economics Research Review 19: 281-192.

Sanogo, I. and M.M. Amadou (2010). Rice market integration and food security in Nepal: the role of cross-border trade with India. Food P:olicy 35: 312-322.

Sato, S. and N. Uphoff (2007). A review of on-farm evaluations of system of rice intensification methods in eastern Indonesia. CAB Reviews: Perspectives in Agriculture, Veterinary Science, Nutrition and Natural Resource 2(54).

Sato, Shuichi. (2006). An evaluation of the System of Rice Intensification (SRI) in Eastern Indonesia for its potential to save water while increasing productivity and profitability. Paper presented at the conference: International Dialogue on Rice and Water: Exploring Options for Food Security and Sustainable Environments. IRRI, Los Baños, Philippines. March 7-8. http://sri.ciifad.cornell.edu/countries/indonesia/wwfindosato06.pdf - accessed 13.10.2015

Satyanarayana, A. (2004). Rice, research and real life in the field. Nature: 429: 803.

Schreier, H., S. Brown, L.M. Lavkulich and P.B. Shah (1999). Phosphorus dynamics and soil P-fertility constraints in Nepal. Soil Science 164: 341-350.

Scoones, I. (2009). Livelihoods perspectives and rural development. Journal of Peasant Studies, 36(1): 171-196.

Scott, James C. (2009). The art of not being governed: an anarchist history of upland Southeast Asia. New Haven: Yale University Press.

Senthilkumar, K., P.S. Bindraban, T,M. Thiyagarajan, N. De Ridder and K.E. Giller (2008). Modified rice cultivation in Tamil Nadu, India: Yield gains and farmers (lack of) acceptance. Agricultural Systems 98: 82-94

Senthilkumar, K., P.S. Bindraban, W. de Boer, N. de Ridder, T.M. Thiyagarajan and K.E. Giller (2009). Characterising rice-based farming systems to identify opportunities for adopting water efficient cultivation methods in Tamil Nadu, India. Agricultural water Management 96: 1851-1860.

Sharma S. (2000). Land tenure and poverty in Nepal. Paper presented in WDR-2000 consultation meeting organised by the World Bank, April 4-6, 1999, Dhaka. http://www.rrojasdatabank.info/wpover/sharma.pdf - accessed 13.10.2015

Sheehy, J., S. Peng, A. Dobermann, P.L. Mitchell, A. Ferrer, J. Yang, Y. Zou, X. Zhong and J. Huang (2004). Fantastic yields in the system of rice intensification: fact or fallacy? Field Crops Research 8: 1-8. 
Sheehy, J.E. P.L. Mitchell and B. Hardy (Eds.), 2000. Redesigning Rice Photosynthesis to Increase Yield. International Rice Research Institute/Elsevier, Makati City, Philippines/Amsterdam.

Sheehy, J.E., T.R. Sinclair and K.G. Cassman (2005). Curiosities, nonsense, nonscience and SRI. Field Crops Research 91: 355-356.

Sherchan D.P., and K.B. Karki (2005). Plant nutrient management for improving crop productivity in Nepal. Country report, FAO.

Shindo H., O. Hirahara, M. Yoshida and A. Yamamoto (2006) Effect of continuous manure application on humus composition and nitrogen fertility of soils in a field subjected to double cropping. Biology and Fertility of Soils 42:437-442.

Shrestha R.K. (2010). Fertiliser policy development in Nepal. The Journal of Agriculture and Environment 11: 126-137

Shrestha, G.L. and D.A. Vaughan (1989). The wild relatives of rice in Nepal. In: Iyama, I.S. and G. Takeda (eds), Proceeding of the 6th International Conference: Society for the advancement of breeding researches in Asia and Oceania; 1989 Aug 21-25; Tsukuba: Japan. p 171-174.

Sinclair, T.R. and K.G. Cassman (2004). Agronomic UFOs. Field Crops Research 88: 9-10.

Singah, A.K. and M.J. Baruah (2011). Farmers' adoption behaviour in rice technology: an analysis of adoption behaviour of farmers in rice technology under different farming systems in Assam. Journal of Human Ecology 35(3): 167-172.

Sinha, S.K. and J. Talati (2005). Impact of the system of rice intensification (SRI) on rice yields: result of a new sample study in Purulia district, India. IWMI-Tata Water Policy Research Highlight, 20/2005. 11p. http://www.iwmi.cgiar.org/iwmi-tata/FILES/zip/H05/20.zip $\quad-\quad$ accessed 13.10.2015

Somaratne, W.G. (2010). The System of Rice Intensification (SRI) and food security among the poor: opportunity and constraints. Proceedings of the national conference on water, food security and climate change in Sri Lanka. BMICH, Colombo, June 9-11, 2009. Volume 1, irrigation for food security.

StatSoft (2012). StatSoft Electronic Statistical Textbook. (accessed on 2.3.2012)

Steele, K.A., S. Gyawali, K.D. Joshi, P. Shresta, B.R. Sthapit and J.R. Witcombe (2009). Has the introduction of modern rice varieties change rice genetic diversity in a high-altitude region of Nepal? Field Crops Research 113: 24-30.

Sthapit, B., R. eana, P. Eyzaguirre and D. Jarvis (2008). The value of plant genetic diversity to resource-poor farmers in Nepal and Vietnam. International Journal of Agricultural Sustainability 6: 148-166.

Stone, G.D., R.M. Netting and M.P. Stone (1990). Seasonality, Labor Scheduling, and Agricultural Intensification in the Nigerian Savanna. American Anthropologist 92: 7-23. 
Stoop, W,A. (2011). The scientific case for system of rice intensification and its relevance for sustainable crop intensification. International Journal of Agricultural Sustainability 9: 443-455.

Stoop, W. and A. Kassam (2005). The SRI controversy: a response. Field Crops Research 91: 357-360.

Stoop, W., A. Adam and A. Kassam (2009). Comparing rice production systems: a challenge for agronomic research and for the dissemination of knowledgeintensive farming practices. Agricultural Water Management 96: 1491-1501.

Stoop, W., N. Uphoff and A. Kassam A. (2002). A review of agriculture research issues raised by the system of rice intensification (SRI) from Madagascar: opportunities for improving

Sugden F. and G. Gurung (2012). Absentee landlordism and agrarian stagnation in Nepal: A case from the eastern terai. Nepal Institute of Development Studies, Kathmandu, Nepal.https://cgspace.cgiar.org/handle/10568/36550 - accessed 13.10.2015

Sumberg J., J. Thompson and P. Woodhouse (2013). Why agronomy in the developing world has become contentious. Agriculture and Human Values 30:71-83.

Sumberg, J., J. Thompson and P. Woodhouse (2012).Contested Agronomy: Agricultural Research in a Changing World. In: J. Sumberg and J. Thompson (eds), Contested Agronomy: Agricultural Research in a Changing World. Earthscan Abingdon.

Suvedi M. and P. McNamara (2012). Strengthening the pluralistic agricultural extension system in Nepal. A MEAS Rapid Scoping Mission https://dl.dropboxusercontent.com/u/15810717/Country\%20Reports/MEAS\% 20Country\%20Report\%20NEPAL\%20-\%20Dec\%202011.pdf - accessed 13.10.2015

Tamang, S., K.P. Paudel and K.K. Shrestha (2014). Feminization of agriculture and its implications for food security in rural Nepal. Journal of Forest and Livelihood 12(1): 20-32.

Thakur, A.K. (2010). Critiquing SRI criticism: beyond scepticism with empiricism. Current Science 98: 1294-129.

Thakur, A.K., S. Rath, S. Roychowdhury and N. Uphoff (2010). Comparative performance of rice with System of Rice Intensification (SRI) and conventional management using different plant spacings. Journal of Agronomy and Crop Science 196(2): 146-159.

Thanunathan, K. and V. Sivasubramanian (2002). Age of Seedling and Crop Management Practices for High Density (HD) Grain in Rice. Crop Research 24: 421-424.

Thapa, Y.B. (2002). Constraints and approach for improving fertiliser supply for meeting domestic demand. Policy paper 30, Economic and Policy Network, GoN/Ministry of Finance and ADB/Nepal Resident Mission, Kathmandu. 
http://s3.amazonaws.com/zanran_storage/www.mof.gov.np/ContentPages/167 97738.pdf - accessed 13.10.2015

Thiyagarajan, T.M., V. Velu, S. Ramasamy, D. Durgadevi, K. Govindaranjan, R. Pryadarshini, C. Sudhalakshmi, K. Senthilkumar, P.T. Nisha, G. Gayathry, H. Hengsdijk, P.S. Bindraban. (2002). System of Rice Intensification (SRI): evaluation of seedling age and selected components in Indonesia. In Bouman, B.A.M., H. Hengsdijk, B. Hardy, P.S. Bindraban, T.P. Toung, J.K.Ladha (ed.), Water-wise Rice production. IRRI, Philippiens. pp 119-127.

Thompson, J. and I. Scoones (2009). Addressing the dynamics of agri-food systems: an emergingagenda for social science research. Environmental Science and Policy 12: 386-397.

Tittonell, P. (2014). Livelihood strategies, resilience and transformability in African agroecosystems. Agricultural Systems 126: 3-14

Tittonell, P., A. Muriuki, K.D. Shepherd, D. Mugendi, K.C. Kaizzi, J. Okeyo, L. Verchot, R. Coe and B. Vanlauwe (2010). The diversity of rural livelihoods and their influence on soil fertility in agricultural systems of East Africa - A typology of smallholder farms. Agricultural Systems 103: 83-97.

Traxler, G. and D. Byerlee (1993). A joint-product analysis of the adoption of modern cereal cultivars in developing countries. American Journal of Agricultural Economics 75: 981-989.

Tsujimoto, Y., T. Horie, H. Randriamihary, T. Shiraiwa and K. Homma (2009). Soil management: they key factors for higher productivity in the field utilizing the system of rice intensification (SRI) in the central highland of Madagascar. Agricultural Systems 100: 61-71.

Turmel, M.-S., J. Espinosa, L. Franco, C. Pérez, H. Hernández, E. González, G. Fernández, C. Rojas, D. Sánchez, N. Fernández, M. Barrios, J.K. Whalen and B.L. Turner (2011a). On-farm evaluation of a low-input rice production system in Panama. Paddy and Water Environment 9: 155-161.

Turmel, M-S., B.L. Turner and J.K. Whalen (2011b). Soil fertility and the yield response to the System of Rice Intensification. Renewable Agriculture and Food Systems 26: 185-192.

Ulimwengu J. and O. Badiane (2011). Vocational training and agricultural productivity: Evidence from rice production in Vietnam. The Journal of Agriculture Education and Extension 16: 399-411.

Upadhyaya M.P., S.R. Gupta, D.B. Thapa, S. Bista and H.B. Khatri-Chhetri (2002). Survey of wild rice in Nepal [abstract]. In: Yadav SP (ed), International Conference on Wild rice; 2002 Oct 21 -27; GEM/Nepal, Anam Nagar, Kathmandu. Abstract no ICWR 6. p 10-1

Upadhyaya, H.K, C.C. David. G.B. Thapa and K. Otsuka (1993). Adoption and productivity impact of modern rice cultivars in Nepal. The Developing Economics, XXXI-1 (March 1993). 
Uphoff, N. (1999). Agro-ecological implications of the System of Rice Intensification (SRI) in Madagascar. Environment, Development and Sustainability 1: 297-313.

Uphoff, N. (2001). The System of Rice Intensification: agroecological opportunities for small farmers? LEISA Magazine 17,4: 15-16.

Uphoff, N. (2003). Higher yields with fewer external inputs? The System of Rice Intensification and potential contributions to agricultural sustainability. International Journal of agricultural Sustainability 1:38-50.

Uphoff, N. (2007). Agroecological alternatives: Capitalising on existing genetic potentials. Journal of Development Studies 43: 218-236.

Uphoff, N. (2013). Rethinking the concept of 'yield ceiling' for rice: implications of theSystem of Rice Intensification (SRI) for agricultural science and practice. Journal of Crop and Weed 9: 1-19.

Uphoff, N., A. Kassam and W. Stoop (2008). A critical assessment of a desk study comparing crop production systems: the example of the 'System of Rice Intensification' versus 'Best Management Practice'. Field Crops Research 108: 109-114.

Upreti, B.C. (2004). Maoists in Nepal. From insurgency to political mainstream. Kalpaz Publications, Delhi.

Uprety, R. (2005). Performance of SRI in Nepal. LEISA, Volume 21(2): 30-31.

Uprety, R. (2005). System of Rice Intensification (SRI) Performance in Morang district during 2005 main season. http://sri.ciifad.cornell.edu/countries/nepal/nepuprety1205.pdf- $\quad$ accessed 18.02.2016.

Uprety, R. (2006). SRI takes root in Nepal. LEISA Magazine 22(4): 25-27.

Uprety, R. (2010). Meshing mechanisation with SRI methods for rice cultivation in Nepal. Paper prepared for the $3^{\text {rd }}$ International Rice Congress, November 8 12 , Hanoi. http://sri.ciifad.cornell.edu/countries/nepal/IRC2010_Uprety_\%20paper.pdf accessed 13.10.2015

Uprety, R. (2011). Participatory learning for technology shaping and its dissemination: a case from Nepal. Extension Farming System Journal, Volume 7(1): 37-40.

Uprety, R. (2013a). Learning from farmers. Farming Matters 29(1): 20-22.

Uprety, R. (2013b). Hybridizing Technology: The Case of Rice Farming in Nepal. http://peoplefoodandnature.org/blog/sri_nepal/ - accessed 18.02.2016.

Van der Ploeg, J.D., C. Laurent, F. Blondeau and P. Bonnafous (2009). Farm diversity classification schemes and multifunctionality. Journal of Environmental Management 90: 124-131.

Vijayakumar, M., S. Ramesh, B. Chandrasekaran and G. Thiyagarajan (2006). Effect of System of Rice Intensification (SRI) practices on yield attributes, yield and 
water productivity of rice (Oryza sativa L.). Research Journal of Agriculture and Biological Science 2 (6): 236-242.

Von Westarp, S., H. Schreier, S. Brown and R.B. Shah (2004). Agricultural intensification and the impacts on soil fertility in the Middle Mountains of Nepal. Canadian Journal of Soil Science 84: 323-332.

Wagh, R.G., Khanvilkar, S.A. and Thorat, S.T. (1988). Effect of age of seedlings at transplanting, plant densities and nitrogen fertilization on the yield of rice variety R- 711. Oryza 25: 188-190.

Wang, G.H., A. Dobermann, C. Witt, Q.Z. Sun and R.X. Fu. (2001). Performance of site-specific nutrient management for irrigated rice in southeast China. Agronomy Journal 93: 869-878.

WFP (2008). Passage to India: Migration as a Coping Strategy in Times of Crisis in Nepal. WFP, Kathmandu http://documents.wfp.org/stellent/groups/public/documents/ena/wfp194034.p df - accessed 13.10.2015

Wily L.A., D. Chapagain and S. Sharma (2008). Land reform in Nepal: where is it coming from and where is it going? DFID, Kathmandu, Nepal. http://www.landcoalition.org/sites/default/files/documents/resources/nepal_la w_book.pdf - accessed 13.10.2015

WWF (2007). More rice with less water: System of Rice Intensification. WWF International- ICRISAT Dialogue Project, ICRISAT, Patancheru - 500324 Andhra Pradesh, India. http://d2ouvy59p0dg6k.cloudfront.net/downloads/wwf_rice_report_2007.pdf - accessed 13.10.2015

Yadao, A.C. and O.B. Zamora (2007). Responses of rice under the system of rice intensification and conventional production systems in Ilocos Norte, Philippines. Philippine Journal of Crop Science 32 (2): 99-107.

Yadaw, R.B., B. Chaudhary, N.P. Adhikari and T. Akhtar (2005). Hardinath 1, an early-maturing rice genotype released in Nepal.

Yang, C., L. Yang, Y. Yang, and Z. Ouyang (2004). Rice root growth and nutrient uptake as influenced by organic manure in continuously and alternately flooded paddy soils. Agricultural Water Management 70: 67-81.

Zhang, Y., D. Zhu, X. Lin, H. Chen and Y. Yang (2007). Effects of dry and wet rice under system irrigation on the growth of rice intensification. Agricultural Research in the Arid Areas 25(5): 109-113.

Zhao, L., L. Wu, Y. Li, X. Lu, D. Zhu and N. Uphoff (2009). Influence of the system of rice intensification on rice yield and nitrogen and water use efficiency with different $\mathrm{N}$ application rates. Experimental Agriculture 45: 275-286. 


\section{Summary}

Agriculture is a means of livelihood for the majority of the people in Nepal. Agricultural intensification, which makes more productive use of available resources, is thus vital for food security and for better livelihoods of Nepalese farmers. This is particularly true for rice intensification, in order to produce more of this major staple grain for domestic use. This thesis summarizes existing realities of agricultural intensification with particular reference to the System of Rice Intensification (SRI), the multiple factors affecting SRI adoption, modification and dissemination, and its effects on overall agricultural and livelihood development.

The study was conducted in two village development committee (VDC) areas of Morang district in Nepal. Indrapur VDC is situated in central Morang. It is more a densely populated and rapidly urbanising VDC than Jhorahat. The majority of people living in this VDC are hill migrants and migration flow to this VDC has been very high. Irrigation sources of Indrapur are small perennial rivers. Irrigation systems are small and farmermanaged. Jhorahat is closer to the district capital Biratnagar and the majority of the farmers in this VDC are terai-indigenous Tharu, Jagad and Sardar people. It is less densely populated than Indrapur. There was no migration flow to Jhorahat and population size is slowly decreasing. Sunsari Morang Irrigation System (SMIS) is the main source of irrigation for this VDC. SMIS is a government-managed irrigation system and Jhorahat is located in the middle part of SMIS.

Rice demand has been increasing year after year in Nepal because of population growth, improved access to rice in the different geographical areas of the country due to better road-network and transportation facilities, and greater purchasing power of the people through non-agricultural sources of income. Increasing domestic rice demand explains why the government puts priority on more rice production and production of other food crops by increasing productivity. But the priorities of farmers are changing in an opposite direction because of the low profit margin in rice farming. Despite government policies, national rice production is declining, due to high production costs and low productivity.

In the meantime other livelihood options became increasingly available to raise household income. So the majority of farmers continue their cereal-based conventional 
farming only for food security of their own families and simultaneously diversify their occupations (vegetable farming and non-agricultural occupations). Foreign employment (earning remittances) has become and remains a very important source of income for the majority of rural-farm families as well. Remittances affect farm families in two ways. Some families use remittances to invest in (purchase) cultivated land, while other families use the remittances to leave agriculture and enter into other occupations.

During my studies I found both diversified and intensified rice farming. Livelihood strategies, as reflected in rice farming systems, and field management strategies were influenced by several agro-ecological and socio-economic factors. Livelihood and field management strategies of rice farmers are interconnected. There were four livelihood strategies and three kinds of field management strategies. Two livelihood strategies can be characterised as more intensive and more productive; the other two are less intensive and less productive. Livelihood strategies are more family resource-based strategies, while farmers' field management strategies are more context-dependent. Field management strategies were characterised by forms of nutrient management. Three groups of field management were recognized, based on mainly organic inputs, inorganic inputs, and a mixture of both. The latter management strategy had most similarities with SRI. Relevant elements of this context that influences field management strategy include: ownership of the land (tenure status), distance of the land from the residence, availability of good (adequate and reliable) irrigation facilities, and competition for manure use between fuel (for cooking) and food production (including also competition for manure use in vegetable growing and rice growing).

Due to the wide diversity in agro-ecological and socio-economic conditions, and hence in rice-farming systems, it is evident that there is not one single solution that suits all farmers and all fields. Rice intensification is not achievable as a general strategy. Rice intensification, and SRI in particular, is therefore more of a choice, an option, than an imperative. Solutions for individual farmers should be appropriate for local situations, and this location-specificity includes both the agro-ecological and socio-economic context. Farmers try to modify or re-shape new technologies and incorporate appropriate parts of them into their farming systems to suit their respective situations. In some cases, doubletransplanting system was the best solution for the farmers. 
Nutrient management is a very important aspect of rice farming. Government policies (fertiliser subsidies) encourage increased fertiliser use. My analysis of nutrient management took field management strategies as point of departure; and within these three forms there were different relations between inputs and outputs. The results indicated that use of higher amounts of inorganic fertiliser did not increase yields; higher amounts of manure correlated with higher yields. The main difference in productivity between the fields of the three management strategies was due to the intrinsic fertility of the fields or the use of fertiliser outside the main rice-growing season. Combinations of organic manure and mineral fertilisers resulted in the highest rice production. Most farmers didn't have sufficient farmyard manure to maintain or improve fertility on their fields. Farmers used organic manure on their own fields, on fields that were close to their residence, and on fields that were used for high-value crops (vegetables and spices). More fertile fields received higher doses of mineral fertiliser and manure; however the amounts of $\mathrm{N}$ and $\mathrm{K}$ added to the fields were lower than the amounts removed by harvesting, which could result in nutrient depletion and declining yields over the longer term. This study indicates that there should be a rethinking and revision of government policy to sustain long-term soil fertility and to enhance rice yields in Nepal.

Irrigation management is another important factor for rice production. But the reliability of water supply turned out to be more important than its amount. Reliable water availability makes land preparation easier and more efficient. Water scarcity, conversely, makes land preparation difficult, and later on, weed control becomes problematic on such fields that have not been well prepared. Water also affects timing for transplanting, as reliable water availability provides an opportunity for early transplanting and encourages the use of younger seedlings as recommended for SRI. Such availability also encourages farmers to transplant fewer seedlings with wider spacing, which reduces seed and labour costs and at the same time enhances yield.

Choice of rice varieties planted influenced the overall rice farming system and cropping intensity. The varieties preferred for rice cultivation by scientists and by farmers were different in eastern Nepal. Scientists of the national research system recommended 14 rainy-season cultivars for the eastern terai, but only three of those were actually used in large areas in Morang. Other recommended cultivars were not adopted by farmers. 
Highyield, high fertiliser use efficiency, and disease resistance are important traits for scientists for cultivar selection. Only highly-productive farmers applied these criteria. Farmers with other livelihood and field management strategies prefer long-duration cultivars that produce larger volumes of straw (for fodder), but these are also less responsive to fertiliser. However, such cultivars also show higher yield stability. More productive and less productive farmers are confronted with the same prevailing negative correlation between yield performance and market price for their cultivars. Because local cultivars perform better in more risk-prone conditions (drought, low soil fertility, labour scarcity conditions that cause delay in transplanting), most farmers continue the use of nonrecommended cultivars, having different criteria for choosing varieties than those stressed by scientists. For Basmati cultivars, high prices also compensate for low yields, and there is a clear niche for such cultivars. However, that niche prevents agricultural intensification, including intensification towards economically-attractive vegetable crops. Other longduration cultivars may similarly hamper intensification.

Agricultural training can play a vital role for technology dissemination and agricultural intensification. The introduction of SRI in Morang district resulted in several changes in rice farming, but only part of the farmers have adopted such technologies, and adoption has been only in part of their fields. Other farmers have incorporated some of the SRI practices in their conventional practices. Current rice growing practices in Morang district can therefore be described as hybrid practices, conforming neither to the norms of conventional practice nor to the ideal type of SRI.

Introduction of SRI in the region has acted more as an additional factor in practices of intensification and de-intensification. After the introduction of SRI, farmers further tested, re-packaged or hybridized SRI methods to make the SRI ideas suitable for their agroecological and socio-economic environments. Therefore, if SRI is promoted as a copy-andpaste practice type of intervention, it is bound to be ineffective, not different from earlier attempts to introduce context-independent practices.

In order to reform Nepalese rice farming, we need to recognize that different farmers, with different livelihood strategies, and with access to different kinds of fields, need different forms for agricultural intensification. Even though some agencies and organizations might try to promote SRI in a formulaic manner, the original ideas of SRI 
have always been to be adaptive and to encourage farmer experimentation and adaptation. There is an ideal type, but the methodology of SRI (not a technology) is to utilize available resources more productively, recognizing that getting more output is not a direct function of using more inputs, but of managing inputs differently and more appropriately.

In conclusion, in order to increase the productivity and production of rice, SRI core ideas can be effective but they are not suitable for all farmers and all agro-ecological conditions without empirically-validated modifications. Another important finding relates to partial adoption and variations of the SRI use. I observed that farmers test and try to reshape any new technology according to their agro-ecological and socio-economic situations. They choose the easiest, least costly or burdensome parts of any package of practices or technology for their regular use. High-intensive farmers prefer to use modified SRI methods where there is good irrigation and drainage facilities. But most of the big farmers who depend on hired labour are not interested in SRI. Therefore, it is medium to small farmers who have suitable land, reliable irrigation facilities, and more family labour for farm work for whom there will be the best prospects for SRI use and benefit. Extension agencies need to facilitate the technology dissemination process, providing to farmers a range of alternatives for improvement that enable farmers to choose the most appropriate practices.

There are many possibilities for improvement of the existing nutrient management practices of rice farmers in Nepal. Nutrient management can increase rice production because the majority of farmers are currently using fertilisers non-judiciously. Two things will be important to improve nutrient management. One is to strengthen the fertiliser supply mechanism, and another is to provide intensive regular training on nutrient management. The SRI-recommended practices (younger seedlings, early weeding, use of organic manure, and AWD (alternate wetting and drying) irrigation) will be useful to improve the nutrient use efficiency of rice farmers. But the training package should be designed according to local need; it should focus on appropriate farmers because training is not useful for all types of farmers.

Improving water distribution systems and maintaining their reliability will be a positive intervention to improve cropping intensity of irrigated land, with greater rice productivity and more rapid technology dissemination. Otherwise in the existing situation, cultivar diversity and diversification in cultivation methods remain essential components of 
rice farming to capture the possibilities latent in Nepal's diverse agro-ecological and socioeconomic conditions, especially in areas where the majority of rice farming is still rain-fed.

Cost-reduction strategies and less labour-intensive cultivation practices will be appropriate options to improve existing rice farming system of Nepal. Mechanization, especially for land preparation (male-dependent work), is a promising option for cost reduction and laboursaving. Participatory cultivar selection and dissemination will be better strategies to introduce new, promising rice cultivars among rice farmers. The majority of cultivars used by the farmers in the study areas were non-recommended and were disseminated farmer-to-farmer. Given such patterns of communication and cooperation, farmers should be accepted as the best selectors of cultivars, suitable for their land and their socio-economic condition.

Finally, this study was conducted in limited areas and in limited time. It is not sufficient to understand all the causes and consequences of rice farming practices in Nepal. Therefore further studies covering wider geographical areas and focusing on several other unexplained variables like the effects of farmers' networking, credit support, and marketing patterns and practices will be essential to understand in-depth dynamics of rice farming systems of Nepal and the options for their intensification. 


\section{Rajendra Uprety}

Wageningen School of Social Sciences (WASS)

Completed Training and Supervision Plan
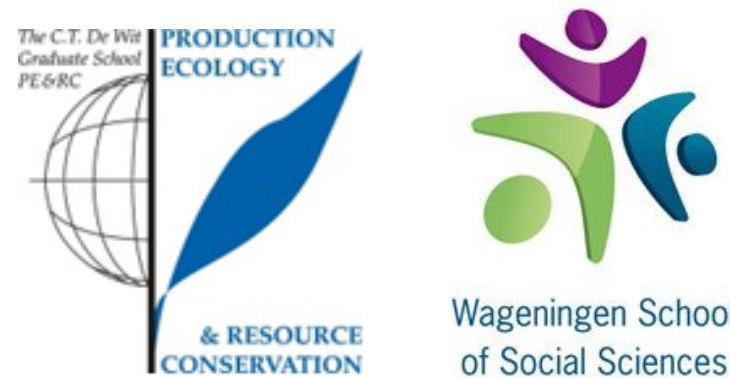

Wageningen School of Social Sciences

\section{Name of the learning activity}

Department/Institute

Year

ECTS*

\section{A) Project related competences}

SOQ 31806 Nutrient Management

Wageningen University

2008

6

TAD 20604 Introduction to technology, agro-ecology Wageningen University

2007

4

and Development

ENP 22306 Research design and research methods

Wageningen University

2007

6

Long-term dynamics of food and human development

Wageningen

Graduate

2008

Schools

\section{B) General research related competences}

TAD 30806 Technography, Researching, Technology Wageningen University

2008

6

and Development

Literature review and proposal writing

Wageningen University

2008

6

TAO Seminars

Wageningen University

2008-2012

3

'System of Rice Intensification (SRI): Experiences of 3rd National SRI Symposium,

2008

Nepal'

Tamilnadu, India

'Meshing mechanization with SRI methods for rice cultivation in Nepal'

3rd International Rice

2010

1

Congress, Hanoi, Vietnam

'Participatory learning for technology shaping and its dissemination: A case of Nepal'

5th WCCA, Brisbane,

2011

1

'Irrigation reliability and its effect on

Australia

rice production system in Nepal'

4th International Rice

2014

1

M.Sc. thesis supervisor (5)

Congress, Bangkok, Thailand

B.Sc. thesis supervisor (2)

TU-IAAS/NULS/WUR

2009-2015

3

Wageningen University

2010-2014

1

\section{C) Career related competences/personal development}

Philosophy and Ethics of Food Science and Technology VLAG, Wageningen

2008

1.5

Total

${ }^{\star}$ One credit according to ECTS is on average equivalent to 28 hours of study load 


\begin{abstract}
About the Author
Rajendra Uprety was born in Panchthar, Nepal on February 12, 1966. He did his secondary education at Sajilal Secondary School, Morang. He graduated from the Tribhuvan University, Institute of Agriculture and Animal Science, Chitwan, Nepal in 1991. Thereafter he was employed by the Ministry of Agriculture and Cooperatives as a horticulturist and posted at the Horticulture Research Center, Dhankuta. Later he started his career as an Agriculture Extension Officer at the District Agriculture Development Office (DADO), Sunsari district. He did his M.Sc. (Agriculture Extension) from the same institute in 2002. After M.Sc. he was transferred to DADO Morang district in 2003 and started System of Rice Intensification (SRI) method testing and promotion work. He was awarded the Nepal Development Marketplace Award 2005 by the World Bank for SRI promotion work. In 2007, he got scholarship to start his sandwich $\mathrm{PhD}$ at the Wageningen University and Research Center. During his $\mathrm{PhD}$ he was promoted to undersecretary level in 2009 and posted at DADO Okhaldhunga as a senior agriculture development officer. Later he served as an Irrigation Specialist (International UNV) in UNDP Zambia for one year in 2013-2014. Currently, he is working at Regional Agriculture Directorate, Biratnagar, Morang as a senior agriculture extension officer. He has participated in several national and international conferences/seminars and presented his works. He has supervised several M.Sc. and B.Sc. thesis works of the students from national and international universities.
\end{abstract}




\section{Publications during the PhD study}

- Underutilize irrigation water and vulnerable livelihood of small farmers in Zambia. Oral paper presented at 6th International Seminar on "Small Scale Irrigation Systems: Challenges to Sustainable Livelihood", Organized by the Farmer Managed Irrigation Systems Promotion Trust, Nepal, February 15-16, 2015 Kathmandu, Nepal

- Getting the most nutritional value out of the farm. 2014. LEISA India, December 2014.

- Farmers in focus: Nutrition from diversity_Farming Matter, December 2014.

- Hybridizing Technology: The case of rice farming in Nepal. 2013. Landscapes Blog for People, Food and Nature. 8th May 2013.

http://blog.ecoagriculture.org/2013/05/08/sri_nepal/

- Learning from farmers. 2013. Farming Matter 29.1, March 2013, The Netherlands.

- Participatory learning for technology shaping and its dissemination: a case from Nepal. 2011. Extension Farming System Journal, Volume 7, Number 1, Australia.

- SRI: A new opportunity to reform rice farming system in Nepal. Poster presented during national conference of Agriculture Development Strategy Planning, 29-30 November 2011, Kathmandu, Nepal.

- Meshing mechanization with SRI methods for rice cultivation in Nepal. Oral paper presented at the 3rd International Rice Congress, 8-12 November 2010, Hanoi, Vietnam.

- Irrigation management systems and their effect on agriculture and livelihood in Nepal. 2010. In the proceeding of Farmer Managed Irrigation Systems (FMIS) Promotion Trust, Nepal 5th International Seminar on Dynamics of Farmers Managed Irrigation Systems: Socio-institutional, Economic and Technical Contest. 25-26 March 2010, Kathmandu, Nepal.

- The large impact of a small article. 2009. LEISA, Volume-25, No-1, The Netherlands.

- Growing much more rice: Nepal can easily boost paddy productivity and be selfsufficient again in Nepali TIMES, 24 October 2008.

http://www.nepalitimes.com/issue/2008/10/24/Nation/15323

\section{Thesis supervised}

- Transforming livelihood through innovative agricultural reform: an insight into the adoption of system of rice intensification (SRI) in Nepal (2015). Master Thesis of International Development Studies submitted by Sadhana Rana at the Department of International Environment and Development Studies of Norwegian University of Life Sciences Norway.

- Spring season rice cultivation and the System of Rice Intensification in Morang, Nepal (2014). B.Sc. Thesis by Hanno Führen at Water Resources Management group and Knowledge Technology and Innovation group of Wageningen University, The Netherlands.

- Impact of sustainable soil management practices on soil fertility and livelihood of smallholder farmers in the mid-hill of Nepal (2012). M.Sc. thesis submitted by Goma Sigdel (Master student of plant science) at the Department of Farming Systems Ecology 
of Wageningen University, The Netherlands.

- System of Rice Intensification: An analysis of adoption and potential environmental benefits (2010). Master thesis submitted by Sudeep Karki at Norwegian University of Life Sciences, Norway.

- Caste and the System of Rice Intensification in Nepal (2009). B.Sc. Thesis submitted by Gerlinde Buit at the Technology and Agrarian Development Group of Wageningen University, The Netherlands.

- Productivity and economic viability of rice under different planting pattern and age of seedlings through System of Rice Intensification (2009). Master thesis submitted by Keshav Bahadur Karki at IAAS, Tribhuvan University, Nepal.

- Effect of weed control methods on rice cultivars under the System of Rice Intensification (2009). Master's thesis submitted by Sharad Pandey at IAAS, Tribhuvan University, Nepal. 